\title{
Legal remedies against the plastic pollution of the oceans
}

Citation for published version (APA):

Cortat Simonetti Goncalves, L. (2020). Legal remedies against the plastic pollution of the oceans: an analysis of the attempts from public international law and private initiatives to face the plastic soup. [Doctoral Thesis, Maastricht University]. ProefschriftMaken. https://doi.org/10.26481/dis.20200611lg

Document status and date:

Published: 01/01/2020

DOI:

10.26481/dis.20200611lg

Document Version:

Publisher's PDF, also known as Version of record

\section{Please check the document version of this publication:}

- A submitted manuscript is the version of the article upon submission and before peer-review. There can be important differences between the submitted version and the official published version of record.

People interested in the research are advised to contact the author for the final version of the publication, or visit the DOI to the publisher's website.

- The final author version and the galley proof are versions of the publication after peer review.

- The final published version features the final layout of the paper including the volume, issue and page numbers.

Link to publication

\footnotetext{
General rights Owners
rights.

- You may freely distribute the URL identifying the publication in the public portal. please follow below link for the End User Agreement:

www.umlib.nl/taverne-license

Take down policy

If you believe that this document breaches copyright please contact us at:

repository@maastrichtuniversity.nl

providing details and we will investigate your claim.
}

Copyright and moral rights for the publications made accessible in the public portal are retained by the authors and/or other copyright owners and it is a condition of accessing publications that users recognise and abide by the legal requirements associated with these

- Users may download and print one copy of any publication from the public portal for the purpose of private study or research.

- You may not further distribute the material or use it for any profit-making activity or commercial gain

If the publication is distributed under the terms of Article $25 \mathrm{fa}$ of the Dutch Copyright Act, indicated by the "Taverne" license above, 
LEGAL REMEDIES AGAINST THE PLASTIC POLLUTION OF THE OCEANS:

AN ANALYSIS OF THE ATTEMPTS FROM PUBLIC INTERNATIONAL LAW AND PRIVATE INITIATIVES TO FACE THE PLASTIC SOUP 
This work is the result of a double degree $\mathrm{PhD}$ research conducted within Maastrich University (Law Faculty - METRO Institute), in the Netherlands, and Faculdade de Direito de Vitoria (FDV), in Brazil. It was partially financed, through different kinds of scholarships, by Coordenação de Aperfeiçoamento de Pessoal de Nível Superior (CAPES), by Faculdade de Direito de Vitoria (FDV), and by the Max Planck Institute Luxembourg for International, European and Regulatory Procedural Law.

Copyright (C) 2020 by Luisa Cortat Simonetti Goncalves Coutinho

All rights reserved

No part of this publication may be reproduced, stored in an automated data system or transmitted in any form or by any means, electronic, mechanical or photocopying, recording, or otherwise, without the prior written permission from the author.

ISBN : 978-94-6380-856-9

Printed by : ProefschriftMaken || www.proefschriftmaken.nl

Layout by : ProefschriftMaken || Ben Riezouw

Cover design by : ProefschriftMaken || Dennis Hendriks 


\title{
Legal Remedies Against the Plastic Pollution of the Oceans:
} an analysis of the attempts from public international law and private
initiatives to face the plastic soup

\author{
Dissertation \\ to obtain the degree of Doctor at the Maastricht University, \\ on the authority of the Rector Magnificus Prof. dr. Rianne M. Letschert \\ in accordance with the decision of the Board of Deans, \\ to be defended in public on 11 June 2020 at 14.45 p.m.
}

by

Luísa Cortat Simonetti Gonçalves 


\section{Supervisors}

Prof. Michael G. Faure

Prof. Adriano Sant'Ana Pedra (Faculdade de Direito de Vitoria)

\section{Assessment Committee}

Prof. Anne Pieter van der Mei, Maastricht University (chair)

Prof. Stefan Weishaar, Rijksuniversiteit Groningen

Prof. Bernard Vanheusden, University Hasselt, Belgium

Prof. Niels Philipsen, Maastricht University 
Não esquecer que por enquanto é tempo de morangos. Sim.

\section{Clarice Lispector}





\section{ACKNOWDLEDGMENTS}

The production of this thesis is the realization of a dream to me. It means that the career as researcher and lecturer that I have always prepared and wished for is materializing. But of course, accomplishments such as this are never individual, and I am very thankful to all of those that made it possible.

I thank my supervisors, for all the guidance and support along the way. It is impossible to list all the ways in which each of you were important, but I draft here some words of gratitude. To Prof. Michael G. Faure, for the precious suggestions and comments; for the endless letters of recommendation that I have asked for; for always being supportive and understanding, either close or with one ocean between us. To Prof. Adriano Sant'Ana Pedra, for being there for me since my Bachelor's times; for understanding every new and challenging situation and for, still keeping walking alongside with me. To Prof. Paula Castello Miguel, who remained by my side even though she could not remain as my Brazilian supervisor until the end. And to Prof. Ludo Veuchelen who, in fact, made all the complex connections possible, for the tireless enthusiasm; and for bringing the wonderful and sweet Caroline into my life, to whom I am also thankful. You were the best team a $\mathrm{PhD}$ can hope for.

I thank Prof. Antonio José Ferreira Abikair, who believed in me since his first meeting with that 19year-old Physics-student girl, and never stopped.

I am also thankful to all professors that were part of this $\mathrm{PhD}$ path. To the members of the assessment committee, whose comments enabled me to improve my work. To Prof. Daury Cesar Fabriz, in the name of who I thank all the professors from Vitoria Law School, where I undertook my formal law studies, from Bachelor to PhD. To the Professors at Maastricht University Law Faculty, who not only shared a little piece of their knowledge with me but also welcomed me to the new city and country.

I thank also Ms. Marina Jodogne for the crucial role in communication, logistics, bureaucracies, and so much more. In whose name I thank the staff of both universities, which were essential to those steps.

Thanks also due to those who made the endeavor financially feasible and to the institutions involved in making this PhD possible. To FDV - Faculdade de Direito de Vitória - for the full scholarship for the programme. To CAPES - Coordenação de Aperfeiçoamento de Pessoal de Nível Superior -, which sponsored me during the year I spent in Maastricht. To the Max Planck Institute Luxembourg for International, European and Regulatory Procedural Law for having me, with scholarship, as a guest researcher for six months. And to the institutions involved: FDV, Maastricht University and METRO Institute.

In a more personal level, it is impossible to describe how thankful I am to my family. My understanding, loving, and caring husband, Renato, who not only supported me in my craziest plans but also agreed to share me and my time with research and Academia. I know it was not easy. Thank you for giving me one more reason to love you. My parents (and stepdad) and grandparents, who are a part of who I am, a source of inspiration and infinite love, and that were with me also in this cycle of my life. To all of them, I thank in the name of my grandma Dora, who inspires me everyday to be a better person and researcher, and whose $\mathrm{PhD}$ defense I had the honor to watch.

I thank my friends, who, fortunately, are too many to be individually listed here. Each one of you, in the different geographical locations I can find you, were essential and were always present. From the oldest friends to the newest ones. And within the newest ones, especially those that were brought to me by Maastricht and by Luxembourg (in the latest, in the middle of a pandemic outbreak), and who were responsible for making those far away cities feel more like home. 


\section{TABLE OF CONTENTS}

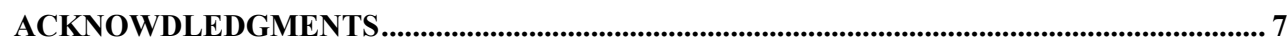

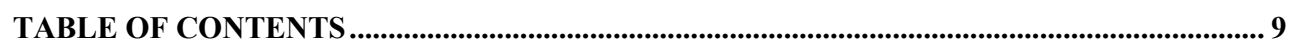

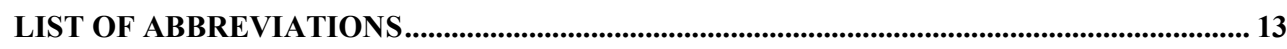

LIST OF TABLES, FIGURES, GRAPHICS.......................................................................... 17

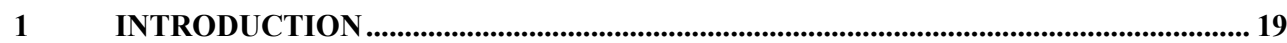

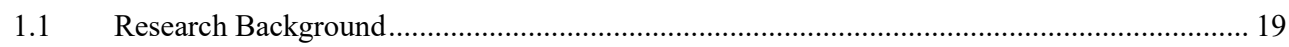

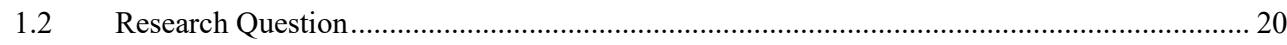

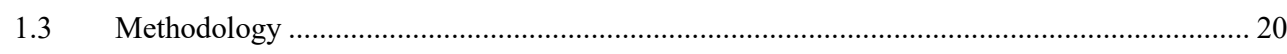

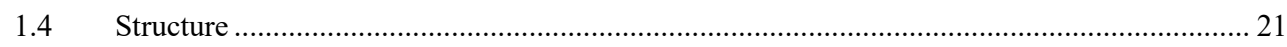

2 OCEAN PLASTIC POLLUTION: AN OVERVIEW OF THE PROBLEM ................... 23

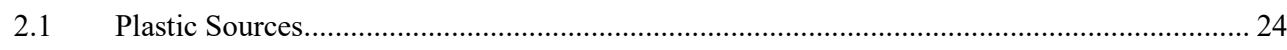

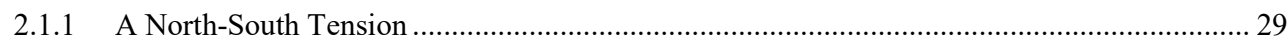

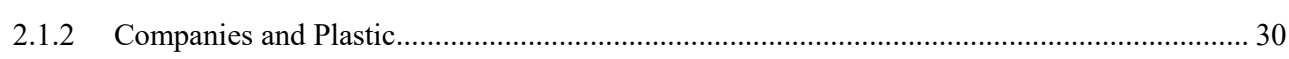

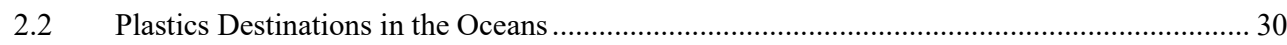

2.3 Consequences for Nature and Human Health .................................................................. 34

$2.4 \quad$ Existing and Proposed Technical Solutions ........................................................................... 36

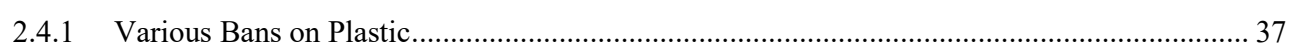

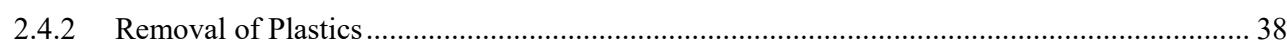

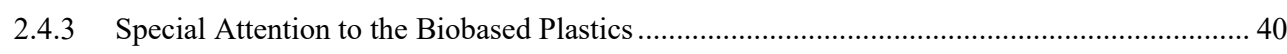

2.5 Stages Leading to Plastic Pollution of the Oceans ................................................................ 41

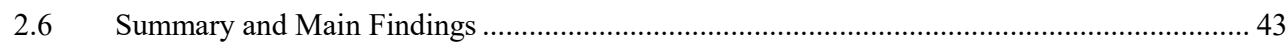

3 THIRD WORLD APPROACHES TO THE INTERNATIONAL LAW AND THE NEED FOR SOLUTIONS BEYOND NATIONAL AND REGIONAL ............................45

3.1 Lessons Learned from a Third World Approach to International Law .................................... 46

3.2 Considerations on the North-South Dynamics to Face the Plastic Soup................................... 48

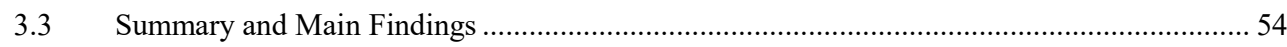

4 PUBLIC INTERNATIONAL LAW INSTRUMENTS TO ADDRESS THE PLASTIC

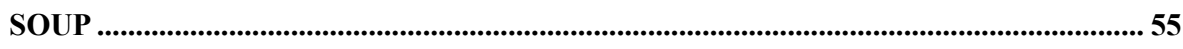

4.1 Distinctiveness of International Environmental Law ............................................................ 56

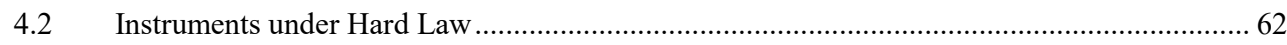

4.2.1 United Nations Convention on the Law of the Sea ................................................................... 62

4.2.2 Convention on the Prevention of Marine Pollution by Dumping of Wastes and Other Matter (1972 London Dumping Convention) and 1996 London Protocol.......................................... 65 
4.2.3 International Convention for the Prevention of Pollution from Ships - Annex V

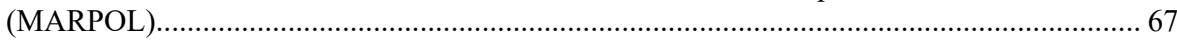

4.2.4 Convention on Biological Diversity and the Jakarta Mandate ................................................ 68

4.2.5 Convention on the Conservation of Migratory Species of Wild Animals................................ 70

4.2.6 Basel Convention on the Control of Transboundary Movements of Hazardous Wastes and

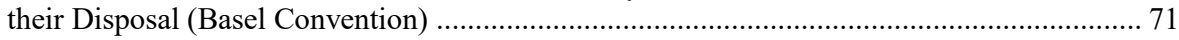

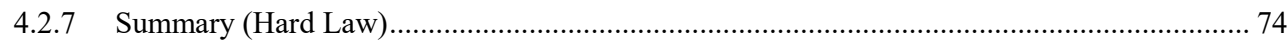

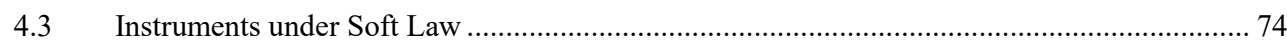

4.3.1 Agenda 21 and the Johannesburg Plan of Implementation ................................................ 75

4.3.2 Global Programme of Action for the Protection of the Marine Environment from Land-Based Activities and Related International Instruments ................................................................. 78

4.3.3 FAO Code of Conduct for Responsible Fisheries ................................................................... 81

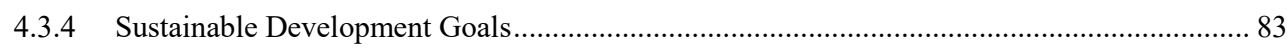

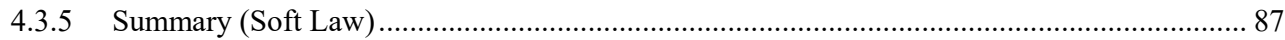

5 CORPORATE SOCIAL RESPONSIBILITY AND PRIVATE INITIATIVES TO

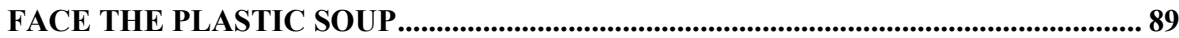

5.1 Current Examples of Private Initiatives to Face the Plastic Pollution..................................... 90

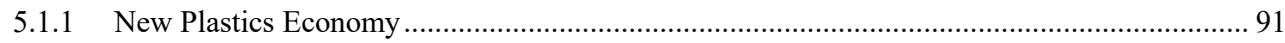

5.1.2 The Dutch Deals: A National Example that Supports the International Hypothesis................ 93

5.1.3 Dow Jones Sustainability Index: An Opportunity to Take.................................................. 99

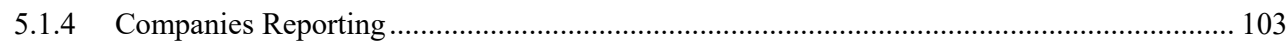

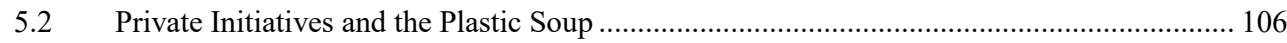

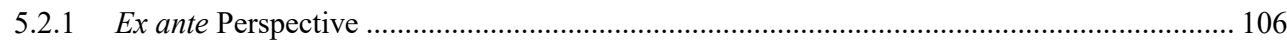

5.2.1.1 Why Would Companies Engage?.................................................................................. 107

5.2.1.2 Joint Action from Governments and Civil Society .......................................................... 107

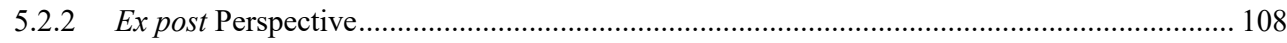

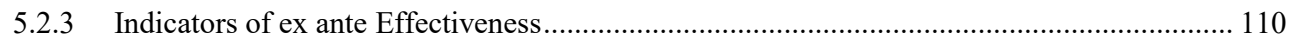

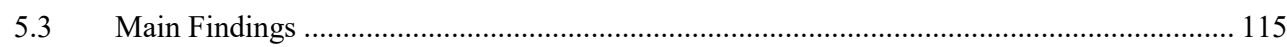

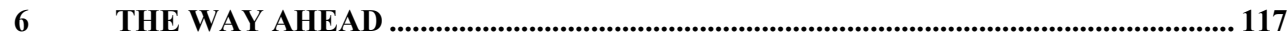

6.1 The Law and Economics in the Four Stages to Fight the Plastic Pollution in the Oceans ..... 119

6.1.1 Ex ante Perspective ........................................................................................................ 120

6.1.1.1 Lessons Learned from the Public International Instruments and the Need for a Mixed

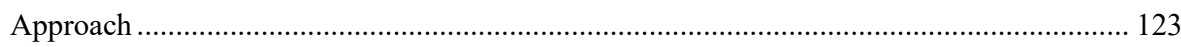

6.1.1.2 Lessons Learned from the Private Initiatives and the Need for a Mixed Approach.............. 126

6.1.2 Ex post Perspective: Perceptions and Lessons Learned ....................................................... 129

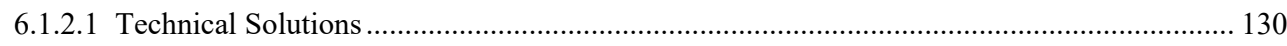

6.1.2.2 A Law and Economics Approach................................................................................... 131

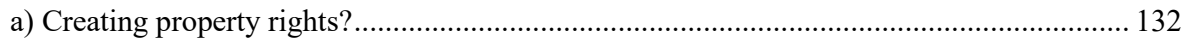

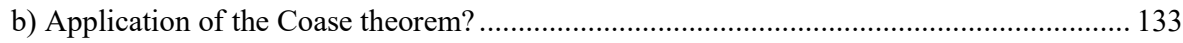




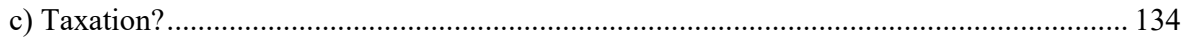

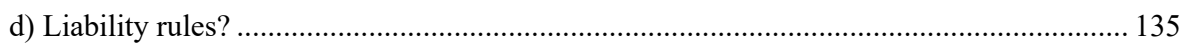

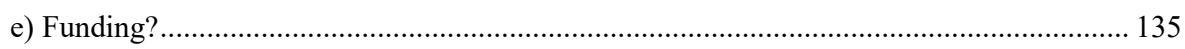

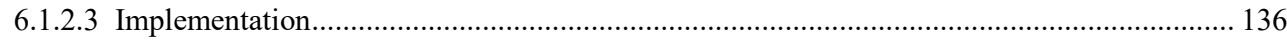

6.2 Priorization and Indications for an Appropriate Regulatory Mix........................................... 137

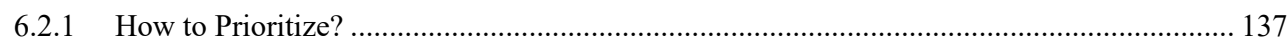

6.2.2 How Different Forms of Regulation Interact in Practice .................................................. 140

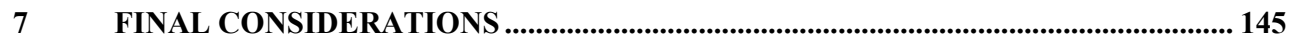

7.1 Concluding Remarks on the Research Question ................................................................ 145

7.1.1 The Challenge of the Plastic Pollution of the Oceans ........................................................... 146

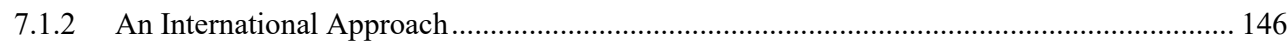

7.1.3 The International Instruments to Address the Plastic Soup................................................... 147

7.1.4 Private Initiatives to Face the Plastic Soup ........................................................................... 147

7.1.5 How to Construct a Mix to Effectively Face the Problem of the Plastic Pollution of the

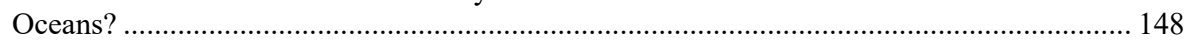

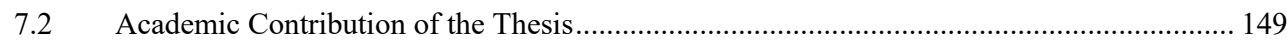

7.3 Societal Relevance of the Thesis....................................................................................... 149

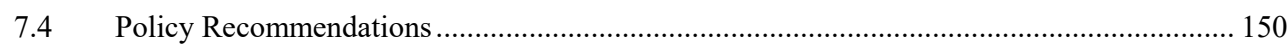

7.5 Limits and Further Research ........................................................................................ 150

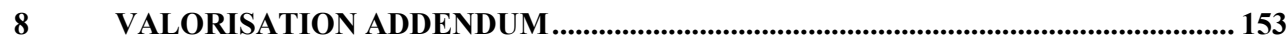

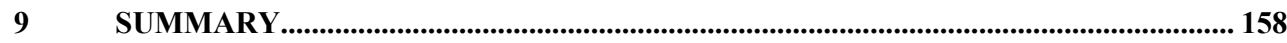

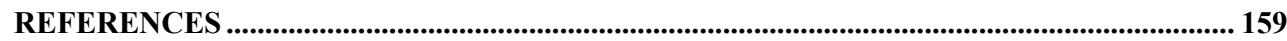

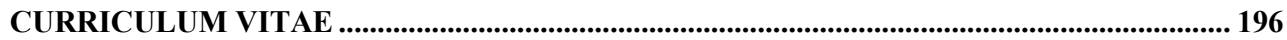




\section{LIST OF ABBREVIATIONS}

$6 \mathrm{R}$

ABS

AIDS

ALE

ASEAN

CBD

CEO

CMS

$\mathrm{CO}_{2}$

COP

CSA

CSD

CSP

CSR

DJSI

EC

ECHA

Eco-92

ECOSOC

EEZ

EPR

EPS

EU

FAO

GDP

GESAMP

GHG

GLOC

GPA

GPML

GPP

GRI

HDPE

HIC

HIV

HRDD

I\&M

IEL

IGR

IHRL

IMF

IMO

ITLOS

KPI

KVNR

LC\&P

LCP
Rethink, Repair, Recondition, Re-manufacture, Re-use, Re-cycling

Acrylonitrile Butadiene Styrene

Acquired Immunodeficiency Syndrome

Alginate-Like Exopolymers

Association of Southeast Asian Nations

Convention on Biological Diversity

Chief Executive Officer

Convention on the Conservation of Migratory Species of Wild Animals /

Bonn Convention

Carbon Dioxide

Conference of the Parties

Corporate Sustainability Assessment

Commission on Sustainable Development

Corporate Social Performance

Corporate Social Responsibility or Corporate Social and Environmental Responsibility

Dow Jones Sustainability Indices

European Community

European Chemicals Agency

UN Conference on Environment and Development

Economic and Social Council

Exclusive Economic Zone

Extended Producer Responsibility

Expandable Polystyrene

European Union

Food and Agriculture Organization of the United Nations

Gross Domestic Product

United Nations Joint Group of Experts on the Scientific Aspects of Marine Pollution

Green House Gases

Global Conference on Land-Ocean Connections

Global Programme of Action for the Protection of the Marine Environment from Land-based Activities

Global Partnership on Marine Litter

Government Public Procurement

Global Reporting Initiative

High Density Polyethylene

High Income

Human Immunodeficiency Virus

Human Rights Due Diligence

Ministry of Infrastructure and the Environment (The Netherlands)

International Environmental Law

Intergovernmental Review Meeting on the Implementation of the GPA

International Human Rights Law

International Monetary Fund

International Maritime Organization

International Tribunal for the Law of the Sea

Key Performance Indicators

Koninklijke Vereniging van Nederlandse Reders (The Netherlands)

London Convention \& Protocol

Liquid Crystal Polymer 


\begin{tabular}{|c|c|}
\hline LDPE & Low Density Polyethylene \\
\hline LI & Low Income \\
\hline LLDPE & Linear Low Density Polyethylene \\
\hline LLP & Limited Liability Partnership \\
\hline LMI & Lower Middle Income \\
\hline M\&S & Marks and Spencer \\
\hline MARPOL & International Convention for the Prevention of Pollution from Ships \\
\hline MDGs & Millenium Development Goals \\
\hline MEA & Multilateral Environmental Agreement \\
\hline MEPS & Mandatory Requirements \\
\hline MIT & Massachusetts Institute of Technology \\
\hline MMT & Million Metric Tons \\
\hline NGO & Non-governmental Organization \\
\hline OECD & Organization for Economic Cooperation and Development \\
\hline$P \& G$ & Procter\&Gamble \\
\hline $\mathrm{PAH}$ & Polycyclic Aromatic Hydrocarbons \\
\hline PBT & Polybutylene Terephthalate \\
\hline PCB & Polychlorinated Biphenyls \\
\hline PCR & Post-Consumer Resin \\
\hline PEEK & Polyether Ether Ketone \\
\hline PET & Polyethylene Terephthalate \\
\hline PHA & Polyhydroxyalkanoate \\
\hline PMMA & Polymethyl Methacrylate \\
\hline PO & Polyolefins \\
\hline POM & Polyoxymethylene \\
\hline PP & Polypropylene \\
\hline PPA & Polyphthalamide \\
\hline PPS & Polyphenylene Sulfide \\
\hline PS & Polystyrene \\
\hline PTFE & Polytetrafluoroethylene \\
\hline PVC & Polyvinyl Chloride \\
\hline PVDF & Polyvinylide Fluoride \\
\hline PUR & Polyurethanes \\
\hline REACH & $\begin{array}{l}\text { European Regulation on Registration, Evaluation, Authorisation, and } \\
\text { Restriction of Chemicals }\end{array}$ \\
\hline RIVM & National Institute for Public Health and the Environment (The Netherlands) \\
\hline RNA & Ribonucleic Acid \\
\hline RVO & The Netherlands Enterprise Agency \\
\hline RWS & Rijkswaterstaat \\
\hline SDGs & Sustainable Development Goals \\
\hline SPP & Sustainable Public Procurement (or Green Public Procurement) \\
\hline STOWA & Foundation for Applied Water Research \\
\hline TPE & Thermoplastic Elastomers \\
\hline TWAIL & Third World Approaches to International Law \\
\hline UHMWPE & Ultra High Molecular Weight Polyethylene \\
\hline UK & United Kingdom \\
\hline UMI & Upper Middle Income \\
\hline UN & United Nations \\
\hline UNCED / Rio92 & United Nations Conference on Environment and Development \\
\hline UNCLOS & United Nations Convention on the Law of the Sea \\
\hline UNDP & United Nations Development Program \\
\hline UNEP & United Nations Environment Programme \\
\hline UNFCCC & United Nations Framework Convention on Climate Change \\
\hline US / USA & United States of America \\
\hline VOMS & $\begin{array}{l}\text { Association of Companies in Environmental Services for the benefit of } \\
\text { Shipping }\end{array}$ \\
\hline
\end{tabular}




\section{LIST OF TABLES, FIGURES, GRAPHICS}

List of Tables

Table 1: Waste estimates for 2010 for the top 20 countries ranked by mass of mismanaged plastic waste.

Table 2: Levels of floating debris in the world's oceans. Data collected by visual sighting from ships

Table 3: Levels of debris on the seafloor of the world's oceans. Data are from studies that used trawl nets to collect the debris.

Table 4: Levels of stranded debris on shorelines throughout the world............................................... 33

Table 5: Levels of stranded debris on shorelines throughout the world............................................ 33

Table 6: Summary of the Amendments adopted during COP14 (May, 2019) ................................. 73

Table 7: Testing the examples with the eleven indicators.............................................................. 114

Table 8: Summary of mentions to plastics in the international instruments .................................. 120

Table 9: Summary of plastic-related aspects and effectiveness of the international instruments .... 121

Table 10: Weighting factors for determining the contribution of various criteria to the prioritization of sources of microplastics.

\section{List of Figures}

Figure 1: Impacts of different sizes of plastic on organisms ..................................................... 35

Figure 2: Countries with plastic bag bans ................................................................................. 38

Figure 3: Scheme representing the chain that leads to the plastic pollution in the oceans and relating them to the technical solutions that may assist in each of the stages

Figure 4: Scheme representing the stages that lead to the plastic pollution in the oceans, relating them to the technical solutions that may assist in each of the stages, but in a desired shape of a circle, representing a potential circular economy through the solutions ........... 43

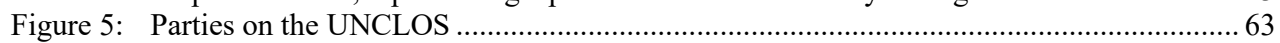

Figure 6: Parties on the London Convention 1972 and London Protocol 1976.....................................6 66

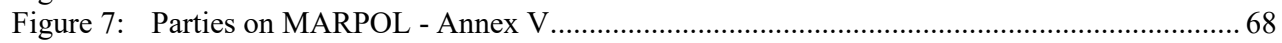

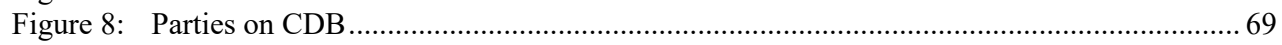

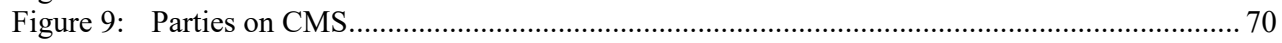

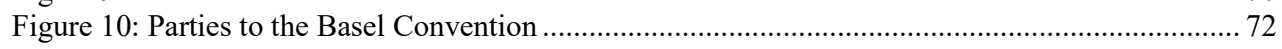

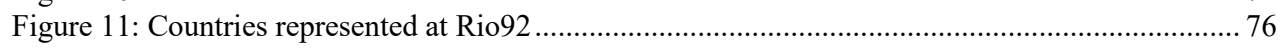

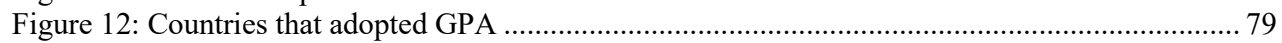

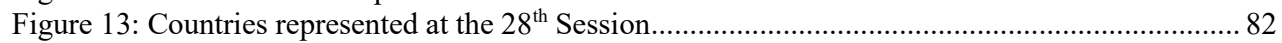

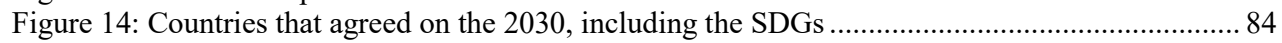

Figure 15: Corporate Sustainability Assessment..................................................................... 100

Figure 16: Criterion Weights by RobecoSAM Industry for Food \& Staples Retailing ..................... 101

Figure 17: Structure of the RobecoSAM Corporate Sustainability Assessment ............................... 101

\section{List of Graphics}

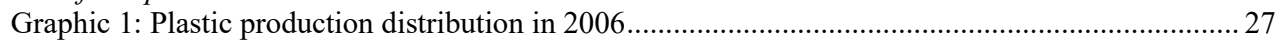

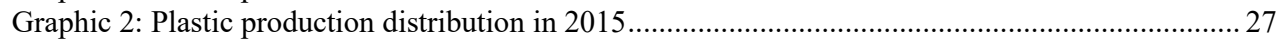

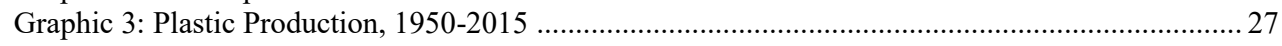

Graphic 4: The change in global production of plastics with the population .................................... 28

Graphic 5: Aquatic life affected by marine litter, classified by species and genera, accordingly to the World Register of Marine Species. 


\section{INTRODUCTION}

\subsection{Research Background}

The problem of the plastic pollution in the oceans is increasingly attracting the attention of the public and of scientists. Although the academic community has been conducting many studies, there is still much to learn about the plastic pollution sources, destinations and consequences for nature and human health. Estimates show that, yearly, at least 8 million tons of plastics end in the oceans. ${ }^{1}$ This is expected to double by 2030 and to quadruple by 2050 , when there may be more plastic than fishes in the oceans. ${ }^{2} 50 \%$ of all plastic produced is used only once, ${ }^{3}$ Only about $9 \%$ of all plastics produced each year in the world is recycled, ${ }^{4}$ and, consequently $80 \%$ of the plastics ending in the oceans are from land-based sources, ${ }^{5}$ These are just a few numbers that indicate that the problem is becoming ever more severe.

There are no doubts about the fact that the plastic pollution is a massive environmental and social problem and that it is caused by human activity on Earth. One of its consequences is on international waters, where it spreads through the oceans, causing what is now called the plastic soup. Many of the consequences - especially on human health - are still unknown, even so, the numbers mentioned above are just a few of the alarming data on the topic.

As with most of the environmental issues, research with respect to plastic pollution of the oceans inherently requires a multidisciplinary approach as there are influences, discussions, and implications in fields like chemistry, biology, political science, economics, and so on. The complexity does not end there. 14 different kinds of plastics, ${ }^{6}$ for example, means at least 14 different challenges to address. Also, dealing with plastics in the oceans means both preventing further pollution from entering those waters, as well as recovering the billions of tons already accumulated over the last century. ${ }^{7}$ All of this dealing with a plastic production that is continuously growing, at a pace faster than the world population's growth. Moreover, the visible objects are just a sign of a much bigger problem, ${ }^{8}$ which comprises microplastics, for example. ${ }^{9}$

Such complexity implies the need for some kind of legal solution, be it public, private, or a mix of the two. Yet, in the legal field, both legislators and legal doctrine have under-estimated the problem. For instance, besides its international nature, public international law has no single particular instrument to address the plastic pollution, and only very recently the discussion started at the international level on how to address the plastic soup. ${ }^{10}$ The international approaches and possibilities are still to be addressed by this thesis, but it is already now clear that there is no specific international convention neither from hard nor from soft law - dealing explicitly with the plastic soup. The problem has also not been intensively addressed in the legal literature.

The complexity also indicates that regulation alone may not be enough to address the extent of the challenge. For that reason, considering all the players involved - civil society and companies, apart from governments - it is essential to adequately face the problem. In other words, initiatives from civil organizations and other private initiatives such as Corporate Social Responsibility have to be analyzed. And analyzed beyond the common prejudices and suspicions that they usually raise.

Ellen MacArthur Foundation (2016).

Ellen MacArthur Foundation (2016).

Hollman, Bouwmeester, and Peters (2013, p. 8).

Parker (2018).

Sheavly (2005).

Plastics Europe (2017).

Plastics Europe (2017).

Greenpeace (2017c).

The plastic which broke into pieces up to $5 \mathrm{~mm}$. Girard et al. (2016, p. 6); Rogers (2019).

10 During the COP14 for the Basel Convention, for example, which took place in May, 2019. Japan Ministry of Economy, Trade and Industry - METI (2019). 
Furthermore, the lack or insipience of technical and technological solutions adds to the complexity. Once more, the variety of applications makes it necessary to also have a variety of solutions. Additionally, even when alternatives to plastics are available, they may be misleading to the general public as to their impacts on the environment, as the case of bioplastics. ${ }^{11}$ The thesis will still address this, but it is important to understand that: (i) bioplastics include more than one kind of material, and not all of them help the fight against plastic pollution; (ii) even if it refers to biodegradable plastics which decompose into non-polluting substances - it is only helpful if compost is available.

For all those reasons, it becomes clear that much research is needed, and, for what concerns constructing policy solutions, especially legal research is still much needed. From such a legal perspective, there are three main approaches equally relevant to the discussion of a problem with many local causes and yet with such an international nature: national, regional, and international. This thesis aims at contributing to the discussion regarding the international context, from both the ex ante and the ex post perspectives, meaning, respectively, avoiding further pollution and recovering the already existing one. Therefore, the thesis also aims at identifying, from the possible paths to start fighting the plastic pollution in the oceans, those which have the highest probability of being effective.

\subsection{Research Question}

The problem of the plastic pollution in the oceans is a clear example of the need for more sustainable development. The lack of balance between the economic, social, and environmental dimensions pose a serious threat to the nature, to humankind, and, therefore, to development itself.

Taking account of all this, and the goals previously explained, this thesis has the following research question: how can a mix of private pathways and public international regulation be constructed, to incentivize more sustainable behavior and effectively face the problem of the plastic pollution in the oceans, both preventing further pollution and recovering the already existing one?

It is important to note that this does not mean an intention to present a final solution, which would be impossible. As mentioned, it intends, however, to indicate the paths that seem more adequate to face the challenges that will be identified.

Naturally, secondary questions will have to be answered to make it possible to reach that point of analysis. It is important, first to understand what are, in fact, the challenges presented. Second, to unveil the need for an inclusive international approach even for preventing further plastic from going into the oceans, a problem to which there is a massive contribution from land-based sources. Third, to analyze the possibilities and limitations in public international law - hard and soft law - to face the problem of the plastic pollution of the oceans. Fourth, to analyze the possibilities and limitations in private initiatives.

As will be further explained in the section about the structure of the thesis, those steps will lead to an answer to the research question.

\subsection{Methodology}

The methodology of the research is a positive analysis using legal dogmatic analysis as well as Law and Economics. To say it is a positive analysis means that the focus is on describing and explaining the problem and, consequently, pointing in the direction of solutions. ${ }^{12}$ Yet, it does have a practical and political relevance, since it looks into possible policy implementations that enhance effectiveness. It does not, however, aim at setting efficiency as a goal, as would a normative analysis of law and Economics do.

11 Odegard et al. (2017, p. 4).

12 Pacces and Visscher (2011, p. 88); Geistfeld (2001, p. 250). 
"The assumptions made by economists are necessary for a tractable analysis of complicated issues". ${ }^{13}$ In general, such an approach enables the use of simplified models to understand and analyze objectively a complex reality, at the same time that it enables us to perceive explicitly the limitations of those models. "The fact that one has analyzed a 'simplified version of reality' is no problem, as long as this can still yield good predictions". ${ }^{14}$ On the contrary, this step allows, in the future, deeper analysis and the use of different methodologies.

The economic concepts are useful to address the research question because they help in setting the characteristics and tools that need to be considered for the analysis of both public and private pathways, as well as for the discussion about a regulatory mix. Furthermore, the economic analysis of law makes it possible to look at law as a tool to correct market failures, or at least reduce their adverse consequences. And the issue of plastic pollution is essentially an externality problem, as well as a problem of information asymmetries. Both are, from an economic perspective, market failures that, consequently, may be adequately addressed by tools from the economic methodology. Finally, the use of economic tools is a common ground for the actors involved - companies, states, and civil society which may help facilitating communication (an essential aspect for having changes implemented faster).

Specific issues use additional methodologies. The main one being international law instruments, since the approach for the thesis is from the international perspective. It is important to highlight here that the problem of the plastic pollution in the oceans is very complex, as will be demonstrated. Somehow like the climate change issue, it has mostly local causes, but with severe international consequences as with the research object here, the pollution of international waters. Therefore, there are three different, but equally essential, complementary perspectives that have to be taken into account: international, regional, and national. The scope of the thesis is international, dealing with the challenges of the need for international action for recovering the plastic pollution and preventing further plastics from going into the oceans. At the same time, of course, not forgetting the interconnections between the three perspectives. Chapter 3 especially relies on a specific technique from international law methodologies, the Third World Approach to International Law (TWAIL), highlighting the importance of international action. Chapter 4 also relies on international law methodologies, which makes a systematic assessment of international instruments that are relevant to the plastic soup discussion.

An interdisciplinary approach places the entire study on center-stage. Although the central dialogue discipline is Economics, because of the elected methodology, other disciplines are necessary. Chemistry is the main one to address available techniques to face the plastic pollution. International relations and international politics help to address the international instruments regarding plastics and the policy-making process. Biology helps to describe the impacts of plastic pollution in nature. All disciplines are invited into the study through available academic papers and their respective conclusions.

The main technique for the thesis is bibliographic research, with the help of semi-structured interviews for the case study concerning the Dutch Green Deals, as there was a shortage of written information available on that topic.

\subsection{Structure}

This thesis is divided into five content chapters - numbered from 2 to 6 .

Chapter 2 gives an overview of the problem, describing the current academic knowledge about data, sources, destinations, role of companies, impact on nature and human health, potential solutions, etc. The research presents ex ante and ex post perspectives, meaning both avoiding further pollution and

13 Pacces and Visscher (2011, p. 87).

14 Pacces and Visscher (2011, p. 87). See also: Friedman (1953, p. 30 onwards); Rubin (1985); Kerkmeester (2000, p. 392); Posner (2003, p. 17 onwards). 
recovering the already existing one. To achieve that, chapter 2 describes the stages of the plastic chain and relates them to the potential technical solutions.

Despite the international nature of the problem, an approach from international law may not be so obvious, especially for the ex ante perspective, considering that the majority of the plastic ending in the oceans has land-based sources. Chapter 3 comes, then, to demonstrate the importance of such an international approach. More than that, to demonstrate the importance of an international approach which looks for balanced solutions between the developing and the developed world, preventing hasty conclusions from data such as the top 10 polluting rivers being from Asia and Africa, contributing with up to $95 \%$ of the plastic pollution in the oceans. ${ }^{15}$

Chapter 4 focuses on the public international instruments dealing - global agreements - with the plastic soup. The analysis of eleven instruments and protocols - from hard and soft law - shows that none specifically deal with the problem, but points to some essential aspects to be considered when designing a solution to face the plastic pollution in international waters.

Chapter 5 has the same approach as chapter 4, but focusing on the private initiatives, mainly regarding corporate social responsibility. It is built upon four case studies that allow it to also indicate essential aspects to be considered when designing a solution to face the plastic pollution in the oceans: (i) the New Plastics Economy; (ii) the Dutch Deals; (iii) the Dow Jones Sustainability Index; and (iv) companies reports. This allows us to understand, for instance, why would companies engage and how may joint actions from companies and government actually work.

Chapter 6 resumes all the discussions and possibilities raised during the thesis to arrive to an answer to the research problem. Therefore, The Way Ahead offers an economic analysis of the prospective policy possibilities and their respective potential effectiveness.

The final considerations, presented in the seventh chapter, provide a summary of the constructed reasoning and the consequent conclusions.

15 Schmidt, Krauth, and Wagner (2017, p. 12246). 


\section{OCEAN PLASTIC POLLUTION: AN OVERVIEW OF THE PROBLEM}

Our planet is a lonely speck in the great enveloping cosmic dark. In our obscurity, in all this vastness, there is no hint that help will come from elsewhere to save us from ourselves.

Carl Sagan

Even though plastic in its modern form has existed since 1855 - or since 1907 , if one considers the first real synthetic, mass-produced plastic, ${ }^{16}$ - the problem of the plastic pollution of oceans became more evident after 1997. It was then that Charles Moore, a sailor, took a shortcut on the way between Hawaii and California and reported to major news and interview programs the Great Pacific Garbage Patch, describing it as a plastic soup twice the size of Texas.

This concentration of garbage in the North Pacific is due to the vortex created there by the ocean currents. It consists of a sub-tropical gyre that covers a large area of the Pacific, in which the water circulates clockwise in a slow spiral that pushes any floating material into its center. ${ }^{17}$

However, long before that, several studies discovered plastics in the ocean. The first of them was in 1972, when a group of researchers "at the Woods Hole Oceanographic Institution in Massachusetts found plastic particles up to 0.5 centimeters in diameter in their surface plankton nets in the North Atlantic's Sargasso Sea". ${ }^{18}$

Even so, there is still a lot to learn about the plastic sources, destinations and consequences to nature and human life. The only certainty is that the amount of plastic that ends up in the ocean is alarming and it is unlikely to decrease any time soon, because of its durability and wide range of use.

The great variety of polymers, their excellent properties, low price and versatility lead to the growth of single-use disposable plastics. This was the result of direct outgrowth of the chemical industries developed during World War II and quickly polymer items became symbolic of the convenience of modern day living. ${ }^{19}$

Each year, at least 8 million tons of plastics leak into the ocean and, if no action is taken, this is expected to double by 2030 and to quadruple by 2050 . With that, the estimate is that by 2050 there will be more plastics than fishes, in weight, in the oceans. Besides, plastics production increased worldwide from 15 million tons in 1964 to 311 million tons in $2014 .^{20}$

The visible objects are just the sign of a much bigger problem. Several natural interactions such as sunlight, wave action and mechanical abrasion make those larger pieces slowly break up into smaller ones. Since the decomposition time of plastics may go up to almost 500 years, although it depends on the type of plastic, and also there is still no consensus on those numbers, virtually every piece of plastic ever produced is still around. ${ }^{21}$

Therefore, plastic does not go away. It just goes from its originally industrialized format to being tiny floating plastic particles that are easily eaten by fish and other marine species, or that simply spread

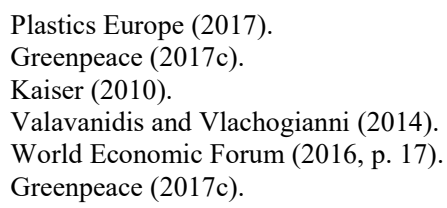


even further afield. "A single one-litre bottle could break down into enough small fragments to put one on every mile of beach in the entire world". ${ }^{22}$

This means that the solution is difficult. The so-called micro-plastics is the plastic which breaks into pieces from 0.1 to $5 \mathrm{~mm}$, signifying that it may not be collected - for instance, like in the beach cleanups that are sometimes organized worldwide - and that most of it may not be seen by naked eye. Yet, it produces the biggest impacts in the food chain, marine life, and even human health and safety, as described further in this chapter.

All this plastic together forms the plastic soup in the seas and oceans. "Plastic can be found on every beach in the world. Micro-plastics are found at 5,000 metres depth, and plastic bottles have been found at depths of 3,500 metres. It's actually 'raining' plastic in the ocean. Scientists are still far from mapping all the plastic pollution in the oceans". ${ }^{23}$

This chapter presents the main information available on the plastic pollution sources, destinations and consequences. However, mainly because of differences in time and methodology, and sometimes because of a lack of transparency in data, there is still some inconsistency in the numbers. Even though the Maths do not always tally, this overview shows the gravity of the situation and enables a starting point to the reflection on the main problems and potential pathways through them.

\subsection{Plastic Sources}

Since plastic's first appearance in the format we know, a great diversity of kinds of polymers - with an enormous range of application - was developed, and we know all of them as plastic. According to the Plastics Europe (Association of Plastics Manufacturers), ${ }^{24}$ there are fourteen types:

(i) bio-based plastics, made in whole or partially from biological resources. Currently, make up an insignificant portion of total world production of plastics. It is mostly used in packaging, but also in sports \& footwear, automotive, industry, agriculture, non-wovens and fibres;

(ii) biodegradable plastics, which are plastics degraded by micro-organisms into water, carbon dioxide (or methane) and biomass under specified conditions. Biodegradability is an intrinsic property of the material, independent of its origin. It can be from fossil or renewable resources. It is used for organic waste collection and diversion, agricultural and horticultural sectors, food packaging, disposable tableware;

(iii) engineering plastics, that include ABS Resins, LCP, PBT, POM, Polyamide, Polycarbonate, TPE, UHMWPE, Polyimides, PVDF, PMMA, PPS, PEEK, PPA, Polyarylsulfone. They are used in applications requiring higher performance in the areas of heat resistance, chemical resistance, impact, fire retardancy or mechanical strength;

(iv) elastomers. A category of pliable plastic material that are good at insulating, withstanding deformation, and moulding into different shapes;

(v) epoxy resins. The applications are extensive and include coatings, adhesives and composite materials such as those using carbon fiber and fiber-glass reinforcements. In general, epoxies are known for their excellent adhesion, chemical and heat resistance, good-to-excellent mechanical properties and very good electrical insulating properties. Many properties of epoxies can be modified to be applicable with good or bad electrical conductivity, or with high thermal insulation or thermal conductivity, for example;

(vi) expandable polystyrene (EPS), a solid foam with a unique combination of characteristics like lightness, insulation properties, durability and an excellent processability. It is used in thermal insulation board in buildings, packaging, cushioning of valuable goods and food packaging;

(vii) fluoropolymers, a family of high-performance plastics, whose best known member is called PTFE. They are used in high-performance automotive and aircraft bearings and seals, flame

22 Greenpeace $(2017 \mathrm{c})$.

23 Plastic Soup Foundation (2017b).

24 Plastics Europe (2017). 
retardants, coatings on many kitchen products, linings of piping and chemical tanks, cable coating in the telecommunications and computer industries, implantable parts and catheters for bio-medical applications;

(viii) polyolefins (PO), which is the collective description for plastics types that include polyethylene - low density polyethylene (LDPE), linear low density polyethylene (LLDPE) and high density polyethylene (HDPE) - and polypropylene (PP). It is used to make films, bags and boxes;

(ix) polyethylene terephthalate (PET), currently the most commonly used in Europe. It is usually related to the production of bottles;

(x) polystyrene (PS), a thermoplastic polymer which softens when heated and can be converted into semi-finished products like films and sheets, as well as a wide range of finished articles;

(xi) polyurethanes (PUR), which is a resilient, flexible and durable manufactured material. Its applications include footwear, furniture and insulation;

(xii) polyvinyl chloride (PVC) is durable and light, strong, fire resistant, with excellent insulating properties and low permeability. Mostly known by its uses in pipes, but is also applicable for coatings, automotive, medical and leisure applications;

(xiii) thermoplastics is a type of plastic made from polymer resins that becomes a homogenized liquid when heated and hard when cooled, and may have the process redone. Different kinds of thermoplastics have different applications, from toys to packaging;

(xiv) thermosets or thermosetting, plastics are synthetic materials that strengthen during being heated, but cannot be successfully remoulded or reheated after their initial heat-forming. Amongst its uses, there are electronic chips, fiber-reinforced composites, spectacle lenses and dental fillings.

Given all those uses and applications of different types of plastic, those that end in the oceans are coming from everywhere. It comes from rubbish that people throw away on the street, from discarded fishnets, from washing synthetic clothing, from used cosmetics, from brushing our teeth, and so on. ${ }^{25}$

The yearly production of plastics in 2005 was around 100 million tons, of which about 10 million ended in the sea. According to the United Nations Joint Group of Experts on the Scientific Aspects of Marine Pollution (GESAMP), about $80 \%$ of it comes from land. ${ }^{26}$ The remainder comes from ships and the fishing industry. For instance, cargo ships are increasingly carrying packing cases using small plastic pellets as stuffing, which are liberally dispersed across the oceans when drum-loads or even container loads are lost at sea. ${ }^{27} 28$

There are four major groups for categorizing the sources of plastic pollution: (i) tourism related litter at the coast; (ii) sewage-related debris; (iii) fishing related debris; and (iv) wastes from ships and boats. ${ }^{29}$ However, as seem, most of the plastic waste in the regional seas and oceans come from landbased sources.

Plastic is blown off the streets and garbage dumps, from garbage trucks and freight trains, to end up in streams, rivers, gullies, and, ultimately, in the sea. The tides draw it out to sea where the currents catch it and transport it to the vortex and there it rotates like in a toilet that is never flushed..$^{30}$

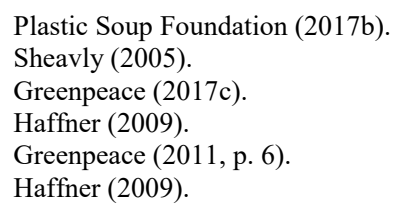


Amongst all the applications of plastics, packaging is the greatest, representing $26 \%$ of the total volume of plastic used..$^{31}$ Nevertheless, it is also clear that other sources, such as electronic waste, electrical equipment and vehicles, are becoming very significant.

Regarding the geographical sources, the numbers vary from region to region and studies get old fast due to the continuous increase of plastic production and pollution. Even so, it is possible to get an idea of the whole picture and understand why there is a consensus around the gravity of the situation.

An estimation from 2010 clearly shows the difference in the contributions to plastic pollution of the oceans from different countries. ${ }^{32}$ The table below summarizes the situation.

\begin{tabular}{|c|c|c|c|c|c|c|c|c|c|}
\hline Rank & Country & $\begin{array}{l}\text { Econ. } \\
\text { classif. }\end{array}$ & $\begin{array}{l}\text { Coastal pop. } \\
\text { [millions] }\end{array}$ & $\begin{array}{l}\text { Waste gen. } \\
\text { rate } \\
\text { [kg/ppd] }\end{array}$ & $\begin{array}{l}\% \text { plastic } \\
\text { waste }\end{array}$ & $\begin{array}{l}\% \text { mismanaged } \\
\text { waste }\end{array}$ & $\begin{array}{l}\text { Mismanaged } \\
\text { plastic } \\
\text { waste } \\
\text { [MMT/year] }\end{array}$ & $\begin{array}{l}\% \text { of total } \\
\text { mismanaged } \\
\text { plastic } \\
\text { waste }\end{array}$ & $\begin{array}{c}\text { Plastic } \\
\text { marine } \\
\text { debris } \\
\text { [MMT/year] }\end{array}$ \\
\hline 1 & China & UMI & 262.9 & 1.10 & 11 & 76 & 8.82 & 27.7 & $1.32-3.53$ \\
\hline 2 & Indonesia & LMI & 187.2 & 0.52 & 11 & 83 & 3.22 & 10.1 & $0.48-1.29$ \\
\hline 3 & Philippines & LMI & 83.4 & 0.5 & 15 & 83 & 1.88 & 5.9 & $0.28-0.75$ \\
\hline 4 & Vietnam & LMI & 55.9 & 0.79 & 13 & 88 & 1.83 & 5.8 & $0.28-0.73$ \\
\hline 5 & Sri Lanka & LMI & 14.6 & 5.1 & 7 & 84 & 1.59 & 5.0 & $0.24-0.64$ \\
\hline 6 & Thailand & UMI & 26.0 & 1.2 & 12 & 75 & 1.03 & 3.2 & $0.15-0.41$ \\
\hline 7 & Egypt & LMI & 21.8 & 1.37 & 13 & 69 & 0.97 & 3.0 & $0.15-0.39$ \\
\hline 8 & Malaysia & UMI & 22.9 & 1.52 & 13 & 57 & 0.94 & 2.9 & $0.14-0.37$ \\
\hline 9 & Nigeria & LMI & 27.5 & 0.79 & 13 & 83 & 0.85 & 2.7 & $0.13-0.34$ \\
\hline 10 & Bangladesh & $\mathrm{LI}$ & 70.9 & 0.43 & 8 & 89 & 0.79 & 2.5 & $0.12-0.31$ \\
\hline 11 & South Africa & UMI & 12.9 & 2.0 & 12 & 56 & 0.63 & 2.0 & $0.09-0.25$ \\
\hline 12 & India & LMI & 187.5 & 0.34 & 3 & 87 & 0.60 & 1.9 & $0.09-0.24$ \\
\hline 13 & Algeria & UMI & 16.6 & 1.2 & 12 & 60 & 0.52 & 1.6 & $0.08-0.21$ \\
\hline 14 & Turkey & UMI & 34.0 & 1.77 & 12 & 18 & 0.49 & 1.5 & $0.07-0.19$ \\
\hline 15 & Pakistan & LMI & 14.6 & 0.79 & 13 & 88 & 0.48 & 1.5 & $0.07-0.19$ \\
\hline 16 & Brazil & UMI & 74.7 & 1.03 & 16 & 11 & 0.47 & 1.5 & $0.07-0.19$ \\
\hline 17 & Burma & LI & 19.0 & 0.44 & 17 & 89 & 0.46 & 1.4 & $0.07-0.18$ \\
\hline $18^{*}$ & Morocco & LMI & 17.3 & 1.46 & 5 & 68 & 0.31 & 1.0 & $0.05-0.12$ \\
\hline 19 & North Korea & $\mathrm{LI}$ & 17.3 & 0.6 & 9 & 90 & 0.30 & 1.0 & $0.05-0.12$ \\
\hline 20 & United States & $\mathrm{HIC}$ & 112.9 & 2.58 & 13 & 2 & 0.28 & 0.9 & $0.04-0.11$ \\
\hline
\end{tabular}

Table 1 - Waste estimates for 2010 for the top 20 countries ranked by mass of mismanaged plastic waste (in units of millions of metric tons per year). Econ. Classif.=economic classification: HIC, high income; UMI, upper middle income; LMI, lower middle income; LI, low income (World Bank definitions based on 2010 Gross National Income). The mismanaged waste is the sum of inadequately managed waste plus $2 \%$ littering. Total mismanaged plastic waste is calculated for populations within $50 \mathrm{~km}$ of the coast in the 192 countries considered. pop.=population, gen.=generation, ppd.=person per day, MMT=million metric tons. ${ }^{33}$

Plastic production also helps on the perspectives of the sources of pollution. In 2012, European countries produced 45.9 Megatons of polymer, from which came $40 \%$ packaging, $22 \%$ appliances, furniture, sport, health etc, $20 \%$ building and construction, $8 \%$ automobile, $5 \%$ electrical and electronic equipment. ${ }^{34}$ The use of plastics materials in Western Europe reached about $100 \mathrm{~kg}$ per capita per year in 2005. North America reached the same amount, whereas in Asian countries it was $20 \mathrm{~kg}$ per capita per year. ${ }^{35}$ An evolution of the amount produced and of the distribution of such a production around the world is reflected in the comparison between graphics 1 and 2:

\footnotetext{
31 World Economic Forum, Ellen MacArthur Foundation and McKinsey \& Company (2016, p. 17).

32 Jambeck et al. (2015).

33 Table reproduced from Jambeck et al. (2015, p. 769).

34 Valavanidis and Vlachogianni $(2014$, p. 3).

35 Hollman, Bouwmeester, and Peters (2013, p. 8).
} 

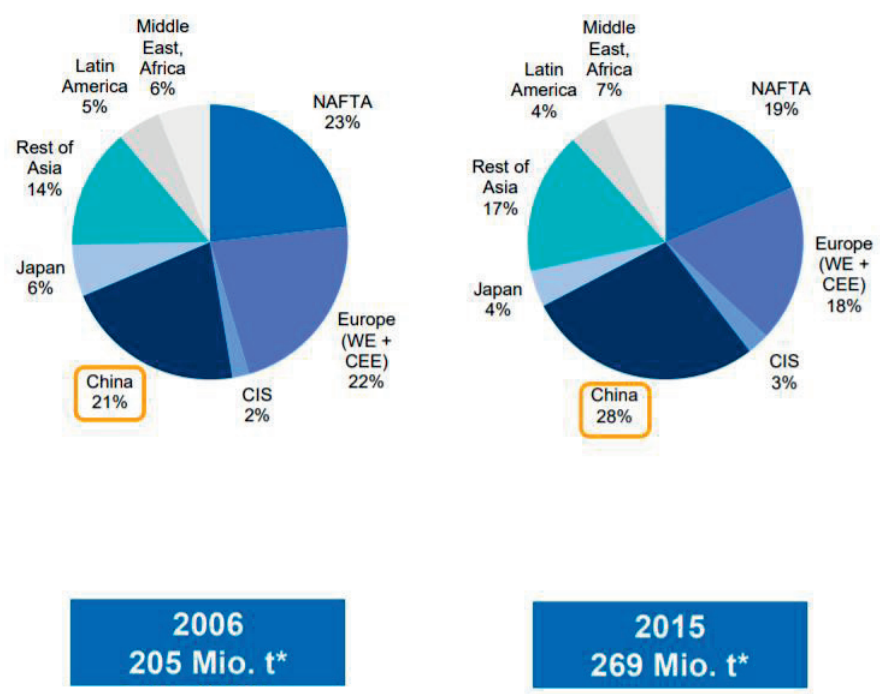

Graphic 1 - plastic production distribution in 2006

Graphic 2 - plastic production distribution in $2015^{36}$

Yet, as mentioned, the great variety of polymers, their properties and versatility, together with the low price, lead to the growth of plastic production and use. Worse, it leads to the growth of single-use disposable plastics. Approximately 50 per cent of plastics are used for single-use disposable applications, such as packaging, agricultural films and disposable consumer items. Only between 20 and $25 \%$ are applicable in long-term infrastructure such as pipes, cable coatings and structural materials, and the remainder for durable consumer applications with intermediate lifespan, such as in electronic goods, furniture, vehicles, etc. ${ }^{37}$

The two figures bellow demonstrate such a spread. In graphic 3 we may see the exponential growth of plastic production, despite the discontinuity in 2009 , not maintained in the following years.

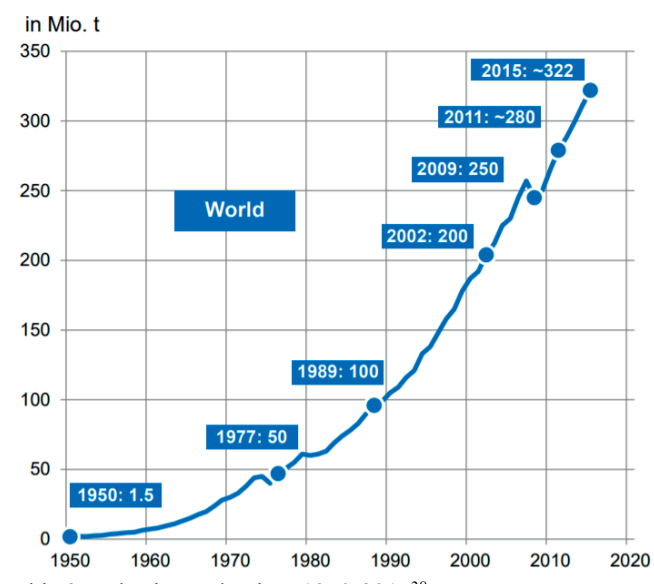

Graphic 3 - Plastic Production, 1950-2015 38

36 Plastics Europe (2016b, p. 2).

37 Hopewell, Dvorak, and Kosior (2009, p. 2115).

38 Plastics Europe (2016a, p. 1). 
Since it has approximately the shape of the well-known graphic representing world human population, one could argue that plastic is merely accompanying population growth. If this was the case, the maintenance of the per capita numbers would already be alarming. Nevertheless, science is providing an even worse scenario.

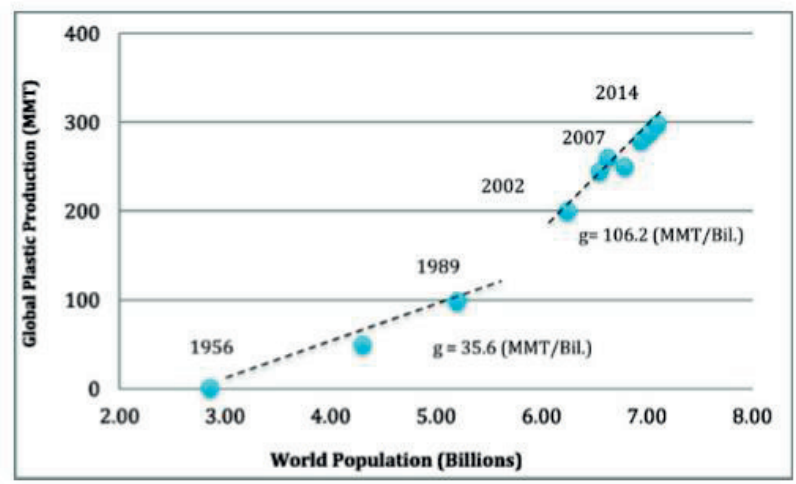

Graphic 4 - The change in global production of plastics with the population ${ }^{39}$

Graphic 4 shows a non-linear relation between world population growth and plastic production growth, meaning that the plastic production growth rate is larger than the world population growth rate.

Besides, this increase comes together with low quantities of reuse or recycling, both leading to the need for large amounts of virgin feedstocks. For instance, packaging alone meant an annual production of 78 tons in 2013, from which $98 \%$ was derived from virgin feedstocks, and 32\% finished directly in waters. If we take the more specific case of PET (polyethylene terephthalate) bottles - the second largest category of plastic packaging used globally - just $14 \%$ of this plastic packaging is recycled globally, whilst a third of it escapes collection entirely, leaving it to pollute streets, beaches and oceans. $^{40}$

That explains why packaging and PET bottles are among the most disputed sources of plastic pollution. There are also other great efforts being made against pollution from straws, laundry and cosmetics, for example, as we describe further on.

With straws, the main concern is that, since it is a small piece of plastic, even where there are recycling initiatives, straws usually are thrown out together with the rest of the trash. This means that straws end in landfills, where wind easily blows them away and make them reach oceans. Moreover, numbers are huge. In the United States alone, people use 500 million plastic straws every day. ${ }^{41}$

Regarding laundry, new findings show that clothes and washing machines contribute greatly to the plastic soup. The apprehension is not only the amount of plastic generated, but also the lack of awareness among people, even those conscientious about plastic pollution. Laundering releases millions of tiny synthetic fibers into the water and large numbers of these then slip undetected through the water treatment plants. So all of us inadvertently contribute to this rapidly growing environmental problem. ${ }^{42}$

Andradry (2017, p. 13).

Greenpeace (2017a, p. 3).

Straw Free (2017).

Plastic Soup Foundation (2017a). 
Cosmetics are likewise among the current biggest concerns. Not only do they constitute another way in which we all unintentionally contribute to plastic consumption and pollution, but also at least 30 different types of polymers appear in the European Union Cosmetic Ingredient 'CosIng' Database, and they have all kind of properties useful for the industry, such as bulking, viscosity controlling, hair fixative, abrasive, and so on. ${ }^{43}$ Once again, those are tiny particles of plastics, which are released into washing water and end up directly in the oceans because they slip undetected through the water treatment plants.

\subsubsection{A North-South Tension}

This subtopic focuses on recent studies that are placing developing countries as the main land-based sources of the plastic that ends up polluting the oceans. Adopting the classification global North and global South serves the purpose of analyzing data according to the Third World Approaches to International Law (TWAIL), which will be done in the next chapter of this thesis.

In continuation to the data displayed in table 1, and in graphics 1 and 2, the core information here is based on a recent study, ${ }^{44}$ where it is argued that ten rivers are responsible for 89 to $95 \%$ of the plastic going into the oceans. Out of those ten, eight are in Asia and two in Africa. That research aimed at building a more comprehensive understanding of the contribution of rivers to plastic debris in the oceans. The estimate provided was derived from data already available in the academic literature about plastic concentration in rivers and the amount of mismanaged plastic waste in the country. ${ }^{45}$

It was not the first study with that approach. Lebreton and others ${ }^{46}$ estimated, earlier in the same year, "that between 1.15 and 2.41 million tons of plastic waste currently enters the ocean every year from rivers, with over $74 \%$ of emissions occurring between May and October. The top 20 polluting rivers, mostly located in Asia, account for $67 \%$ of the global total". ${ }^{47}$ The latter was research that expanded the analysis of Jambeck et. al. from $2015 .^{48}$

Schmidt, Krauth, and Wagner's work innovates by including inner land data, instead of only considering coastal contributions, with the assumption that "the entire river catchment is connected to the coastal sea via the river network" ${ }^{49}$ It meant the inclusion of 41 countries to the consideration. Although their conclusions align with the conclusions from Jambeck et al., Schmidt, Krauth, and Wagner highlight an important uncertainty that arises from the estimation mathematical models used in both studies.

Assuming Model 1 being realistic would suggest that pathways other than rivers such as direct stormwater runoff, wind dispersal and littering potentially account for a considerable fraction of total land-based inputs. If Model 2 would best represent reality, rivers would indeed be a major pathway for land-based plastic inputs to the sea. ${ }^{50}$

Those uncertainties must be accounted for when analyzing the data and conclusions of the studies.

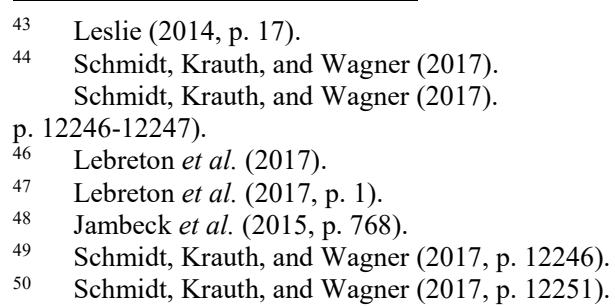


In a way, the geographical heterogeneity comes as no surprise, since "urban land use and population density have been shown to be positively related to plastic concentrations". ${ }^{51}$ However, it has to be analyzed very cautiously. First, because there are estimates based on studies with different approaches and methodologies. Although those factors have been accounted for, even the researchers are alert to the uncertainty of the estimated values and discrepancies depending on the model adopted. ${ }^{52}$ Second, because of the consequences that misinterpretation and misuse of information may cause, which will be further discussed in the third chapter of this thesis. Third, because those consider only the immediate causes, when there are also secondary causes, as will also be further discussed in chapter 3 .

\subsubsection{Companies and Plastic}

There is a general assumption that companies, especially large multinationals, play a major role in the described scenario. This assumption is well grounded, since companies at least determine what products and materials enter the market. However, there is a lack of data to prove it, which is commonly attributed to the fact that collecting and sharing those numbers depend on companies themselves. ${ }^{53}$

Yet, it is possible to gather information, especially from the companies' reports. Some numbers will be displayed in section 5.1.4. They are only estimates, and sometimes contradictory if confronted with others, but they are also only a small part of the contribution of companies to the plastic pollution. This is of even greater concern if we remember that those are companies usually adhering to sustainability initiatives, so they are aligned, at least in speech, with a more sustainable development. Therefore, the original assumption that multinationals are great contributors to the plastic pollution problem is proven right.

\subsection{Plastics Destinations in the Oceans}

As waste in general, plastics that go out of use can be recycled, incinerated, end in landfills or in nature. Since the focus of this research is the plastic soup, the aim is to describe the destination of plastics once it is in the oceans, thus allowing a perception of the kind, amount and paths of such pollution.

The most known destination of the waste that ends in the ocean is the North Pacific Gyre. The winds and the rotation of the Earth, the ocean currents in the high-pressure zone of the North Pacific Gyre form an enormous vortex that revolves in a clockwise direction and collects flotsam from the coasts of Japan and China, as well as from the Pacific coast of Mexico, the United States, and Canada. This means that something entering into the sea at the beach at Sao Francisco is carried by the currents of California, North Equatorial and Kuroshio, until it lands in the Garbage Patch one year later. ${ }^{54}$

Nonetheless, there are four other vortexes where plastic concentrates because of circulating ocean currents: South Pacific, Indian Ocean, North Atlantic and South Atlantic Gyres. They are in subtropical areas, above and below the equator, and all of them have higher concentrations of plastic rubbish compared to other parts of the oceans. In the North Atlantic Gyre, 20,328 pieces of plastic were found per square kilometer, while in the North Pacific Gyre, it was 334,271 pieces per square kilometer. $^{55}$

Besides, there are hotspots inland too, such as the Mediterranean Sea, the Black Sea and the Baltic Sea. These places include bays lined with large cities, bays into which plastic floats and remains, river mouths, coastlines where industries are situated, places or islands where different ocean currents

Baldwin, Corsi, and Mason (2016, p. 10377).

Schmidt, Krauth, and Wagner (2017, p. 12251).

Eroglu (2014).

Haffner (2009).

Plastic Soup Foundation (2017b). 
congregate. Shipping lanes and around fishing areas are other zones where high concentrations of debris are found. ${ }^{56}$

In the case of the Mediterranean Sea, on the one hand, there is a permanent supply of plastic coming from the rivers that flow into the Mediterranean Sea and from the coastal cities. On the other hand, the connection to the Atlantic Ocean at the Strait of Gibraltar is so narrow that the plastic that ends up in the Mediterranean Sea stays there. Reports states an average of 116,000 pieces of plastic per square kilometer. ${ }^{57}$

Other than that, marine litter is distributed along water columns, sea-beds, and beaches and shores. In the water column, they are transported horizontally and vertically and most of it is floating on or close to the water surface $-90 \%$ are light plastics or related polymer items. $70 \%$ of the heavier components go to the seabed, $15 \%$ are deposited on beaches and shores worldwide, and the other $15 \%$ float around the world..$^{58}$

Speaking about a more general framework, a comparison between studies shows that plastic pollution affects Pacific and Atlantic Oceans equally. Meanwhile, a north-south analysis shows that the South Atlantic and Southern Ocean values are low in comparison with those reported from the North Pacific Ocean, except around the United Kingdom. Even the densities of floating debris are lower in the North Atlantic compared with equivalent values for the North Pacific and Caribbean Atlantic. Finally, there is a trend of tropics to poles decrease in a 3 items $/ \mathrm{km}^{2}$ rate, so that the lowest quantities are found towards the poles. ${ }^{59}$

A large review in the literature from 1990 to 2005 allowed a comparison between regions, resulting in tables, divided by the different methods used in each of the research projects. ${ }^{60}$ All of the four tables report the number of items per square kilometer, by location and date. Table 2 shows the levels of floating debris visually seen by observers on ships. Table 3 brings data regarding debris in the ocean floor from studies that used trawl nets to collect the debris. Both tables 4 and 5 display the levels of stranded debris on shorelines throughout the world. They are reproduced below.

\footnotetext{
56 Galgani et al (1995, p. 713).

57 Plastic Soup Foundation (2017b).

58 De Guchte (2005).

59 Barnes and Milner (2005, p. 822).

60 Allsop et al. (2006).
} 


\begin{tabular}{|c|c|c|}
\hline Location and Date & $\begin{array}{l}\text { Mean Number of Items } \\
\text { of Debris per } \mathrm{km}^{\text {? }}\end{array}$ & Reference \\
\hline $\begin{array}{l}\text { West Spitsbergen, } \\
\text { Arctic }(2002)\end{array}$ & $0-3$ & Barnes and Milner 2005 \\
\hline $\begin{array}{l}\text { North Atlantic, latitude } 0^{\circ} \\
\text { to } 50^{\circ} \mathrm{N}(2002)\end{array}$ & $0-20$ & Barnes and Milner 2005 \\
\hline English Channel (2002) & $10-100+$ & Barnes and Milner 2005 \\
\hline $\begin{array}{l}\text { Mediterranean } \\
(1997) \\
(2000)\end{array}$ & $\begin{array}{l}\text { Density of the order of: } \\
1.5-2.5 \\
1.5-3\end{array}$ & Aliani et al. 2003 \\
\hline $\begin{array}{l}\text { NE Pacific, latitude }<20^{\circ} \mathrm{N} \\
(1986-91)\end{array}$ & 1.8 & Thiel et al. 2003 \\
\hline $\begin{array}{l}\text { NE Pacific, latitude } 20^{\circ} \mathrm{N} \text { to } 40^{\circ} \mathrm{N} \\
(1986-91)^{\circ}\end{array}$ & $\mathbf{I}$ & Thied et al. 2003 \\
\hline $\begin{array}{l}\text { NE Pacific, latitude }>40^{\circ} \mathrm{N} \\
(1986-91)^{\circ}\end{array}$ & 1 & Thied et al. 2003 \\
\hline $\begin{array}{l}\text { NW Pacific, latitude }<20^{\circ} \mathrm{N} \\
(1986-91)\end{array}$ & 0.25 & Thied et al. 2003 \\
\hline $\begin{array}{l}\text { NW Pacific, latitude } 20^{\circ} \mathrm{N} \text { to } \\
40^{\circ} \mathrm{N}(1986-91)\end{array}$ & 0.8 & Thied et al. 2003 \\
\hline $\begin{array}{l}\text { NW Pacific, latitude }>-40^{\circ} \mathrm{N} \\
(1986-91)\end{array}$ & 0.2 & Thied et al. 2003 \\
\hline $\begin{array}{l}\text { Southern Atlantic, latitude } 50^{\circ} \mathrm{S} \\
\text { to } 0^{\circ} \mathrm{S}(2002)\end{array}$ & $0-10$ & Barnes and Milner 2005 \\
\hline $\begin{array}{l}\text { Indonesia (Ambon Bay) } \\
\text { Figure is for worst affect areas } \\
\text { (199.4/5) }\end{array}$ & $>4$ per $\mathrm{m}^{2}$ & Uneputty and Evans 1997 \\
\hline $\begin{array}{l}\text { Chile, coastal waters, latitude } 20^{\circ} \mathrm{S} \\
\text { to } 40^{\circ} \mathrm{S}(2002)\end{array}$ & $1-36$ & Thiel et al. 2003 \\
\hline $\begin{array}{l}\text { Chile, coastal waters, latitude } 40^{\circ} \mathrm{S} \\
\text { to } 50^{\circ} \mathrm{S}(2002)\end{array}$ & $<\mathbf{1}$ & Thied et al. 2003 \\
\hline $\begin{array}{l}\text { Southern Ocean, near Antarctic } \\
\text { Peninsula }\end{array}$ & $0-1$ & Barnes and Milner 2005 \\
\hline Southern Ocean, Drakes Passage & $0-3$ & Barnes and Milner 2005 \\
\hline
\end{tabular}

Table 2 - Levels of floating debris in the world's oceans. Data collected by visual sighting from ships

\begin{tabular}{|c|c|c|}
\hline Location and Date & $\begin{array}{l}\text { Mean Number of Items } \\
\text { of Debris per km² }\end{array}$ & Reference \\
\hline $\begin{array}{l}\text { Alaska, Kodiak Island } \\
\text { (1994-6) } \\
\text { Debris in coastal inlets }\end{array}$ & $\begin{array}{l}\text { Plastic debris only, given } \\
\text { as the range not the mean } \\
22-31.5\end{array}$ & Hess et al. 1999 \\
\hline Debris outside inlets & $7.8-18.8$ & \\
\hline Baltic Sea (1992-8) & 126 & Galganl et al. 2000 \\
\hline North Sea (1992-8) & 156 & Galganl et al. 2000 \\
\hline Celtic Sea (1992-8) & 528 & Galgani et al. 2000 \\
\hline Bay of Blscaye (1992-8) & 142 & Galganl et al. 2000 \\
\hline Gulf of Lion (1992-8) & 143 & Galgani et al. 2000 \\
\hline NW Mediterranean (1992-8) & 1935 & Galganl et al. 2000 \\
\hline $\begin{array}{l}\text { Mediterranean, coastal Greece, } 2 \text { sltes } \\
1997 / 8\end{array}$ & 89 and 240 & Stefatos et al. 1999 \\
\hline $\begin{array}{l}\text { Indonesia, Ambon Bay, } \\
5 \text { sltes }(1994 / 5)\end{array}$ & 0.05 to 0.69 per $\mathrm{m}^{2}$ & Uneputty and Evans 1997 \\
\hline $\begin{array}{l}\text { Caribbean, curacao } \\
5 \text { recreational beaches }\end{array}$ & $19.8-66.0$ per $100 \mathrm{~m}^{2}$ & Nagelkerken et al. 2001 \\
\hline 2 non-recreational beaches & $0.9-1.1$ per $100 \mathrm{~m}^{2}$ & \\
\hline
\end{tabular}

Table 3 - Levels of debris in the seafloor of the world's oceans. Data are from studies that used trawl nets to collect the debris 


\begin{tabular}{|c|c|c|}
\hline Location and Date & $\begin{array}{l}\text { Mean Number of Items } \\
\text { of Debris per km }\end{array}$ & Reference \\
\hline $\begin{array}{l}\text { USA } \\
\text { Hawall (1989) } \\
\text { Callfornla } \\
\text { Texas } \\
\text { Mexico }\end{array}$ & $\begin{array}{l}262 \\
814 \\
1712 \\
8000\end{array}$ & Jones 1995 \\
\hline $\begin{array}{l}\text { NE Brazll, Costa dos Conquelros } \\
(2002-4)\end{array}$ & 14.6 & Santos et al. 2005 \\
\hline Carlbbean St. Lucla (1991/2) & $4500-11,200$ & Corbin and Singh 1993 \\
\hline Carlbbean Dominica (1991/2) & $1900-6200$ & Corbin and SIngh 1993 \\
\hline Indonesla (23 Islands) & Range $0-29,100$ & Willoughby et al. 1997 \\
\hline Tasmanla (1990/1) & 300 & Jones 1995 \\
\hline Western Australia (1992) & 3660 & Jones 1995 \\
\hline
\end{tabular}

Table 4 - Levels of stranded debris on shorelines throughout the world

\begin{tabular}{|c|c|c|}
\hline Location and Date & $\begin{array}{l}\text { Mean or Range of } \\
\text { Number of Items }\end{array}$ & Reference \\
\hline $\begin{array}{l}\text { Northern Atlantlc shores, } \\
\text { latitude } 9.5^{\circ} \mathrm{N} \text { to } 57^{\circ} \mathrm{N}(1984-2001)\end{array}$ & $0.15-70.9$ per $m$ & Barnes and Milner 1995 \\
\hline UK, EdInburgh (1994) & 0.8 per $\mathrm{m}^{2}$ & $\begin{array}{l}\text { Velander and Mocognl } \\
1998\end{array}$ \\
\hline Mediterranean & & Barnes and Milner 2005 \\
\hline $\begin{array}{l}\text { Croatla (2000) } \\
\text { SIclly (1988) } \\
\text { Spain (1991) } \\
\text { Cyprus (1988) } \\
\text { Israel (1988/9) }\end{array}$ & $\begin{array}{l}\text { 6.4 } \text { per } \mathrm{m} \\
9-231 \text { per } \mathrm{m} \\
33.2 \text { per } \mathrm{m} \\
10.4 \text { per } \mathrm{m} \\
7.3-8.7 \text { per } \mathrm{m}\end{array}$ & \\
\hline Gulf of Oman, Omanl coast (2002) & 1.79 per $\mathrm{m}$ & Claereboudt 2004 \\
\hline $\begin{array}{l}\text { Gulf of Aqaba, Jordanian coast } \\
\text { (1995) }\end{array}$ & 3 per $\mathrm{m}^{2}$ & $\begin{array}{l}\text { Abu-HIlal and AINajJar } \\
2004\end{array}$ \\
\hline Southern Atlantic & & Barnes and Milner 2005 \\
\hline Tristan da Cunha (1984) & $0.3-0.8$ per $\mathrm{m}$ & \\
\hline Gough (1984) & 0.019 per $\mathrm{m}$ & \\
\hline
\end{tabular}

Table 5 - levels of stranded debris on shorelines throughout the world.

Analyzing the data, despite the time differences of when the studies were held, it is possible to confirm the general affirmation that debris distribution is ubiquitous around the world, and that the latitude plays an important role in the density of plastic pollution. Specifically, the floating debris tends to move towards mid-latitudes, meaning higher concentrations in those areas in comparison to areas near the poles. ${ }^{61}$

Nonetheless, the volumes at the north gyres, and especially at the North Pacific, are larger. This occurs, presumably, because of its vast area and because of the large inputs of plastic waste from the coastlines of Asia and the United States. ${ }^{62}$ Other factors that influence the type and amount of debris present include proximity to urban centers, industrial and recreational areas. ${ }^{63}$

\footnotetext{
$61 \quad$ Allsop et al. (2006, p. 23).

62 Sebille et al. $(2015$, p. 9$)$.

63 Sheavly (2005).
} 
Lastly, a recent study brought a major concern: although the numbers are already alarming, they may be an underestimation of the real scenario. Sebille and others explain that the data standardization that is most commonly used may lead to a miscalculation. This together with variations in data collection, sample analysis, count-to-mass conversions, and model designs, made their conclusions point to much larger amounts of plastics debris in the oceans than calculated before. ${ }^{64}$

\subsection{Consequences for Nature and Human Health}

The consequences of all that pollution are incalculable, starting with visible ones, especially with plastics that end up on the shore or with the floating pollution, which already damages human and nature's health. Then, passing through direct influences on animals' health, and arriving at the impacts on the food chain, from plankton and reaching human feeding.

Among the specific dangers to marine life, there are the threats of entanglement, ingestion, destruction, destruction or smothering of the seabed - including coral reefs and seagrasses -, and transportation of invasive species. ${ }^{65}$ Species encounter marine litter through ingestion $(35.92 \%)$, entanglement $(30.55 \%)$, colonization $(28.1 \%)$, coverage $(2.85 \%)$, and other $(2.27 \%)$, and reports already show 1,441 species affected. ${ }^{66}$

The effects strike all kinds of aquatic animals, as a summary of scientific research shows in graphic 5:

\section{Aquatic life affected by litter}

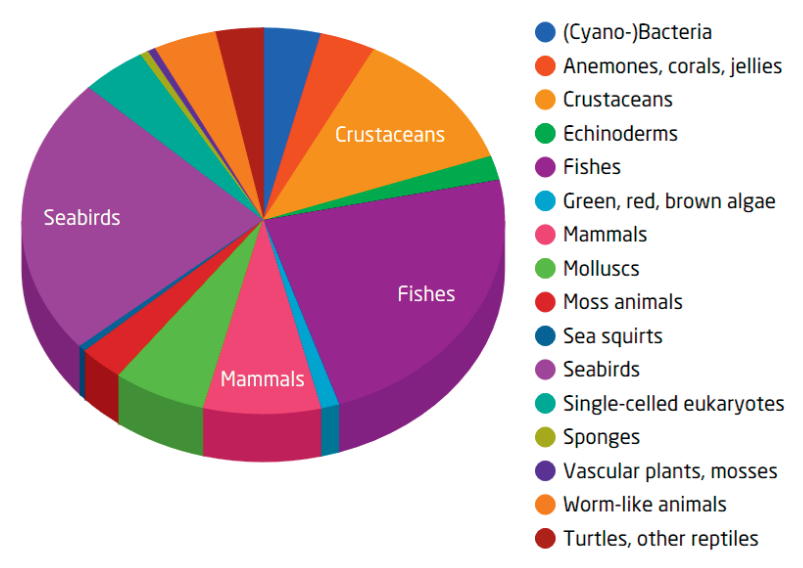

(c) AWI-LITTERBASE

Graphic 5 - aquatic life affected by marine litter, classified by species and genera, accordingly to the World Register of Marine Species ${ }^{67}$

Seabirds are the most affected, representing $23.15 \%$ of the registers. According to a UNEP report, a million seabirds die every year because they mistake plastic for food. ${ }^{68}$ All kinds of waste are found inside dead animals around the world, and they usually starved to death with a stomach full of plastic.

64 Sebille et al. (2015, p. 9).

65 De Guchte (2005).

66 Tekman, Gutow, and Bergman (2017).

67 Reproduced from Tekman, Gutow, and Bergman (2017).

68 UNEP GPA (2001, p. 10). 
Moreover, hundreds of thousands of marine mammals and turtles die in fishing nets or grow up crippled. One of the most famous cases was of "Mae West", a turtle whose shell was constricted at the middle into a wasp waist by a plastic ring. ${ }^{69}$

Another serious consequence perpetrated by plastic pollution is the spread of toxic materials. For example, plastic acts like a sponge for polychlorinated biphenyls (PCB) and other toxins. They were banned during the 1970's, after the appearance of hermaphrodite fish and after polar bears showed the damage they cause to animals' hormonal balance. Still, plastic produced before this time will continue to contaminate the oceans with PCB. ${ }^{70}$

A study from $2005^{71}$ - or, in other words, three decades after the ban of the substance - determined that, although heterogeneously, pellets are highly contaminated by PCB, even in remote areas. Similarly, a study from $2013^{72}$ demonstrated that, even though heterogeneously, there is still much contamination by polycyclic aromatic hydrocarbons (PAHs) in plastic pellets.

Figure 1 summarizes the main impacts of the plastic soup on aquatic life, as described so far.

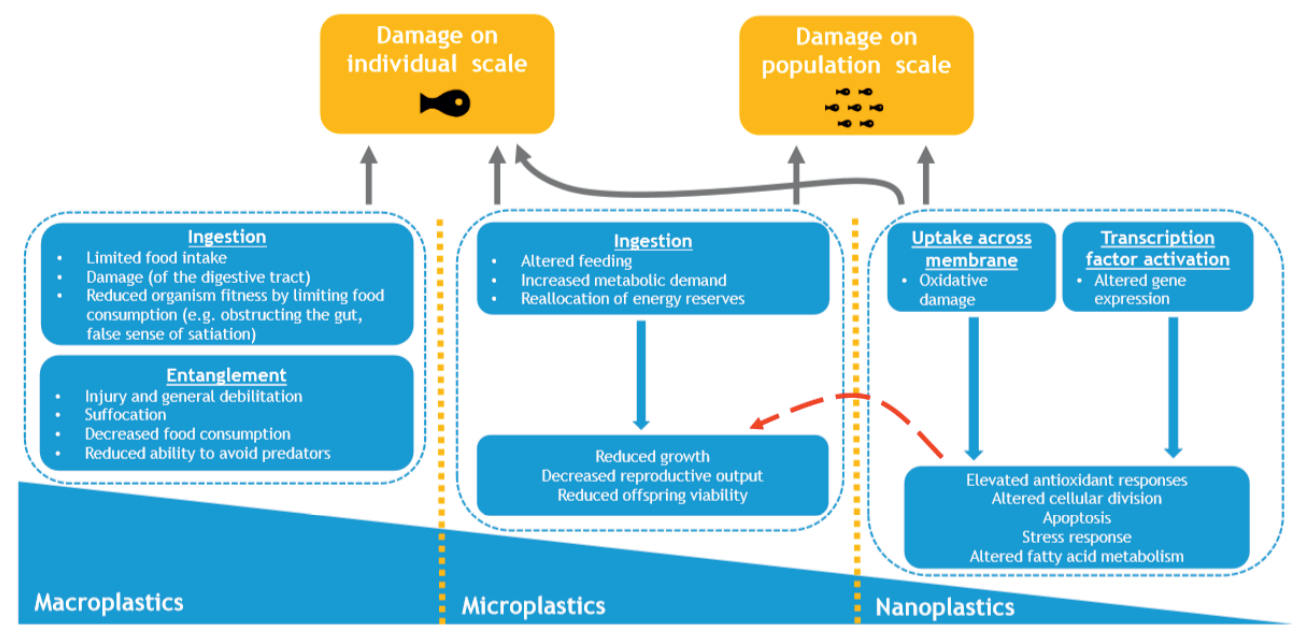

Figure 1 - Impacts of different sizes of plastic on organisms ${ }^{73}$

Aggravating the problem, more than one third of the lantern fish have plastic particles contaminated with toxins in their stomachs. This happens because this fish eats zooplankton, but, in its haste, it snaps at everything they see, including microplastics. Such a discovery proves the hazard to the food chain, since at one time lantern fish were the most widespread fish in the ocean and the main food of tuna, swordfish, and dolphinfish. The accumulation in the food chain makes plastic, pollution and toxins land on our plates, and the consequences of it are still unknown. ${ }^{74}$

Therefore, although the effects of the plastic soup are easier to identify in animals than in humans, there are many concerns regarding human health and safety. There are the immediate risks, especially because items such as medical waste, rope, and fishing lines impose a direct risk to those enjoying or working in beaches and in the ocean. In addition, discarded syringes, condoms, and tampon applicators bring more problems that are serious for water quality. In addition, floating debris may

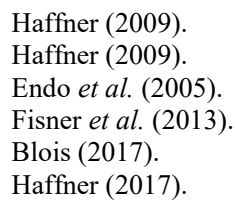


entangle swimmers, divers and snorkelers. Furthermore, medical and hygiene plastic debris often carry invisible pathogens, such as streptococci, fecal coliform, and other bacterial contamination, which can result in infectious hepatitis, diarrhea, bacillary dysentery, skin rashes, typhoid and cholera. ${ }^{75}$ More recently, scientists from Orb Media also found out that microplastics are even in tap water around the world. ${ }^{76}$ Finally, it has been demonstrated that the release of toxicity from microplastic may be even more harmful to human health than the ingested plastic itself. ${ }^{77}$

So far, I have described the consequences of plastic waste ending in the oceans. At the other end of the matter, there is feedstock, a major problem since over $90 \%$ of plastics produced derive from virgin fossil feedstocks. This represents approximately $6 \%$ of global oil consumption - or the same as the global aviation sector. ${ }^{78}$ Just to make plastic bottles, every year we use 17 billion barrels of oil, which would be enough to fuel one million cars. ${ }^{79}$ This is to say that the environmental impacts go further than the pollution caused by plastics itself. In this example, it relates to the environmental harm of oil exploitation.

As the manufacture of plastics also requires energy, its production is responsible for the consumption of a similar additional quantity of fossil fuels. ${ }^{80}$ Consequently, there are implications for other environmental issues, such as global warming, and implications for marine life directly related to oil extraction. As this is not the focus of the research, it will not be taken further, but it has to be accounted for when referring to consequences of plastics to human health and marine life.

\subsection{Existing and Proposed Technical Solutions}

When the subject is solving environmental issues, some approaches are on common ground, such as public awareness and the "6R's" $"$ " that lead to an attempt of a circular economy. ${ }^{82}$ In any of those, innovation is essential. I will bring to this topic some examples of current initiatives on the technical edge, which are the ones needed so that law may mediate and enable their implementation. Regarding awareness, it is necessary in all of them in order that they are achievable.

The first " $R$ " is rethink, and it is necessary in all of the other five. The second " $R$ " is repair, which extends the life of a product by repairing its parts. The third is re-condition, by which the life of a product is extended by significantly overhauling it. In the fourth " $R$ ", re-manufacture, the old products serve as a base for new ones. All four of them help to diminish the amount of plastic that needs to be discarded and that, for the most part, ends in the oceans.

For the moment the fifth "R" will be put aside, and will be addressed in topic 2.4.1. As the sixth and last " $\mathrm{R}$ " we have recycling, meaning that "products can be reprocessed and converted into raw material to be used in another or the same product". ${ }^{83}$ However, it is more complex when it concerns plastic recycling, because it includes four categories: "primary (mechanical reprocessing into a product with equivalent properties), secondary (mechanical reprocessing into products requiring lower properties), tertiary (recovery of chemical constituents) and quaternary (recovery of energy)". 84

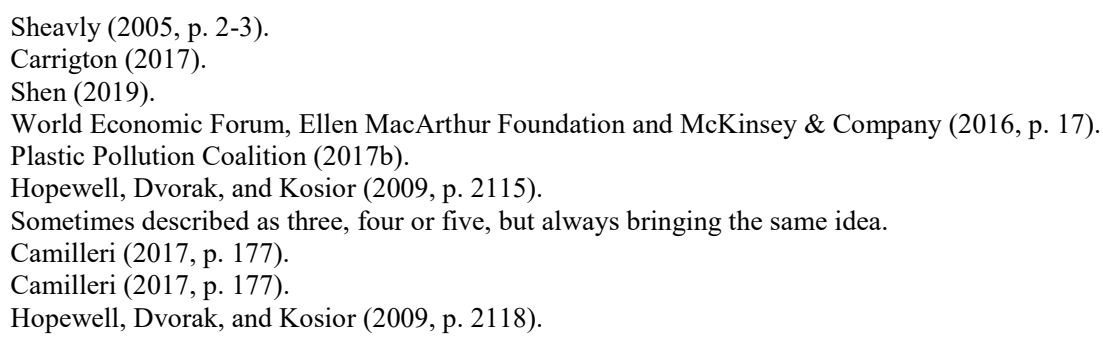




\subsubsection{Various Bans on Plastic}

As the fifth $\mathrm{R}$, there is re-use. In that sense, a movement that is continuously growing is the refuse single-use plastics. For example, Plastic Pollution Coalition "is a growing global alliance of organizations, businesses, and thought leaders working toward a world free of plastic pollution and its toxic impact on humans, animals, and the environment". ${ }^{85}$ The more than hundred suggestions for a plastic-free life ${ }^{86}$ usually relate to changing daily habits.

Among those, I highlight not using a plastic straw and bringing your own bag, because they lead to the " $R$ " of reducing - which is closely related to the previous one - and to two other current movements that are trying to help solving the plastic problem. However, it is important to remember that there are other engagements, from the more general, such as Costa Rica aiming to eliminate single-use plastics by $2021,{ }^{87}$ to another also with specific targets, such as the United Kingdom starting a ban on microplastics in cosmetic products. ${ }^{88}$

The first of the two mentioned movements is Be Straw Free. It started in 2011 when a nine-year-old asked for a soda in a restaurant and it came with a straw. Indignant with the useless use of plastic, Milo Cress not only refused his straw but also went to the restaurants of his city and asked them not to give straws unless requested by customers. The campaign shows some results: it reached Walt Disney World's Animal Kingdom and the food concession areas of Smithsonian Institution museums. Even a managing director for plastics markets at the American Chemistry Council said in a National Geographic article that the group would make attempts to eliminate plastic straws, although a spokesperson said they would not be able to comment. However, it is possible to see more and more progress after 2015, when a video showing the removal of a straw from a turtle's nose went viral in YouTube. ${ }^{89}$

With the same purpose, the efforts to abolish single-use plastic bags are increasing, although mostly still on the planning stage. Numerous news and data collections are trying to map the attempts and advances in that sense. The Kenya case is attracting a lot of attention because making, selling or using a plastic bag is now a crime in the country, and those who disobey may face imprisonment or fines that may reach $U \$ 40,000.00$.

The toughest law in the matter yields news worldwide, ${ }^{90}$ but many countries already have legislation to ban partially or completely single-use plastic bags. Figure 2 represents the 40 countries $^{91}$ and a diversity of dates and types of prohibition, as at August $28^{\text {th }}, 2017$.

\footnotetext{
85 Plastic Pollution Coalition (2017).

86 Terry (2015).

87 Lofgren (2017).

88 Johnston (2017).

89 Fears (2017).

90 Some examples are: Lant (2017); Houreld and Ndiso (2017); Hickman (2017); Chow (2017); Lui (2017); O Globo (2017); Karumba (2017).

91 Note that not all country names are shown, and especially the European ones may be difficult to identify.
} 


\section{Countries with plastic bag bans}

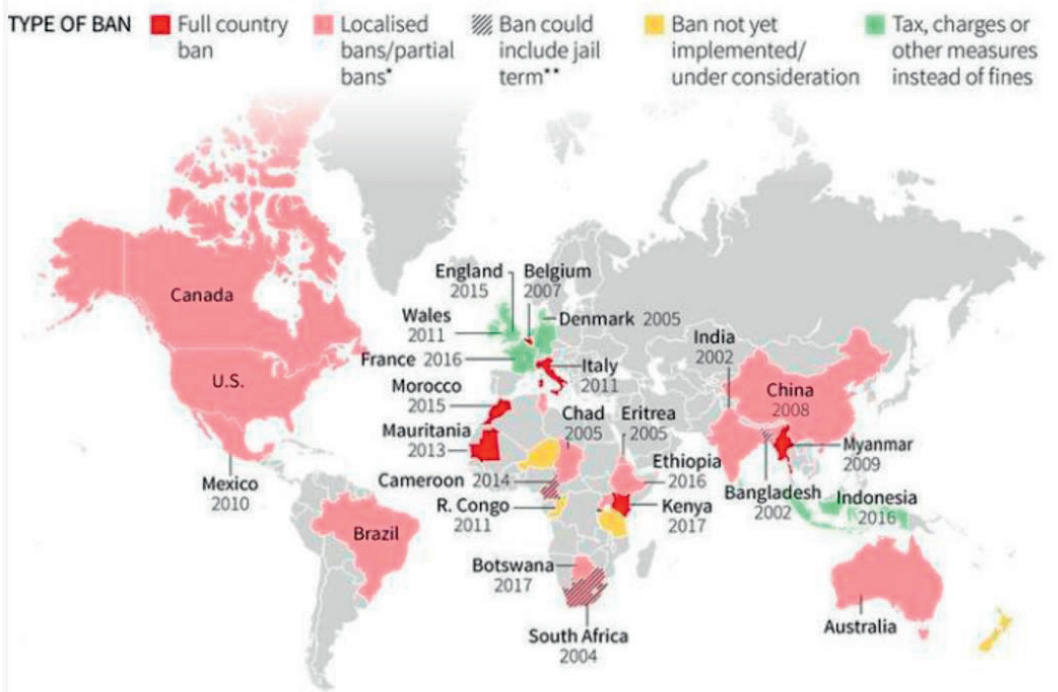

Sources: UNEP; Greenpeace, national governments. "Countries without dates have bans placed on various dates. " For some cases. Figure $2-40$ countries with plastic bag bans ${ }^{92}$

The example of plastic bags also reinforces the importance of public awareness. Although observing the growth of initiatives against the plastic bags, and knowing that plastic bags are one of the biggest villains of the environment, ${ }^{93}$ population resistance to change is still a major issue. In Brazil, for instance, bans are still partial and localized because the laws in that way are regional. In the country, cities such as Belo Horizonte and Sao Paulo already have regulations against the distribution of plastic bags in supermarkets. ${ }^{94}$ On the other hand, in the Metropolitan Area of Vitoria ${ }^{95}$ the government went back on laws because people were unwilling to obey and in the city of Rio de Janeiro the law is inefficient. ${ }^{96}$ Similarly, at a national level, there are two legislative proposals, dating from 2011 and 2012, which Congress still has to analyze.

The last examples are a clear warning on the challenges related to regulation frameworks. From passing a proposal until its enforcement, there are many influences and obstacles involved. That implies that the well and long known problem of efficacy in law is of great concern when discussing solutions to the plastic pollution problem, where identifying precise influences, causes and consequences is even more challenging.

\subsubsection{Removal of Plastics}

All of the possibilities described above are parts of the solution, but, as seen, they are not enough. Innovation plays a big role in trying to keep pace with or even to identify the differences of all plastic pollution. From now on, I describe some advances in that sense.

As a first example, there is scientific research to improve already existing processes. Plastics and resource consultancy Nextek has come up with a new pigment to replace carbon black, since this is not

\footnotetext{
92 Cabrera (2017).

93 Lima (2016).

94 Lima (2016).

95 Folha Vitória (2012).

96 Costa (2015).
} 
identifiable by infrared sensor in sorting facilities, making it difficult to recycle. Scientists from the University of Bath developed biodegradable cellulose microbeads that may be used to replace those made from plastic in cosmetics. ${ }^{97}$

Solving packaging, and mainly water bottles issue, is a common concern. I highlight in that sense innovative solutions aiming at "edible packaging". A British startup created an eatable bubble that explodes in the mouth and the person may drink the water inside it normally. Those are the Ooho Bubbles and they keep the water inside because of a thin membrane made of natural sugar extract, and if they are not consumed within four weeks, it biodegrades completely. ${ }^{98}$ Another "edible packaging" solution is being developed by the biomedical David Edwards. The bottles would be made of biodegradable material and have a taste close to the beverage. ${ }^{99}$ Similarly, Ari Jonsson, an Icelander student, found a way to make plastic bottles from seaweed, which may also be eaten after use and, if not, the empty bottle starts to degrade. ${ }^{100}$

Those innovative solutions described so far focus on the input edge. Many studies also concentrate on the output of plastics in the ocean, even though we are still far from a real solution, since there are possibilities for removal processes, but their rates are essentially unknown. ${ }^{101}$

Some studies demonstrate what may be expected. Depending on the species of the seabird, for example, removal of plastic from stomach content can be quite rapid if exposure to plastic stops. ${ }^{102}$ This gains particular importance because microplastics might fragment to undetectable sizes, sink, be deposited on shorelines, or be ingested and subsequently reduced in size (e.g., due to digestive grinding) and/or transported to land or the seafloor upon egestion. ${ }^{103}$ This indicates that the challenge of removing plastic from the environment is huge and diverse, but may grow to show results also in the fauna, which shows remarkable capacity for recovering from damage once exposure ceases.

Therefore, although at first the news may appear optimistic, the amount of work to even diagnose the dimension of the problem and then to deal with it is still enormous and science is only beginning.

Here, I describe some advances for removal of plastics from the ocean. The first one is the discovery in Japan, on 2016, of a bacterium that is capable of completely decomposing PET plastic. ${ }^{104}$ Before that, the only description of a species interacting with PET was of two filamentous fungi that could grow in mineral mediums containing PET, and even the substances capable of hydrolyzing PET are very few. The bacteria Ideonella sakaienses adheres to PET and secretes PETase, and also achieves an intermediate reaction, leading to an efficient conversion of PET into its environmentally benign monomers. A group of scientists has identified through the RNA-sequence the enzymes responsible for PET degradation. ${ }^{105}$

Two other young scientists are going through a similar path, but from the creation of a genetically modified bacterium that can break down plastics 80 times faster than the best known organism. The chemical products of the reaction are water and $\mathrm{CO} 2$, and the resulting cell bacteria may be used to feed fish. ${ }^{106}$

Another approach is the one of The Ocean Cleanup, a non-governmental organization whose plans are to clean $50 \%$ of the Great Pacific Garbage Patch in 5 years with the full-scale deployment of their

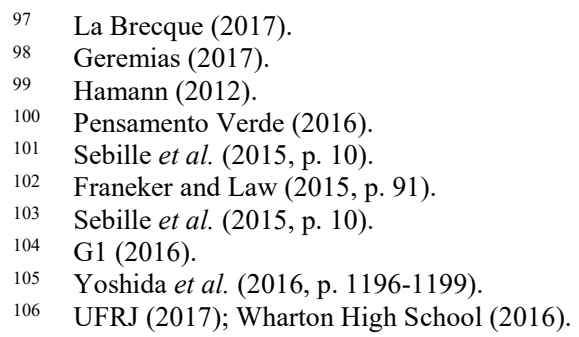


technological systems. ${ }^{107}$ The idea of Boyan Slat, founder and CEO of The Ocean Cleanup, is to use the concentration of plastics due to plastics currents and apply the technology he developed. ${ }^{108} \mathrm{~A}$ continuous hard-walled floating pipe made from high density polyethylene would autonomously stay in the gyre. Real-time telemetry coupled with algorithms would allow the situation to be monitored, for condition, performance and trajectory, as well as to determine optimal deployment locations. ${ }^{109}$

In 2017, the Ocean Cleanup planned to start the Pacific cleanup by 2018 and scale up globally by 2020. In order to do so, the non-profit organization is preparing the first cleanup system deployment, finalizing detailed engineering, and testing system components. To arrive at this point, the institution organized a crowdfunding, produced the first high-resolution map of the Great Pacific Garbage Patch, tested in a scale model, launched a prototype, and did an aerial expedition.

Naturally, this is not an exhaustive description of all the attempts around the world, but it demonstrates the challenge, the innumerous possibilities, and the road ahead. Finally, I did not enter the discussions about solutions through the law, which will be the focus of the next chapter.

\subsubsection{Special Attention to the Biobased Plastics}

Regarding technical solutions, and particularly regarding solutions as alternatives to the material itself, biobased plastics may be appealing, but are also slightly misleading. The term refers to different kinds of products, but not all of them may be considered sustainable:

The term 'bioplastics' is often used for a group of different materials; materials based on biomass, materials that are biodegradable, or a combination of both. For example, there are fossil-based biodegradable materials and also biobased materials that are not biodegradable. Plastics can also occur in blends or in multilayer structures with fossil based plastics. ${ }^{110}$

Biodegradability, in its turn, is the characteristic of the plastic that is converted into water and $\mathrm{CO} 2$ by a micro-organism in the presence of oxygen, and it depends on the 'aggressiveness' 111 of the environment. ${ }^{112}$

Odegard and others ${ }^{113}$ summarized the criteria to identify the sustainability of biobased and biobased biodegradable plastics: (i) Green House Gases (GHG) balance; (ii) the use of (natural) resources throughout the life cycle; (iii) biodegradability; (iv) influence on litter and plastic soup; (v) end-of-life. The fourth one is logically the most relevant for the purposes of this research, more specifically the approach of Odegard's report to answering the question: can biobased plastics play a role in minimizing plastic soup risks?

In that research, they point out that, for macro-plastic, the technical solutions including biobased plastics are not as effective as using public awareness, by communicating to citizens on how to properly dispose of waste. With regard to micro-plastic, the potential results depend on its original source. "Biodegradable plastics can be a (partial) solution in the case of the use of consumer products and in agricultural products. In all other instances biodegradable and biobased plastics are not a solution for the plastic soup". ${ }^{114}$

107 The Ocean Cleanup (2017b).

108 Slat (2017).

109 The Ocean Cleanup (2017a).

110 Odegard et al. $(2017$, p. 4).

111 Aggressiveness vary depending on several chemical characteristics of the environment. For instance, it increases from marine water to fresh water to soil and to a composting facility. Deconinck, and Wilde (2013, p. 21).

112 Deconinck and Wilde (2013).

113 Odegard et al. (2017).

114 Odegard et al. (2017, p. 52). 
Furthermore, oxo-degradable plastics do not contribute to a circular economy, although they degrade when exposed to sunlight or heat. Because, still, their degradation takes 2-5 years, ${ }^{115}$ and "they are not compostable, are reusable only to a limited extent, and are not suitable for recycling in current recycling schemes". ${ }^{116}$

However, biodegradable plastics may come as solutions to particular cases. The first particular example is the use of micro-plastic in consumer goods, such as in cosmetics. In several cases, they may just be excluded from the composition, and in others, they may be replaced by biodegradable plastics that respond to the marine environmental conditions. ${ }^{177}$ The second particular example is with industrial and agricultural products, since it is common to that use that products are unintentionally left in nature, which is the reason why biodegradable plastics may come as a solution. ${ }^{118}$ The third and final particular example is the effort to substitute bags for waste disposal, which is considered a solution, especially for the disposal of compostable waste. ${ }^{119}$

\subsection{Stages Leading to Plastic Pollution of the Oceans}

Just as most of the pollution caused by waste, a chain that starts with the production and goes all the way to the final destination causes the plastic pollution of the oceans. The immediate harm is naturally the misleading final destination, in this case making plastics arrive to the oceans. However, it is possible to envision the harm in every step in the way, and, therefore, look for solutions in each one of them.

Starting from the previously description, I now organize the process in the identified stages and connect them to the technical proposed solutions, accordingly to how they intend to influence in the chain.

The first step is production, which is increasing continuously. In this, the pathways that influence most are those innovating by changing the materials, that is, the edible packaging - Oohoo Bubbles, edible bottles, seaweed bottles -, and sustainable biobased plastics. Then, sale and consumption, where actions towards reducing the use of plastics play a major role, thus: refuse single-use plastics, $B e$ Straw Free, and support the ban on plastic bags. Finally, disposal and final destination, in which more traditional approaches are still highlights: increasing public awareness and improving waste management.

Another important aspect is that the chain is not complete by itself. Since a core issue of the plastic pollution problem is leakage - precisely what makes plastic find its wrong way until arriving at the oceans -, recovering what ended there has to be considered in the process. Here, innovation comes in again bringing options such as the plastic eating bacteria, the genetically modified plastic eating bacterium, and the hard-walled floating pipe proposed by The Ocean Cleanup.

Because this last stage is not a necessary one, on the contrary, is the undesired one, it comes in a discrepant color at the representation brought in figure 3 .

\footnotetext{
115 I concur with the conclusion, but keeping in mind that it is still much better than the regular plastics degradation period, that takes hundreds of years.

116 Thomas et al. (2010).

117 Odegard et al. (2017, p. 53).

118 Odegard et al. (2017, p. 53).

119 Green Deal (2015b).
} 


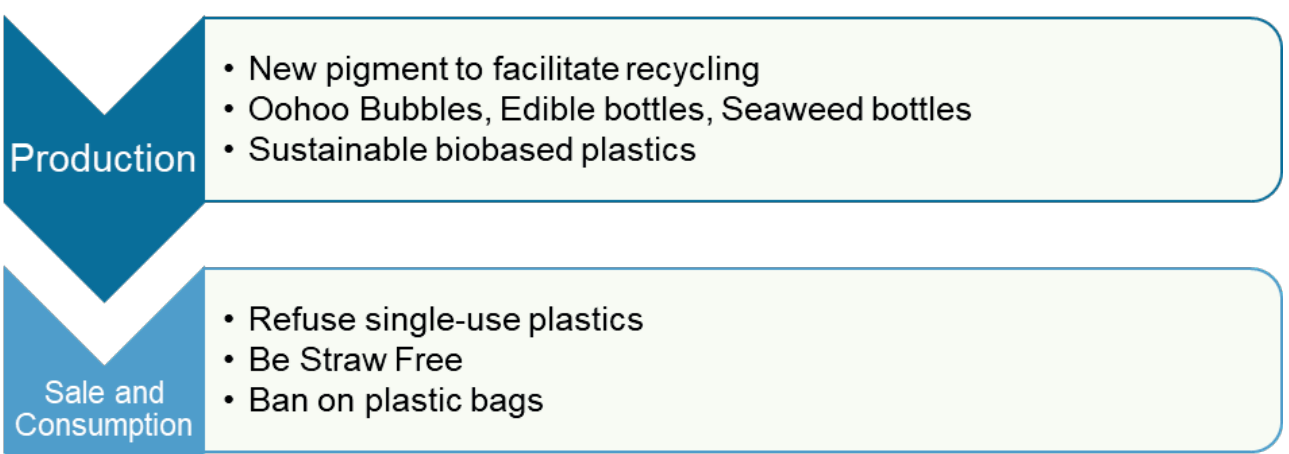

- Increase awareness

- Waste Management

and Final

Destination

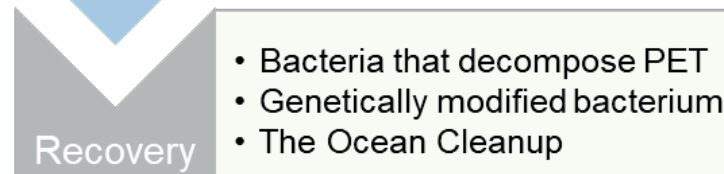

Figure 3 - Scheme representing the chain that leads to the plastic pollution in the oceans and relating them to the technical solutions that may assist in each of the stages.

Influencing the shape of the path that plastic follows is also an important manner to try a more sustainable approach regarding plastics. So, the proposals towards a circular economy, especially repair, re-condition, re-manufacture, re-use and recycle, of the $6 \mathrm{R}$ 's, could help in that sense. Figure 4 shows how the chain would look if the circular economy is achieved, whilst maintaining the indication of where each of the technical solutions influence the most. 


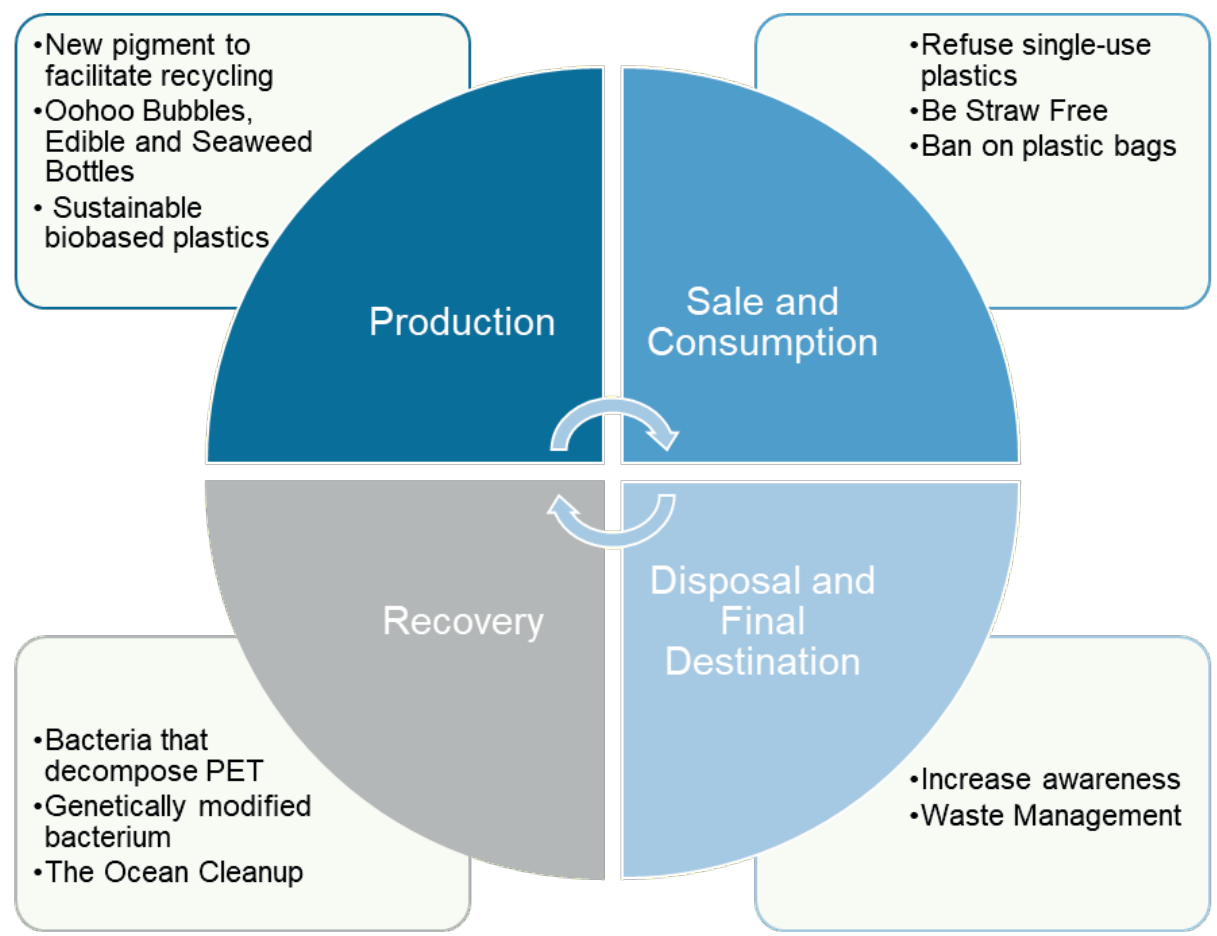

Figure 4 - Scheme representing the stages that lead to the plastic pollution in the oceans, relating them to the technical solutions that may assist in each of the stages, but in a desired shape of a circle, representing a potential circular economy through the solutions.

\subsection{Summary and Main Findings}

This overview of the plastic pollution in the oceans confirms the complexity of the issue: (i) plastics are produced and used in different manners; (ii) pollution originates in all stages of the chain, from production to final destination; (iii) recovering the plastic that is already in the oceans - and continuously increasing - is, so far, a virtually impossible task; (iv) the solutions must be analyzed for each particular case; (v) it is an international problem caused mostly by national actions; (vi) it involves all social actors - States, individuals, corporations, and organizations.

The overview also indicates, however, priority aspects towards solutions, for instance: (i) $80 \%$ of the plastic ending in the ocean comes from land-based sources, ${ }^{120}$ (ii) packaging answers for $26 \%$ of the volume of plastic used; ${ }^{121}$ (iii) $50 \%$ of the plastic produced is used only once; ${ }^{122}$ (iv) there are methodologies already available to prioritize action; ${ }^{123}$ (v) attempts and partial solutions seem to be emerging everywhere - geographically and from public and private initiatives - although they are still far from solving the plastic soup; and, consequently, (vi) it is necessary to have further investment in research, technology, and innovation, for the development of solutions involving all stages that lead to the plastic pollution of the oceans, as well as recovering the tons of plastics that are already in the oceans; (vii) the main issues vary depending on the country where the pollution originates, especially between the so called developing and developed world.

120 Sheavly (2005).

121 World Economic Forum, Ellen MacArthur Foundation and McKinsey \& Company (2016, p. 17).

122 Hollman, Bouwmeester, and Peters (2013, p. 8).

123 E.g.: Odegard et al. (2017); National Institute for Public Health and the Environment (RIVM) (2014); Woldendorp (2017). 
All the aspects displayed and discussed in this second chapter, including - and mainly - the complexities and the priorities, will guide the following chapters towards the goals of the research. Therefore, chapter 3 follows by firstly sketching which legal approaches are central to this thesis. 


\title{
3 THIRD WORLD APPROACHES TO THE INTERNATIONAL LAW AND THE NEED FOR SOLUTIONS BEYOND NATIONAL AND REGIONAL
}

\author{
Marvin, agora é só você \\ E não vai adiantar \\ Chorar vai me fazer sofrer \\ Marvin, a vida é pra valer \\ Eu fiz o meu melhor \\ E o seu destino eu sei de cor
}

Titãs

There are no doubts about the fact that the plastic pollution is a massive environmental and social problem and that it is caused by human activity on Earth. The object of this research, the plastic soup, is one of the aspects of such pollution, which causes several consequences and involves great complexity, as analyzed in detail in the previous chapter. Solutions include ex ante and ex post perspectives, meaning both preventing further pollution from going into the oceans and recovering the one which is already there.

Since this thesis is dealing with pollution in international waters, for the ex post perspective it is inevitable that the analysis comes from international approaches. However, considering the data presented in chapter 2, showing the major contribution from land-based sources, it may not come as logical for the ex ante perspective to urge for international approaches.

The basic premise here is that focusing on the sources of the plastic pollution could be an effective way to begin standing up to the ex ante side of the problem. This would mean dealing with the entire plastic chain - for example, design, production, distribution, consumption, re-utilization, recycling, and discard. ${ }^{124}$ Some numbers and information concerning those aspects are particularly relevant to the purposes of this chapter. For example, around $80 \%$ of the plastic that ends up in the oceans comes from land-based sources. ${ }^{125}$ This means, mainly, debris carried by rivers to their mouths.

Furthermore, recent studies calculate that 88 to $95 \%$ of the top plastic polluting rivers are located in the developing world - mostly Asia. ${ }^{126}$ From an international perspective, this raises the concern of a potential North-South global tension, if the numbers lead to directing all responsibility to those countries, while excluding the responsibility from others. It is important, however, to consider the problem in its entirety and to mainstream the dynamics between developed and developing countries, no matter which solution is adopted.

In other words, chapter 2 seems to suggest that the plastic soup as it has been caused today, is merely a third world problem, as most of the plastic that ends up in the ocean comes from rivers in Africa and, mostly, Asia. However, the goal of chapter 3 is to balance that position as well as to ask the question of which type of legal rules we should look - international, regional or domestic - to solve problems related to the plastic soup. Domestic solutions come as more obvious, followed by regional solutions mainly where the polluting rivers are concentrated. The use of Third World Approaches to International Law (TWAIL), however, provides a much broader picture, showing not only that domestic efforts may not suffice, but also that in fact it is also a developed world problem. That is why the focus of this thesis, on international law, is also so important for the ex ante side of the plastic soup problem.

\footnotetext{
$124 \quad$ See figures 3 and 4.

125 Sheavly (2005).

126 Schmidt, Krauth, and Wagner (2017, p. 12246).
} 


\subsection{Lessons Learned from a Third World Approach to International Law}

Following the overview of the challenges in the international scenario to face the plastic soup, this section presents a more specific theoretical description which will enable an approach to one of the main challenges: the North-South global dynamics and its role in the implementation of international law. Therefore, comprehending the studies on the Third World Approaches to International Law (TWAIL) is essential to address issues that highlight global heterogeneity, because "the Earth is one, but the world is not". ${ }^{127}$

From the 2000s onwards, concerns about under-developed and/or developing countries have favored the emergence of the academic segment called TWAIL. The approaches, although often criticized for the use of the expression Third World ${ }^{128}$ are considered emancipatory energies with the objective of contemplating, in international legal discussions, the interests, the priorities, and the needs of countries marked by colonial backgrounds. ${ }^{129}$ It is important to note that, when referring to the third world, the theory is referring to the least developed countries, so the tag chosen to identify should not be central, at least not for the purposes of this research. Similarly, when referring to north and south, the theory is actually referring to countries in different stages of development, so, although in general it coincides with geographical location, it is not always the case.

The TWAIL concerns are particularly important in what relates to the Right to the Environment, ${ }^{130}$ not only because of the universalism and the influence of the colonial historical position, but also because social and financial deficiencies usually lead to poorer environmental protection. Furthermore, an historical approach to the international environmental law from the global South perspective highlights the colonial background of the discipline. It started with conventions drafted and pushed forward by the historical metropolis but directed to the historical colonies, mainly to the African territory. ${ }^{131}$ Those are the same discrepancies identified in the plastic soup problem, and the reason why TWAIL is tailored for a study dealing with an international environmental problem such as this.

Scientific production also plays an important role in the above-mentioned universalism and global influence, because "the world's scientific community is heavily dominated by developed countries, whether one looks at resources, the number of researchers, or scientific production" ${ }^{132}$ Hence, an additional concern is that the scientific production that is taken into account for the definition of global issues and proposed solutions is mostly written by OECD countries, often leaving the worries, priorities, and needs of the global South off the agenda.

The TWAIL emerge in the described context, then, as a tool for effecting the rights and interests of under-developed and/or developing countries as international actors, by contributing to withdraw them from the blind spot zone. In this sense, it is worth investigating the influence of the approach in the implementation of international instruments, especially those that seek to establish protective norms of environmental law. From there, a "new generation of International environmental agreements" treaties concluded between the UN on the Human Environment 1972 and the World Summit on Sustainable Development 2002 Conference - arose. ${ }^{133}$

To evolve even more, it is essential to keep in mind that most of the environmental concerns are global, but countries set different priorities, and those differences must be considered. Those distinctions are particularly perceptible between the Global North and the Global South priorities and concerns on environmental issues. ${ }^{134}$ While the North focuses on global issues such as the ozone layer, climate change, and protection of endangered species, the South focuses on problems that have

\footnotetext{
127 United Nations (1987).

128 Chimni (2006, p. 4); Young (2001, p. 5).

129 Okafor $(2005$, p. 176).

130 Badaru (2008, p. 382).

131 Mickelson (2000, p. 52).

132 Karlsson (2002, p. 2).

133 Rajamani (2006, p. 9).

134 Gonzalez (2015, p. 160).
} 
immediate impact on vulnerable populations, such as reliable food, access to water, and atmospheric pollution.

Those are the main reasons why overcoming or at least adapting the North-South relationship is certainly one of the challenges to international environmental law. But of course, although differentiation is described in international instruments and widely studied by academia as an instrument to pursue a balance among States, it is not necessarily the solution to all questions, especially because its application may become excessive and/or inadequate. Other than that, its practical application is more complex than identifying its need in a theoretical situation.

With these premises comes the legacy of TWAIL to the implementation of international instruments and goals. There is an inevitable connection between third world studies and the scope of environmental solutions. Therefore, differentiation "must be understood as a pre-condition for any successful international environmental regime rather than as a potential obstacle". ${ }^{135}$

In summary, TWAIL shows that, of course, differentiations cannot be applied unrestrictedly, but rather with limits and considering the criticisms involved. I do recognize, for instance, that there have been significant changes to the international setting and to the challenges that it is supposed to face. Still,

\begin{abstract}
It is all too easy to dismiss the idea of the 'global South' as opportunistic posturing or naive pleading. At worst, it appears to be an artificial coalition in which the larger developing countries hide behind the smaller, and differences are denied or swept under the carpet. At best, it could be seen as a quaint invocation of platitudes about solidarity and shared aspirations. Yet these types of criticisms have been raised against any and every attempt by developing countries to capitalise on the strength in numbers that has tended to be a poor substitute for real economic clout and political leverage. For, in the end, what may be most remarkable about the idea of the South is its staying power. The idea that developing countries are united by more than what divides them has a resonance that somehow transcends the passage of time as well as changes in circumstance and nomenclature. ${ }^{136}$
\end{abstract}

The perspective of TWAIL that I adopt here is "pleading in favour of an 'integrationist' approach one that brings the concerns of the South into the mainstream of the discipline". ${ }^{137}$ Still, studying international law from a perspective of the least favored countries allows a more detailed understanding of the global dynamics, in order to face complex challenges, such as the plastic pollution in the oceans. In that specific case, a study from this perspective also helps to prevent premature, incomplete, and prejudiced judgments. The application of the theory here intends to guide international environmental law to a different path, preventing it from again failing to respond to Third World concerns in a meaningful way. ${ }^{138}$

In order to achieve the goals mentioned in this section, I adopt the three progressive aspects indicated by Mutua. ${ }^{139}$ The first is to understand, uncover and deconstruct impaired development conditions. The second is to build and present an alternative. And the third is to eradicate the condition of inequality, giving effect to the right to development. Once a situation is identified involving discrepancies between developed and developing worlds, it is important to segment the analysis of the issue and to apply the three steps. Those are the steps that will be followed for the analysis of the present chapter.

\footnotetext{
135 Cullet (2016, p. 327).

136 Mickelson (2009, p. 422).

137 Mickelson (2000, p. 54).

138 Mickelson (2000, p. 52).

139 Mutua (2000, p. 31-32).
} 


\subsection{Considerations on the North-South Dynamics to Face the Plastic Soup}

The description of the main sources of the plastic soup demonstrated that it is not only a complex global environmental challenge, but also a challenge that makes explicit several of the differences between the Global North and the Global South. This, by itself, already asks for an international attempt, which usually comes through international instruments, such as conventions and protocols. The contribution of the present chapter is, however, to design preliminary suggestions to prevent the pitfalls of the North-South dilemma and potentialize future attempts. Moreover, this chapter aims at demonstrating the importance of going beyond national and regional approaches.

As seen, TWAIL already provides the steps to such purposes. The first one is to understand, uncover, and deconstruct impaired development conditions. The second is to build and present an alternative. The third and final is to eradicate the condition of inequality, giving effect to the right to development.

Three stages are necessary to fulfill step one: (i) understanding impaired development conditions; (ii) uncovering those conditions; and (iii) deconstructing them.

With step one, then, first comes the stage of understanding the impaired development conditions. Regarding the central problem of this research, the plastic pollution that ends up in the oceans, it comes as no surprise that Asian and African countries are major land-based sources. Places that have bigger social problems and lower development rates often also struggle with environmental issues such as waste and sewerage management. That is the most evident and immediate cause of plastic leaking into the environment.

The second stage of the first step, nonetheless, is much more complex, but it helps going beyond the impaired development conditions. In other words, to uncover the impaired development conditions it is necessary to be more critical than looking at the final edge of the pollution sources, which is only one side of the coin. For instance, industrial production without the corresponding prevention and solutions must not be left aside. Therefore, it is essential to keep in mind that the companies responsible for a great part of the plastic production are based in Europe or in North America, as also demonstrated in chapter 2. This means that, although developed countries seem not to figure as the main immediate cause of the plastic soup, they contribute greatly as mediate cause.

Besides, the global sales for plastic items exports by country totaled US $\$ 79$ billion in 2018 , out of which 15 countries are accountable for $78 \% .{ }^{140}$ Eleven of those countries are members of the Organization for Economic Cooperation and Development (OECD) $)^{141}$ and are responsible for US\$37.2 billion in exports that same year - or over $47 \%$ of the values in plastic exports. The whole list is reproduced here:

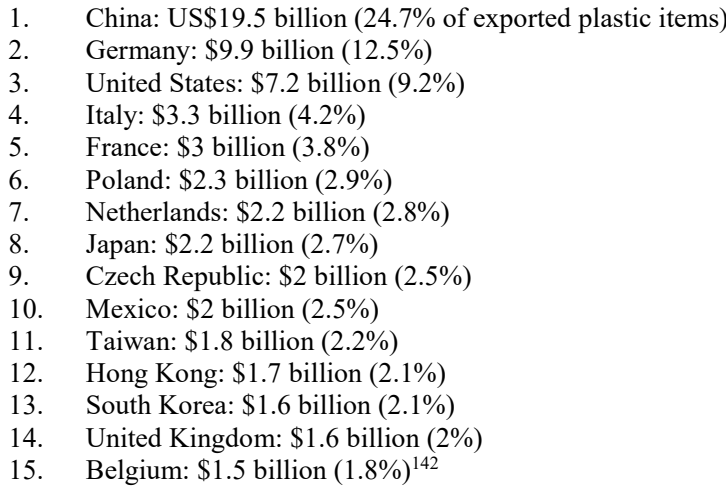

\footnotetext{
140 World's Top Exports (2019).

141 OECD (2019).

142 World's Top Exports (2019).
} 
Moreover, the exports of plastic waste indicate a similar reality. $73.9 \%$ are made from 15 countries, eleven of which are OECD countries and responsible for $55.3 \%$ of the scrap plastic exported in the world in 2017. The compiled list is:

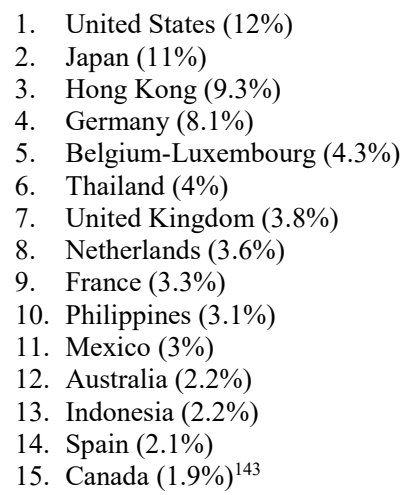

Complementing the scenario comes the data about the global imports of scrap plastic by country. Although amongst the top 15 importers the majority - nine - is again of OECD members, the six nonOECD countries account for $66.5 \%$ of the global imports of plastic waste. China alone imported $47 \%$ in 2017:

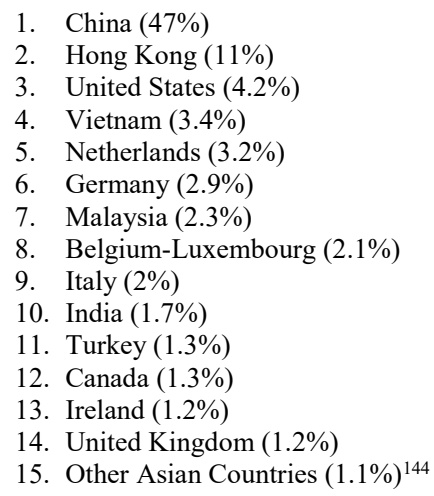

It is important to remember that, even though the international trade of plastic waste is meant for recycling, in China - the, by far, most common destination during 2017 - there are "signs of [imported] plastic dumped in ravines and waterways. For the plastic that did reach a recycling factory, there were reports of poor working conditions and contaminated water being discharged into local creeks from such facilities". ${ }^{145}$ In the low-income countries, over $90 \%$ of waste is "often disposed of in unregulated dumps or openly burned...[creating] serious health, safety and environmental consequences". ${ }^{146}$

This last list also explains the reactions from other countries to China's ban on plastic waste imports. The legislation restricting this kind of importation came as a result of bad waste separation in exporting countries, and of the impossibility for China to adequately process such huge amounts of

\footnotetext{
143 Based on the data available at: OEC (2017a).

144 Based on the data available at: OEC (2017b).

145 Watson (2019).

146 Kaza et. al (2018, p. xii).
} 
plastic waste. ${ }^{147}$ The impact of such Chinese legislation is easily perceived from the reactions, mainly of countries that were halting their recycling programs because of cost, ${ }^{148}$ and because " 95 percent of the plastics collected for recycling in the European Union and 70 percent in the U.S. were sold and shipped to Chinese processors". ${ }^{49}$ For example, the global trade of plastic waste was, in general, shifted to Southeast Asia, to countries as Malaysia, Thailand, Vietnam, Indonesia, and India. ${ }^{150}$ The United States shifted its plastic waste export to be sent to Malaysia, which, in its turn, also banned though temporarily - that kind of imports, from October, 2018. ${ }^{151}{ }^{152}$ Many North-American and European recycling programs were halted or diminished, and incineration has increased, among other consequences. ${ }^{153}$

Naturally, the data on the commercialization of plastic and plastic data cannot be considered alone. However, they are an important addition when understanding the global flow of plastics and, mainly, when understanding that no country - or set of countries - is alone in the responsibility for the polluting outcome. More important than that, they show how the plastic waste flows mainly from developed to developing countries.

Still on stage two of the first step, some of the data regarding the main polluting rivers/countries need to be deconstructed. For instance, targeting only the 5, 10 or 20 top-ranked countries (in plastic marine debris per year) "would require substantial infrastructure investment primarily in low- and middleincome countries", ${ }^{154}$ which still struggle to guarantee fundamental human rights such as food, quality water, education, security, and so on. They also point out, however, that the alternative of reducing waste generation and plastic use would also decrease the amount of mismanaged plastic waste. So,

if per capita waste generation were reduced to the 2010 average $(1.7 \mathrm{~kg} / \mathrm{day})$ in the 91 coastal countries that exceed it, and the percent plastic in the waste stream were capped at $11 \%$ (the 192-country average in 2010), a $26 \%$ decrease would be achieved by 2025 . This strategy would target higher-income countries and might require smaller global investments. ${ }^{155}$

This is the same reduction amount as if the top five countries (China, Indonesia, Philippines, Vietnam, and Sri Lanka) reduced their fraction of mismanaged waste by $50 \% .{ }^{156}$ The 5 of them are ranked at the Human Development Index, respectively, as $85^{\circ}, 111^{\circ}, 106^{\circ}, 118^{\circ}$, and $71^{\circ}$, out of the 189 countries considered. ${ }^{157}$

Naturally, I do not agree that the social and historical issues are a reason for excusing environmental harm. The case is that when shifting to a broader, more globalized view, it is possible to understand that causes and, therefore, solutions, lie with every country, as well to understand the need for a costbenefit analysis that may lead to a solution that is socially, environmentally, and economically more adequate, therefore also more respectful of human rights - an aspect that will be further developed in chapter 4, under the subtopic 4.1.1. Additional and relevant information is that "if considered collectively, coastal European Union countries (23 in total) would rank eighteenth on the list". ${ }^{158}$

\footnotetext{
147 Katz (2019); Lee (2018).

148 Mcnaughton, and Nowakowski (2019).

149 Katz (2019).

150 DW (2019).

151 Watson et al. (2019); Lee (2019).

152 Countries such as Thailand, Vietnam and Indonesia have also decided to restrict plastic waste import. Greenpeace (2018, p. 9).

153 Katz (2019); DW (2019).

154 Jambeck et al. (2015, p. 770).

155 Jambeck et al. (2015, p. 770).

156 Jambeck et al. (2015, p. 770).

157 UN Development Programme: Human Development Reports (2019).

158 Jambeck et al. (2015, p. 769).
} 
In other words, there are several aspects to be considered when understanding the impaired development conditions related to plastic waste. Other than that, there are the uncertainties and discrepancies in the available data, as mentioned in the previous chapter, which increase the need for caution in the conclusions.

Those numbers also finalize stage three of the first step: deconstructing impaired development conditions. Countries from the global North may not have the rivers that most contribute to the plastic pollution in the oceans, but they do have: (i) the companies that most produce plastics (see topic 5.1.4); (ii) the highest productions of plastic and respective profits rates; (iii) the most expressive contributions of scrap plastics, which, in turn, is mostly imported by countries from the global South.

The second step proposed by TWAIL is to build and present an alternative. In the case of the plastic soup problem, the North-South heterogeneity and contradictions end up also leading to an alternative. It should focus on balancing those two edges of the plastic pollution chain. On the one hand, there is the perspective that international solutions could concentrate on searching for alternative materials and products, and to make producers liable for the pollution caused by their products. On the other hand, there is the perspective that international solutions could concentrate on helping enhancing recycling and management solutions to the post-consumer edge. Both of those perspectives would make the global North advance in the fight against the plastic pollution in the oceans. The global South would gain especially from the second perspective.

More than that, the two edges of the plastic chain match: several options that focus on the producers have a secondary influence on solutions to the post-consumer edge. For instance, the imposition of a tax to stimulate reducing plastic or recycling, or an extended producer responsibility, ${ }^{159}$ or reversal logistics, ${ }^{160}$ in any case imposed upon the producers of plastic. Although those instruments primarily aim at prevention (reducing emissions of plastics into the ocean) they could potentially also generate finances for cleaning up the current plastic soup problem. In the same way, although those instruments aim at the producer, they generate ways and revenue for actions focused at post-consumer actions. Nonetheless, they would have to be implemented at the domestic (or regional) level, since international actors and organizations do not have the competency to regulate the subjects. Still, the complexity demonstrated here shows the need for integrated action at an international level.

Last, but not least, in what concerns looking for alternatives, there are the multilateral environmental agreements (MEAs). Not only are they instruments under the international law that have been particularly stimulated by the UNEP Working Group on International Environmental Governance, ${ }^{161}$ but also they are instruments that enable South-South cooperation.

In that case, the Regional Seas Programmes of the United Nations Environment Programme could serve as a starting point. They are indeed already moving in this direction by addressing marine litter, especially plastics, through initiatives to strengthen laws that prevent industries and individuals from dumping trash into oceans, and through working on capacity building to help national governments enforce these laws, although more specific and concrete measures are still lacking. ${ }^{162}$ Similarly, the Association of Southeast Asian Nations (ASEAN) could also serve as a starting point for multilateral agreements at the Asian region. Six (Indonesia, Philippines, Vietnam, Thailand, Malaysia, and Myanmar) of its ten Member States ${ }^{163}$ are among the top-20 plastic polluting rivers in the world, ${ }^{164}$ which make it a potentially fruitful forum for such initiatives. ${ }^{165}$ Moreover, it seems that ASEAN's

159 "a policy approach under which producers are given a significant responsibility - financial and/or physical - for the treatment or disposal of post-consumer products". OECD (2018).

160 Freely translated from the expression logística reversa, adopted by the Brazilian legislation. It explicitly considers that those who insert the product in the market should be responsible for collecting it.

161 Oberthur (2005, p. 40).

162 UN Environment Programme (2020).

163 Association of Southeast Asian Nations - ASEAN (2020).

164 Jambeck et al. (2018).

165 Kheng-Lian, Robinson, and Lin-Heng (2016, p. 124-125 and p. 220-221). 
awareness of the problem of the plastic pollution has increased. When comparing the Fourth ASEAN State of the Environment Report $2009^{166}$ with the Fifth ASEAN State of the Environment Report $2017,{ }^{167}$ this increase is easily noticeable. For instance, in 2009 , the references to plastics are merely exemplifications and there are no mentions of marine litter, while in 2017 there is an overview of the plastic problem, several references to it, and a whole section dedicated to the marine litter discussion. Still, from experience, concerns are in place regarding implementation, in contrast with adhesion to regional commitments. ${ }^{168}$

Although the biggest polluter, China, is not an ASEAN Member, it also seems to be looking in the direction of need for action regarding marine litter and plastic pollution, both from the government ${ }^{169}$ and from civil society sides, ${ }^{170}$ despite its lack of environmental concerns towards the sea in the past. ${ }^{171}$ This may indicate possible openness for joining regional action.

Regarding the use of regional treaties in Africa, there is also room for cautious optimism. For example, in what concerns water regimes, "the history of benefit sharing and cooperation in the use of shared water resources is a cornerstone of stability and peace in the region". ${ }^{172}$ Yet, even if legal and institutional frameworks are in place, challenges with compliance, enforcement and resourcing should be expected, as experience shows - see, for example, the case of Southern Africa with water law. ${ }^{173}$ As well as challenges with coordinated management, and lack of political trust - see, for example, the case of the Aral Sea basin, ${ }^{174}$ and the South Asian Water Treaty, ${ }^{175}$ respectively.

Therefore, if a MEA alternative is in place, it is important to keep in mind that "coordination is imperative among MEAs because of the fragmented nature of their coverage and the inter-relationship of environmental problems and solutions", ${ }^{176}$ including in coherence terms. Besides, an increase in the number of MEAs may lead to a proliferation of norms and meetings, which could make it difficult - or even impossible - for States to attend, particularly for developing States. ${ }^{177}$

This leads to the third and last step proposed by the TWAIL: to eradicate the condition of inequality, giving effect to the right to development. This is the general way of TWAIL of referring to the third step. When applied to facing the plastic pollution in the oceans from the international law, it means eliminating the factors that may unbalance proposed solutions. That is to say, avoiding solutions that burden the global south. An important aspect to that is to produce more qualified and all-embracing data on the plastic pollution. In other words, stimulating scientific production that goes beyond the works written in OECD countries and/or by OECD researchers. This is a relevant path - reminded by TWAIL - to guarantee more comprehensive and impartial studies. The majority of the research about plastics is done, financed, or housed by developed countries. ${ }^{178}$ Stimulating research and creating fairer conditions in education and data collection is an aspect that may be adequately addressed by the instruments provided by public international law. For instance, by using the UN educational means, ${ }^{179}$ or by international cooperation between universities or research centers, or finally by technological or financial transfer - through bi or multi-national agreements.

166 Fourth ASEAN State of the Environment Report (2009).

167 Fifth ASEAN State of the Environment Report (2017).

168 Kheng-Lian, Robinson, and Lin-Heng (2016, p. 90-91 and 124-125).

169 See, e.g.: DW (2019); European Commission (2019); McCauley (2019).

170 See, e.g.: WWF (2020).

171 McCauley (2019).

172 Mbengue and Odili (2019, p. 378).

173 Paisley and Curlier (2019).

174 Ziganshina (2019).

175 Uprety (2019).

176 Magraw and Udomritthiruj (2019, p. 176).

177 Magraw and Udomritthiruj (2019, p. 178).

178 See the references in this research.

179 See, e.g.: United Nations University (2019). One of the several initiatives on e-learning, such as: United Nations Environment Program (2019). 
Another aspect that may be addressed directly by public international law and that may help in implementing step three is international trade. Even if mainly undertaken by private actors, trade depends upon several tools and instruments, most of which are regulated, controlled, or influenced by States. States, in their turn, are subjects of international law. This means that actions could be taken, for example, in the sense of imposing conditions or restrictions when concerning the trade of plastic products and, mainly, of plastic waste.

Also, a compensation fund could potentially solve many of the problems. To the extent that the states finance the fund, it could be created through international law. Since contributions by the states to the fund could be differentiated, for example taking into account GDP, the creation of a fund could equally align with principle 7 of the Rio Declaration. ${ }^{180}$ Examples are the Multilateral Fund for the implementation of the Montreal Protocol, ${ }^{181}$ the Green Climate Fund, ${ }^{182}$ the Climate Investment Funds, ${ }^{183}$ and the Global Environmental Facility. ${ }^{184}$ Regarding the first one, many analyses are cautiously optimistic, ${ }^{185}$ but with the caveat that the case of "the stock of ozone-depleting chemicals was technically discoverable and calculable, and substitutes were for the most part already present or on offer", ${ }^{186}$ which is not the case with the plastic pollution. ${ }^{187}$

Undoubtedly, the transfer of financial and technological assets to developing countries is no news to the international law discussions, in the entire range of its potentialities and obstacles. Specifically to that purpose, what still needs a lot of maturation is politics, since the legal possibilities are already gaining shape. More than that, we need to be cautious not to propose too many funds, which would create an unsustainable situation.

Those and other suggestions to be implemented through public international law are treated in more detail in chapter 4 . Beyond that, the role that private actors may play will be discussed in chapter 5 . This chapter was focusing on the potential North-South tension related to the plastic pollution of the ocean and analyzed ways to prevent its harmful effects. Therefore, one message here is that regardless of the path chosen, global heterogeneity between North and South should always be considered, and that such a concern aligns with the envisaged solutions. Furthermore, the core message is that, although the main causes are local, local solutions will surely not be satisfactory.

180 "States shall co-operate in a spirit of global partnership to conserve, protect and restore the health and integrity of the Earth's ecosystem. In view of the different contributions to global environmental degradation, States have common but differentiated responsibilities. The developed countries acknowledge the responsibility that they bear in the international pursuit of sustainable development in view of the pressures their societies place on the global environment and of the technologies and financial resources they command". United Nations (1992, Principle 7).

181 Established in 1991 after a decision of the Second Meeting of the Parties to the Montreal Protocol. It is dedicated to reversing the deterioration of the Earth's ozone layer. See more: http://www.multilateralfund.org/default.aspx.

182 Established in 2010 by the 194 countries parties to the United Nations Framework Convention on Climate Change (UNFCCC) as a financial mechanism to help developing countries to limit or reduce carbon emissions. See more: https://www.greenclimate.fund/who-we-are/about-the-fund.

183 Comprised of four programs, was established in 2008 and focus on efforts to empower transformations in the energy, climate resilience, transport and forestry sectors. Only 14 countries are listed as donors. See more: https://www.climateinvestmentfunds.org/about.

184 Established in 1992, in the eve of the Rio Earth Summit. Counts 39 donor countries and is provided to government agencies, civil society organizations, private sector companies, research institutions, among the broad diversity of potential partners, to implement projects and programs in developing countries. See more: https://www.thegef.org/about/funding.

185 See, e.g.: Jordan, and O’Riordan (1998, p. 171); Raubenheimer, and McIlgorm (2017, p. 322); Biermann, and Simonis (1999, p. 239); Luken, and Grof. (2006, p. 241); Garcia (2014).

186 Jordan, and O'Riordan (1998, p. 171).

187 Raubenheimer, and McIlgorm (2017, p. 322). The authors had suggested a model based on the Montreal Protocol to address the marine plastic debris problem. However, the conditions that explain the success of the Montreal Protocol (that technical solutions were available as well as substitutes for the ozone depleting substances) unfortunately do not apply to the problem of the plastic soup. 


\subsection{Summary and Main Findings}

The challenges posed by the plastic pollution in the oceans are huge and, to a certain extent, still unknown. Since $80 \%$ of its sources are land-based, ${ }^{188}$ the main cause is located in specific countries and regions. Nonetheless, oceans are basically international waters, turning such a pollution into an international problem.

The concern here is to prevent the common pitfalls derived from the distinctions between developed and developing countries. This is always a valid preoccupation in the international scenario, even more when it concerns international environmental law. In the case of the plastic soup, it is particularly relevant, since chemistry research is placing a vast majority of land-based plastic pollution sources in the least developed countries from Asia and Africa.

For a hasty observer, those recent researches would demonstrate that the developing world is to blame - and, maybe, therefore to find a solution - for the plastic soup. Immediate sources are not, however, the only causes of the problem. It comes without saying that I am not disregarding the importance to find solutions to those contributions from the global South. ${ }^{189} \mathrm{I}$ do, however, highlight the relevance to see the problem in its entirety. I describe, for instance, the large contribution of multinational companies, which put the plastic products on the market, ${ }^{190}$ Those companies are generally from the developed world.

More than that, the leakage of plastic into the oceans from the so-called third world countries should not be considered a deliberate action, but a consequence of social and economic deficiencies, which necessarily reflect on environmental protection. The deficiencies, by their turn, are also a reflection of global discrepancies. Furthermore, although the developed world seems to have a more adequate collection of recyclable waste, most of it is exported to the developing world, uncovering a second and significant contribution of those countries to the plastic pollution that ends up in the oceans. On top of that, the recent decision of China and other Asian countries to restrict or ban the plastic waste imports unveiled that the quality of the waste separation in the developed world has greatly decreased while the quantity of waste production greatly increased, making recycling financially unattractive to some extent, and impossible to be done in an environmentally adequate way with the quantities arriving.

Perhaps the most important contribution of this chapter is that it shows how international the problem of the plastic soup actually is, demonstrating that it is essential to address the problem from international approaches. The concerns with global heterogeneity are also the core of Third World Approaches to International Law (TWAIL), which is the reason why it was used to address the plastic soup case. Using that theory, it was possible to derive the practical aspects to be considered, and, consequently, to conclude that there are legal solutions that combine remedies to the producer edge with remedies to the post-consumer edge. Those are the solutions indicated as priorities for the upcoming decisions that will hopefully come in the near future to face the problem of the plastic pollution in the oceans through public international law. Public international law may also contribute to solutions by encouraging a more responsible international trade of plastics products or plastic waste, or by helping technological and financial transfer, for example.

The reflections of both chapters 2 and 3 signal that public international law must act fast against the plastic soup, but making sure to have a solution that is, indeed, international to a problem which is, inevitably, international. That is the reason why chapter 4 will focus on the aspects of public international law and its current and potential efforts towards preventing and recovering the plastic pollution of the oceans.

\footnotetext{
188 Sheavly (2005).

189 As well as from local regulation sources. On the interactions between transnational regulatory mixes and local politics and policy making, see e.g.: Bartley (2011).

190 See the whole analysis in section 5.1.4.
} 


\title{
4 PUBLIC INTERNATIONAL LAW INSTRUMENTS TO ADDRESS THE PLASTIC SOUP'191
}

\author{
So come with me, where dreams are born, and time is never planned. Just \\ think of happy things, and your heart will fly on wings, forever, in Never \\ Never Land!
}

It has already been established that plastic pollution is a problem caused by human activity on Earth. The major issue, addressed here, is the manner by which to face this problem. This chapter is dedicated to the analysis of the existing international instruments to face the problem of plastic pollution of the oceans - both hard and soft law. Solely through this state-of-the-art approach is it possible to analyze critically the laws, possibilities, and limitations, as well as to formulate suggestions on how to proceed with effective remedies. Therefore, this chapter aims to evaluate the extent to which those instruments of public international law deal with the plastic soup issue, from both the ex ante and from the ex post perspectives.

Of course, international instruments and their complex contexts often bring up several positive and several negative aspects. All of them will be taken into account to evaluate the relative effectiveness of international laws regarding the plastic soup problem, according to the available academic literature. Achieving this goal is essential to assess the role of international law and, consequently, the importance of alternative, private, pathways.

As discussed in the main findings of this chapter, an approach based on private governance will, so it is argued, be indispensable to enable effective solutions. Those will be analyzed in the following chapter. As far as international law is concerned, it will focus on treaties as well as on soft law instruments. It does not, however, discuss principles applicable to the relationships between states, such as the "no harm" principle, as these are not directly applicable to this topic. ${ }^{192}$

There is no single international instrument solely dealing with the plastic soup, but there are particular instruments that may have some relevance for the plastic soup issue. ${ }^{193}$ This number of international instruments that have, at least potentially, some relevance for the plastic soup problem ${ }^{194}$ will be examined within the scope of this chapter. The question that will particularly be addressed is the extent to which certain international instruments are able to address the plastic soup problem.

The chapter starts with a reminder of the distinct characteristics of public international law, including what concerns the interrelationship between international invironmental law and international human rights law. Next, the description of each instrument provides a brief summary of the specific convention and an explanation about how it can relate to the plastic pollution of the oceans. Each description also includes a concise analysis about enforceability and progress, based on the academic literature available. The same approach is used to address hard law and soft law.

This chapter aims at concluding to what extent those specific instruments are applicable. A further critical analysis, also with a view to the future, will follow from there, but in chapter 6 , after private initiatives are also analyzed (chapter 5). The focus will, then, be on analyzing whether international law currently facilitates the possible technical solutions or whether particular changes are needed to

191 Largely based on an earlier publication: Goncalves and Faure (2019).

192 These principles should be considered when inserting provisions into international instruments and when a court - either national or international - is to decide on a case.

193 See, e.g., this summary of the instruments in the protection of the oceans made by the United Nations: United Nations (2019).

194 See, e.g., United Nations (2019) (describing how the United Nations protect biodiversity). 
implement those solutions. So, from the conclusions in this chapter regarding to what extent the plastic soup problem is addressed in international hard and soft law instruments and how effective the academic literature considers them to be so far, chapter 6 will discuss the limits of both kinds of instruments, and address the potential role of international law instruments in remedying the plastic soup problem.

\subsection{Distinctiveness of International Environmental Law}

Conceptualizing and determining the core elements of traditional national law has always raised several discussions and disagreements, not only in the legal field itself, but also in related areas such as Philosophy, Sociology, History and so on. It is not the focus of this research to discuss those aspects. However, it is useful to have in mind the characteristics that are generally expected, usually related to a consensus built around the positivist model. In other words, it is useful to remember that there is an expectation that law refers to a normative system endowed with formalized and institutionalized sanctions and enforcement tools. ${ }^{195}$

The issue is yet more controversial and complex when analyzing international law. This is partially due to the fact that international law commonly does not count with one or more of those characteristics, starting with the lack of central power. In order to arrive at an international law content, different countries and, thus, several contexts and approaches, have to agree on it. This means having to deal with the delicate issue of sovereignty.

For around a thousand years, sovereignty was not a problem in the Western World, since the pontifical authority exercised the necessary political supra-nationality. Between the $14^{\text {th }}$ and $17^{\text {th }}$ centuries, however, the States consolidated as nations, having sovereignty as a central element of their identity. Especially from 1648, with the Peace of Westphalia, new features for the global organization started to appear. It is considered a decisive step towards the great agreements between nations without the Church at the center.

International law is founded on the principle of sovereignty; every State is sovereign over its territory, and all States are co-equal. Historically, international law was limited primarily to interactions between States that consented to bind themselves (and thereby limit their sovereignty) whether by treaty or recognizing a principle of customary law. ${ }^{196}$

More recently, "this State-centric, treaty-oriented view of international law has evolved to include a broader range of actors and types of law". ${ }^{197}$ Even more important, this view has evolved to allow instruments that do not count with the binding element, hence soft law. The lack of one more elements of the traditional law concept contributes greatly to the divisions in opinions.

Some legal scholars argue that international law should be neither hard nor soft law, since it is not law at all. ${ }^{198}$ Nonetheless, even with less traditional approaches there is controversy, with many stating the same about the nature of soft law.

Therefore, the first position to settle is that the author is in the group ${ }^{199}$ that considers international law, in all of its forms, as, in fact, law. Of course, as happens with the different fields of law, it brings its unique characteristics, but it is nonetheless, law.

Moving to other developments of the distinctiveness of international law, we have international environmental law, which adds greatly to the discussion, especially because it "speaks of

195 Sousa Junior (2018).

196 Bruch and Broderick (2016, p. 36).

197 Bruch and Broderick (2016, p. 36).

198 Weil (1983, p. 415).

199 See, for example: Guzman, and Meyer (2010); Senden (2005). 
'commitments' rather than 'obligations', 'non-compliance' rather than 'breach', and 'consequences' rather than 'remedies' or "sanctions"' ${ }^{200}$ This means that this specific field has a huge influence on, and forms a basis for, the soft law. ${ }^{201}$

Furthermore, international environmental law has some distinctive challenges, as described by Bodansky et al., the international environmental problems: (i) are caused primarily by private conduct, whilst international law deals primarily with states' behaviour; (ii) have a physical and technological basis; (iii) involve significant scientific uncertainties; (iv) are extremely dynamic; (v) are interconnected and need to be addressed holistically.

Also, because of their importance to solving global problems, all of those challenges will be addressed later in this research. However, for this topic, the main concern is to highlight that international law, more than other areas, has adapted to significant societal changes and has found ways to accommodate specific interests of the large variety of international actors.

Thanks mainly to those features, the theoretical discussions regarding international law are even less important in this context.

Finally, although those issues should not influence the conclusions reached in this chapter, they are important for understanding the approach to the instruments to be analyzed. Similarly, understanding some features of the human rights and the environment in the international law helps situating the discussion.

The International Human Rights Law (IHRL) is not only an important branch inside international law, but also an even more distinctive one, with close connections and implications for environmental protection. It is relevant to the fight against the plastic soup because of many reasons, but mainly because of four. First, because most of the instruments that will be analyzed in this chapter - the ones that somehow connect to the topic of plastics - are inside the IHRL framework. Second, because, as briefly mentioned before, approaching the problem from a TWAIL perspective directly relates to social and development aspects, and therefore, directly relates to human rights issues. Third, because there is still controversy, in the international law, regarding the status of the right to a balanced environment. Fourth, because it leads to discussions regarding duties as a means to implementing fundamental rights. Should it be considered a human right, should it also be protected under the entire theoretical and institutional scope of IHRL.

In the context previously described, of the construction of international law, the globalization processes need to be taken into account. The connections between countries and people are increasing and, with them, so are the challenges: "[...] if the means described [of traditional law] appeared insufficient for dealing with changes and new circumstances in domestic contexts, governance in transboundary contexts and large-scales cases concerning health and the environment is even more complex and more likely to fail". ${ }^{202}$

Purely State-based solutions seem to be ineffective mostly in two levels. The first one in failing to acknowledge the new actors in the political scene, especially individuals and corporations. The second one is the inadequacy of the design and range of the institutions to deal with a new, more complex, order. Some of those flaws were particularly evident during the Second World War, leading to changes in international law aiming at enabling a broader protection of the human rights. "The Nuremberg trial and several provisions of the United Nations Charter of 1945 held centre stage in the incipient human rights regime until 1948, when the UN General Assembly approved the Universal Declaration of Human Rights" (UDHR). ${ }^{203}$ After the International Covenant on Civil and Political Rights and the International Covenant on Economic, Social and Cultural Rights became effective in 1976, the three

200 Bodansky, Brunnee, and Hey (2012, p. 17).

201 In this sense, see, for example: Souza, and Leister (2015).

202 Ebbeson (2010, p. 420).

203 Alston and Goodman (2013, p. 139). 
documents form the International Bill of Human Rights. The UDHR is considered the legal baseline for modern international human rights law, ${ }^{204}$ and its declaration kick started the universal protection of human rights by the rule of law. ${ }^{205}$

Although the UDHR was the first UN instrument listing internationally recognized human rights, ${ }^{206}$ it comes as no surprise that the right to a balanced environment does not come between them, as the international discussions related to environmental protection only strengthen from the 1970's onwards.

Of course initial approaches to an international regulation of environmental issues arose much earlier, from the late XIX century, "namely the rules governing the exploitation of certain resources, transboundary damage, and the use of shared watercourses". ${ }^{207}$ However, the international attention to environmental problems was only catalyzed during the $1960 \mathrm{~s},{ }^{208}$ culminating in the important milestone of the report The Limits to Growth, ${ }^{209}$ elaborated by the Club of Rome ${ }^{210}$ in 1972. In it, a group of specialists of the Massachusetts Institute of Technology (MIT) explored different scenarios demonstrating the inherent contradictions within the exploratory behavior, and highlighted possibilities for society to reconcile (sustainable) progress with environmental limits.

From those reflections,

Debates over the links between the global economy, population growth, and environmental change on the one hand, and the sense of mutual interdependence and vulnerability on the other, were at the core of the United Nations Conference on the Human Environment, held in Stockholm, Sweden, in June 1972. ${ }^{211}$

Yet, it was only in 1987 that the expression sustainable development was forged, in the document Our Common Future, also known as Brundtland Report, which based the UN Conference on Environment and Development (Eco-92). That conference was an essential step on embracing a development that "meets the needs of the present without compromising the ability of future generations to meet their own needs", ${ }^{212}$ mainly through the adoption of Agenda $21^{213}$ and Rio Declaration on Environment and Development. $^{214}$

"Since Stockholm, global institutions have become increasingly active in promoting global environmental protection". Among those, there are, for instance, the United Nations Environmental Programme (UNEP), the United Nations Development Programme (UNDP), the Commission on Sustainable Development (CSD), and many others, all within or linked to the United Nations. With that, we go back to the importance of the UN and of the IHRL framework.

"The process of universalization of the human rights enabled the formation of an international system of protection of those rights - it is, then, shaped the normative global system of human rights protection". ${ }^{215}$ Such a system, nowadays, includes not only the UN bodies themselves but also regional

Baderin and Ssenyonjo (2010, p. 3).

Glendon (2004, p. 2).

Baderin and Ssenyonjo (2010, p. 8).

Dupuy and Viñuales (2015, p. 4).

Dupuy and Viñuales (2015, p. 8).

Meadows et al. (1972).

The Club of Rome was born in 1968, with a small group from diplomacy, industry, Academia, and civil society, with the objective of discussing short terms dilemma in international subjects, mainly regarding the unlimited consumption in an interdependent and growing world. Club of Rome (2020).

Clapp and Dauvergne (2016, p. 124).

UN (1987).

United Nations - Sustainable Development (1992).

United Nations (1992).

Freely translated. In the original: "o processo de universalização dos direitos humanos permitiu a formação de um sistema internacional de proteção destes direitos - forma-se, assim, o sistema normativo global de proteção dos direitos humanos, no âmbito das Nações Unidas". Piovesan (2001). 
systems - Inter-American, European, and African - and several rules of different nature and at both international and regional levels. Regardless of the interconnections between human rights and environmental protection, the right to a balanced environment ${ }^{216}$ is not yet a human right under international law.

Despite the parallel evolution over 60 years, since the proclamations made in Stockholm, in 1972, there is an academic search for jurisprudential basis for linking IHRL and International Environmental Law (IEL). ${ }^{217}$ The UN itself recognizes the interconnection:

It is increasingly recognized that human rights are essential to achieve Sustainable Development. The Millennium Development Goals (MDGs) served as a proxy for certain economic and social rights but ignored other important human rights linkages. By contrast, human rights principles and standards are now strongly reflected in an ambitious new global development framework, the 2030 Agenda for Sustainable Development. ${ }^{218}$

In 1994, Fatma-Zohra Ksentini, UN special rapporteur on toxic wastes presented her report ${ }^{219}$ on human rights and the environment, exposing the importance of recognizing the right to a healthy environment as a human right. The Ksentini Report proposed a draft for principles on human rights and the environment. Later, the discussion was raised inside the UN framework to the point that a special rapporteur - John Knox - was appointed by the UN Human Rights Council in 2015, after being Independent Expert from 2012. This resulted in the proposition of principles for human rights and the environment ${ }^{220}$ and in conclusions such as: there are several national and international efforts recognizing, or pushing to recognize, the human right to a healthy environment; the inherent connection between human rights such as life and health and the right to a healthy environment; and the movement towards international recognition, for example in the Global Pact for the Environment. 221

Those interconnections already allow the use of part of the structure built for the IHRL, through the mentioned UN bodies or even through court decisions. In what concerns courts, however, there are several particularities, mainly deriving from the fact that the human right to a healthy environment is not yet internationally recognized. Consequently, the international courts in general do not have competence - which needs to be explicit - to analyze environmental violations. It raises multiple and interesting discussions, as the ones ongoing, for example, in the regional courts for human rights protection. ${ }^{222} 223$ The nationalization of international law debates is also very important to the

216 Also called: right to a health environment, right to the environment, and similar.

217 Anton and Shelton (2011, p. 118-119).

218 United Nations (2016).

219 United Nations: Economic and Social Council (1994).

220 United Nations Human Rights Especial Procedures (2018).

221 Knox (2019).

222 The Inter-American Court, for instance, has no explicit competence, but has been ruling in cases with environmental repercussions, mainly through the argument of ricochet damage. For case-law, see e.g.: Afro-Descendant Communities Displaced from the Cacarica River Basin (Operation Genesis) V. Colombia (2013); Kichwa Indigenous People of Sarayaku V. Ecuador (2012); Case of the Saramaka People v. Suriname (2007); Case of the Mayagna (Sumo) Awas Tingni Community v. Nicaragua (2001). See also: Mazzuoli and Teixeira (2013). Similarly, at the European Court of Human Rights, see e.g.: López Ostra vs. Spain (1994); Öneryildiz v. Turkey (2004); Guerra and Others v. Italy (1998); Taşkin and Others V. Turkey (2004); Powell and Rayner V. The United Kingdom (1990); Hatton and Others V. The United Kingdom (2003); Fadeyeva v. Russia (2005); Dzemyuk v. Ukraine (2014). The case of the African system is a little different, since the article 21 of the African Charter on Human and People's Rights foresees the human right to dispose of natural resources. Although with an anthropogenic approach, this enables the Commission and the Court to assess environmental issues directly. As was with the case Ogoni People v. Nigeria (2002).

223 There are also discussions on the need of an international court specialized in the environment, which will not be brought here, again because of the scope of the thesis. See, e.g.: Pauwelyn (2005); Hey (2000); McCallion and Sharma (2000); Rest (1998); Postiglione (1990); Murphy (2000); Jennings (1992). 
implementation of international provisions. Those are similar to the processes ongoing on the international human rights courts, evolving towards a stronger environmental protection, as, for example, climate litigation $\operatorname{cases}^{224}$ show.

The case law on international courts regarding environmental issues show, therefore, the potential importance of such an application also for the plastic pollution. Although analyzing correlated cases plastic cases are not yet available - or analyzing the possibilities for facing the plastic problem using international courts is outside the scope of this thesis, it is essential to keep them in mind when going over the instruments that are addressed in this chapter.

Still on the relationship between IHRL and IEL, we must consider the influences of IHRL on international law as a whole. Influences comprising, for instance, the structure and harmonization of international rules, their concepts and instruments, and even the possibilities for internalizing them into national law. ${ }^{225}$ Therefore, the mutual influences on the likely introduction of IEL into the IHRL are also of high potential. Besides, the adoption of such a perspective ${ }^{226}$ seems every day closer and many of the positive consequences are felt already.

Two other issues are important to understand the distinctiveness of international law in what concerns the connections of IHRL with the plastic pollution problem. The first was already addressed in chapter 3 and relates to the differences in development between the global North and the global South ${ }^{227}$ and the reflections it causes on causation and on the choice for an international solution. ${ }^{228}$ The second is the possible construction of fundamental duties, ${ }^{229}$ having the IHRL as a starting point, even with effects to private parties, such as corporations.

One possibility in the direction of those fundamental duties comes from discussions ongoing in the Brazilian Constitutional context. The Brazilian Constitution of 1988 explicitly refers to fundamental duties only in chapter I, of title II, even though it brings a list of rights and warranties, but not of duties. Some duties may be found, scattered, along the constitutional text: the duties of civil police (article 24, XVI); professional duties (articles 103-B $\S 4^{\circ}$, and 130-A, $\S 2^{\circ}$ ); and marriage duties (article 226). ${ }^{230}$

Probably because fundamental duties restrict people's freedoms, the subject is much less approached in scientific studies than the fundamental rights are. However, facing the subject is showing the other side of the coin: fundamental duties also serve the purpose of accomplishing rights. Moreover, the consolidation of the studies on fundamental duties highlights the need for balancing the (positive or negative) sacrifices demanded from each person in order that there is no excess. ${ }^{231}$

The gap regarding fundamental duties on scientific studies has been filled by the research group State, Constitutional Democracy and Fundamental Rights, ${ }^{232}$ which not only analyzed specific duties, but also constructed a concept, based in the state-of-the-art of the global scientific literature: ${ }^{233}$

224 See, e.g.: The Urgenda Case (Supreme Court of The Netherlands, 2019); Espiner (2020); Carrington (2020).

225 See, e.g.: Weiss and Thouvenin (2015).

226 For the interrelationships between human rights law and environmental protection, see e.g.: Anton and Shelton (2011, p. 130-133); Dupuy and Viñuales (2015, p. 298-338). And reinforcing the need and possibilities for a right to a healthy environment as a human right, see e.g.: Kotzé (2015); Gonçalves (2018); Brioschi, Gonçalves, and Pedra (2019).

227 See also: Alam et al. (2015).

228 See the cost-benefit reference in section 3.2.

229 With especial attention to the caveat of universalism vs. regionalism, in order to maintain respect to all cultures.

230 The same unbalance between provisions conferring rights than imposing duties is oberved globally in modern constitutions, as in international documents. Alston and Goodman (2013, p. 515-525).

231 Pedra (2013, p. 296).

232 Freely translated from "Estado, Democracia Constitucional e Direitos Fundamentais". Research group from Vitoria Law School (Brazil). 
Fundamental duty is a legal-constitutional category, founded upon solidarity, which imposes proportional conducts on those submitted to a democratic order, liable or not to sanctions, with the aim of promoting fundamental rights. ${ }^{234}$

Already in the context that it was conceived, the concept is neither consensual nor of simple implementation. Here, the challenge goes beyond, because it is inserted in the international legal context.

Almost all aspects of the concept may be transported automatically to the international context, except for the legal-constitutional categorization, because of an obvious reason: there is no constitutional norm in the international legal order. However, this may be solved by the basis of international law itself, which has in its sources the normative foundation for interpretations and applications as that one. In other words, I propose $\mathrm{e}^{235}$ that an international human duty be understood as an international legal-normative category, founded upon solidarity, which imposes proportional conducts to those submitted to the democratic international order, liable or not to sanctions, with the aim of promoting fundamental rights.

It is important to remember that article 38 of the Statute of the International Court of Justice ${ }^{236}$ makes explicit such sources:

1. The Court, whose function is to decide in accordance with international law such disputes as are submitted to it, shall apply:

a. international conventions, whether general or particular, establishing rules expressly recognized by the contesting states;

b. international custom, as evidence of a general practice accepted as law;

c. the general principles of law recognized by civilized nations;

d. subject to the provisions of Article 59, judicial decisions and the teachings of the most highly qualified publicists of the various nations, as subsidiary means for the determination of rules of law ${ }^{237}$

2. This provision shall not prejudice the power of the Court to decide a case ex aequo et bono, if the parties agree thereto.

This means, in the mentioned proposal, that an international human duty should find foundation in one of those provisions.

Notwithstanding the bigger complexity and fragility of a human duty based upon a document ex aequo et bono and, to a certain measure, despite its contradiction, it opens application possibilities for provisions that are accepted by the involved parties in a particular case. To refer to only one example, it even opens the possibility of applying a corporate responsibility document, ${ }^{238}$ which would be a groundbreaking implementation in the field.

It is important to highlight that the source on general principles strengthens the proposition, since the foundation of the duties is solidarity, which may be considered an international principle.

233 E.g.: Alegre Martínez (2009); Bayón Mohino (1986); Díaz Revorio (2011); Di Cosimo (2011); Garzón Valdés (1986a); Garzón Valdés (1986b); Koubi (2000); Lanchester (2010); Laporta (1986); Meyer-Bisch (1989); Nabais (2002); Nabais (2007); Palombella (2007); Peces-Barba Martínez (1987); Roca (2002); Rubio Llorente (2001); Varela Díaz (1982); Vernengo (1993).

234 Gonçalves and Fabriz (2013, p. 92).

235 Gonçalves and Pedra (publication pending).

236 International Court of Justice (1945).

237 International Court of Justice (1945, article 38).

238 In a process similar to some that are being tried in national private law, as well be briefly mentioned in chapter 5 . 
Much more could be discussed in all of the four aspects of IHRL highlighted in this subtopic, which would, however, go beyond the scope of the thesis. The most important is to keep in mind when going through the analysis of the instruments related to the plastic soup is the distinctiveness of the international law field and the multiplicity of possibilities it opens, especially under the connections between IHRL and IEL

\subsection{Instruments under Hard Law}

In this section of the chapter, I will first review potential international environmental (hard) law instruments that could have some relevance for the plastic soup problem. Of course, I will address those instruments in a problem-oriented way. This implies that I am not going to discuss every amendment or protocol which may have changed the original instrument. A list of all conventions, multilateral instruments, and amendments under the scope of the International Maritime Organization (IMO), as of July $10^{\text {th }}, 2017$, is available on the IMO website. ${ }^{239}$ That list of course contains instruments not considered in this research because they are not related to plastic pollution. Besides, the selected instruments all belong to the strict international scenario. Others - such as regional instruments - are beyond the scope of this research.

\subsubsection{United Nations Convention on the Law of the Sea}

Adopted in 1982 in Montego Bay, the United Nations Convention on the Law of the Sea (UNCLOS) focuses on solving problems related to the economic exploitation of the oceans and correlated sovereignty issues. ${ }^{240}$ Nevertheless, UNCLOS also adopted several approaches on preventing, reducing, and controlling pollution of the marine environment, especially from articles 192 onward. ${ }^{241}$ As no reservations to its terms are allowed, all of the contracting parties have to agree with all of its clauses.

The contracting countries - plus the European Community - are shown in the map in figure 5, which is built according to the United Nations ${ }^{242}$ information about the signatures. It is important to notice that some countries that did not ratify it, now accept UNCLOS as customary international law.

239 International Maritime Organization - IMO (2017).

240 Oceans \& Law of the Sea - United Nations (1998).

241 United Nations Convention on the Law of the Oceans (1982).

242 Oceans \& Law of the Sea - United Nations (2018). 


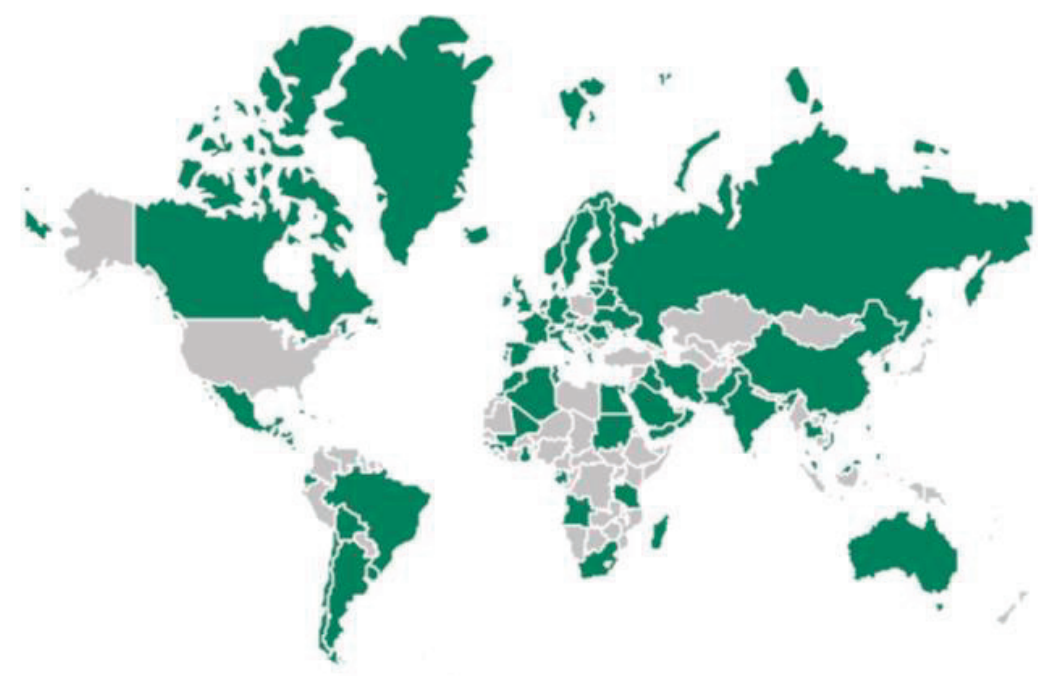

Figure 5 - Parties on the UNCLOS (shown in green)

The scope of UNCLOS is primarily to regulate shipping, not to protect the environment. Thus, even with the considered approaches concerning pollution, when it does relate to the environment, UNCLOS mostly focuses on fishing. Although UNCLOS does not literally state which are the "living resources" under its scope of protection, it is clear that an important goal of UNCLOS is to protect fisheries. UNCLOS is therefore primarily focused on fish stocks, not with a view on protecting the maritime environment, but rather to enable the availability of the fish resources to all those interested in exploring marine resources in the future.

Still, "UNCLOS provides a comprehensive legal framework for the protection and preservation of the marine environment under Part XII", ${ }^{243}$ reinforcing the first idea about the comprehensiveness of the instrument's focus on environmental protection. This elevates the importance of UNCLOS, even concerning plastics, especially considering the definition of marine pollution - under article 1(1)(4):

[T] he introduction by man, directly or indirectly, of substances or energy into the marine environment, including estuaries, which results or is likely to result in such deleterious effects as harm to living resources and marine life, hazards to human health, hindrance to marine activities, including fishing and other legitimate uses of the sea, impairment of quality for use of sea water and reduction of amenities. ${ }^{244}$

This definition enables concerns related to the plastic pollution of the oceans to be directly placed under UNCLOS' protection. Besides, UNCLOS enhances the likelihood of success insofar as it covers six types of marine pollution: (i) from land-based sources; (ii) from seabed activities subject to national jurisdiction; (iii) from activities in the Area; ${ }^{245}$ (iv) by dumping; (v) from vessels; and (vi) from or through the atmosphere. ${ }^{246}$ In other words, UNCLOS has approaches that cover all sources of plastic pollution.

Moreover, article 210(4) of UNCLOS provides that "States [...] shall endeavour to establish global and regional rules, standards and recommended practices and procedures to prevent, reduce and

243 Wong (2017).

244 United Nations Convention on the Law of the Oceans (1982).

245 According to article 1(1) of UNCLOS, "Area means the seabed and ocean floor and subsoil thereof, beyond the limits of national jurisdiction".

246 Wong (2017). 
control such pollution". ${ }^{247}$ This means that UNCLOS, as a binding instrument, imposes obligations on States that are provided under other instruments, consequently enabling a reflexive binding effect to those other international and regional instruments. This provides for a major protection, not only by introducing new and more specific approaches, but also by encouraging States to adopt such documents in order to be able to influence decisions.

UNCLOS, pursuant to article 235(1), also provides that "States are responsible for the fulfilment of their international obligations concerning the protection and preservation of the marine environment," and that "they shall be liable in accordance with international law". ${ }^{248}$ Together with the establishment of the International Tribunal for the Law of the Sea (ITLOS), this means that the Convention includes several tools for dispute settlement and an imposition of remedies.

In spite of not being the first international instrument to the law of the sea and even for the protection against marine pollution, UNCLOS appears first in this list because of the importance it plays in the development of the international law of the sea and several related treaties. Furthermore, it codified the basic principles, such as the protection of the marine environment, as customary international law, and "contains rules of reference to 'generally accepted international rules and standards' with regard to the preservation and protection of the marine environment". ${ }^{249}$ The 1972 London Dumping Convention, which will be discussed in the next session, is an important example of conferring binding effects on other international instruments. "Nonetheless [the pacta tertis nec nocent nec prosunt principle], the Secretary General of the United Nations, in his 1995 Report on the Law of the Sea, has affirmed that the provisions of the London Convention qualify as the "global rules and standards" 250 mentioned in article 210(4) of UNCLOS.

The main importance regarding UNCLOS is that, for specific issues, it requires the relevant provisions to be read in the light of other conventions, regional treaties and standards set by competent international organizations. This means that UNCLOS itself does not provide any framework for the plastic pollution of the oceans.

There is, however, another relevant aspect to the discussion. As mentioned, the main purpose of UNCLOS is to solve sovereignty issues in seas and oceans. Those competency aspects may influence the discussion about plastic pollution especially from an ex post perspective, meaning that recovering the plastic pollution from international waters directly relates to those who have authority over it.

Thus, before being able to assess to what extent this actually covers the problem of plastic pollution, we need to identify how the law of the sea deals with the jurisdiction matter in a broader sense.

The first relevant aspect to determine sovereignty in the seas and oceans is to establish the region being referred to. In that sense, the Convention establishes different zones. The Territorial Sea extends up to 12 nautical miles from the baseline ${ }^{251}$ (article 3). The Contiguous Zone may extend such control for specific purposes, but no more than 12 more nautical miles (article 33). The Exclusive Economic Zone (EEZ) goes up to 200 nautical miles from the baseline (article 57). Apart from those, the convention also defines the continental shelf and the Area - respectively, seabed under the EEZ and High Seas -, as well as the seas and the enclosed seas. Finally, there are the High Seas, which are any international waters "that are not included in the exclusive economic zone, in the territorial sea or in the internal waters of a State, or in the archipelagic waters of an archipelagic State". ${ }^{252}$

247 United Nations Convention on the Law of the Oceans (1982).

248 United Nations Convention on the Law of the Sea (1982, at article 210).

249 United Nations Convention on the Law of the Sea (1982, at article 211).

250 Farnelli and Tanzi (2017).

251 The baseline is defined by UNCLOS, under article 5: "Except where otherwise provided in this Convention, the normal baseline for measuring the breadth of the territorial sea is the low-water line along the coast as marked on large-scale charts officially recognized by the coastal State". United Nations Convention on the Law of the Oceans (1982).

252 United Nations Convention on the Law of the Oceans (1982). 
From there, UNCLOS details the competencies, jurisdictions, rights and duties of the States in each of those parts. For the purposes of this thesis, it is enough to know that: (i) in the Territorial Sea, coastal States exercise control; (ii) in the contiguous zone, coastal States exercise control only when necessary for the specific purpose why the zone was established; (iii) in the EEZ, the rights and jurisdiction of the coastal State and the rights and freedoms of other States are governed by UNCLOS; additionally, the coastal State only has certain rights of exploitation at the EZZ (article 55); (iv) the High Seas are open to all States and ruled by international law.

As described before, all of those zones are relevant to the plastic pollution, however, the high seas present the highest concentrations, mainly in the gyres. Moreover, the approach to the pollution in the Territorial Sea, in the contiguous zone and in the EEZ, to different extents, demand much more from a national and regional approach than from an international one. This is, of course, also important and will be mentioned further in this thesis, but for now we should focus on understanding how the international law addresses the competencies and jurisdiction of the High Seas.

Articles 91 and 92 of UNCLOS solve this issue by entitling nationality to a ship, that must be under the jurisdiction of its flag. This is not enough for the plastic soup problem not only because the main concern are the land-based sources but also because: (i) the so-called flags of convenience are a challenge to this solution; (ii) preventing and recovering the plastic pollution will rarely happen inside a ship.

The flag of a ship serves the purpose of indicating the applicable regulation to the relationships and facts occurring inside the ship, when it is at sea. It is especially important since ships travel in international waters, where it would be difficult to determine who is responsible and what rules would have to be followed.

By 1905 , as was made clear in a decision by the Permanent Court of Arbitration at The Hague, the ability of 'every sovereign to decide to wh[ich ships] he will accord the rights to fly his flag and [...] to prescribe the rules governing such grant' had passed into customary international law. ${ }^{253}$

However, this solution is also the cause of the mentioned problem of the flags of convenience. Historically, ship-owners have strategically chosen to fly under other States' flags, either to avoid taxes, or to prevent difficulties during wars, among other reasons. This behavior has relevant impacts on environmental protection, because it usually means lowering the environmental, safety and labor standards. ${ }^{254}$

\subsubsection{Convention on the Prevention of Marine Pollution by Dumping of Wastes and Other Matter (1972 London Dumping Convention) and 1996 London Protocol}

The Convention on the Prevention of Marine Pollution by Dumping Wastes and Other Matter, also known as the 1972 London Dumping Convention, addresses the waste issue in a general way. Being one of the first international instruments to protect the marine environment - it entered into force in 1975 - emphasizes its importance.

Another relevant aspect is that it explicitly prohibits the dumping of "persistent plastics and other persistent synthetic materials, for example, netting and ropes, which may float or may remain in suspension in the sea in such a manner as to interfere materially with fishing, navigation or other legitimate uses of the sea". Such a statement may be found in article IV(1)a, combined with Annex

\footnotetext{
253 Sombre (2006, p. 69).

254 See, for example: Anderson III (1996); Carlisle (1981, p. 115); Morris (1996, p. 15); Sombre (2006, p. 14).
} 
I(4). ${ }^{255}$ However, the inclusion of Annex I only happened in 2006. It was introduced by the 1996 London Protocol, which only entered into force in 2006 and "was agreed to further modernize the Convention and, eventually, replace it". ${ }^{256}$ Furthermore, article XII establishes which polluting substances States should prevent but it does not list plastic.

Regarding consequences of non-compliance, the Convention establishes the development of procedures for the assessment of liability and settlement of disputes (article X) and recommends that parties "at their first consultative meeting consider procedures for the settlement of disputes concerning the interpretation and application of this Convention" (article XI).

A list of the contracting parties - as at October $9^{\text {th }}, 2017$ - is available at the $\mathrm{IMO},{ }^{257}$ from which was built the map shown in figure 6, representing the signatures on the Convention, on the Protocol, on both or on none.

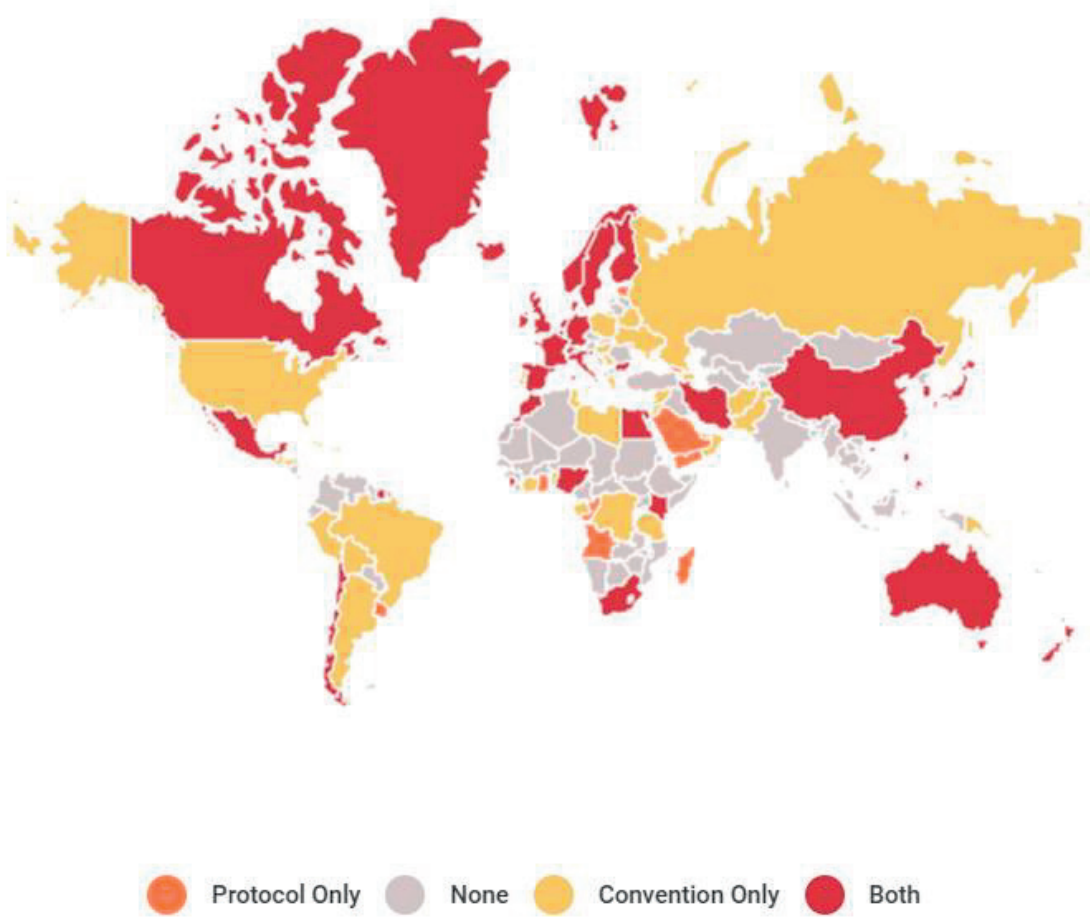

Figure 6 - Parties on the London Convention 1972 and London Protocol 1976

In order to assist national authorities, the contracting parties developed guidelines on how to regulate ocean dumps and on how to meet their obligations under the two instruments. Specific guidelines are available addressing the materials listed in Annex I of the Convention. ${ }^{258}$

For a long time there were discussions regarding the application and effectiveness of the Convention, which explains in great part the many protocols and assessment procedures. ${ }^{259}$ In that sense, one of the

255 Convention on the Prevention of Marine Pollution by Dumping of Wastes and Other Matter (with amendments) (1972).

256 International Maritime Organization - IMO (2018).

257 International Maritime Organization - IMO (2017).

258 United States Environmental Protection Agency - EPA (2017). 
most important tools under the Convention framework is the compliance review mechanism. Each contracting state is required "[n]o later than two years after the entry into force of [the] Protocol . . [to] establish those procedures and mechanisms necessary to assess and promote compliance with [the] Protocol", accordingly to the article 11(1) of the 1996 Protocol. ${ }^{260}$ In addition, the $29^{\text {th }}$ Consultative Meeting, in 2007, approved the Compliance Group, which monitors the extent to which member states abide by it. ${ }^{261}$

Regarding the effectiveness of the London Convention \& Protocol (LC\&P), it "mainly depends on its capacity to attract participation, in order to foster environmental awareness". Because of that, one of the main problems with the applicability of the Convention is the lack of provisions to solve technical, scientific, and mainly financial obstacles to change the behavior of sea dumping.

All in all, it is considered in legal doctrine to be "a positive achievement in the field of protection of the marine environment". ${ }^{262}$ However, if considering specifically its ability to face the plastic pollution in the oceans, the London Convention is even more limited. "It covers dumping from ships, platforms and aircraft. It does not cover emissions from land based sources nor wastes coming from exploration and operations of seabed resources, nor storage of material with a purpose other than eliminating". ${ }^{263}$ Confronting this with data that show that $80 \%$ of the plastic that ends up in the ocean comes from land-based sources ${ }^{264}$ the conclusion is that, even if effective, the London Convention and Protocols deal with a restricted part of the plastic problem.

\subsubsection{International Convention for the Prevention of Pollution from Ships - Annex $V$ (MARPOL)}

The current content of the International Convention for the Prevention of Pollution from Ships is a combination of the 1973 Convention and the 1978 Protocol. The Annex V was adopted in 2011 and is responsible for the only mention to plastics in the document, prohibiting the discharge into the sea of all plastics, as stated by Regulation 3(2). The only exceptions to this prohibition are those listed in Regulation 7, but they are not relevant for the purposes of this analysis, since they are the usual legal exceptions, such as accidents or the necessity of protecting life. ${ }^{265}$

A list of the contracting parties - as at October $9^{\text {th }}, 2017$ - is available at the International Maritime Organization (IMO), ${ }^{266}$ from which is built the map of figure 7 , representing the signatories to the Convention:

\footnotetext{
259 Peet (1991).

2601996 Protocol to the Convention on the Prevention of Marine Pollution by Dumping of Wastes and Other Matter (1972 - as amended in 2006).

261 Farnelli and Tanzi (2017).

262 Farnelli and Tanzi (2017).

263 International Navigation Association - Environment Commission (2013, p. 23).

264 Sheavly (2005).

265 Annex V of the International Convention for the Prevention of Pollution from Ships (2011.)

266 International Maritime Organization - IMO (2017).
} 


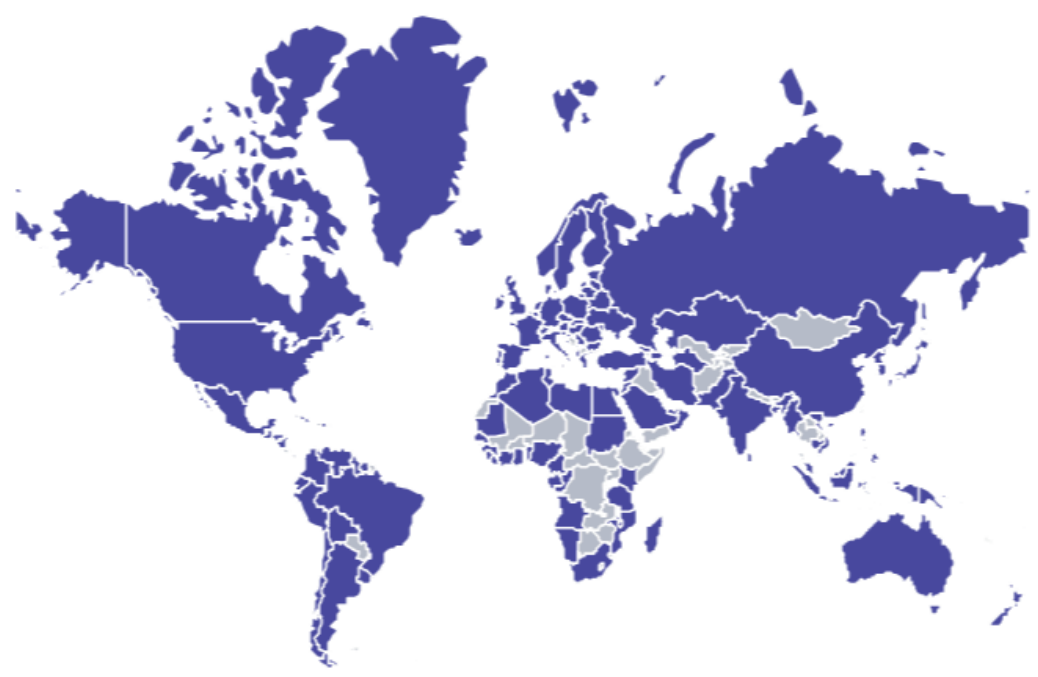

Figure 7 - Parties on MARPOL - Annex V (shown in blue)

The MARPOL Convention has a particular relevance in the sense that it explicitly regulates plastic disposal in the oceans. The main problem of the approach starting with MARPOL is that, once again, it prevents pollution from ships, while $80 \%$ of the plastic pollution of the oceans comes from landbased sources. However, MARPOL is recognized to necessitate a specific convention to address specific kinds of pollutions, since its scope is too broad. ${ }^{267}$ In the case of plastic, this would probably mean referring back to the London Convention and Protocols, including its limitations. Moreover, there are no mentions in the MARPOL relative to implementation issues.

One of the main limitations of MARPOL is an old problem of maritime law, the flags of convenience, which, as explained previously in this thesis, means that ship-owners often choose to navigate under the flag that has lower standards of regulation, or, in this case, that is not a party to MARPOL.

Another limitation of MARPOL is the lack of economic incentives to promote innovation in the construction of ships, ${ }^{268}$ which is mostly not applicable to plastics, because such lack of investment is relevant to leaks and accidents - typically related to pollution as oil. The use of grandfather clauses ${ }^{269}$ is also a caveat directed ${ }^{270}$ to MARPOL, but they do not apply to Annex V.

Finally, the general conclusion is that MARPOL may be considered effective, due to its mandatory technical regime. On the other hand, those restraints show that there is still much to improve. Literature $^{271}$ considers Annex I - related to oil discharge - as a large success, whilst Annex III to VI is impaired due to its optional nature.

\subsubsection{Convention on Biological Diversity and the Jakarta Mandate}

The relationship between the Convention on Biological Diversity (CBD) and the problem of the plastic pollution of the oceans is not as direct as with the other international documents. However, it

267 International Navigation Association - Environment Commission (2013, p. 22).

268 Farnelli and Tanzi (2017).

269 Rules that provide that an old rule continues to apply to some existing situations while a new rule will apply to all future cases.

$270 \quad$ Farnelli and Tanzi (2017).

271 Farnelli and Tanzi (2017). 
plays an important role in the sense that plastics have a great impact on nature and marine life. That is also recognized by the convention itself when noting, for instance, that "it is vital to anticipate, prevent and attack the causes of significant reduction or loss of biological diversity at source". ${ }^{272}$

The Convention is also important because of the number of countries that have signed and ratified it: 196, according to the official website. The United States have also signed, but not ratified, and that is why it is not shown in the map in figure 8 as a contracting party. Finally, the European Union is also a party to the Convention.

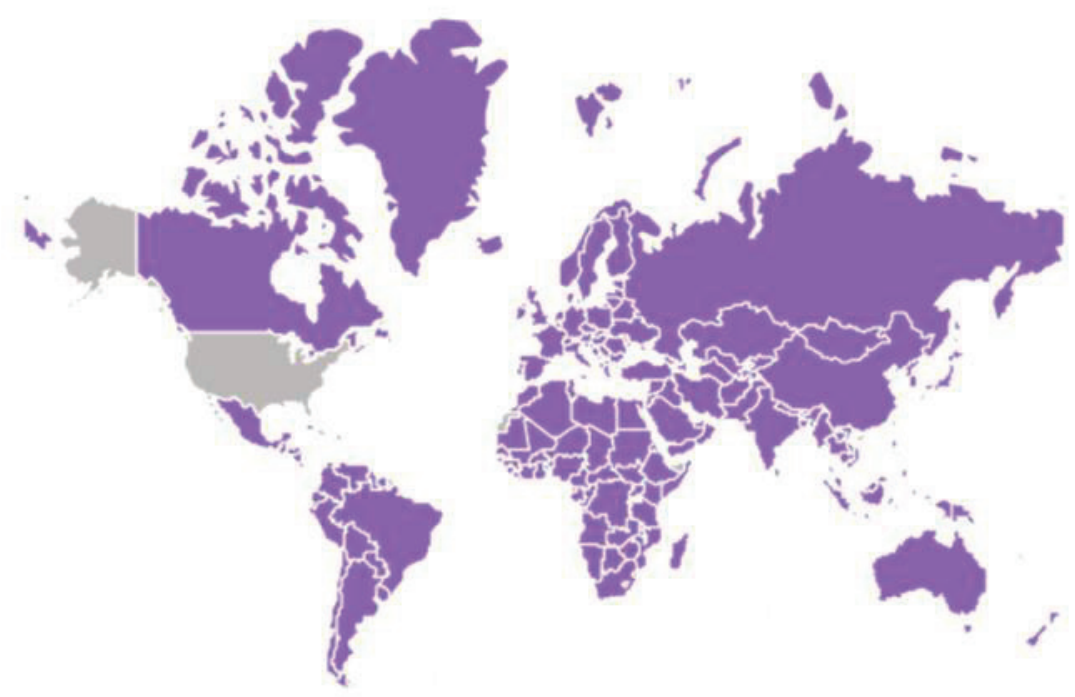

Figure 8 - Parties to CDB (shown in purple)

Hence, once more the approach on pollution is general, but, especially due to the nature and breadth of the document, it is possible to assume that plastic pollution is included.

The Conferences of the Parties (COP) of the CBD play a major role, and the marine environment has been central since COP2, which took place in 1995. At that occasion, the decisions taken on this topic were collected in the Ministerial Statement issued as the Jakarta Mandate on Marine and Coastal Biodiversity (Jakarta Mandate).

The Jakarta Mandate represents a significant step forward, because it establishes a checklist of concrete measures that parties to the $\mathrm{CBD}$ should take. It also invites major international bodies to improve their existing activities and develop new actions, to promote the conservation and sustainable use of marine biodiversity, and it sets in motion a process under the CBD to address the most urgent threats to marine and coastal biodiversity. 273

In 2001, a workshop to evaluate progress on CBD implementation in Eastern Africa ${ }^{274}$ concluded that more work needs to be done in all aspects addressed by the Convention, even though a great range of national and regional plans and strategies were already in place. It also concluded on the importance of the action by international and by non-governmental and non-profit organizations for the development of the region.

\footnotetext{
272 Convention on Biological Diversity (1995).

273 IUCN Eastern Africa Programme. (2001, p. 2).

274 IUCN Eastern Africa Programme (2001).
} 
On the other hand, during COP10 the parties on the CBD agreed that the countdown to achieve the targets planned by 2010 had failed. For this reason, contracting parties decided to establish The Strategic Plan for Biodiversity 2011-2020 and the Aichi Targets. Naturally, they do not focus solely on the ocean and even less on the plastic pollution of the oceans. Yet, it is possible to apply the same reasoning as done so far, which can be supported by the statement on Targets 8 and 11 .

Target 8 proposes that "by 2020, pollution, including from excess nutrients, has been brought to levels that are not detrimental to ecosystem function and biodiversity". ${ }^{275}$ Target 11 , provides effective and equitable management to terrestrial and inland water, as well as coastal and marine areas. ${ }^{276}$ Future data and analysis will show if the Aichi Targets had a better impact than the targets planned until 2010.

\subsubsection{Convention on the Conservation of Migratory Species of Wild Animals}

As with the CBD, the Convention on the Conservation of Migratory Species of Wild Animals (CMS or the Bonn Convention $)^{277}$ presents a relationship with the plastic pollution of the oceans because this type of pollution may harm wild animals. More specifically in this case, because addressing migratory species means also addressing species on international waters, as stated in the preamble of the convention, when referring to recommendation 32 of the Action Plan adopted by the United Nations Conference on the Human Environment (Stockholm, 1972). ${ }^{278}$

Also like the CDB, the CMS, has many parties, although not as many: 126 as of December $1^{\text {st }} 2017 .{ }^{279}$ Again, the European Union is also a party.

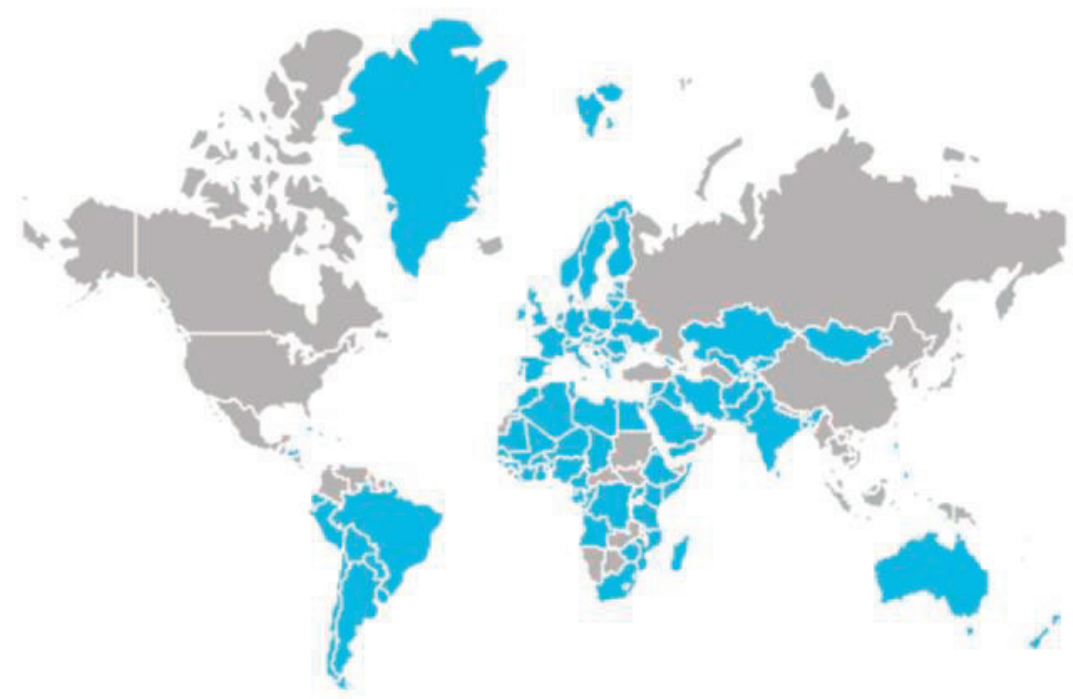

Figure 9 - Parties to CMS (shown in light blue)

275 Secretariat of the Convention on Biological Diversity (2011).

276 Secretariat of the Convention on Biological Diversity (2011).

277 Convention on the Conservation of Migratory Species of Wild Animals (1992).

278 United Nations - UN (1972).

279 UN Environment - CMS (1992). 
According to the Secretariat of the Convention, "the legal instruments under CMS may range from legally binding Agreements to less formal Memoranda of Understanding and can be adapted to fit the requirements of each region", ${ }^{280}$

The CMS was adopted in 1979, but the more significant advances have been registered in the year of 2014, mainly because of COP11 on the CMS. The Conference witnessed the realignment of a series of policy directions for the CMS and the elaboration of a new Strategic Plan for Migratory Species for the years 2015-2023.

In a broader perspective, "the CMS regime stands out for its dynamic development since the adoption of the Bonn Convention, more than for its substantive provisions". ${ }^{281}$ Among those developments, there is a constant increase in the number of parties, listed species and subsidiary instruments. Another positive aspect of the Bonn Convention implementation is the flexible approach to its application, as for example, with the growing relevance of the CMS regime for non-migratory species. ${ }^{282}$

On the negative broader aspects, there are resource constraints, which frustrate the possibilities of adequate implementation, especially considering the wide range of activities related to the Convention. This is the main reason why CMS is not considered to be effective. ${ }^{283}$

Regardless of the (in)effectiveness of the Bonn Convention, its effects on facing the plastic pollution of the oceans seem irrelevant to the present analysis. There are, however, specific agreements brought under the Bonn Convention, which each focus on particular species to be protected. ${ }^{284}$ Those are undoubtedly useful, but still the question arises as to the immediate influence of the Bonn Convention or its related agreements on the fight against the plastic pollution of the oceans.

\subsubsection{Basel Convention on the Control of Transboundary Movements of Hazardous Wastes and their Disposal (Basel Convention)}

The Basel Convention is the only international binding convention regarding the global movement of waste. ${ }^{285}$ It entered into force in May $5^{\text {th }}, 1992$, and has 187 parties, represented in the map in figure 10.

\footnotetext{
280 U.N Bonn (2017)

Lewis and Trouwborst (2017).

Lewis and Trouwborst (2017).

Lewis and Trouwborst (2017).

284 United Nations Environment Programme - UNEP (1979).

285 Grosz (2011, p. 20).
} 


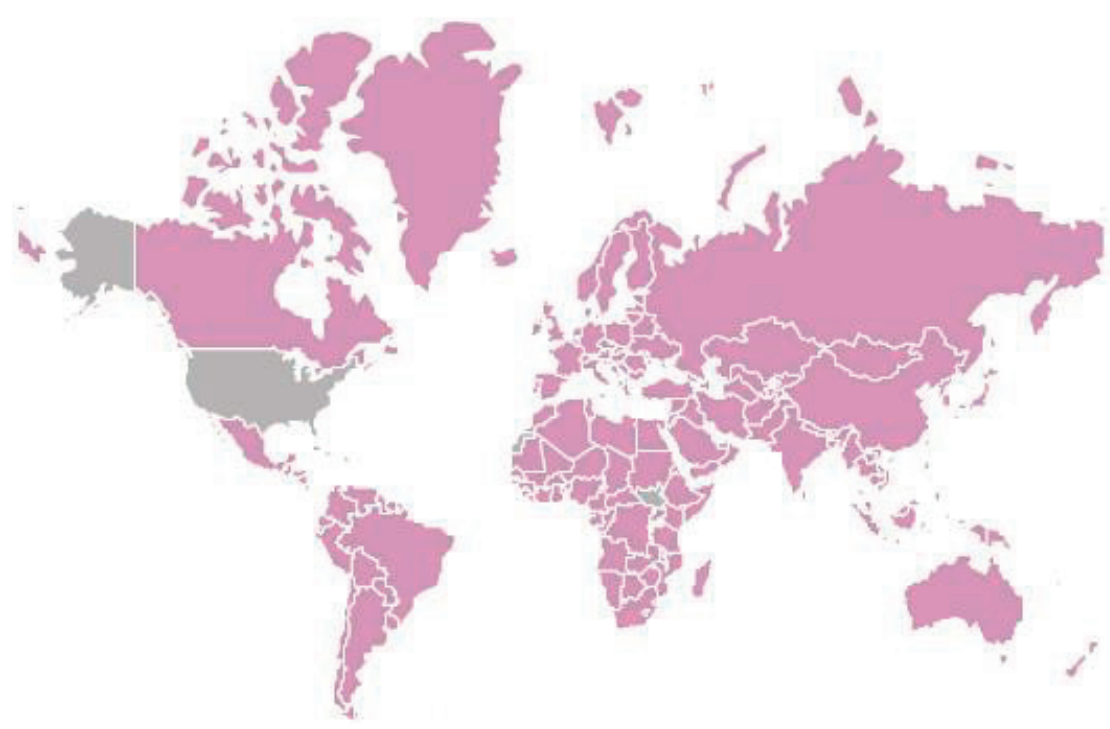

Figure 10 - Parties to the Basel Convention (shown in pink)

Under article 2(1), "wastes are substances or objects which are disposed of or are intended to be disposed of or are required to be disposed of by the provisions of national law". ${ }^{286}$ This shows an operational approach ${ }^{287}$ on the definition adopted by the convention. It follows by categorizing wastes into hazardous and other wastes, since the convention arose in the context of an overwhelming growth of the hazardous waste generated yearly in the planet. ${ }^{288}$ The focus is not solely on the hazardous wastes, but also on the impacts that their global movements could have in the developing world. Such a concern is clearly shown in the preamble (paragraph 7) although added in 1995, during COP 3 : "Recognizing that transboundary movements of hazardous wastes, especially to developing countries, have a high risk of not constituting an environmentally sound management of hazardous wastes as required by this Convention". ${ }^{289}$

COP 3 is also known for approving the Ban Amendment, which was meant to ban exports of hazardous wastes from Lichtenstein, and OECD and EC countries to all other countries. ${ }^{290}$ It took over two decades to enter into force, because

[t]he challenge of protecting vulnerable countries from unwanted hazardous waste imports, while not precluding the import of wastes considered valuable secondary raw materials to countries in a position to manage them in an environmentally sound manner has therefore gained importance. ${ }^{291}$

Also, it does not concern plastics, since they were not considered hazardous. ${ }^{292}$ Still, the reasoning behind the delay on implementing may also apply to the complexity of the plastics waste world trade. For instance, there is criticism about: (i) "the potential lack of broad-based support for the instrument,

\footnotetext{
286 United Nations Environment Program - UNEP (1989).

287 Grosz (2011, p. 21).

288 Hackett (1990, p. 294).

289 United Nations Environment Program - UNEP (1989).

290 United Nations Environment Program - UNEP (1989, Annex III).

291 UNEP - Basel Convention (2019b).

292 Plastics are listed on Annex IX and do not have the characteristics under Annex III. Therefore, they do not fall under the scope of Article 1(1), that defines hazardous wastes.
} 
the scope of the ban on scrap material intended for recycling"; 293 and (ii) the disregard for the interests of the global South, such as "the lack of attention to South-South trade, uncertainty as to the continued availability of Article 11 agreements, and the nature, if any, of obligations undertaken by potential developing country states [who import waste]". ${ }^{294}{ }^{295}$ Some even argue that enabling such a trade could improve the Convention's ability to achieve environmental justice. ${ }^{296}$ All in all, a practical assessment will be possible soon, since the Ban Amendment entered into force in December $5^{\text {th }}, 2019 .^{297}$

From the beginning, the Basel Convention faced criticism. For example, although it is admittedly a necessary advance on the search for a global and comprehensive regulatory system, it is considered too traditional in approach and not capable of protecting the global commons from hazardous wastes, with the exception of Antarctica. ${ }^{298}$ If that is the case for the more dangerous wastes, even less should be expected for other wastes - which can be freely traded globally -, plastics included. Additionally, plastics were only incorporated as a waste regulated by the Convention from COP 4 (1998) onwards, when Annex IX was adopted.

The concerns regarding the effectiveness of the Basel Convention were addressed during COP 6, in 2002, when the Mechanism for Promoting Implementation and Compliance was established. ${ }^{299}$ "The objective of this mechanism is to assist parties to comply with their obligations under the Convention and to facilitate, promote, monitor and aim to secure the implementation of, and compliance with, the obligations under the Convention". ${ }^{300}$ Still, the effectiveness of "[t]he Basel Convention and Ban seem to have had no effect on the growth of international hazardous waste, and almost no effect on shipments from developed to developing countries". ${ }^{301}$

Regardless of compliance and implementation issues, the Basel Convention is still key to the analysis of the advances in public international law to face the plastic pollution. In June 2018, the Norwegian government proposed an amendment regarding the treatment of plastics, which was adopted during COP14, in May, 2019. The changes will come into force in January $1^{\text {st }}, 2021$, and establish especial caution for plastic waste transboundary trade. "After the enforcement of these amended Annexes, if a company in any of the member countries intends to export such wastes, it is required to acquire prior informed consent from the destination country involving the exports". ${ }^{302}$ A summary of the approved changes is available in table 6 .

\begin{tabular}{|l|l|l|}
\hline Annexes & Details & Highlights of the amended Annexes \\
\hline $\begin{array}{l}\text { Annex II (plastic wastes } \\
\text { controlled under the } \\
\text { Convention) }\end{array}$ & $\begin{array}{l}\text { List of “Other Wastes" to be } \\
\text { controlled under the } \\
\text { Convention }\end{array}$ & $\begin{array}{l}\text { New listing of plastic wastes, excepts those } \\
\text { listed in Annexes VIII and IX }\end{array}$ \\
\hline
\end{tabular}

293 Wirth (1998, p. 245).

294 Wirth (1998, p. 245).

295 See also: Schneider (1996).

296 See, e.g.: Widawski (2008).

297 UNEP - Basel Convention (2019a).

298 Kummer (1992, p. 559).

299 UNEP - Basel Convention (2019b).

300 UNEP - Basel Convention (2019b).

301 Kellenberg, and Levinson (2013, p. 29).

302 Japan Ministry of Economy, Trade and Industry - METI (2019). 


\begin{tabular}{|l|l|l|}
\hline \multicolumn{1}{|l|}{$\begin{array}{l}\text { Annex VIII (plastic wastes } \\
\text { controlled under the } \\
\text { Convention) }\end{array}$} & $\begin{array}{l}\text { List of examples of hazardous } \\
\text { wastes }\end{array}$ & $\begin{array}{l}\text { New listing of plastic wastes as hazardous } \\
\text { wastes that have hazardous features identified } \\
\text { based on discarding processes or chemical } \\
\text { characteristics }\end{array}$ \\
\hline $\begin{array}{l}\text { Annex IX (plastic wastes not } \\
\text { controlled under the } \\
\text { Convention) }\end{array}$ & $\begin{array}{l}\text { List of examples of hazardous } \\
\text { wastes not controlled under the } \\
\text { Convention }\end{array}$ & $\begin{array}{l}\text { Further clarification of the scope of clean } \\
\text { plastic wastes that are appropriate for } \\
\text { recycling }\end{array}$ \\
\hline
\end{tabular}

Table 6 - Summary of the Amendments adopted during COP14 (May, 2019) (103 $^{303}$

More than that, COP14 established new initiatives to look into solutions for the plastic pollution: (i) a working group was "to hold discussions on the revision of the Guidelines for Environmentally Sound Management of Plastic Wastes"; 304 and (ii) "a Partnership on Plastic Wastes to encourage member countries to manage plastic wastes in an environmentally sound manner", 305 which will engage in activities to gather data and to raise public awareness, starting in 2020.

Even though the new provisions are yet to be implemented, and therefore, to be assessed, the mere fact that the parties to the Basel Convention are moving fast to a consensus on actions to fight the plastic pollution is already a sign. It is more than any of the other analyzed hard law instruments has done to address the problem so far.

\subsubsection{Summary (Hard Law)}

This brief overview of a representative sample of international conventions shows that there are conventions that indirectly could have some influence on plastic pollution. On the other hand, it equally shows that none of the conventions directly focuses on the central issue of this contribution, the plastic soup. MARPOL and other conventions prohibiting the discharge of plastics into the sea are undoubtedly important as they can contribute to a prevention of emissions of plastic. More recently, the Basel Convention has become an important instrument to deal with the issue in the near future. Others are more of an indirect interest, such as the convention on the migratory species. Those species can undoubtedly be negatively affected by plastics. Yet, the Bonn Convention does not indicate specific measures on how those migratory species will be protected from the increasing plastic. As a result, under the currently applicable legal framework, there are no international conventions that can directly contribute to preventing the problem of the plastic soup. This means that it may for the future be important to at least ask the question whether a specific convention would be appropriate to deal with the plastic soup problem. Those aspects will be reviewed and critically analyzed in chapter 6 , together with the findings concerning the soft law instruments, that could play a role in this respect.

\subsection{Instruments under Soft Law}

This section of the thesis will examine the plastic pollution problem from the perspective of international environmental soft law instruments. First, however, the concept of soft law in international law merits some explanation.

\footnotetext{
303 Japan Ministry of Economy, Trade and Industry - METI (2019).

304 Japan Ministry of Economy, Trade and Industry - METI (2019).

305 Japan Ministry of Economy, Trade and Industry - METI (2019).
} 
International law is founded on the principle of sovereignty: every State is sovereign over its territory, and all States are coequal. Historically, international law was limited primarily to interactions between States that consented to bind themselves (and thereby limit their sovereignty) whether by treaty or recognizing a principle of customary law. ${ }^{306}$

More recently, "this State-centric, treaty-oriented view of international law has evolved to include a broader range of actors and types of law". ${ }^{307}$ Even more important, this view has evolved to allow instruments that do not count with a binding element - soft law. The lack of one more element of the traditional law concept contributes greatly to the divisions in opinions.

Some legal scholars defend that international law should be neither hard nor soft law, since it is not law at all. ${ }^{308}$ Nonetheless, even amongst those who do not share this opinion, there is controversy, with many stating the same about the soft law nature.

I, however, side with the group ${ }^{309}$ that considers international law - in all of its forms - as, in fact, law. Of course, as happens with the different fields of law, it brings its unique characteristics, but it is nonetheless, law.

I will now address relevant soft law instruments in a problem-oriented manner. This implies that I am not going to discuss every provision of those instruments. The approach is to address in a general way the discussion and implementation steps as well as the academic conclusions regarding the effectiveness of each instrument. When relevant to the focus of the plastic soup, some specific provision will also be discussed.

The soft law instruments will be discussed in a chronological order, which obviously does not necessarily reflect their importance.

\subsubsection{Agenda 21 and the Johannesburg Plan of Implementation}

Agenda 21, together with the Rio Declaration on Environment and Development, and the Statement of principles for the Sustainable Management of Forests, was one of the main results from the United Nations Conference on Environment and Development (UNCED or Rio92). The States represented at the Conference are displayed in the map in figure 11, built in accordance with the list available at the UN website. ${ }^{310}$

306 Bruch and Broderick (2016, p. 36).

307 Bruch and Broderick (2016, p. 36).

308 Weil (1983, p. 415).

309 See, for example: Guzman, and Meyer (2010); Senden (2005).

310 United Nations - UN (2018b). 


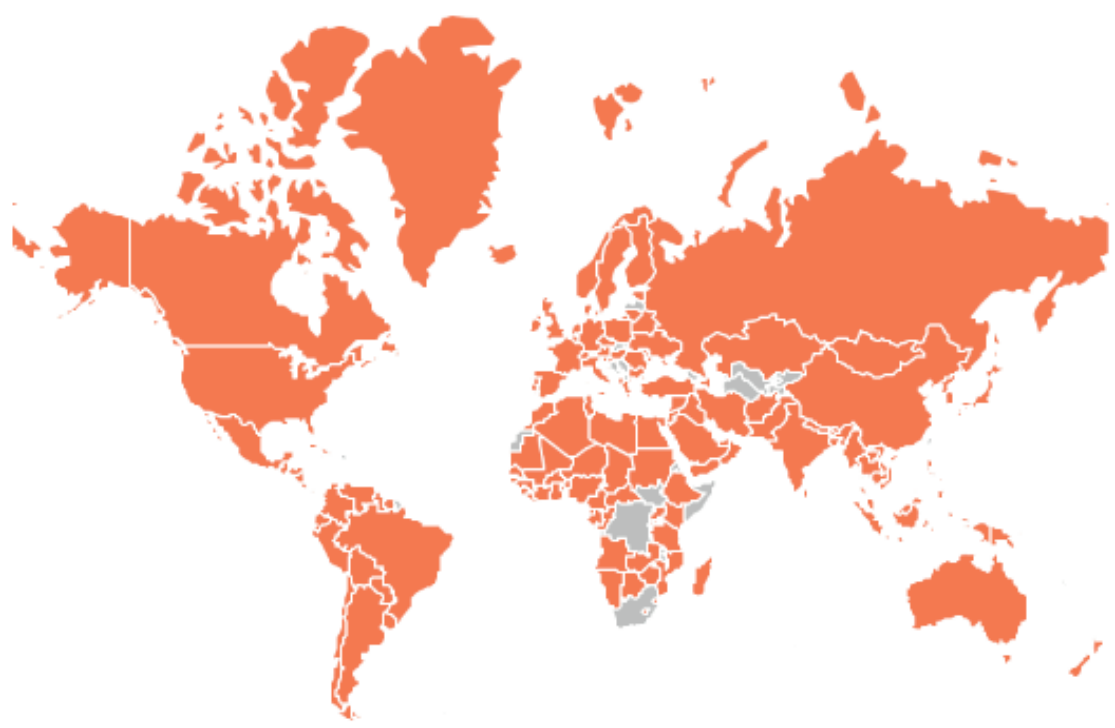

Figure 11 - Countries represented at Rio92 (shown in orange)

It delivered several development and environmental objectives that are too broad and too complex to be implemented in a short term or with simple solutions.

That is why "the full implementation of Agenda 21, the Programme for Further Implementation of Agenda 21 and the Commitments to the Rio principles, were strongly reaffirmed at the World Summit on Sustainable Development (WSSD) held in Johannesburg" ${ }^{\text {s11 }}$ in 2002.

The document is more focused on general statements, such as eradicating poverty and changing unsustainable patterns of production and consumption. This can be explained by the main goal of the Agenda, which is promoting change in national and local governments, by boosting action on the 115 programs to facilitate transition towards sustainable development. Still, there is no mention of plastics.

Thereby, actual practical changes enabled by the plans are difficult to measure, but the number of local governments constitutes a safe indicator for progress towards the programs proposed. Already in 2002, the year of the World Summit on Sustainable Development, 85 countries had developed strategies for implementing Agenda 21, ${ }^{312}$ meaning less than half of the signatory countries.

If considered as an absolute number, this may be taken as an impressive number of countries introducing sustainability into their home policies, but the local outcomes - which would be the core impact intended by Agenda 21 - do not give reason to celebrate. The national and regional results of Agenda 21 are mostly non-existent or weak, according to academic literature. This happens for different reasons in the different countries, so they can be described even though the key element to successful implementation, at least in the European Union, seems to be related to the interest and engagement of government and of local administrations.

Australia's lack of progress with Agenda 21, for example, seems to be a consensus. Political and financial barriers lead to a lack of progress in councils in the state of Victoria, ${ }^{313}$ where the programme

311 United Nations Sustainable Development Knowledge Platform (1992).

312 United Nations Department of Economic and Social Affairs - Division for Sustainable Development (2012).

313 Mercer, and Jotkowitz (2000). 
should have been discussed and implemented. Even those scholars who consider that the Australian councils showed progress through political willingness, administrative capacity and ability to network, say that raising awareness and involving people is one of the main difficulties, leading to a tendency that Agenda 21 stays at the abstract level without real impacts. ${ }^{314}$

In the Brazilian context, pessimism is also dominant, mostly because of the lack of concern and the absence or incompleteness of instruments from the government to evaluate the implemented actions, but also due to the necessity to improve the participative process. ${ }^{315}$

The analysis regarding China is still negative, but a little bit more positive, although the reported environmental advances are only partially attributed to Agenda 21 and other soft law international instruments. ${ }^{316}$ Among the factors that limit progress there are bad planning, administrative fragmentation, failure of the private sector to involve, ${ }^{317}$ bureaucratic infighting, disagreements between central and provincial governments, and corruption. ${ }^{318}$ Furthermore, the perspective is that the environment will still decline for a long time in the future, due to China's development plan. ${ }^{319}$

Italy appears as a mostly positive example, despite the several challenges still to be overcome. Effective frameworks for enhancing local sustainability policies, capacity building within local communities, and improving innovation in local government and decision-making processes are some of the positive aspects. ${ }^{320}$

Reviews like those appear regarding several countries. Many of them report mostly negative conclusions, as is the case of Indonesia, ${ }^{321}$ New Zealand, ${ }^{322}$ Norway, ${ }^{323}$ Poland, ${ }^{324}$ Seoul (South Korea), ${ }^{325}$ and USA. ${ }^{326}$ Others, report mostly positive conclusions, such as the example of the Czech Republic, ${ }^{327}$ Germany, ${ }^{328}$ Peru, ${ }^{329}$ and Sweden. ${ }^{330}$ Some - for instance, Japan ${ }^{331}$ - report some progress but still do not conclude on having positive or negative results. Finally, for countries such as Portugal $^{332}$ and the United Kingdom ${ }^{333}$ conclusions go in two completely different directions.

Overall, what is seen is that results are heterogeneous around the world and sometimes even inside a country. Moreover, the practical results are hard to measure.

It is unlikely that a first glance would suggest that efforts are different in distinct regions. A comparative example showed that "close to 6,000 sustainability plans have been prepared for European communities versus about 100 for North American communities. A total of 20 Indian cities

\footnotetext{
314 Whittaker (1997, p. 319-328).

315 Malheiros, Phlippi Jr., and Coutinho (2008).

316 Harris, and Udagawa (2004).

317 Yang, and Pang (2006, p. 362-368).

318 Harris, and Udagawa (2004).

319 Harris, and Udagawa (2004).

320 Sancassiani (2005. p. 189-200).

321 Atkinson (2001).

322 Knight (2000).

323 Aall (2000); Aall (2012).

324 Grochowalska (1998).

325 Choi (1999).

326 Berry, and Portney (2017).

327 Kveton, Louda, Slavik, and Pelucha (2014).

328 Kern, Koll, and Schophaus (2007).

329 Steinberg and Miranda (2005).

330 For the optimistic conclusions, see: Khakee (2002); Jorby (2002); Jorby (2000). For the conclusions on possible positive outcomes, see: Eckeberg and Forsberg (1998).

331 Barrett and Usui (2002).

332 For the optimistic conclusions, see: Carter, Silva, and Magalhaes (2000, p. 181-186). For the pessimistic conclusions, see: Fidélis and Pires (2009).

333 For the optimistic conclusions, see: Selman (1998). For the pessimistic conclusions, see: Patterson and Theobald (1995, p. 773-778); Jackson and Morpeth (1999). Reporting some progresses: Scott (1999).
} 
have started sustainability planning efforts. There is an extensive support network for European communities and much less so in North American and Indian communities. Most sustainability/biodiversity/urban ecosystems research is ongoing in Europe and North America and there is the beginning of a surge of activity in India". 334

However, even when the efforts are existent and effective, there is virtually no direct effect on plastic pollution. Some common strategies are the development of: thematic policies that articulate broad sustainable development objectives; traditional master plans based on national planning cycles; mechanisms for coordination with donors; and strategies to address international obligations to integrate environmental considerations into thematic activities.

The same conclusion derives from another success of Agenda 21, of helping to "put the concept of sustainable human development at the heart of development, as opposed to more technology-oriented "solutions" in the so-called "development decades" of the 1960s and 1970s". ${ }^{335}$

Agenda 21 also had some early accomplishment through the creation of the Commission on Sustainable Development (CSD) and its placement in the Economic and Social Council (ECOSOC). This resulted in many areas, including in the issue of the oceans - the United Nations Open-ended Informal Consultative Process on Oceans and the Law of the Sea. ${ }^{336}$

Consumption and production patterns, on the other hand, consist of a failure of the instrument. Although it focuses on advancing towards a circular economy or more sustainable production/consumption models, business as usual prevails and global commons, such as the oceans, continue to be managed unsustainably and to be degraded beyond their ability to recover. ${ }^{337}$

In a summary of the evolution of the state of the oceans, under the analysis of chapter 17 of Agenda 21 , experts state that it has severely declined in the 20 years that followed Rio. A small exception appears regarding commitments with the integrated coastal zone management and regarding the EU Marine Strategy Framework Directive. I also highlight the Global Program of Action for the protection of the marine environment from land-based Activities (abbreviated GPA) as a positive outcome of Agenda 21 - as will be further explained in the following section - since the GPA came as a response to the recommendations in Agenda 21.

\subsubsection{Global Programme of Action for the Protection of the Marine Environment from Land-Based Activities and Related International Instruments}

The Global Programme of Action for the Protection of the Marine Environment from Land-based Activities (or GPA) is "the only global intergovernmental mechanism directly addressing the connectivity between terrestrial, freshwater, coastal and marine ecosystems". ${ }^{338}$ Its main goal is to provide a conceptual and practical guide for national and regional authorities on how "to prevent, reduce, control and/or eliminate marine degradation from land-based activities". ${ }^{339}$ That is already a significant upside of this document from the plastic pollution perspective, since $80 \%$ of it comes from land-based sources.

In addition, although the GPA generally addresses all kinds of marine degradation, it is also possible to identify specific concerns regarding plastics. As an example, the Mobile Apps offered in their website, ${ }^{340}$ which includes Marine LitterWatch, ${ }^{341}$ Planet Ocean ${ }^{342}$ and Beat the MicroBead. ${ }^{343}$

\footnotetext{
334 Smardon (2008).

335 Stakeholder Forum for a Sustainable Future (2012, p. 5).

336 Stakeholder Forum for a Sustainable Future (2012, p. 6).

337 Stakeholder Forum for a Sustainable Future (2012, p. 15).

338 United Nations Environmental Programme - UNEP (1995).

339 United Nations Environmental Programme - UNEP (1995).

340 United Nations Environmental Programme - UNEP (2017b).
} 
108 countries - plus the European Commission - adopted GPA at the intergovernmental conference convened in Washington, DC. They, plus the ones that adopted through regional programmes, ${ }^{344}$ are represented on the map in figure 12 .

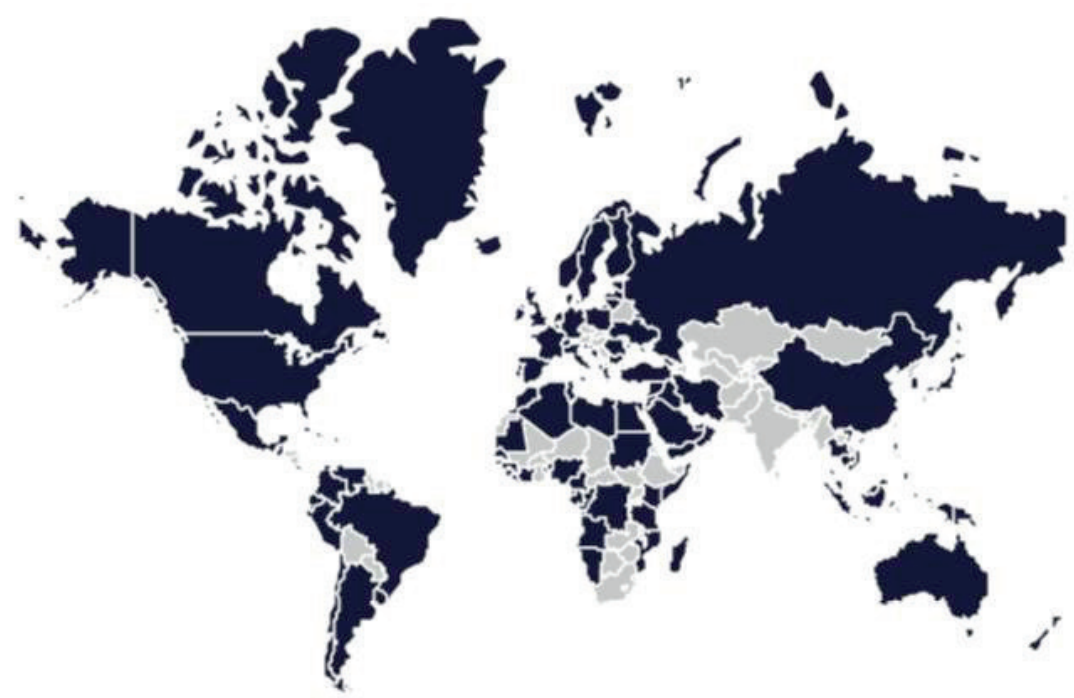

Figure 12 - Countries that adopted GPA (shown in grey)

UNEP, as secretariat to the GPA, aims at facilitating implementation at the national, regional and international levels. The GPA Coordination Office receives its mandate every 5-years through a process known as Intergovernmental Reviews. ${ }^{345}$ After its adoption, in 1995, GPA passed through four reviews: ${ }^{346}$ (i) in 2001, the IGR-1, held in Montreal - Canada; (ii) in 2006, the IGR-2, held in Beijing - China; (iii) in 2012, the IGR-3, held in Manila - Philippines; (iv) in 2017, the IGR-4, held in Bali, Jakarta Raya - Indonesia. Each of them with its specific objectives and outcomes.

The First Intergovernmental Review Meeting on the Implementation of the GPA (IGR-1) focused on reviewing the status of implementation in order to define realistic targets, activities and responsibilities, as well as devise feasible financial, institutional and technological arrangements. The delegates addressed: (i) a review of the accomplishments in GPA implementation from 1995 to 2001; (ii) the GPA's Strategic Action Plan on Municipal Waste-water; (iii) the 2002-2006 work programme for the GPA Coordination Office; coastal and ocean governance. Finally, the delegates

adopted the Montreal Declaration on the Protection of the Marine Environment from Land-based Activities, in which they commit to improving and accelerating implementation of the GPA through actions related to mainstreaming of the GPA, oceans and coastal governance, and financing of the GPA. ${ }^{347}$

341 A mobile app created by the European Environment Agency to target communities interested in marine litter activities. As a result, more information and data are being collected. See more: Marine Litter Watch (2018).

342 A mobile app with the same scope of Marine Litter Watch, but globally.

343 A mobile app created by the North Sea Foundation and the Plastic Soup Foundation to easily check if a product contains microbeads. See more: Beat the Microbead App (2018).

344 United Nations Environmental Programma: GPA Coordination Office (1999).

345 UN Atlas of the Oceans (2012).

346 United Nations Environmental Program - UNEP (1995).

347 United Nations Environmental Program - UNEP (2001). 
The second review concentrated on strengthening the implementation of the GPA at national, regional and global levels; contributing to the achievement of specific targets of the Johannesburg Plan of Implementation, as they relate to the GPA, the ecosystems approach, and sanitation; and providing guidance on the work programme for the UNEP/GPA Coordination Office for the period 2007-2011. The major outcomes of this effort were the review of accomplishments from 2001 to 2006, the development of guidance for the implementation from 2007 to 2011, the establishment of 19 partnerships on mainstreaming the implementation of the GPA, and the elaboration of the Beijing Declaration on Furthering the Implementation of the GPA.

The First Global Conference on Land-Ocean Connections (GLOC), a gathering of scientists, experts, policy makers and NGOs, preceded, and made recommendations for, the Third Intergovernmental Review. ${ }^{348}$ This one aimed to: (i) review the implementation of the GPA Coordination Office Work Programme 2007-2011 and define its future programme; (ii) identify, discuss and build recommendations to address emerging issues in relation to the protection of the marine environment from land-based activities; (iii) prepare input from the governments to the Rio+20 process. The delegates achieved all of the goals through the release of reports and/or declarations. ${ }^{349}$

At the IGR-3, 64 Governments and the European Commission recommended the establishment of the Global Partnership on Marine Litter (GPML) as contained in the Manila Declaration on Furthering the Implementation of the Global Programme of Action for the Protection of the Marine Environment from Land-based Activities (Manila Declaration). Launched officially at Rio+20, the GPML is a multi-stakeholder global partnership, which brings together international agencies, governments, NGOs, academia, the private sector, civil society and individuals under the common vision to reduce and better manage marine litter. The core of the GPML is to implement the Honolulu Strategy, which has three main goals to reduce the amount and the impact of: (i) land-based litter and solid waste introduced into the marine environment; (ii) sea-based sources of marine debris; and (iii) accumulated marine debris on shorelines, in benthic habitats, and pelagic waters. ${ }^{350}$

Finally, IGR-4 was held in 2017, with the following topics for discussion; ${ }^{351}$ (i) strategic directions for the Programme in addressing the challenge of marine pollution and supporting commitments and actions from governments and other actors; (ii) options in the development of a targeted global approach to combat marine litter; (iii) innovative approaches to finance investments in wastewater treatment particularly in developing countries; (iv) consideration of norms and standard setting with relevant private sector interests in addressing nutrient pollution; (v) options for diversifying the Programme's funding; (vi) strengthening cooperation with the Regional Seas Programmes to curb marine pollution originating on land.

In a general evaluation of the GPA, first it is possible to affirm its necessity, because of the amount of land-based sources of marine pollution. Meier-Wehren ${ }^{352}$ remind us that even the common assumption that developed countries have cleaned up their actions after the efforts beginning in the 1970's is wrong, presenting the example of Australia.

\footnotetext{
348 United Nations Environmental Program - UNEP (2006).

349 United Nations Environmental Program - UNEP (2011).

350 United Nations Environmental Program - UNEP (2016, p. 2-3).

351 United Nations Environmental Program - UNEP (2017c).

352 Meier- Wehren (2013).
} 
Regardless of the importance, many challenges still oppose the successful implementation of the GPA. Primarily, there are "the lack of interest on the side of states, the non-binding status of the GPA and lack of compliance mechanisms, as well as a lack of assistance for developing countries". ${ }^{353}$ Moreover, there are no signs of changes in those respects, which leads to the risk of failure of such practical instrument. ${ }^{354}$

UNEP/GPA did, however, make important advances, including plastic-related. For example, the GPA publication Valuing Plastics, "which noted that the overall natural capital cost of plastics use in the consumer goods sector each year is US\$75 billion - calculated as the negative financial impact of issues such as pollution of the marine environment or air pollution caused by incinerating plastics". 355 Also, GPA lead to the Resolution 1/6 of the United Nations Environment Assembly, ${ }^{356}$ on Marine plastic debris and microplastics, requesting a study containing most of the aspects about plastic pollution. Likewise, UNEP/GPA enables the subject to arrive at high political levels, such as the G7 Summit 2015. In addition, the Global Partnership on Marine Litter is working on the online Marine Litter Network and on education and awareness activities, such as the Massive Open Online Course on Marine Litter. ${ }^{357}$

UNEP is also helping to develop regional programmes, which are one of the main ways to achieve GPA's goals. They transpose the programme's content, but in a more specific and contextualized manner. There are, for example, the Abidjan Convention ${ }^{358}$ and the Barcelona Convention, ${ }^{359}$ and at least 13 others. $^{360}$

\subsubsection{FAO Code of Conduct for Responsible Fisheries}

The FAO Code of Conduct for Responsible Fisheries is a voluntary document constructed because of emerging concerns of States on how to responsibly conduct fisheries in the EEZ's, ${ }^{361}$ which, according to UNCLOS, was under their management. One of the Code's main goals is establishing a basis for regulating fisheries in the high seas, thus its importance to the goals of the present study.

353 Meier- Wehren (2013, p. 36-40).

354 Meier- Wehren (2013, p. 36-40).

355 United Nations Environmental Program - UNEP (2016, p. 3).

356 United Nations Environment Assembly - UNEPEA (2012).

357 United Nations Environmental Program - UNEP (1995, p. 4-5).

358 The Convention for Cooperation in the Protection, Management and Development of the Marine and Coastal Environment of the Atlantic Coast of the West, Central and Southern Africa Region (or Abidjan Convention). It covers a coastline of over $14,000 \mathrm{~km}$, in a marine area from Mauritania to South Africa. "The Convention provides an over-arching legal framework for all marine-related programmes in West, Central and Southern Africa". United Nations Environmental Program - UNEP (1984).

359 Adopted in 1995 to replace the Mediterranean Action Plan of 1975. It involves 22 parties amongst which countries from the European Union and from the Mediterranean area. As to 2017, it includes seven protocols to deal with specific issues, such as dumping, land-based activities, hazardous waste, etc. For more information see, e.g.: European Commission (2018b).

360 Bucharest Convention, Cartagena Convention, Action Plan for the Protection and Development of the Marine Environment and Coastal Areas of the East Asian Region, Nairobi Convention, Kuwait Convention, Action Plan for the Protection, Management and Development of the Marine and Coastal environment of the North-West Pacific Region, Jeddah Convention, South Asian Seas Action Plan, Lima Convention, Noumea Convention, Helsinki Convention, Oslo Convention, Paris Convention. For more details, see: UNEP: Partners in Implementing the Global Programme of Action for the Protection of the Marine Environment from Land-based Activities: Regional.Seas, UNEP/ GPA Coordination Office, issue 1, September 1999.

361 The EEZ's contain approximately $90 \%$ of the world's marine fisheries. Those and other information about the history of the construction of the Code may be found in its preface. Food and Agriculture Organization of the United Nations - FAO (1995). 
The Code was adopted during the twenty-eighth session of the FAO Conference. The map in figure 13 displays the countries represented in the meeting, according to the FAO Repository. ${ }^{362}$

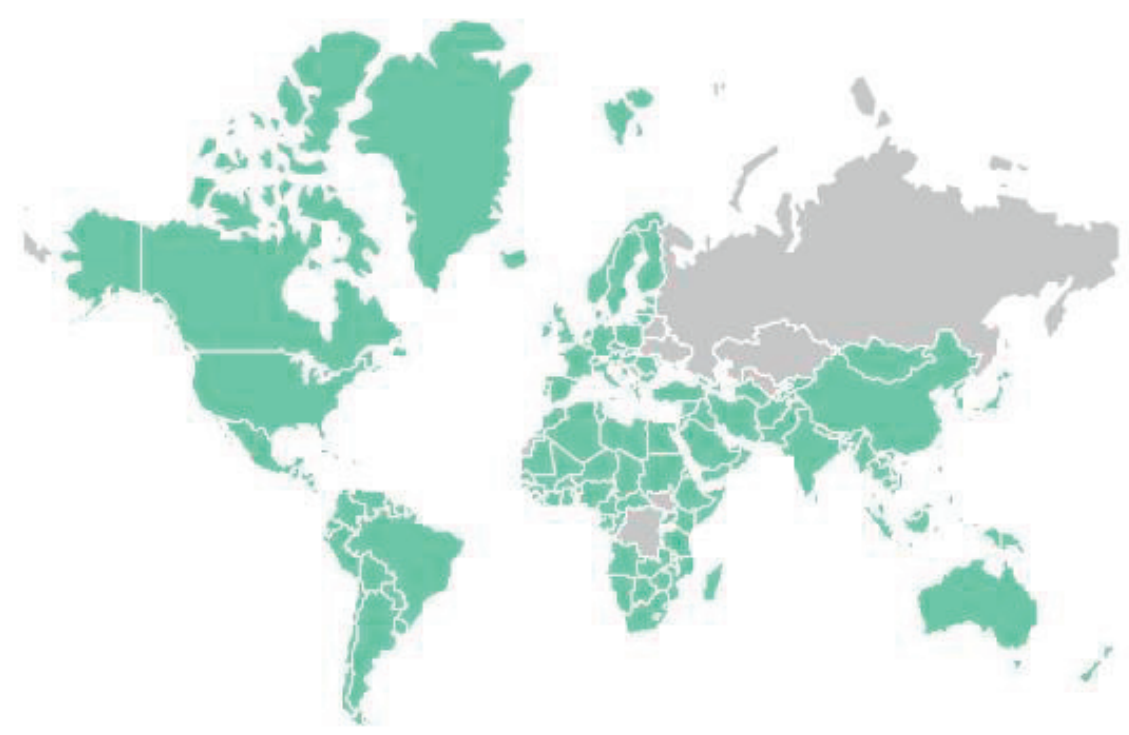

Figure 13 - Countries represented at the $28^{\text {th }}$ Session (shown in light green)

Fisheries and the plastic pollution of the oceans are involved in a two-way relation, in the sense that the plastic pollution affects marine life but also that fishery is one of the sources of plastic pollution. Still, there are no specific mentions to plastic in the Code of Conduct, although pollution and conservation are recurring themes.

Adopted in 1995, the Code has a voluntary nature. However, certain parts are based on relevant rules of international law, including UNCLOS. Some of its provisions already have or may have in the future a binding effect by means of other obligatory legal instruments among the countries who are parties. $^{363}$

The principles and standards brought under the Code inspired the adoption of some regional and national initiatives, such as the European Council Regulation EC 2371/2002, ${ }^{364}$ Canada's Ocean Act, and the US Commission on Ocean Policy. This already shows positive outcomes from the Code, although there are still only a few countries in the path to compliance. ${ }^{365}$

A study about the effectiveness of article 7, conducted in 2013, showed the potential of the Code of Conduct, concluding on many positive impacts on the countries that have adopted it. Considering the loss in production index and the related probability of sustainable fishing index, the mean trophic level of the catch, total catches, and the primary production required to sustain the catch, the study showed a decrease in the loss in production index and an increase in fisheries sustainability for the countries with higher levels of compliance. ${ }^{366}$

362 Food and Agriculture Organization of the United Nations - FAO (Corporate Document Repository) (2018).

363 Food and Agriculture Organization of the United Nations - FAO (1995).

364 European Commission (2002).

365 Coll et al. (2013).

366 Coll et al. (2013). 
Thus, the conclusions of the study bring interesting reflections to the analysis here intended, but they cannot be directly extended to the issue of the plastic pollution of the oceans. However, the same study mentioned before its conclusion that compliance with the Code clearly lead to an improvement in marine exploited ecosystems.

Another study, conducted in 2011, brought slightly different results, attesting that "the Code as an international policy instrument remains relevant and adaptable to the current international fisheries context, and that its guiding principles and provisions have been endorsed and adopted in almost unanimous fashion [...] and integrated into fisheries policy letters and legal frameworks" by countries in Asia, Africa and Caribbean. ${ }^{367}$

However, they both agree that there are still major challenges regarding effectiveness. The latest stress out that there is yet necessity for much more efficiency, improving elements such as combating illegal, unreported and unregulated fishing, and designing and implementing necessary measures. It presents administrative inertia, lack of political will and stamina, and short-sighted economic considerations as important causes. ${ }^{368}$

\subsubsection{Sustainable Development Goals}

In the year of 2000, during the UN Millenium Summit, the world leaders adopted the United Nations Millenium Declaration, ${ }^{369}$ committing to a global partnership to reduce poverty through eight targets, with a 2015 deadline. An independent advisory board lead a taskforce of "more than 250 experts from around the world, including scientists, development practitioners, parliamentarians, policymakers, and representatives from civil society, UN agencies, the World Bank, the IMF, and the private sector", ${ }^{370}$ and submitted its recommendations to the UN Secretary General.

Those eight targets were: (i) eradicate extreme poverty and hunger; (ii) achieve universal primary education; (iii) promote gender equality and empower women; (iv) reduce child mortality; (v) improve maternal health; (vi) combat HIV/AIDS, malaria and other diseases; (vii) ensure environmental sustainability; (viii) develop a global partnership for development.

Since the UN considered the Millenium Development Goals (MDGs) a success, it encouraged the adoption of the 17 Sustainable Development Goals (SDGs), as a post-2015 agenda. The process involved in the elaboration of the later was very different and included much more political actors, in an intergovernmental discussion that lasted three years. ${ }^{371}$ The aim of the new approach was mainly to try to guarantee a greater involvement of the member states and of civil society, ${ }^{372}$ and it also explains in a major part the higher number and elevated degree of complexity of the SDGs, since consensus was necessary.

The 193 (UN) countries that agreed on the new 2030 Agendam, ${ }^{373}$ including the SDG's are represented in the map in figure 14.

\footnotetext{
367 Hosch, Ferraro, and Faillier (2011, p. 189).

368 Hosch, Ferraro, and Faillier (2011).

369 United Nations General Assembly (2000).

370 UNDP \& Millennium (2005).

371 Jeffrey Sachs Center on Sustainable Development (2017).

372 A discussion about this process and about the democratic aspects involved may be found in Gonçalves (2012).

373 United Nations Development Programme - UNDP (2015).
} 


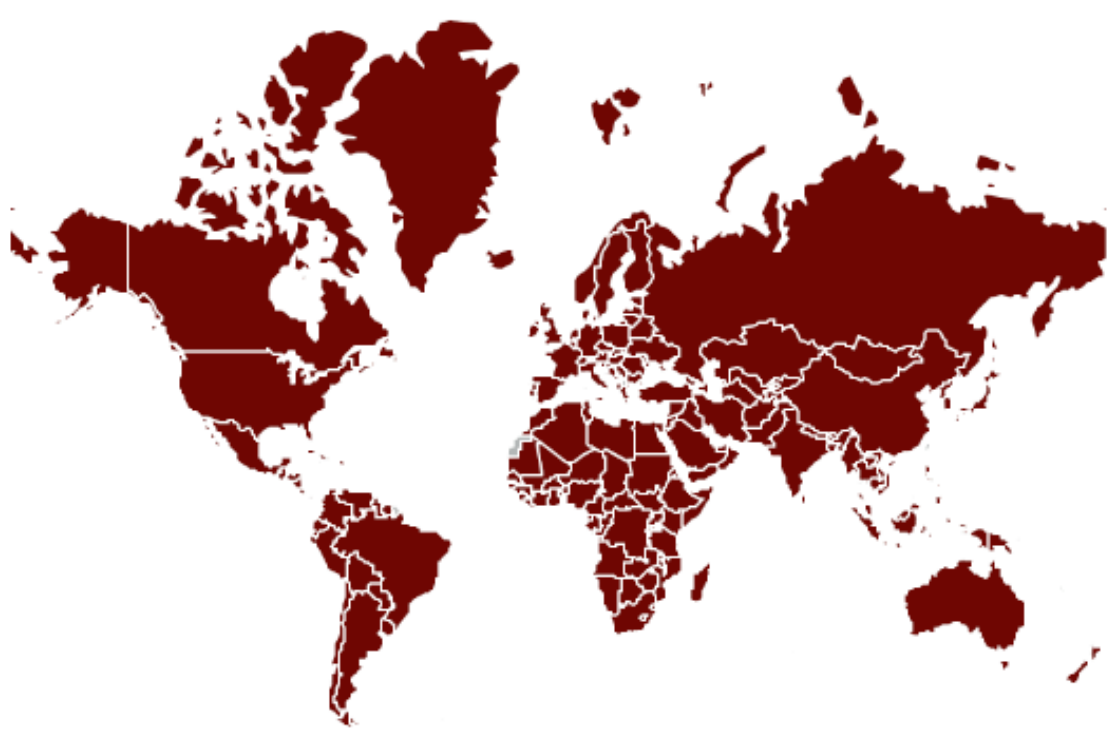

Figure 14 - Countries that agreed on the 2030, including the SDGs (shown in brown)

Each of the goals deals with a specific target or targets - 169 in total - and with indicators that are used to monitor and review progress of the goals. All goals, targets and indicators are available at the UN Sustainable Development Knowledge Platform, ${ }^{374}$ but since there are too many to specify here, it highlights those that have a closer relationship with the plastic pollution of the oceans.

Goal 6 objectives to "ensure availability and sustainable management of water and sanitation for all". Although it relates more to drinking and inland waters, it also influences the subject under analysis, especially regarding the levels of pollution, since rivers will end up in seas or oceans. In that sense, target 6.3 is of particular importance: "improve water quality by reducing pollution, eliminating dumping and minimizing release of hazardous chemicals and materials, halving the proportion of untreated wastewater and substantially increasing recycling and safe re-use globally".

On the other edge of the problem, there is goal 12, of which the focus is to "ensure sustainable consumption and production patterns". This one presents a clearer and closer relationship with the plastic pollution of the oceans, mainly through targets $12.5,12.6$, and 12.8 .

Target 12.5 aims to reduce substantially, by 2030, "waste generation through prevention, reduction, recycling and re-use", and it will be monitored by measuring the national recycling rate in tons of material recycled - indicator 12.5.1. It naturally does not specify the plastic, since it has to be broader in order to achieve the main goal, but plastics are obviously included in the efforts.

The same happens with target 12.6, which proposes to "encourage companies, especially large and transnational companies, to adopt sustainable practices and to integrate sustainability information into their reporting cycle", and counts with the number of companies publishing sustainability reports as an indicator (12.6.1) of progress. The main problem here seems to be with overestimating the power of reporting. First, because publishing those reports has the advantage of forcing companies to think about it and to have something to report, but it does not necessarily mean adopting more sustainable practices. That leads to the second aspect, that many times those reports bring broad projects and more intentions than actions. 
Target 12.8, in its turn, tries to ensure that by 2030 "people everywhere have the relevant information and awareness for sustainable development and lifestyles in harmony with nature". This constitutes a very important aspect for facing the problem of the plastic pollution of the oceans, as discussed in the previous parts of this article. Indicator 12.8.1 tries to cover all the extent that should be included in information access and public awareness, by measuring to what extent: "(i) global citizenship education and (ii) education for sustainable development (including climate change education) are considered important in (a) national education policies; (b) curricula; (c) teacher education; and (d) student assessment)".

Finally, there is goal 14: "conserve and sustainably use the oceans, seas and marine resources for sustainable development". So, it is possible to assert that the entire goal is related to the plastic pollution of the oceans, but some targets and indicators seem to be even closer, which explains why they are highlighted here.

Target 14.1 addresses the important aspects of land-based sources and of marine debris, by aiming to "prevent and significantly reduce marine pollution of all kinds, in particular from land-based activities, including marine debris and nutrient pollution" by 2025. The centrality of land-based sources is already something remarkable by itself, as has been discussed along the thesis.

Indicator 14.1.1 then specifically addresses plastic, since it establishes the index of coastal eutrophication and floating plastic debris density as a way to measure progress in this regard. Of course, a big part of the problem, such as microplastics and plastics in the oceans' beds, is left in a second plan, but this indicator visibly acknowledges the importance of fighting plastics for conservation and to a sustainable use of the oceans, seas, and marine resources.

Helping with the issue of necessity for further studies and research, and, consequently, more accurate data and information regarding plastics, there is target 14.A, even if it does not mention plastics explicitly. Some of the focuses for achieving better ocean health is to "increase scientific knowledge, develop research capacity and transfer marine technology". Indicator 14.A.1 provides that monitoring should consider the "proportion of the total research budget allocated to research in the field of marine technology".

Target 14.C addresses the dominant discussion of this chapter, by trying to stimulate compliance with the international instruments related to the protection of the oceans. The target intends to "enhance the conservation and sustainable use of oceans and their resources by implementing international law as reflected in UNCLOS, which provides the legal framework for the conservation and sustainable use of oceans and their resources, as recalled in paragraph 158 of The Future We Want". And the indicator (14.C.1) of the progress towards that is the "number of countries making progress in ratifying, accepting and implementing through legal, policy and institutional frameworks, ocean-related instruments that implement international law, as reflected in the United Nation Convention on the Law of the Sea, for the conservation and sustainable use of the oceans and their resources". This means a significant advance for the effectiveness of international instruments, even if considered that there are no fixed ways to measure implementation.

Specifically, regarding goal 14, there is an interesting outcome inside the UN itself. The meeting involving heads of States, civil society and stakeholders - held in New York in June of 2017 resulted in a document entitled Our Ocean, Our Future: call for action. It explicitly mentions plastics as an urgent issue to be addressed and takes care of referring to plastic and microplastic, as well as to the necessity of reducing the use. ${ }^{375}$

With less than two years since adoption to the day of this analysis, it is not yet possible to conclude on the effectiveness of the SDGs. However, the results with the MDGs can yield what may be expected. At the same time, the challenges and difficulties experienced with the MDGs were addressed in the elaboration of SDGs, trying not to repeat them, which opens space for some optimism.

375 United Nations - UN (2018). 
For that reason, we can return to the UN assumption that the MDGs were a success, by looking into the conclusions displayed in The Millenium Development Goals Report 2015. ${ }^{376}$ In the report the success is justified by the numbers in each of the eight goals, which shows "profound achievements". As an example, I propose some of the outcomes of goal 7 ("ensure environmental sustainability"):

- 1,9 billion people have gained access to piped drinking water - from 2.3 million in 1990 to 4.2 million in $2015 ; 377$

- $98 \%$ of the ozone-depleting substances eliminated;

- 147 countries have met the drinking water target, 95 countries have met the sanitation target and 77 countries have met both;

- Worldwide, 2.1 billion people have gained access to improved sanitation; $;^{378}$

- The proportion of urban population living in slums in the developing regions fell from approximately $39.4 \%$ in 2000 to $29.7 \%$ in 2014 .

However, the same report stresses that "despite many successes, the poorer and most vulnerable people are being left behind". It also highlights the importance of sustainable data to sustainable development, and concludes that:

(i) what gets measured, gets done;

(ii) real data improvement occurs when demand and policy support meet;

(iii) despite improvement, critical data for the development of policymaking are still lacking only by counting the uncounted can we reach the unreached;

(iv) real-time data are needed to deliver better decisions faster;

(v) geospatial data can support monitoring in many aspects of development, from health care to natural resource management;

(vi) strengthening statistical capacity is the foundation for monitoring progress of the new development agenda;

(vii) new technology is changing the way data are collected and disseminated;

(viii) global standards and an integrated statistics system are key elements for effective monitoring;

(ix) promoting open, easily accessible data and data literacy is key for effective use of data for development decision-making;

(x) together we can measure what we treasure.

More than that, there are doubts around the apparently good results. If we take the example of the first so called success here highlighted - about access to piped drinking water - it already shows different ways to analyze the same data. The increase in the world population in the same years was approximately 2.1 billion people. ${ }^{379}$ Remembering that the increase in access was to 1.9 billion people, we may argue that there was no real growth, and it is also even possible to argue that there was a decrease.

Nonetheless, "while not entirely satisfactory they nevertheless reflect that a certain progress was made towards realization of the goals and targets which were to be fulfilled by 2015 ". 380

The conclusions - even, and maybe especially, the negative ones - also come as suggestions for improvement in the Post-2015 Agenda. Besides, they seem to have been taken into consideration in the SDGs, mainly in the elaboration process and in the indicators chosen. Finally, regarding the plastic

\footnotetext{
376 United Nations - UN (2015).

377 Already shows different ways to analyze the same data. The increase in the population between the same years was of around 2.1 billion people, so there is no real growth, and it is also possible to argue that there was a decrease.

378 Applying here the reasoning that was applied to the numbers on drinking water, it is also possible to argue that this actually means a continuance, instead of an improvement.

379 World Bank (2017).

380 Wysokinska (2017).
} 
pollution of the oceans, we have seen that the SDG's came as an improvement, with provisions closely related to the problem. In other words, there is room for cautious optimism regarding the SDGs.

\subsubsection{Summary (Soft Law)}

This brief overview of a few international soft law instruments shows that on the one hand there are documents that indirectly could have some influence on plastic pollution. On the other hand, it equally shows that none of the instruments directly focuses on the central issue of this contribution, the plastic soup. In general, they are broader and, therefore, more challenging than hard law for measuring results, as we saw with the heterogeneous outcomes and controversial academic analysis. However, all of them show signs of progress, especially regarding awareness raising and incentivizing regional and local initiatives. Therefore, soft law has shown, in general, more positive results than hard law. Yet, under the currently applicable legal framework, there are no international soft law instruments that can directly contribute to prevent the problem of the plastic soup. This means that it may for the future be important to at least ask the question of whether a specific one would be appropriate to deal with the plastic soup problem, mainly as an important step to an international change of behavior in this respect.

The analysis in chapter 4 made it clear that international law, neither hard law nor soft law, does not yet provide convincing solutions for the plastic soup problem. That, together with the fact that private companies are directly and greatly involved to the problem, is the reason why chapter 5 will look at Corporate Social Responsibility (CSR) and other private initiatives to face the plastic soup. The combination of the conclusions on public (chapter 4) and private (chapter 5) initiatives will allow the more analytical and critical part (chapter 6), aiming at reflections to help future endeavors to fight the plastic soup. 


\section{CORPORATE SOCIAL RESPONSIBILITY AND PRIVATE INITIATIVES TO FACE THE PLASTIC SOUP}

If it's consensus, it isn't science. If it's science, it isn't consensus. Period.

Michael Crichton

The previous chapters have demonstrated the dimension of the challenges involved in fighting the plastic soup. They have also demonstrated the gaps in international regulation, both when dealing with preventing the plastic pollution from coming into the oceans, and when dealing with recovering the pollution that is already there and constantly increasing.

Clearly, public international law has important contributions and, mainly, potentiality. However, there is much room for helping and for enhancing international action. The roles that civil society ${ }^{381}$ and companies $^{382}$ play naturally leads to discussing contributions from private initiatives. Those can assume different formats, which are usually described by academic literature as self-regulation, private regulation, or Corporate Social Responsibility (CSR). ${ }^{383}$ Keeping a clear theoretical separation is not, however, among the concerns here. In other words, the concerns of this research are more from the practical aspects, where the theoretical boundaries are usually not clear.

The focus is, then, to understand the possibilities that the CSR-related private initiatives are posing. From there, also to analyze the contributions they may bring to future actions to face the plastic pollution in the oceans. The reasoning is, therefore, very similar to the one in the chapter about the public international instruments.

As mentioned, attesting the restrictions of public law leads naturally to discussing private initiatives. More specifically, in the case of environmental impact(s), the discussion about CSR arises precisely to address the governance gap in the international scenario, which has been intensified by globalization. This means that governments face the challenge of territoriality when regulating multinational companies: States have restricted options and willingness to regulate extra-territorially. Furthermore, corporations are not subjects of international law, meaning the instruments available through international law cannot directly regulate corporations. All of this together leads to the governance gap mentioned previously.

Such a gap relates to every aspect of international regulation, but the focus on corporate behavior can be explained by the nature of those institutions as well as by the impacts they cause. Of the 100 top economies in the world, 69 are companies ${ }^{384}$ which demonstrates the global economic importance and, consequently, influence - of companies. Aside from the economic impacts and pressure, there are legal challenges as well. Corporations exist as autonomous personalities because national legislation recognizes them as such. Corporations often exist, however, in several nations concomitantly. The problem is if and how could governments address externalities in a context like this.

Even in the national context, it is possible to question the assumption that the government is capable of adequately "setting the rules in such a way that the consequences of market exchange contribute to (or at least do not harm) the well-being of society". ${ }^{385}$ Nonetheless, the focus here is in a major and more

381 Especially with consumption and disposal, as polluters, and with innovation, as part of the solution.

382 Especially with production and disposal, as polluters, and with innovation and financing, as part of the solution.

383 Although I acknowledge the existence of different expressions, such as Corporate Responsibility, Corporate Environmental Responsibility, and Corporate Social and Environmental Responsibility, I will use the general expression Corporate Social Responsibility, or CSR, as referring to the broader concerns, involving both social and environmental aspects.

384 Global Justice Now (2018).

385 Scherer and Palazzo (2008, p. 413). 
complex reality. A globalized world undermines the aptitude of the state to regulate economic behavior and to fix the terms for market exchange, ${ }^{386}$ because "this regulatory framework [...] has proven to be less useful in the management of multinational corporations and similar entities". ${ }^{387}$

The general failure of traditional regulation towards multinational companies may not only leave the problem unresolved but also exacerbate it. A race to the bottom between countries to attract those companies to their territory, ${ }^{388}$ for example, results in even more relaxed and/or flexible legislations and, consequently, in companies even less concerned about their externalities. If such a race to the bottom actually happens or will happen in a specific case depends, however, on empirical evidence. Theoretically, a race to the top could also emerge, ${ }^{389}$ for instance, because of technological improvement and, thus, competitive advantages. ${ }^{390}$ In this case, then, we should be careful about the development of entry barriers through the regulation competition.

Particularly regarding the theme under analysis, plastics in international waters, the problem is that the options through regulation are clearly not working at the pace required. Hence, this chapter aims at analyzing to what extent the private initiatives may contribute. The hypothesis is that private initiatives may provide a quicker start and help increasing knowledge about the technical aspects involved in the problems and in the solutions, and regulation would come as mediation and consolidation of the paths that worked.

All that considered, this chapter starts with a brief introduction about the conceptual and theoretical presumptions regarding private initiatives. It follows with four examples of those initiatives related to plastics: (i) the New Plastics Economy; (ii) the Dutch collaborative deals; (iii) the Dow Jones Sustainability Indices; (iv) sustainability reports from companies that claim to be committed to fight plastic pollution.

The cases were selected based on three main criteria: (i) existence; (ii) differences in approach; (iii) data availability. With existence, I mean that the initiatives to fight the plastic soup, although growing, are yet scarce. Thus, the thesis deals with the initiatives that are on course. With differences in approach, I mean examples that differ from each other and that may bring diversified contributions to the study. In that sense, the New Plastics Economy is a company-led international initiative, the Dutch collaborative deals, although mostly national, is based on a government, but non-binding and company-centered. The Dow Jones Sustainability Indices is inserted in the financial market. Sustainability reports serve different purposes, but always rely on information provided by companies themselves. Finally, with data availability, an example helps tp clarify. I did not include the Alliance to End Plastic Waste, ${ }^{391}$ for instance, because: (i) it is very new (2019) and was inexistent when I started researching; (ii) it would not be worth it to include it even later on, because its approach is too similar to the one of The New Plastics Economy; (iii) there is no data available for sufficient analysis, in this case, mostly because of how new the initiative is.

From there, the chapter derives the lessons learned from the cases, to conclude on which complementary role CSR-related initiatives may - or should - have on fighting the plastic soup.

\subsection{Current Examples of Private Initiatives to Face the Plastic Pollution}

Similarly to the approach used in the chapter about international instruments, this section analyzes the private initiatives to address the plastic pollution in the oceans. Unlike the findings related to the

\footnotetext{
386 Scherer and Palazzo (2008, p. 430).

387 Backer (2008 p. 503).

388 See, e.g.: Trebilcock and Howse (2005. p. 15); Faure (2003, p. 26 onwards); Heine, Faure, and Lan (2017).

389 See, e.g.: Ogus (1999); Christmann and Taylor (2001); Faure (2003, p. 28 onwards); Vogel (1995, p. 1314).

390 Faure (2003, p. 29); Ogus (1999, p. 415).

391 Alliance to End Plastic Waste (2020).
} 
international instruments, though, there are already a few international actions under way in the private scenario.

The New Plastics Economy is an appropriate example for the goals of this study, since it is an initiative to bring "together key stakeholders to rethink and redesign the future of plastics, starting with packaging". ${ }^{392}$ This is, then, the first private initiative analyzed, although it is still in a very initial stage. Transnational Company Agreements would follow, nevertheless, there are no identified agreements about plastics or even marine litter. ${ }^{393}$ In addition, the complete list of identified agreements $^{394}$ shows a focus on the social dimension, and almost nothing on the environmental dimension. ${ }^{395}$ The analysis continues, then, with the example of the Dow Jones Sustainability Indices and follows with the example of the Dutch "green deals", a governmental approach for private solutions. The final example would come from companies reporting, but, as we will see in 6.2.4, they only allow partial conclusions, that are not enough to build a case study. Still, the descriptions of the reports are maintained here because they are important to situate current companies' individual positioning and to evaluate them as tools to fight the plastic pollution in the oceans.

\subsubsection{New Plastics Economy}

In 2014, the World Economic Forum and the MacArthur Foundation, with McKinsey \& Company as knowledge partner, launched the Project MainStream. Led by the chief executive officers of nine global companies, one of the outcomes of this umbrella project was the report The New Plastics Economy, released in 2016. Such a report aimed to "set an initial direction and contribute to the evidence base by synthesizing information from across many dispersed sources". ${ }^{396}$ Besides, it aimed to "bring together for the first time a comprehensive global perspective of the broader plastic packaging economy, present a vision, and propose a roadmap as well as a vehicle for progressing this roadmap, and providing a much-needed global focal point to carry this agenda forward". ${ }^{397}$ The report plans to achieve its objectives by structuring the scattered available knowledge, which resulted in a report structured in four parts.

Part one registers a summary of findings and conclusions. It focused on rethinking plastics starting with packaging, on capturing the economic opportunity that the plastic externalities mean, and on constructing a new approach to such a new and globalized challenge.

Part two suggests approaches to create an effective after-use plastics economy. It faces the issue from three different angles: recycling, re-using, and compostable packaging. In order to do so, this part of the report tackles those issues from key discussions to the problem, such as, for recycling, cross-value chain, redesign, technological innovation with upscaling, mono-material plastics, and secondary market for recycled plastics. It finished the recycling debate by highlighting the need to explore the enabling role of policy, but without deepening the discussion, which is understandable due to the private focus of the document. For the re-use section, the report discussed business-to-business and business-to-consumer applications.

Part three brings suggestions to reduce the leakage of plastics into natural systems and to minimize other externalities. This is closely related to what is being called the ex ante approach in the present

392 New Plastics Economy (2018c).

393 According to the database constructed and maintained by the European Union and the International Labor Organization. The research terms used were "plastic", "microplastic", and "marine litter", on April 2018. The database is available at: http://ec.europa.eu/social/main.jsp?catId=978\&langId=en.

394 European Commission (2018a).

395 Applying the search-filter to show only the agreements that are listed under the theme "Sustainability, Governance and Ethics", the 282 results become restricted to five, and yet the focus on the social dimension remains.

396 Ellen MacArthur Foundation (2017b, p. 4).

397 Ellen MacArthur Foundation (2017b, p. 4). 
study. The report refers to the urgent improvement of after-use collection, storage and reprocessing infrastructure in high-leakage countries as "a critical first step in addressing leakage". ${ }^{398}$ It also refers to the need to increase the economic attractiveness of keeping materials in the system, and to steer innovation investment towards creating materials and formats that reduce the negative environmental impact of plastic packaging leakage.

Part four addresses the need to decouple plastics from fossil feedstocks. This means, mainly, a focus on plastics derived from biomass or greenhouse gases.

A first utility of the report is the amount of details and the steps envisioned. It provides a wellinformed starting point to address the real problems. In that sense, it is possible to consider the achievement of the two mentioned goals. It is relevant to remember that the report is an outcome of a purely private initiative. Yet, assessing practical results is a different challenge.

A more practical goal of the New Plastics Economy initiative is "to build momentum towards a plastics system that works", ${ }^{399}$ in a three-year period. To achieve it, the strategy of the initiative is to base itself in the applied principles of the circular economy, and to use a systemic and collaborative approach. The focus is "on five interlinked and mutually reinforcing building blocks to create the enabling conditions for a system re-design":400

(i) Dialogue mechanism: between global consumer goods companies, retailers, plastic producers and packaging manufacturers, cities and businesses involved in collection, sorting and reprocessing.

(ii) Global Plastics Protocol: change the current fragmented, uncoordinated and incremental innovation, to move the needle on economic value loss and negative externalities in effective markets.

(iii) Innovation moonshots.

(iv) Evidence base: "A robust evidence base informs the direction of change. Economic assessments guide the prioritisation of potential improvements. Creating transparency on the realities and best practices of today's system informs the global debate".

(v) Stakeholder engagement: "Businesses, policymakers, students, educators, academics, designers, citizens, NGOs, industry associations, and others all play a role in transitioning to a new system. The initiative learns from, informs, and engages all these stakeholders".

Since the main goal for the three-year period that started in May 2016 was "to build momentum", it is relatively safe to conclude on the effectiveness of the strategy. Not only new engagements and initiatives $^{401}$ demonstrate that, but also observing the milestones of the project gives some indication on what to expect. The umbrella project started in 2014, resulting in a comprehensive and unprecedented report in 2016. The initiative was, then, launched in May that same year, with the participation of several key partners. ${ }^{402}$ Already in 2017, the initiative released a new report, "to provide a clear transition strategy for the global plastics industry to design better packaging, increase recycling rates, and introduce new models for making better use of packaging". 403

The 2017 effort highlighted three distinct strategies to drive the transition to a new plastics economy: (i) fundamental redesign and innovation for $30 \%$ of the plastic packaging; (ii) re-use for at least $20 \%$ of plastic packaging; (iii) making recycling economically attractive for the remaining $50 \%$ of plastic packaging, through design and after-use systems. In other words, it raises data and gather details for the implementation of the plan established by the 2016 report.

\footnotetext{
398 Ellen MacArthur Foundation (2017b, p. 76)

399 New Plastics Economy (2018c).

400 New Plastics Economy (2018b).

401 See, e.g.: Ellen MacArthur Foundation (2018a); Ellen MacArthur Foundation (2018b).

402 As listed in 4.1.4.

403 Ellen MacArthur Foundation (2017c).
} 
On the one hand, the milestones demonstrate a fast progress towards the objectives of the project - or at least much faster than the public international law progresses to face the plastic pollution problem. On the other hand, the comparison between those milestones and the reporting by the companies involved results in a picture which is a cause for concern. As will be analyzed in 4.1.4, the reports are commonly vague or inconclusive.

Although it still looks vague, if the new plastics economy initiative accomplishes its goal of creating momentum, we could expect to have, at least, more transparency of companies' goals and results in the near future. Similarly, we could expect companies to engage locally more often, leading and/or involving in integrated actions with governments, NGO's and others, through the Plastic Pact, ${ }^{404}$ for example. It is "a network of national and regional implementation initiatives. Each of those initiatives will be led by a national organization and unite local authorities, businesses involved in designing, producing, using, re-using and recycling plastics, as well as NGOs, innovators and citizens, behind a shared global vision based on the principles of a circular economy". ${ }^{405}$

A case in which the Plastic Pact proposal is already ongoing is the UK. ${ }^{406}$ There, it led to: a new $£ 1.4$ million flagship projects competition; the UK Plastic Pact Roadmap, which "sets out the key actions and intermediate milestones that businesses, and other members, will need to achieve to deliver each target by 2025, as well as highlighting the challenges ahead"; support to research on plastic packaging; among others. A second case is Chile, where the first steps were already taken towards the national implementation promoted by the New Plastics Economy. ${ }^{407}$

The reasoning behind the Plastic Pact can be compared to the one behind the Dutch example, explained in the next section. Also, this could be a way to enhance the successful regional and local initiatives through international actions.

\subsubsection{The Dutch Deals: A National Example that Supports the International Hypothesis}

Currently, the Dutch deals with the private sector regarding environmental issues are done under the format of Green Deals. Since the Green Deals started, in 2011, 193 were closed ${ }^{408}$ in nine themes: energy, bio-based economy, mobility, water, food, biodiversity, resources, construction and climate. ${ }^{409}$ They usually follow a bottom-up approach, with the ideas coming from society and government playing the role of organizing the deal, since "companies, community organizations and other government bodies that want to take steps towards sustainability sometimes encounter barriers. Central Government can help them overcome such barriers by closing a Green Deal with other parties". ${ }^{410}$ Each deal is connected to one of the Dutch ministries involved, depending on their respective theme, but the procedural steps are a responsibility of one of the two governmental agencies: the Netherlands Enterprise Agency (RVO) or the Rijkswaterstaat (RWS).

The deals are voluntary and non-binding and are established for a restricted period, usually around three years. Although there is a standard format to be followed, every deal can specify aspects that are relevant to its particular goals. Most of the information about format, specific ongoing and closed deals, and history about the Green Deals is available in Dutch on the website. Some of it is also available in English in the same website. For this section of the study, interviews have also been

\footnotetext{
404 See: New Plastics Economy (2018a).

405 New Plastics Economy (2018a).

406 The UK Plastics Pact (2018).

407 WRAP (2018).

408 Meaning only the numbers of those that came to a conclusion.

409 Green Deals - English (2018).

410 Green Deal (2018b).
} 
conducted with people involved in the negotiation and implementation of the deals, ${ }^{411}$ in order to gain perspective on the more practical aspects involved and that may not be perceived through reports and registers.

Regarding the deals related with plastic pollution, on which this section focuses, there are some relevant examples. However, those examples are not restricted to the Green Deals format. The Netherlands has a history of collaborative working between the government and companies, therefore, deals with such a collaborative happened before the establishment of the Green Deals format, as well as continuing to happen parallel to it. This is the reason why the examples selected to this study are not necessarily Green Deals, but have the same nature. Besides, there are also more deals related to the plastic pollution than the ones mentioned in this section. Since there were several to be considered, the selection accounted for the ones more directly focusing on the plastic pollution itself or the ones adding more to such a discussion.

The first example is the set of initiatives regarding bioplastics. Before detailing the path they took, it is important to distinguish between the two kinds of bioplastics. One focus is on changing the raw material used in the production and, therefore, aims at diminishing the oil exploitation for plastic production. The other focus is on the degradability ${ }^{412}$ of the plastics and, therefore, aims at diminishing the environmental impact of the plastic after-use. Of course, they are both important for reducing the environmental impact of plastic, but only the second one relates to the scope of this thesis.

The efforts of the Dutch government have also been focusing on the second type of bioplastics, which is the reason why this example was chosen. Actually, the Dutch efforts contribute to both edges, integrating the two kinds of bioplastics. The research uses a type of technology that enables the fermentation of organic waste ${ }^{413}$ and green waste ${ }^{414}$ by a microbe, resulting in Polyhydroxyalkanoate (PHA). Although PHA is expensive to be produced, it may replace various kinds of plastics and is completely compostable.

The first deal about the theme was the Green Deal on bioplastics, signed in $2013 .{ }^{415}$ The parties to the deal were - besides the National Government of the Netherlands - the companies Paques and Attero, the Municipality of Venlo, and the Delft University of Technology. Paques is a Dutch company with subsidiaries in Sao Paulo, Mumbai, and Xangai. The company's expertise is building silos for fermentation of waste, producing biogas. Attero is a company specialized in collecting organic and green waste. The Delft University of Technology was involved because professor Mark van Loosdrecht developed the process to create bioplastics from vegetable waste sources, making use of microbes. The Municipality of Venlo wanted to buy organic plastic bags for house use - the kind that can go together with the waste, since it is also compostable. ${ }^{416}$

In summary, all parties necessary to make the deal work were involved. However, Attero was bought by an investment company that did not want to invest in new processes. This caused the Green Deal to

411 People interviewed were: Hans Woldendorp, Henk Hoving, Arnoud Passanier, Eli de Vries, and Judith Eijs. To them, I wish to show my gratitude for their time, interest and essential support, although any errors are my own and should not tarnish the reputations of these esteemed persons.

412 Biodegradable plastics may also refer to different kinds of plastics. Some are a big threat to the environment, since it only breaks down easily once in nature. But it breaks down into smaller pieces of plastics, because in nature the conditions are not needed for really degrading. So, in the end, it contributes to the increase of microplastics in the environment - also increasing the cost of recovering. In here, I will be referring to PHA, as will be further explained in the main text.

413 Expression here used to refer to the regular household organic waste. It counts for around 1.3 million tons a year in the Netherlands.

414 Expression here used to refer to the waste from parks and gardens. It counts for around 2.5 million tons a year in the Netherlands.

415 Text of the deal available at: https://www.greendeals.nl/wp-content/uploads/2015/06/GD157-samenvattingProductie-Bioplastics-uit-Groente-Fruit-en-tuinafval.pdf.

416 Vries (2018). 
be stopped without reaching its goals. The main goal was to cooperate to create a small factory - about 1.5 million euros - where the bioplastic could be produced.

Although this first attempt on bioplastics failed, other efforts towards PHA are showing better results, specially stimulated by STOWA - the Foundation for Applied Water Research. To understand those, it is necessary to go a little bit back in time. Around the year 2009, because of the world financial crisis, the Dutch government observed an increase in raw materials' prices. Therefore, they

started an investigation on the scarcity of raw materials in the context of climate change, biodiversity laws, and geopolitical shifts in power. So, [looking at] the upcoming economies, like China and India, and what that would mean strategically for Dutch international policies. By looking at that we saw first that we should have a Strategic Raw Materials Policy, which we didn't have before. ${ }^{417}$

Although this first report did not analyze plastics, it generated momentum for the next steps, especially because of its conclusions - mainly economically based - on the central role that the Netherlands could play on sustainable innovation as a way to prevent the effects of the crisis. ${ }^{418}$

"In order to stimulate innovations, different Green Deals have been signed respectively in 2012 for energy and phosphate, in 2014 for cellulose, bioplastics, phosphate, bio-ALE (Alginate-Like Exopolymers), biogas and CO2, and in 2016 for energy like solar energy, wind energy, and geothermal energy". ${ }^{419}$ The Green Deal signed in 2014 is naturally of greater importance to this study. The main goals were to "stimulate, accelerate and scale up the (recovery) of raw materials from sewage water; to realize pilot and demonstration projects; to focus primarily on the production and supply of phosphate, cellulose, bioplastics, alginate and CO2", and changes in legislation to be adequate to the technical classifications of raw materials were also envisioned. ${ }^{420} 421$

The 2014 Green Deal on raw materials led to a new initiative to the production of PHA: the PHARIO. PHARIO was a "PHA production and biobased value chain demonstration project", ${ }_{222}$ conducted in 2015 and 2016. It tested the feasibility of producing PHA in wastewater treatment facilities. The results showed that the PHA produced was of high quality and with good thermal and mechanical characteristics, so it is a material not currently widely available in the market but with interesting niche applications. ${ }^{423}$

The 2014 Green Deal on raw materials also led to an international Green Deal on raw materials: the International Green Deal North Sea Resources Roundabout. ${ }^{424}$ Its objectives, to be accomplished by March 2021, are: (1) to increase industry uptake of secondary resources by facilitating cross border use of secondary resources; (2) to enable cooperation between Private Initiators and Governmental Participants, to identify barriers and consider solutions for a limited number of specific secondary resource cases between countries; (3) to increase investments related to secondary resource use in the case of solid solutions by the Private Initiators; (4) to share the lessons learnt in the cases with all Participants and Observers and even more widely with the objective of facilitating the movement of secondary resources within and eventually beyond the North Sea Region in Europe. The parties to this international Green Deal are the governments of the Netherlands, Flandres, France, and United Kingdom, 8 companies, and 12 stakeholders as associations and NGO's. Besides, the European Commission takes part as observer.

\footnotetext{
417 Passenier (2018).

418 Dutch Government (2015).

419 Leeuwen, Vries, Koop, and Roest (2018, p. 787-788).

420 Green Deal (2014b).

421 Green Deal (2015a).

422 Bengtsson, Werker, Visser, and Korving (2018).

423 Bengtsson, Werker, Visser, and Korving (2018, p. 84).

424 Green Deal (2016).
} 
The second example in this section derives from all those milestones, which are also the context for the approach towards a circular economy. From 2011 to 2015, the Dutch Government signed 59 Green Deals in resources and circular economy, involving 443 participants and 190 companies. Those, as explained before, are very specific, but still provide an interesting and diverse overview when grouped by themes: 10 deals in preventing the use of resources; 9 deals on making the origin, design and use of products (and the product chain) as sustainable as possible; 20 deals on encouraging the use of renewable, biobased resources; 7 on encouraging the use of sustainable products and services; 5 on using new revenue models and incentive models; 11 on improving waste separation and waste collection; 11 on optimizing re-use; and 16 on linking knowledge and education of the circular economy. ${ }^{425}$

A broader approach started with the Circular Procurement Green Deals. The initial one began in 2013 and was finalized at the end of 2017. Each of the involved organizations had to deliver at least 2 pilots. The programme involved 45 organizations and created over 100 pilot-projects, with an investment of more than 100 million euros. The success of the Dutch pilot led Finland and Belgium to copy the programme. ${ }^{426}$

Also, "the success of this programme resulted in the Dutch Government placing special emphasis on circular procurement and the consideration of life-cycle costs in its 2016 Roadmap to a Circular Economy". ${ }^{427}$ In 2016, the Dutch Government released its policy on circular economy, ${ }^{428}$ with a focus on five economic sectors and value chains to switch to a circular economy: (i) biomass and food; (ii) plastics; (iii) manufacturing industry; (iv) construction sector; (v) consumer goods. The interim objective of the policy is to achieve "a $50 \%$ reduction in the use of primary raw materials (from minerals, fossil fuels and metals) by 2030" and its final objective is that "by 2050 raw materials will be used and re-used efficiently without any harmful emissions into the environment. In case new raw materials are needed, they will be obtained in a sustainable manner and further damage to social and physical living environments and public health will be prevented". ${ }^{429}$ In order to do so, the programme describes the steps to be taken by 2050 and the government takes responsibility to put in motion actions aiming at such objectives. ${ }^{430}$

The following Circular Procurement Green Deal started in 2018 and is planned until 2021, the Circulair inkopen 2.0. The approach is similar to the one used in the 2013-2017 cycle, but including "a sector based approach and scaling of initiatives and even cooperation between countries and regions". ${ }^{431}$ In June $7^{\text {th }}, 2018$, at least 50 private and public companies and organizations signed it, and it remained open to new interested parties. ${ }^{432}$

As a part of the efforts related to achieving a circular economy in the Netherlands by 2050, the national government has an initiative focusing on fighting the plastic soup by reducing the proportion of plastic bottles in litter. The Ministry of Infrastructure and Water Management has been working together, since March 2018, with the packaging sector, municipalities, and other parties "to set down new goals and measures: reducing the proportion of plastic bottles in litter by 70 to 90 percent, and 90 per cent of small bottles to be re-used". ${ }^{433}$ Unlikely most of the deals, this one already sets a legislation in case the targets are not reached by the autumn of 2020: "a plastic bottle deposit scheme will be introduced with effect from 1 January 2021. Plastic bottles up to 1 litre will be subject to a deposit of 10 to 15 cents. Considerations will apply to small shopkeepers if the scheme is introduced". ${ }^{434}$

\footnotetext{
425 Government of the Netherlands (2015, p. 44-46).

426 One Planet (2018).

427 European Commission (2017, p. 7).

428 The Ministry of Infrastructure and the Environment and the Ministry of Economic Affairs (2016).

429 The Ministry of Infrastructure and the Environment and the Ministry of Economic Affairs (2016, p. 7).

430 The Ministry of Infrastructure and the Environment and the Ministry of Economic Affairs (2016, p. 7).

431 One Planet (2018).

432 Vtrek (2018).

433 Government of the Netherlands (2018).

434 Government of the Netherlands (2018).
} 
The third example is an informal deal with the Dutch cosmetic industry about intentionally added plastic microbeads. Although it is a small portion of the plastic market and, thus, of the plastic pollution, "cosmetics have been assigned a high priority because alternatives are available, publicity and awareness of microplastics in cosmetics is high and both consumers and the industry have a clear perspective for action". ${ }^{435}$ So, the government of the Netherlands started an informal conversation with the cosmetic industry, recommending a ban, by adding other materials than the microplastic to the cosmetics. Within two and a half years, around $85 \%$ of the industry in the country voluntarily changed microplastic for more nature-based substitutes. The other $15 \%$ not involved were already greener companies. ${ }^{436}$

As a next step, the Dutch cosmetic industry and "the Dutch government, together with other EU member states, has been calling for a European ban for some time. The environment ministers of EU members states are unanimously in favor of one". ${ }^{437}$ So, they are working together with the European Chemicals Agency (ECHA) to organize procedures at the European level. ${ }^{438}$ In March 2018, ECHA received a call, and "at the request of the European Commission, it will investigate the need for a restriction on the placing on the market and/or use of 'intentionally added' microplastic particles in products or uses that 'intentionally release' microplastic particles to the environment". ${ }^{439}$ Such a call is broader than the actions taken in the Netherlands, since they will gather information on all possible intentional uses of microplastic in products, as well as determine potential socio-economic impacts of prospective restriction. ${ }^{440}$ Furthermore, commissioned by the European Commission, consultancy agency Eunomia identified three current regulations that could offer possibilities to regulate microbeads: the Cosmetics Regulation, the REACH Regulation and the Ecodesign Directive. ${ }^{441}$

The fourth example is even closer related to the topic of this research, since it aims at diminishing and preventing the plastic pollution in the seas. The Green Deal on waste from ships (Scheepsafvalketen) aims at helping to close the plastic cycle and therefore to diminish the floating litter in the oceans. The goal is to prevent, separate and recycle plastic in ships, as well as to improve the supervision and harmonization of waste delivery in ports. "Because maritime shipping is by definition international in nature, the Ministry of Infrastructure and the Environment (I\&M) will also approach the neighboring countries. In this way, plastic that is separated on board in foreign ports is prevented from becoming one again", ${ }^{442}$

The incentives to ships are through positive stimulation - remember that the Green Deals have a voluntary, non-binding, nature and cannot create regulation. The remuneration can take the form of a discount on the port waste contribution for ships or the non-charging of the collection and processing costs of separately issued plastic. ${ }^{443}$

The deal on waste from ships is from 2014 and intended to have, by 2017: (i) 50 percent of the issuing vessels delivering plastic separately in Dutch ports where separate collection and processing is possible; (ii) 75 percent of the issuing ships of KVNR members delivering plastic separately in Dutch ports where separate collection and processing is possible; and (iii) separate collection by the VOMS members of delivered plastic waste, to be then completely recycled or processed into fuel. ${ }^{444}$ The concrete measures in the ports of Amsterdam and Rotterdam started on January $1^{\text {st }}, 2016,{ }^{445}$ and no

\footnotetext{
435 National Institute for Public Health and the Environment (RIVM) (2014, p. 27).

436 Passenier (2018).

437 Plastic Soup Foundation (2016).

438 Arnoud Passenier (2018).

439 ECHA - European Chemicals Agency (2018).

440 ECHA - European Chemicals Agency (2018).

441 Jansen, Veldhuis, and Schreuder (2017).

442 Green Deal (2014a).

443 Green Deal (2014a).

444 Green Deal (2014a).

445 Green Deal (2018d).
} 
assessments of the results and impacts are available to date. ${ }^{446}$ The general assessment - at the end of 2017 - of the initiative, however, is very optimistic despite a few theoretical critic. ${ }^{447}$

On December 2019, the Dutch government published a report ${ }^{448}$ assessing the results of the deal on waste from ships, mainly from two perspectives. The first one was looking to what extent each of the goals of the Green Deal are achieved, by going through the "status of the activities, the expectation of the contribution that these activities make to the achievement of the goals of the Green Deal and the importance of cooperation within the Green Deal for the implementation of the activities" ${ }^{449}$ All assessments are still qualitative and based on the impressions of the participants, because the data collection is incomplete at this time. The interviewees were questioned about the success rate of the deal, on a scale from 1 to 5, in four different criteria: (i) closing the waste cycle; (ii) separation of plastic; (iii) increase in the effectiveness of supervision; (iv) harmonization of the port facilities for the reception of waste. The average score was 3.2 , considered moderately positive by the report's authrs. The report ponders, however, the possibility that the actors are not fully informed about the activities, because, in 2017, 74\% and 67\% of the ships in Rotterdam and Amsterdam separated the plastic waste properly. And because these ports have more than $75 \%$ of the total amount covering the Netherlands, the goal of an adequate separation is expected to have been achieved. ${ }^{450}$

The second perspective in the report's assessment is on the parties' perception of the status of implementation of activities. The goal is to evaluate to what extent these activities contribute to the Green Deal objectives and to what extent the Green Deal has helped in the execution of the activities. Here, again the conclusions are optimistic in all four aspects of the Green Deal, although the parties feel there is room for improvement. In this sense, suggestions are: (i) for better plastic waste separation, that the financial stimulus no longer ends at the port, that there is a better coordination between suppliers and waste collectors, and that a plan is designed specifically for packaging material; (ii) for better harmonization, that the criteria for defining a "green ship" are measurable and verifiable; (iii) for better prevention, that the suppliers receive help, since they consider themselves too small to influence their own suppliers to use less packaging materials; and (iv) for enforcement, better solution for checking the ships at the port of Rotterdam, because it indicates that too many ships leave every day for them all to be checked. ${ }^{451}$

The fifth and last example regarding the Dutch Deals is not a formal deal, but rather an informal aid provided to The Ocean Cleanup Foundation. It is, in short, an NGO that is voluntarily developing a technology to clean the plastics from the ocean. The organization counted with the support of the Dutch government on at least two different occasions. ${ }^{452}$ The first one was helping the foundation with the research permits to conduct the studies in the seas and beaches under the sovereignty of foreign countries. The second one was indeed a formal agreement, adapting international regulation to give a Dutch "flag" to their cleaning system, equating it to the seagoing vessels. ${ }^{453}$

As explained before, the focus of this chapter is on the private initiatives. Thus, the focus of this section is on the Dutch actions that involve companies and NGO's but do not involve legislation and regulatory enforcement. However, to better understand the current scenario of the Netherlands in facing the plastic pollution, a brief look at its public policies on the subject is also important.

\footnotetext{
446 August $7^{\text {th }}, 2018$.

447 See: Oosterhuis (2016).

448 Witteveen+Bos (2019) - Only available in Dutch.

449 Freely translated. In the original: "status van de activiteiten, de verwachting over de bijdrage die deze activiteiten leveren aan de behalen van de doelen van de Green Deal en het belang van de samenwerking binnen de Green Deal voor de uitvoering van de activiteiten". Witteveen+Bos (2019, p. 16).

450 Witteveen+Bos (2019, p. 20).

451 Witteveen+Bos (2019, p. 26).

452 Passenier (2018).

453 Hoogland (2018).
} 
When analyzing the broader environmental legislation in the Netherlands, the process was as follows. At first, for each new environmental problem, there was a new legislation, with different scopes and different objectives. This led to high complexity and consequently to a necessity to integrate legislation, which meant a legislation drawn under environmental fields: water, spatial planning, nature conservation, and a general environmental law. Still, for permits purposes, this did not mean integration, mainly from the businesses' perspective. Regardless of the specificities, an important lesson learned was the need for a balance between integration from the government perspective - i.e., by theme - and integration from the business perspective - i.e., by economic activity. ${ }^{454}$

Specifically with constructing the legislation to tackle plastic, then, the concern was trying to prevent redoing the whole path and to shape the legislation already with the desired balance. From the analysis done so far by the ministries and by advisors, legislation for plastics should be at first spread, as with the broader environmental legislation started, because jumping to the current broader shape would not be practical. ${ }^{45} 456457$ More importantly, all the analysis and policy construction focuses on microplastic and is based on a prioritization study which made an inventory of the different kinds of plastic pollution land-based sources. The study then prioritized the sources for policy-making, taking into consideration "volume of the emission, the essentiality nature of the source, the possibility of quick win measures, social perception and presence of alternatives for the consumer". ${ }^{458}$

All in all, what can be observed in the Dutch context is an intricate net of deals and legislation that apparently are not always thought of together but seem to fit together. Despite some pitfalls and even the suspension of the deals for a while, ${ }^{459}$ the work to fight the plastic pollution is showing a progressively improving path, with a mix of integrated solutions involving national and local governments, companies, and NGO's.

In general, those in the government involved with the negotiation and implementation processes consider them to be a success. Among the strengths of the approach, the government staff highlight being able to make bureaucracy work in favor of innovation, building networks, and obtaining information - that can even help better legislation in the future. They also highlight the role played by the agencies on maintaining the network of each deal and on enabling the success of the deals. Among the weaknesses, they stress the complexity of environmental challenges, leading to deals that are too specific, or the lack of follow-up initiatives, as well as depending upon the personal motivation and enthusiasm of the parties involved. Still, positive and negative aspects considered, they all describe the collaborative approach as a success, the same being true for the plastic initiatives.

The formal reports evaluating the results of the Green Deals approach arrive at similar conclusions, and indicate the confident perception of all parties involved. ${ }^{460}$

\subsubsection{Dow Jones Sustainability Index: An Opportunity to Take}

One way of trying to induce companies' behavior is through investments, which also aligns with the discussion about the profitability of companies which adopt socially responsible behavior. In other words, if the investors are willing to invest in companies with a particular sort of behavior, it is more likely that an increasing number of companies will adopt such behavior. In that sense, having stock markets that consider sustainability indicators to evaluate companies enables investors to choose companies leading in sustainability rather than others. It is an increasing movement because "companies with sustainability management are perceived to be successful by tapping the potential for

\footnotetext{
454 Woldendorp (2018).

455 Woldendorp (2018).

456 Woldendorp (2017).

457 The conclusions are for microplastic, but an extension is possible.

458 National Institute for Public Health and the Environment (RIVM (2014).

459 Hoving (2018).

460 See, e.g.: Planbureau voor de Leefomgeving (2016).
} 
sustainability products and services on the one hand and minimizing sustainability risks and costs on the other. The precept is that corporate sustainability creates long-term value for shareholders". ${ }^{461}$

Launched in 1999, the Dow Jones Sustainability World Index was the first one of the kind, which is one of the main reasons, together with the level of complexity and organization, and with the range of it, for choosing this example. It "comprises global sustainability leaders as identified by RobecoSAM. ${ }^{462}$ It represents the top $10 \%$ of the largest 2,500 companies in the S\&P Global BMI based on long-term economic, environmental and social criteria" ${ }^{463}$ However, the Dow Jones Sustainability Indices (DJSI) are a family of indexes that use the same methodology to cover different regions, sectors, currencies, and other criteria. The list includes DJSI: World, North America, Europe, Asia Pacific, Emerging Markets, Korea, Australia, and Chile. Besides, RobecoSAM offers the possibility of excluding controversial industries, such as armaments and tobacco. ${ }^{464}$ Apart from that, they have divisions on 19 supersectors and 58 sectors.

The methodology used is the Corporate Sustainability Assessment (CSA). It started as a paper questionnaire in 1999 and progressively developed into the format that it has nowadays. ${ }^{465}$ Figure 15 shows the applications of CSA, all of which relate to sustainable investment, but not restricted to the Dow Jones Sustainability Indices. The data are collected through questionnaires designed specifically for each industry, comprising 80 to 120 questions "on financially relevant economic, environmental and social factors". ${ }^{466}$ Each of the three sustainable dimensions "consists of, on average, 6-10 broad criteria and each of these contains between 2-10 questions" ${ }^{467}$ Each criterion is evaluated on a 100 scale and is assigned a percentage weight. Figure 16 is a sample of the weights in the Food \& Staples Retailing Industry Group. The methodology has as an outcome a sustainability score of a maximum of 100 points. Figure 17 displays this general structure.

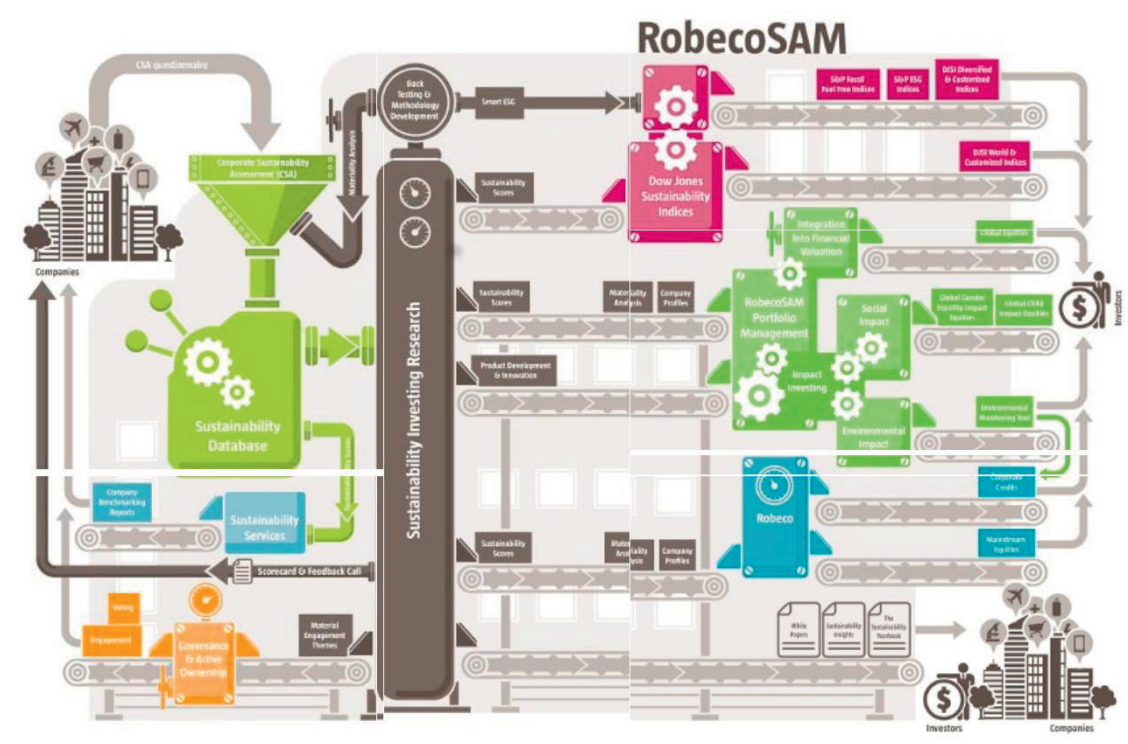

Figure 15 - Corporate Sustainability Assessment ${ }^{468}$

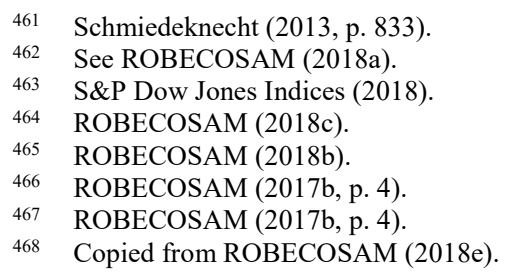




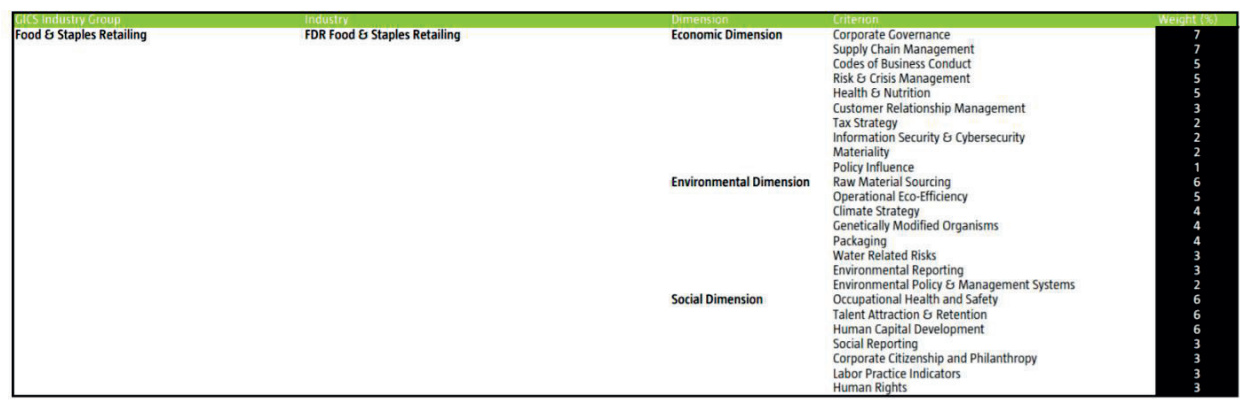

Figure 16 - Criterion Weights by RobecoSAM Industry for Food \& Staples Retailing ${ }^{469}$

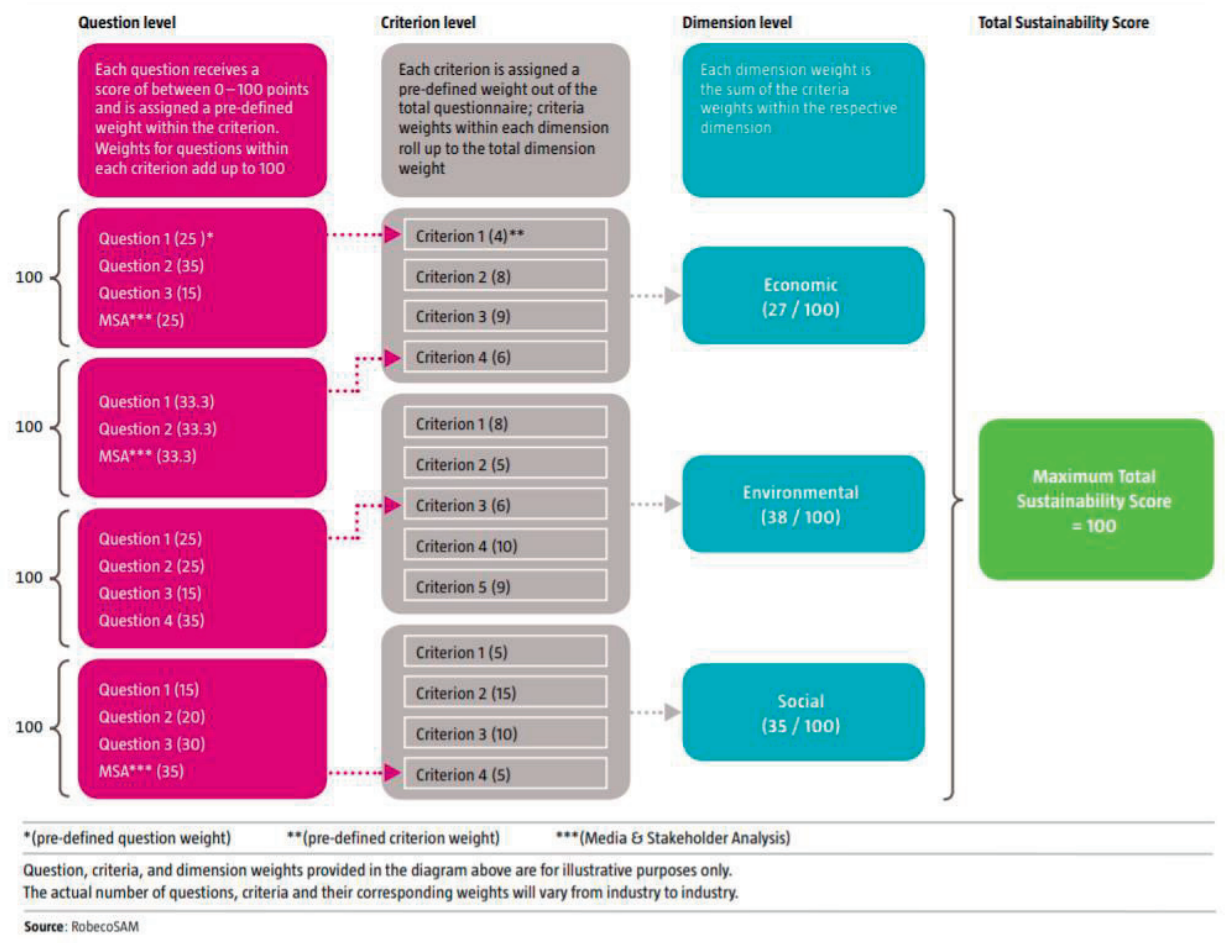

Figure 17 - Structure of the RobecoSAM Corporate Sustainability Assessment ${ }^{470}$

Measuring companies' sustainability performance is pointed out by some researchers ${ }^{471}$ as a limitation of CSR, because it would be a hard and still undefined task. However, the level of detail and complexity of the methodology of the Dow Jones Sustainability Indices is a good example of the possibilities in the field of sustainability assessment. Nonetheless, the same characteristics also raise some concerns.

469 ROBECOSAM (2018d, p. 27).

470 Copied from ROBECOSAM (2017b, p. 4).

471 See, e.g.: Landes (2013); Turker (2013). Many also contribute to enhancing the available tools. See, e.g.: Lee, and Saen (2012). 
The first concern is that, similarly to reporting initiatives, it could be considered self-declaratory. ${ }^{472}$ This would be a major problem if the companies were not obliged to submit documentation that supports the answers they provide. ${ }^{473}$ This not only decreases the uncertainty but also increases the level of transparency, insofar as it enables, for example, future auditing.

The second concern is precisely regarding transparency. On the one hand, complexity is good news because it is the best way to assess sustainability. On the other hand, complexity is bad news because it hinders understanding both by the public and by the companies. There are two facts that ease this concern. One, that RobecoSAM stimulates companies to provide all documentation in the form of publicly available documentation. ${ }^{474}$ Two, that all the steps and criteria of CSA are completely and publicly disclosed in the website.

The third concern is related to the process for selecting criteria and their respective weight. This is one of the aspects that is not completely clear in the methodology. However, RobecoSAM states that those aspects are defined by their analysts and are reviewed every year. Furthermore, the information available about the methodology also shows what is taken into consideration in this selection process. "In most industries of the questionnaire covers industry specific risks and opportunities that focus on economic, environmental and social challenges and trends that are particularly relevant to companies within that industry". ${ }^{475}$ Regarding this industry differentiation, "the relative weights of the economic, environmental and social dimension of the questionnaire vary by industry", ${ }^{476}$ as well as "criteria within the questionnaire will vary from industry to industry to reflect industry-specific drivers". ${ }^{477}$

The fourth and final concern is with the kind of behavior that is considered sustainable. CSA considers both practices of disclosure and practices of performance for scoring purposes. ${ }^{478}$ Besides, the analysts try designing the questions within each criterion to capture and evaluate the following elements: ${ }^{479}$

1. Awareness of the importance of these factors to its financial success;

2. Determination of the potential financial impact (i.e. materiality) of its exposure to sustainability factors;

3. Implementation of strategies to manage these sustainability risks or to capitalize on related opportunities in a manner that is consistent with its business models;

4. Measurement of results in relation to stated Key Performance Indicators (KPI) in order to evaluate the effectiveness of its sustainability strategy;

5. Validation or external audit of stated results;

6. Transparent communication of its corporate sustainability strategies and extent to which stated targets have been met.

Finally, when adding a new criterion, it starts with a low weight to give the companies the opportunity to progressively adapt to it. ${ }^{480}$

From the companies' perspective, research with Canadian companies ${ }^{481}$ showed that the causes for concern are the lengthy questions, the lack of compatibility with the GRI, and the lack of published results. This is no surprise, considering the format of the questionnaires. Still, companies seem to view DJSI as a way to increase visibility, recognition by investors, and to provide a basis for improving performance. More important, the same research highlighted the steps that companies take to enter and to maintain themselves in the list. Those steps are likely to increase their sustainable values. For

\footnotetext{
472 Schmiedeknecht (2013, p. 838).

473 ROBECOSAM (2017b, p. 8).

474 Although it is only considered as such if in English, since it is the official CSA language.

475 ROBECOSAM (2017b, p. 5).

476 ROBECOSAM (2017b, p. 5).

477 ROBECOSAM (2017b, p. 5).

478 ROBECOSAM (2017a, p. 5).

479 ROBECOSAM (2017b, p. 7).

480 ROBECOSAM (2017a, p. 5).

481 Searcy and Elkhhawas (2012).
} 
example, companies need to evaluate their current performance, to introduce new corporate sustainability initiatives, and to consult with the SAM group.

The experts summarized several actions that their corporations take to maintain their inclusion, including improving the company's scores in some identified areas, promoting greater staff involvement in completing the SAM questionnaire, working with third parties, and following up on the feedback provided by the assessors. ${ }^{482}$

Another empirical research, ${ }^{483}$ but in Germany, delivered unfavorable results. It affirmed that in the short term, up to six days after the event, an average decrease of more than $2 \%$ of the stocks returned for companies entering DJSI World. ${ }^{484}$

\begin{abstract}
Assuming that the inclusion in a sustainability stock index is an appropriate indicator for CSR, our results therefore would suggest that a higher corporate environmental or social performance and thus possible associated reputation gains or cost savings were not financially rewarded. However, it should be noted that the assessment and selection process for the composition of sustainability stock indexes is not yet standardized. ${ }^{485}$
\end{abstract}

In general, studies that conclude on the benefits, or on a neutral correlation, of sustainable stock markets to company performance focus on long terms results, ${ }^{486}$ while the one study that analyzes in value terms only does so for the mentioned short term. This makes comparisons and conclusions regarding values uncertain. Still, in summary, it is safe to affirm that DJSI provides a viable path to sustainable investment, even if more changes are needed in the near future to look for more effectiveness. From there, the possibility arises to include plastics in the criteria.

Actually, some of the current criteria already include plastics indirectly. For example, packaging is taken into account for relevant industries. CSA evaluates if companies consider any environmental aspects when developing their packaging solutions to make their packaging more sustainable. Such considerations include a reduction in packaging, using recycled or recyclable material in packaging, etc. Moreover, the questionnaire includes asking companies whether they have any quantitative targets regarding their packaging. Finally, there are questions about the companies' emissions and their disposed waste. Despite of all that, none focuses specifically on plastics and, worse, when the issue is waste, only the amount generated directly by the company is considered, meaning that the product that they put in the market is not taken into consideration.

\title{
5.1.4 Companies Reporting
}

There is a general lack of data regarding the actions of corporations to prevent and remedy plastic pollution. This information gap is commonly attributed to the fact that collecting and sharing the numbers depend on companies themselves. ${ }^{487}$ Therefore, this subsection is not really a case study, but it brings inferences from data provided by companies, which are important to understand the overall participation of corporations in the plastic pollution situation. Besides reports, some scattered data may also help in understanding the situation.

\footnotetext{
482 Searcy and Elkhhawas (2012, p. 90).

483 Oberndorfer, Schmidt, Wagner, and Ziegler (2013).

484 Opposite to what happened with companies entering DJ STOXX 600.

485 Oberndorfer, Schmidt, Wagner, and Ziegler (2013, p. 506).

486 See e.g.: Hayward (2018); Stekelenburg et.al. (2015); Zago, Jabbour, and Bruhn (2018); Ortas and Moneva (2011). Those results are in consonance with the scientific indications that more sustainable companies perform better in the market. In that sense, see e.g.: Orlitzky, Schmidt, and Rynes (2003); Rowley and Berman (2000); Wahba (2008); Chang and Kuo (2008); Wang, Dou, and Jia (2016); Attenborough (2012). 
One of the cases where some data is available is the one of PET bottles. This example is important mainly because those bottles are the most commonly used for soft drinks, and because PET is the second largest category of plastic packaging used globally. ${ }^{488}$ We have a sample detailing how much multinational enterprises really contribute to plastic pollution.

In 2014 alone, 530 billion PET bottles were produced across the world and their production is predicted to grow by $4.7 \%$ a year. ${ }^{489}$ Greenpeace surveyed ${ }^{490}$ six global soft drinks brands. PepsiCo, Suntory, Danone, Dr Pepper Snapple and Nestlè. They combine a total of over 2 million tons of plastic bottles each year. When joined with their other plastic packaging, this rises to a total of 3.6 million tons. Those numbers do not even include sales from Coca-Cola, which refused to disclose its data on plastic. As the world's largest soft drinks company, this giant alone sells more than 1.9 billion drinks per day. An estimate from Coca-Cola's sales accounts the company to be responsible for $18 \%$ to $22 \%$ of the world production of plastic bottles. More than that, over $60 \%$ of Coca-Cola's global packaging is single-use plastic bottles. ${ }^{491}$ It probably produces over 100 billion throwaway plastic bottles every year - an average of 3,400 a second. ${ }^{492}$

Despite the lack of specific information, some numbers can be reinterpreted from companies' reports. The companies here analyzed are the ones that agreed in Davos ${ }^{493}$ at the beginning of 2017, "to come up with cleaner ways to make and consume plastic". ${ }^{494}$ From their sustainability reports, it is possible to reinterpret the available numbers. Almost all of the analyzed reports contain goals regarding plastics, but none of them is clear on the companies' current and past contribution to the plastic pollution. Another interesting aspect is that The Coca-Cola Company is among those corporations which do not report on its use of plastics.

In its 2015 Sustainability Report, Procter \& Gamble (P\&G) presents a result of "nearly 10\% less plastic, which saved 900 tons of plastic". ${ }^{495}$ In other words, P\&G puts in the market 8100 tons of plastic, presumably every year. Moreover, this is only regarding Pampers, one of the companies' branches, and in only some Western Europe countries. Also in the P\&G Report, it is possible to find the information of an increase of $12 \%$ or 29,200 tons of post-consumer resin (PCR) ${ }^{496}$ in plastic packaging. ${ }^{497}$ Although it does not allow any conclusion on the total amount of plastic produced by the company, it means that, only in PCR, the annual production is more than 272,530 tons. P\&G also announces that it is preventing 640,000 metric tons of plastic waste of going to landfills. ${ }^{498}$ However, this means that only two plants of the company - the ones in Mandideep and Baddi, India - produce at least this amount of plastic every year.

Moving on to Unilever, I could only find numbers about one of its branches: Domestos. The Report ${ }^{499}$ confirms an intention to reduce by $15 \%$ the amount of plastic in the bottles of the product, adding that it would mean a reduction of 1,000 tons of plastic per year. Reinterpreting, this is the same as saying that in bottles of Domestos alone, Unilever places in the market almost 6,700 tons of plastic each year.

488 World Economic Forum, Ellen MacArthur Foundation and McKinsey \& Company (2016, p. 27).

489 Greenpeace (2017a, p. 3).

490 Greenpeace (2017a, p. 4).

491 Data recovered from Greenpeace (2017b, p. 2-4).

492 Snowdon (2017).

493 Ellen Macarthur Foundation (2017a).

494 The Local (2017); DW (2017).

495 P\&G (2015, p. 7).

496 "Post consumer recycled (PCR) resin is the recycled product of waste created by consumers. Before the plastic waste is turned into resin, the plastic materials are gathered and sent through a proprietary process to produce plastic resin pellets". Kralstein (2019).

497 P\&G (2015, p. 11 and 33).

498 P\&G (2015, p. 11 and 46).

499 UNILEVER (2015). 
Although there are several references and commitments to plastic reduction, it proved impossible to find numbers that could be used to the intended conclusions regarding Dow Chemical's, ${ }^{500}$ Amco,${ }^{501}$ $\mathrm{Suez}^{502}$ and Veolia ${ }^{503}$ contributions to plastic pollution. The same happens with Indorama Ventures, ${ }^{504}$ whose report also includes an approach on the circular economy, and with Marks and Spencer (M\&S), ${ }^{505}$ even though it presents as a focus reducing the pressure of plastic pollution in the oceans, ${ }^{506}$ It is again observed in the report of Sealed Air, even with a whole section dedicated to explaining its commitment with the New Plastics Economy initiative. Mars, ${ }^{507}$ by its turn, only has one reference to plastic reduction in one specific packaging in China ${ }^{508}$ but no specific numbers. While Dupont ${ }^{509}$ and $\mathrm{L}^{\prime} \mathrm{Orea} \mathrm{l}^{510}$ have no references to plastics issues in their sustainability reports, respectively from 2016 and 2015.

Natureworks ${ }^{511}$ presented a different challenge, since its production is of sustainable plastic. In other words, at this initial moment, its numbers do not directly affect the analysis, because all of Natureworks' production is already of bioplastics, ${ }^{512}$ so the changes and evolutions in production do not impact upon in the sample here constructed. The same thing happens with Novamont, ${ }^{513}$ which alleges that the differential in its policy is the base on "growing integration of the production chain, and [in 2015] aimed at increasing the content of renewable material in bioplastics and improving our environmental profile". 514

The analysis of the Greenpeace report on PET bottles already addressed other companies included in that group of 40 actors joined the New Plastic Economy initiative. However, specifically regarding Nestle, other interpreted numbers are also interesting, although those numbers do not come directly from the company. For instance, in the Michigan operation alone, which "is only one small part of Nestlé", the ten lines of production pump 500 to 1,200 PET bottles per minute. Even if we take the lowest estimate, it still means 7,200,000 bottles a day only in Michigan. ${ }^{515}$

The numbers displayed in this section are only estimates, and sometimes they are contradictory if confronted with others, but they are also only a small part of the contribution of companies to the plastic pollution. This is even more concerning if we remember that those are companies usually adhering to sustainability initiatives, so they are aligned, at least in speech, with a more sustainable development. Therefore, the original assumption that multinationals are great contributors to the plastic pollution problem is proven right.

The major problem is that the estimates that are possible from the scarce data give a glance of the situation's gravity, but nothing else. Companies do not announce clear or precise plans and results, and when they set goals, they are usually incomplete and imprecise, so it is not possible to really understand or accompany them.

\footnotetext{
500 Dow (2016).

501 Amcor (2016)

502 Suez (2017).

503 Veolia (2016).

504 Indorame Ventures (2016).

505 M\&S (2017).

$506 \operatorname{M\& S}(2017$, p. 1).

507 Mars (2017).

508 Mars (2009).

509 Dupont divides its reports. I checked all available at the website: Dupont (2017).

510 L'Oreal (2015).

511 Natureworks (2017).

512 In its own words: "NatureWorks is now a world-leading biopolymers supplier and innovator with its Ingeo portfolio of naturally advanced materials made from renewable, abundant feedstocks with performance and economics that compete with oil-based intermediates, plastics, and fibers. These materials also provide brand owners new cradle-to-cradle options after the use of their products. Natureworks (2017).

513 Novamont (2015).

514 Novamont (2015, p. 2).

515 Winter (2017).
} 


\subsection{Private Initiatives and the Plastic Soup}

The descriptions and discussions about the private initiatives lead to the conclusion that, in general, such an approach already has more concrete measures, as with the New Plastics Economy and the Dow Jones Sustainability Indices, than the approach from the public international law discussed previously. However, at the same time, they lead to the conclusion that an approach focusing on private actions seems to be enhanced by the cooperation with the government, which is clearly demonstrated by the Dutch experience, for example.

Considering those partial conclusions together with the partial conclusions in previous chapters, it becomes clear that there are several lessons to be learned from the private initiatives, and which go much beyond the theoretical distinctions raised by legal theory. Of course, the complexity of the issue makes it inevitable to observe negative aspects as well. Therefore, the analysis here will follow the same division in the analysis of the international instruments, which should also allow a better interconnection of the results later on. So, the issue is discussed from two perspectives. The first regards the ex ante perspective, and the focus is on avoiding the emission of plastics into the ocean. The second perspective is the ex post, looking at recovering the plastic that is already polluting the oceans. For both perspectives, such an analysis is made through evaluating possibilities and balancing lessons learned.

This chapter also relies on a third analysis, based on indicators of ex ante effectiveness. This is essential to assess if the four examples of private initiatives have the elements necessary to produce the desired effects. Also, there is no academic literature that has already analyzed results as it was possible to do with the international instruments.

\subsubsection{Ex ante Perspective}

Almost all of the examples in this chapter work with an ex ante perspective and share aspects with one another, which are precisely the lessons learned that we are looking for in this section. The approach here, as already explained in the beginning of the chapter, is through company-led actions, regardless of the format it takes and of other social actors that may be involved.

Remembering that the three stages of the ex ante perspective are production, consumption, and final disposal, companies are involved in all of them. With production, mostly to rethink packaging and to drive innovation, preferably through new non-plastic materials, but also with plastics that facilitate a sustainable after-use, enabling recycling, re-use, and composting. With consumption not only as part of the value-chain, but also enabling and influencing consumers. And with final disposal, by participating in the so-called reversal logistics ${ }^{516}$ or extended producer liability, ${ }^{517}$ for example.

What to do, nonetheless, is not the hardest part. As seen, technical, business, and legal solutions are, to some extent, available and feasible. Also to a certain extent, companies are starting to use them. But why companies, and, more specifically, multinational corporations, would engage is a trickier question. Summarizing the reasoning that will follow, the derived question is why would companies engage in a meaningful way, not only by green or by blue-washing. ${ }^{518}$ Since one of the answers to that

516 Freely translated from the expression logística reversa, adopted by the Brazilian legislation. It explicitly considers those who insert the product in the market responsible for collecting it.

517 "a policy approach under which producers are given a significant responsibility - financial and/or physical - for the treatment or disposal of post-consumer products". OECD (2018).

518 Greenwashing may be defined as the "act of misleading consumers regarding the environmental practices of a company or the environmental benefits of a product or service" (Terrachoice, 2007). "In economic terms, greenwash are opportunistic behaviours firms undertake due to the informational failures in the environmental-goods market. Greenwashers are the free-riders of the environmental market, as they reap the benefits without incurring any of the costs. More informal interpretations of greenwash add that such 
is the importance of civil society and governments, the final step will be understanding why governments and civil society should invest time, energy, and money, in such company-led actions.

\subsubsection{Why Would Companies Engage?}

The importance of companies' engagement is already well established and clear. The more controversial aspect is why would they engage if not demanded and inspected by state legislation. The examples in this study demonstrate that not only would companies do so, but some already do. Actually, if we consider the international scenario separately, they are more involved with specific actions against the plastic pollution than States themselves. It is possible to perceive a few motives why.

Reason number one is probably the most mentioned and raises concerns. Good public relations is increasingly related to sustainability. The positive side is raising awareness to the subject. The negative side is that commonly it remains restricted to public relations and becomes merely green or blue-washing.

Reason number two is attracting investments. The involvement of companies in initiatives such as the Dow Jones Sustainability Indices shows they are willing to make changes to attract investors in the market. Regarding plastics, it is still a wasted opportunity, but surely an opportunity to take.

Reason number three is multiplicity of choices. Some changes regarding social and environmental protection are inevitable and may take longer if moved by social pressure or new legislation. Nevertheless faster, they may assume the format that is more convenient to the company if it chooses to act pro-actively. When a private actor takes the lead, it has the advantage of achieving a goal by choosing the path, instead of being obliged to follow the steps demanded by legislation. This may not only be lucrative through innovation but also prevent costly investments in the ways and times imposed by state legislation.

Reason number four derives from the previous one: influencing future legislation. Taking the lead opens a possibility to influence legislation-making, causing it to be more beneficial being the lead than to follow. The reservation here is that such an influence is convenient for society as a whole only if rent seeking is prevented.

Reason number five is achieving financial benefits or incentives. Even if optional, it depends on existing legislation, deferring a bit in nature from the other reasons.

Summarizing, there are several motives why companies would engage in actions to help prevent plastic pollution. All of them resulting in higher sustainability, but also all of them raising some small concerns. However, the joint action from civil society, also private actors, and governments, may help to overcome these concerns.

\subsubsection{Joint Action from Governments and Civil Society}

Beginning with the reasons listed above, it is possible to notice a few ways in which the interaction with governments and civil society may enhance the possibilities of success for private initiatives.

disinformation "is perceived as being unfounded or intentionally misleading". In this sense, misleading is intentional, producers know that the information is distorted, incomplete or simply false and they still disseminate it. Which is a different context from 'unknown' information, in which the information simply does not exist". (Gandara, 2013, p. 133-134). Bluewashing is the equivalent within Corporate Social Responsibility. 
With reason number one - good public relations -, for example, government and civil society may help preventing green and blue-ashing. Civil society could help mostly through NGO's, which contribute with research, assessments, auditing, standards, labels, and others. NGO's may also increase the impacts of citizens, by organizing campaigns and raising awareness, as well as the impacts of governments, by lobbying. Governments mostly through regulation and controlling, which have an increasing role in private-led initiatives.

With reason number two - attracting investments - international law influences mainly through the reporting systems and through the CSR guidelines. ${ }^{519}$ However, the most direct guides come from other private initiatives, as with the case of the Dow Jones Sustainability Indices, which have the ability to influence behaviour from both companies and investors.

With reason number three - multiplicity of choices - there are no specific concerns if one considers that all possibilities are socially adequate. Yet, civil society may have a role in affecting the option to be chosen.

With reason number four - influencing future legislation - the main concern, as mentioned, is preventing rent seeking, which is "unproductive from a social welfare point of view" ${ }^{220}$ Relatively to the public at large, companies are generally small, single-issue oriented, and well organized. Those elements lead, simultaneously, to potential success in lobbying and a high probability of rent seeking for interests that are only their own. Governments may help preventing rent seeking by being part of the process and by imposing rules that guide policy-making, as happens to some extent with the Dutch deals example. Civil society, in turn, may also lobby to try to balance the equation.

Internationally, the complexity and heterogeneity is even bigger. Therefore, the scientific community seems to be even more careful when dealing with potential rent seeking, and advises to allow differentiation only in exceptional circumstances. ${ }^{521}$ The caution refers, however, to a different effect of rent seeking on environmental policy. It refers to the relationship between States and differential treatment, which is an aspect from public international law, and therefore was considered in the chapter regarding international instruments.

With reason number five - achieving financial benefits or incentives - the interaction with governments is a premise, meaning that it may solely be achieved if there is action from governments. ${ }^{52}$

All those aspects, together with the lack of data and information of companies' actions and results, reinforce the need to focus on the incentives of the private initiatives, mainly involving transparency of the numbers related to plastic pollution. Better data and information would help companies to innovate and to be leaders in plastic initiatives, as well as help governments to establish more adequate and feasible policies. For both sides, improving data gathering and disclosure enables them to: (i) identify if the actions are effective and go beyond green or blue-washing; (ii) search for public and private solutions based on a more precise diagnosis and establishing more realistic goals; (iii) generate trust from the general public, thus facilitating an increase in population awareness.

\subsubsection{Ex post Perspective}

The only reference to an ex post perspective in the examples in this study is the initiative from The Ocean Cleanup Foundation. It already differs in nature from the ex ante examples because it is an

519 The most prominent being the UN Guidelines on Business and Human Rights, and the OECD Guidelines for Multinational Enterprises.

520 Philipsen (2009).

521 Swanson (2001).

522 For a deeper discussion on the subject, see e.g.: Faure and Weishaar (2012). 
initiative from a civil society organization. Nonetheless, it is a private initiative and it brings lessons to learn.

Another important participation of the private sector is innovating, since the technology to clean the plastic from the oceans is not yet established. There are a few examples of that, which have not been described so far in the study because they are still incipient and lack data. It is worth mentioning them, however, for the purposes of this subsection.

Beginning with the example of The Ocean Cleanup, the two main aspects are the ones directly related to the role of law. The CEO and founder of the organization, Boyan Slat, had legal difficulties with research on a national beach in America. More recently, the foundation struggled with international regulations for launching its deployment system in the Pacific Ocean. As seen before, both international incidents were mediated and resolved by the Dutch Government, showing a fruitful relation between government and civil society to face the plastic pollution. Companies also add to the equation, especially helping to overcome financial obstacles, and The Ocean Cleanup Foundation is also a good example of that, since it is financed by private companies.

The second example may be represented by Adidas and Procter \& Gamble. They are collecting plastic from the oceans to make new products. They are not yet recovering from international waters, since the recovery is on the coast, but it is surely a step towards it. Besides, it helps preventing such plastics from being carried away to international waters.

Adidas, in partnership with Parley, is producing and selling shoes made from recovered plastics. From November 15th, 2016, to March 15th, 2018, they sold one million pairs, while their financial performance is continuously increasing. The same partnership is producing jerseys out of recovered plastics, which are already being used by Real Madrid and Bayern Munchen. ${ }^{523}$

Procter \& Gamble, after initiatives focusing on recycling plastics, released in April 2018 a limited edition of Head and Shoulder's bottles produced from recovered plastics. Technical aspects brought a future environmental concern, however. Because of the colour of the new plastics, they add black pigments, making the recycling of those bottles virtually impossible. Combining their solution with a new black pigment ${ }^{524}$ could possibly be an alternative, but that would demand a higher integration between private parties. Procter \& Gamble also launched (October 2017) a 100\% recycled bottle, being $10 \%$ of plastics recovered from oceans, and $90 \%$ from post-consumer recycled plastics. ${ }^{525}$

Other companies have also made small attempts of the same nature, but these two examples are the more representative and are enough to evidence the aspects that are relevant to this study. ${ }^{526}$

These initiatives, however, use plastics from bottles recovered from beaches, not the high seas, which shows that they are actually not yet directly dealing with the core of the problem addressed by this thesis. Even so, they indirectly act, since they recover plastics that would probably end up in high seas. Besides, they serve to show that recovering and recycling plastics meet the purposes of the company, including profitability. The main distinction is that recovering plastics from international waters would include investments in technology, meaning higher costs.

523 See: Wentworth (2018); Dreizen (2017); Cunha (2018).

524 Plastics and resource consultancy Nextek has come up with a new pigment to replace carbon black, since this is not identifiable by infrared sensors in sorting facilities, making it difficult to recycle. See: La Brecque (2017).

525 Dreizen (2017).

526 See, e.g.: "Dell, which is using $25 \%$ ocean plastic in its $100 \%$ post-consumer recycled content laptop trays, stress that this is a deliberate aspect to their sustainability initiatives". Dreizen (2017). 


\subsubsection{Indicators of ex ante Effectiveness}

In the chapter regarding international public law, it was possible to do a literature review on the effectiveness of existing instruments, mainly because most of them are long-existing treaties and protocols, and none of them address directly the plastic pollution in the oceans. Moreover, using available academic literature made it possible to avoid the discussions about the effectiveness definition by relying on the definitions adopted by those who did the primary analysis.

The current chapter not only demonstrates that there are initiatives focusing on plastic pollution, but mainly that they are very recent. Considering that effectiveness is "the ability to reach the desired goals" ${ }^{527}$ the lack of measured results because of those factors makes it virtually impossible to assess effectiveness in this case. Still, there are indicators to assess ex ante effectiveness, which help to analyze if the initiatives are on the right track.

The referred assessment can be of a different nature, but the one that matters the most here is the legal aspect. Let us take here the work of Scheltema, ${ }^{528}$ who presents eleven indicators to assess private governance initiatives. In this section, I present each of them and apply, when possible, to the problem of the plastic soup.

The first indicator is "whether transnational private regulation entails specific and assessable objectives (and if so, whether they have been achieved) and does not aim at objectives which are effectively achieved by other public or private regulation". ${ }^{529}$ Not setting such goals is a common weakness of private initiatives, "because these objectives are easily changed over time". ${ }^{530}$ If we take the examples described here, however, it seems more heterogeneous than anticipated.

The New Plastics Economy lacks specificity in its goals, but is slowly moving in this direction, especially with regional projects such as the Plastic Pact. The Dutch Deals and the Dow Jones Sustainability Indices set clear and measurable objectives, implying possibilities that are more effective. Reporting initiatives are the broader example.

The second indicator is "whether it entails "conflict of law' rules". ${ }^{531}$ This one will not be used in the current analysis, because it does not appear to be a necessary premise to the effectiveness of rules, either private or public. Resolution of conflict of laws is an aspect of the general theory of law, even international law. Therefore, not every legislation needs to envisage this kind of rule.

The third indicator is "the regular evaluation of the regulation and its functioning (and if necessary) review of the regulation". ${ }^{532}$ This is the basic tool for any successful project, ${ }^{53}$ which does not necessarily mean that it is observable in all private initiatives.

The New Plastics Economy presents periodic reports that improve the previous one by giving more clarity to the directions and by envisioning instruments and goals that are more specific. The Dutch Deals necessarily bring evaluation tools designed for each of them, but the problem there is that those are rarely used to improve the process and the results, because there is no extension of the deals, as there is no interaction between the deals. The analysts of RobecoSAM review each year the Dow Jones Sustainability Indices criteria, which is the reason why we may say that they also obey the third indicator. Reporting initiatives are too open and do not establish evaluation or review mechanisms.

Scheltema (2014, p. 404).

Scheltema (2014).

Scheltema (2014, p. 404).

Scheltema (2014, p. 393).

Scheltema (2014, p. 404).

Scheltema (2014, p. 404).

See, e.g.: Casa Civil da Presidência da República, Instituto de Pesquisa Econômica Aplicada (2018); Austrian Development Cooperation (2009). 
The fourth indicator is "the existence of a supervisory body to which the parties to the regulatory regime are accountable (and have to provide relevant information to this body), and the power of the supervisory body to pass judgment and to impose sanctions on non-compliant parties". ${ }^{534}$ Such an indicator relates directly to the classical perception that obedience depends on the existence of sanctions in case of non-compliance. Research shows it is not always the case, as will be discussed later. Still, it is maintained as a possible indicator, since it is one of the factors that may influence effectiveness, but interpreting broadly the expression of the supervisory body.

The New Plastics Economy has a horizontal structure, so companies are not accountable to each other. The Dutch Deals always indicate a professional who is responsible for accompanying the implementation of the deal, usually from one of the governmental agencies (RVO or RWS) or, in some cases, the related ministry. RobecoSAM, to whom companies have to report with proof, and he verifies compliance to the Dow Jones Sustainability Indices' requirements. Reporting initiatives when isolated, however, respond to no one.

The fifth indicator is "the existence of a supervisory body which controls access to scarce resources". ${ }^{535}$ It relates to the legitimacy discussion, since it depends on an authority to impose access and control. The main risk is that "one can push too far, sacrificing so much legitimacy in the name of authority that the entire endeavour is under-mined". ${ }^{536}$ Regardless of the important discussion involved, the specific concern of the fifth indicator does not apply to the problem of the plastic pollution in the oceans. Plastic is quite the opposite of a scarce resource. That is why this indicator will not be used to the current analysis.

The sixth indicator is that there is "sufficient bureaucratic capacity and (legal) knowledge of the private rule-maker". ${ }^{537}$ The New Plastics Economy has knowledge as a basis, with consultancies and companies writing together the projects and reports. It also seems to be slowly building its bureaucratic capacity, through the specific initiatives. The Dutch Deals are company-led, but happen inside the governmental structure, so they clearly have sufficient capacity. The Dow Jones Sustainability Indices counts on enough structure to establish guidelines and analyze compliance. Reporting initiatives do not have a specific structure, because the reports are the responsibility of each company, but considered individually, it is safe to affirm that companies do have bureaucratic capacity and legal knowledge.

The seventh indicator is "the existence of (a) serious (threat of) contractual enforcement or other means of enforcement if necessary through state legislation and/or (effective) enforcement by states". ${ }^{538}$ This is the indicator that relates closely to a common criticism of private initiatives: their non-binding characteristic. Understanding the effectiveness goes far beyond checking for binding effects, but still, the seventh indicator of the analysis will be considered, mainly because it is a part of a greater picture.

The New Plastics Economy does not rely on any enforcement tools, because it is purely voluntary. The same happens with the Dutch Deals, which, actually, not being enforceable are one of the main attractive aspects of the agreements. The Dow Jones Sustainability Indices have an intrinsic binding effect, meaning that the contractual enforcement is only to the initiative itself, because it expels companies that do not comply. A secondary effect is the blaming and shaming results in the market. Reporting initiatives are becoming more complex in their analysis. Originally, they had zero binding effects. More recently, however, codes of conduct and reports that are made public are being considered binding for consumer law purposes ${ }^{539}$ Moreover, some companies use those documents to

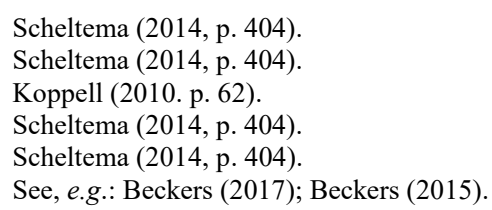


produce effects on the supply-chain. ${ }^{540}$ Another increasing discussion is about contractual consequences that are more general. ${ }^{541}$

The eighth indicator is "the specificity of the rules/standards set forward by the transnational private regulation". ${ }^{52}$ Except for the Dutch Deals and, to some extent, to the Dow Jones Sustainability Indices, the other examples lack specificity in rules and standards, which is in line with the conclusions drawn from the first indicator (goals specificity).

The New Plastics Economy and reporting initiatives, although for different reasons, do not even set rules or standards. The Dow Jones Sustainability Indices set guidelines, which are very clear, specific, and well explained to the companies. So, considering rules in a broader meaning, the Indices meet the indicator. The Dutch Deals set rules that fit the objectives, all very specific. It is a positive aspect, as here explained, but it is also a limitation, in the sense that it commonly leads to a lack of linkage between the different deals. ${ }^{543}$

The ninth indicator is "whether the initiative entails an effective complaint and dispute management mechanism to prevent and deal with non-compliance". ${ }^{544}$ It derives from the Communication of the European Commission of October 25 2011 for a "renewed EU strategy 2011-14 for Corporate Social Responsibility", ${ }^{45}$ and aligns with the UN Guiding Principles on Business and Human Rights. ${ }^{546}$ Still, as with the fourth indicator, we should remember that compliance does not always relate to the possibility of sanctioning.

All four examples fail the ninth indicator. However, as mentioned before, in some cases reports may use regular State's conflict resolution mechanisms, mainly applying consumer and contract law. In other cases, as is the case of the Dutch Deals, the impossibility of using means for complaint is what makes them attractive to industry, so they will never adapt to meet that indicator.

The tenth indicator is "the possibility of certification or assessment of compliance by independent third parties whereby reporting requirements in the regulatory framework are helpful". ${ }^{547}$

The New Plastics Economy does not provide any assessment possibility, although reporting requirements could be helpful. The Dow Jones Sustainability Indices almost match the description of the tenth indicator. The Dutch Deals always count with assessment mechanisms designed specifically to each of them. Reporting initiatives are assessment mechanisms, but they do not submit to independent third parties per se.

Regarding initiatives relating to plastics, this indicator may lead us even further than the examples in this chapter. Research ${ }^{58}$ shows, for instance, that standardization and certification - which, by definition, depend upon independent third parties - have a high potentiality for success in the plastics industry. Even though the analyzed instruments are almost restricted to the expressions biodegradable, biocompatible, and compostable, these may still indirectly help to fight the plastic soup.

\footnotetext{
540 See, e.g.: Mitkidis (2014).

541 See, e.g.: Poncibò (2016); Eijsbouts (2017); Van Dam (2015).

542 Scheltema (2014, p. 404).

543 Eijs (2018).

544 Scheltema (2014, p. 405).

545 European Commission (2011).

546 United Nations - Human Rights Office of the High Commissioner (2011).

547 Scheltema (2014, p. 405).

548 Krzan (2006).
} 
Other specific industries are also showing positive results, although with much still to evolve. ${ }^{549}$ Besides, general studies complement the optimism with certification for the plastic industry, mainly because

\begin{abstract}
Asymmetries in information, where sellers have more information than buyers about product qualities, may prevent firms from supplying some goods and services despite the fact that consumers are willing to pay adequately for them. The frequency and importance of such market failures is growing with the increase in buyers' interest in unobservable qualities (attributes) of products, including the nature of their production processes. Certification by credible third parties may reduce the frequency and mitigate consequences of market failures. Certification creates a variety of challenges for both marketers and regulators. In this paper, we examine the emergence of alternative domestic and international regulatory regimes for certifying some qualities of products and services. We explore the implications of these regimes and country and product characteristics to the formulation of international marketing strategies. We illustrate our findings through a case study of the forest products industry. ${ }^{550}$
\end{abstract}

Even so, government has an essential role in eco-labeling. Besides, it is important to keep in mind that, as any market instrument, the equilibrium with standards, certifications, and labels is delicate. ${ }^{551}$ Those instruments are, in approach, similar to what can be observed from the Dow Jones Sustainability Indices.

The eleventh indicator is "whether a certain business incurs (severe) reputational damage if negative (social) media attention is directed at it because of a violation of international private regulation and whether (active) NGOs or other organizations monitor the compliance with these rules, provided that at least there is a moderate chance of detection of the violation". 552

This final indicator does not allow a direct assessment as with the others, mainly because the mentioned consequences vary highly depending on their kind and do not appear isolated in each private regulation. With labeling alone, for instance, different kinds of impacts are observed. ${ }^{553}$ Moreover, naming and shaming sometimes comes as a powerful tool in private markets. ${ }^{554}$ On the other hand, there are indications "that legal penalties, and not reputational losses, are most important in disciplining and deterring environmental violations", ${ }^{555}$ regardless of whether they are civil or criminal, although the research showing that is not clear if it accounted for the relationship between legal punishment and reputational effects.

Regardless of those challenges, it is still possible to conclude briefly if each of the examples meet the eleventh indicator. The New Plastics Economy is still too new, so there are no specific cases to conclude from. However, it does not indicate potential to reputational damage in the case of noncompliance. The Dutch Deals fail this test, also because of their nature. The Dow Jones Sustainability Indices is the example that has better results in that sense, mainly because companies that do not comply with the requirements are excluded. Reporting Initiatives are increasingly showing potential to lead to reputational damage, since they are becoming more public, either voluntarily or through consumer and contract law discussions, as shown before.

549 See e.g.: Albersmeier, Schulze, and Spiller (2009); Elgert (2012); Harris (2007a); Harris (2007b); Magar et al. (2011); Hatanaka and Busch (2008); Dam et al. (2008); Schmitz (2007); Zhang, Joglekar, and Verma (2014); Delzeit and Holm-Muller (2009); Smeets et al. (2008).

550 Vertinsky and Zhou (2000, p. 231).

551 Gándara (2013, p. 345 and 368).

552 Scheltema (2014, p. 405).

553 Gándara (2013, p. 34-48).

554 Erp (2008).

555 Lott, Karpoff, and Rankine (1999). 
Table 1 summarizes the brief conclusions to each of the eleven indicators of ex ante effectiveness assessment for the four private initiatives. It shows that: (i) no example completely succeeds or completely fails the indicators' test; (ii) some of them seem to perform better, though.

\begin{tabular}{|l|c|c|c|c|}
\hline \multicolumn{1}{|c|}{ INDICATOR } & $\begin{array}{c}\text { NEW PLASTICS } \\
\text { ECONOMY }\end{array}$ & $\begin{array}{c}\text { DUTCH } \\
\text { DEALS }\end{array}$ & $\begin{array}{c}\text { DOW } \\
\text { JONES }\end{array}$ & REPORTING \\
\hline 1 - specific and assessable objectives & Fail & Succeed & Succeed & Fail \\
\hline 2 - conflict of law rules & - & - & - & - \\
\hline 3 - evaluation and review & Succeed & Fail & Succeed & Fail \\
\hline 4 - accountable to a supervisory body & Fail & Succeed & Succeed & Fail \\
\hline $\begin{array}{l}5 \text { - supervisory body which controls access } \\
\text { to scarce resources }\end{array}$ & - & - & - & - \\
\hline 6 - bureaucratic and legal capacity & Succeed & Succeed & Succeed & Succeed \\
\hline 7 - contractual enforcement & Fail & Fail & Succeed & Neither \\
\hline 8 - specificity of rules / standards & Fail & Succeed & Succeed & Fail \\
\hline $\begin{array}{l}9 \text { - complaint and dispute management } \\
\text { mechanism }\end{array}$ & Fail & Fail & Fail & Fail \\
\hline $\begin{array}{l}10 \text { - certification or assessment of } \\
\text { compliance by independent third parties }\end{array}$ & Fail & Succeed & Succeed & Fail \\
\hline 11 - reputational damage & Fail & Fail & Succeed & Transitioning \\
\hline
\end{tabular}

Table 7 - Testing the examples with the eleven indicators

Other than that, some of the arguments discussed here show that, at several moments, private initiatives need to interact with governments and/or civil society to achieve effectiveness. This is perceived, for example, when public institutions help by filling the lack of dispute mechanisms in private initiatives. Or when public law, such as consumer or contract law, provides deeper effects, including legal enforceability, than the ones initially planned for the private instruments. This last example leads to a final important aspect to note.

The high value that the indicators attribute to binding characteristics and compliance mechanisms. Take, for instance, indicators $3,5,7$, and 10 . Only indicator 11 focuses on purely market consequences although the indicators are analyzing market initiatives. However, this still relates to a classic perspective of law and to a public law approach. Research demonstrates that compliance with companies' codes of conduct relates more to the involvement of stakeholders in the codification than to their content. ${ }^{556}$ Furthermore, the increasing attention to company-led initiatives in the international scenario derives from a governance gap left by purely state-based regulation, which lacks the tools to address fully the transnational externality issue. The main reason for such a gap is the complexity of the context. One of the reasons for that complexity is the lack of technical information, which sometimes only the corporations hold. Hence, inviting the corporations to voluntarily join the efforts is also a strategy to access the missing information.

Another aspect weakens the argument that advocates the necessity of binding effect in order to observe compliance: there is a difficulty in solving the gap in governance through binding international instruments. The impossibility of getting an agreement on a treaty on CSR is an example of how such an approach may delay the implementation of solutions. ${ }^{557}$ 
Moreover, that criticism seems to come from a general assumption that a non-binding norm is necessarily inefficient. Nevertheless, studies show that it is not always the case, and that the efficiency of CSR voluntary initiatives depends more on other factors than on legal enforceability. ${ }^{558}$ Demonstrating that, there is an empirical research from a project on business and human rights due diligence, conducted by the British Institute of International and Comparative Law and the Business Ethics \& the Anti-Corruption Group of the global law firm Norton Rose Fulbright LLP. ${ }^{559}$ The group collected data from a survey responded to by 152 companies $^{560}$ and concluded that twelve components can be summarized for the process of CSR implementation inside business. "One or more of these components are being undertaken to varying degrees within all the companies [...] interviewed, although in many companies they are not expressly referred to as steps within a HRDD ${ }^{561}$ process". ${ }^{562}$ More than that, "there is, accordingly, a forward-looking, ongoing process of 'learning by doing". ${ }^{563}$ The HRDD process "requires detailed knowledge of company practices to ensure that any developments in regulation assists both the companies and those affected by their human rights impact". ${ }^{564}$ In general, studies like this reaffirm that voluntary norms alone do not solve the problem, but they must play a role in the regulatory mix leading to efficient and effective CSR. ${ }^{565}$

Finally, even the critics of non-binding initiatives agree that

[...] these arguments should not lead to the conclusion that CSR or sustainability policies are not resourceful. It is worth mentioning that conducting business in line with moral norms is also a stakeholder value-increasing business approach. There is no doubt that these soft law additions to hard law considerably contribute to bringing important issues to the attention of companies and also altering management behavior. ${ }^{566}$

Thus, once again the evidence points to the necessity of a regulatory mix, in which voluntary norms play an important role.

\subsection{Main Findings}

The first conclusion of this chapter should be obvious, but taking it from the current international actions, it is not. In the same way that public international law needs the support of private initiatives to work faster and more effectively, private initiatives need the support of public international law and of civil society to work faster and more effectively.

Secondly, the hypothesis is confirmed and, indeed, private initiatives may provide a quicker start and help to increase knowledge about the technical aspects involved in the problems and in the solutions, and regulation would come as mediation of, and consolidation of, the paths that worked.

Thirdly, the chapter demonstrates that, internationally, the private sector is currently more active than governments regarding concrete measures. However, this is not such good news as it seems. The pace is not compatible with the challenge ahead. Production of plastics is increasing exponentially, and even if the good practices are strengthened and reproduced, the accumulated mass of plastics in the oceans poses a challenge against which only one NGO is taking action.

\footnotetext{
558 See, e.g.: Lozano (2019).

559 Mccorquodale, Smit, Neely, and Brooks (2017).

560 Mccorquodale, Smit, Neely, and Brooks (2017, p. 197).

561 Human Rights Due Diligence.

562 Mccorquodale, Smit, Neely, and Brooks (2017, p. 224).

563 Mccorquodale, Smit, Neely, and Brooks (2017, p. 224).

564 Mccorquodale, Smit, Neely, and Brooks (2017, p. 224).

565 In that sense, see also e.g.: Locke (2013); Locke and Romis (2010); Eijsbouts (2011).

566 Eroglu (2014, p. 98).
} 
The lessons learned give room for cautious optimism. Not only do they show that private initiatives are contributing to face the plastic pollution in the oceans, but mainly they reveal mid-term possibilities. Mixed solutions in between public regulation and purely voluntary private actions show a high potential for success.

In that sense, the Dutch deals indicate that if trust is built between governments, companies, and civil society, their roles are enhanced. The signs point to a central role of States in setting goals and priorities, of civil society, especially through NGO's, in mediating interests and expanding research and pressure, and of companies in innovating and leading informed changes.

More than that, the examples show that scalability is one of the positive aspects of such an approach, including in the international scenario. It has happened with the Dutch Deals, take the examples of the circular economy green deal and the informal agreement regarding microbeads in cosmetics, for instance, and it is happening with the New Plastics Economy, especially through the Plastic Pact.

This aspect is also confirmed by the observations about market solutions, such as labeling and certification, and by experiences like the Dow Jones Sustainability Indices.

A further and more complex step is defining the details of such interactions and of such a regulation mix. This will be the object of a later chapter.

The contribution that may have a more rapid impact at the moment is effectively inserting actions affecting plastics as a criterion for investments and market approaches, particularly in the Dow Jones Sustainability Indices. The core lesson, though, is to overcome prejudice against company-led initiatives, build trust, and understand the roles that each social actor may play in order to facilitate action. The analysis of the ex ante effectiveness of the four examples in this chapter demonstrate that no path to this goal is perfect, but it helps understanding their strengths and weaknesses.

We have to keep in mind that this action is already late, and now we are trying not to be too late, by working with those possibilities. 


\section{THE WAY AHEAD}

The very least you can do in your life is to figure out what you hope for. The most you can do is live inside that hope, running down its hallways, touching the walls on both sides.

Barbara Kingsolver

In this sixth chapter the aim is to identify the most promising paths to face the plastic pollution in the oceans, both from the ex ante and the ex post perspectives, therefore answering the research question. As already stated in the previous chapters, this requires paths that integrate public and private actions. Once again, it is stressed that the research does not intend to present a final solution. It would be impossible, mainly because of the complex nature of the problem. It does, however, indicate the aspects and paths that are potentially more effective ways to fight the plastics pollution in the oceans. Its main contribution is, then, to enable an actual start to take actions which are already late.

In order to do so, this chapter is based on the partial conclusions reached in the other chapters. Thus, after having described the status of the legal solutions - and their limits - in the previous chapters, chapter 6 now goes more into detail the critical analysis of the findings, using the economic analysis of law.

Chapter 2 was essentially a diagnosis of the plastic soup problem. It indicated that the complexity of the issue manifests itself mainly in the following factors: (i) plastics are produced and used in different manners; (ii) pollution originates in all stages of the chain, from production to final destination; (iii) recovering the plastic that is already in the oceans, and continuously increasing, is, so far, a virtually impossible task; (iv) the solutions must be analyzed for each particular case; (v) it is an international problem caused mostly by national actions; (vi) it involves all social actors - States, individuals, corporations, and organizations. More than that, chapter 2 already indicated priority aspects: (i) $80 \%$ of the plastic ending in the ocean comes from land-based sources; ${ }^{567}$ (ii) packaging answers for $26 \%$ of the volume of plastic used; ${ }^{568}$ (iii) $50 \%$ of the plastic produced is used only once; ${ }^{569}$ (iv) there are methodologies already available to prioritize action; ${ }^{570}(\mathrm{v})$ attempts and partial solutions seem to be emerging everywhere - geographically and from public and private initiatives - although they are still far from solving the plastic soup; and, consequently, (vi) it is necessary to have further investment in research, technology, and innovation, for the development of solutions involving all stages that lead to the plastic pollution of the oceans, as well as to the recovery of the tons of plastics that are already in the oceans; (vii) the main issues vary depending on the country where the pollution originates, especially between the so called developing and developed world.

Chapter 3 served the purpose of justifying the central role of international solutions and of raising awareness of the North-South relation concerning the plastic soup.

Chapter 4 analyzed eleven instruments from the public international law perspective and concluded on the lack of protection both from the ex ante and from the ex post perspectives. Most of the instruments, all of which were selected because of their connection to the theme, do not even mention plastics. Only three just briefly refer to it. The only one that does so with the focus on fighting the current pollution problem is the Basel Convention, which only recently, in 2019, brought such a change, which has still not entered into force. Also, many of the eleven instruments are struggling with effectiveness. However, even the lack of effectiveness allowed a better understanding of the functioning of such tools, since the criticisms arise from a detailed analysis of their implementation.

567 Sheavly (2005).

568 World Economic Forum, Ellen MacArthur Foundation and McKinsey \& Company (2016, p. 17).

569 Hollman, Bouwmeester, and Peters (2013, p. 8).

570 E.g.: Odegard et al. (2017); National Institute for Public Health and the Environment (RIVM) (2014); Woldendorp (2017). 
Therefore, even the lack of effectiveness leads to a better understanding of the possible paths to the problem under analysis.

Chapter 5 went the same way, but investigated private initiatives - both from companies and from civil organizations. Although still at a pace much lower than needed, there are actions that give room to optimism. Here, there are three main challenges: (i) lack of access to information and data from companies, especially when dealing with the production stage; (ii) market dependence, and the markets in general are not yet integrated with sustainable behavior; (iii) need to gain scale. The good news regarding the third aspect is that the cases studied seem to already have scalability.

In general, the partial conclusions fitted in with Orlitzky, Schmidt, and Rynes ${ }^{\text {,571 }}$ statement that CSR and corporate social performance (CSP) in practice neither confirms nor rejects the affirmations from neoclassical economists such as Friedman, ${ }^{572}$ which state an inherent contradiction between a corporation profit-led goal and concerns with social and environmental performance. This reinforces the need for integration between social actors - States, corporations, and civil organizations -, and, consequently, the need to build trust among them.

Before it is possible to articulate all those preliminary statements, there is still a need for a better understanding of regulation and its obstacles and intended consequences. For this reason, this chapter unifies the partial conclusions of the thesis, through a Law and Economics analysis, applying the economic tools to answer the research question. From there, it is finally possible to propose answers that should mainstream the solutions to the plastic soup.

Also before articulating those, and precisely because the analysis is made by using $\mathrm{a}^{573}$ Law and Economics methodology, it is important to briefly introduce those tools before proceeding to the analysis itself.

The economic analysis of law has increased importance, especially in the legal field, "since the midor late 1970 s - about 40 years. Its initial appeal was that it brought a new set of tools to bear on the core issues of the law and seemed to give fresh justifications for core legal doctrines". ${ }^{574}$ As a starting point, Economics use some assumptions ${ }^{575}$ regarding the market and the actors related to it, as it is expected in a scientific model. An economic analysis of law will focus on regulation, no matter if it is a positive - focus is on describing and explaining the problem - or a normative - aims on building the most efficient regulation - analysis. ${ }^{576}$

Historically, the first group of economic theories of regulation are the so-called public interest theories ${ }^{577}$ From those, "government regulation may be efficient when market failures are present and private law offers no efficient solution". ${ }^{578}$ Many reasons are presented by academic literature to justify government interventions, but it generally distinguishes between four kinds of market failure: (i) information problems; (ii) externalities; (iii) the presence of public goods; and (iv) market power. ${ }^{579}$ The two that interest the most when analyzing the plastic pollution in the oceans are information asymmetry - since not all information is available to every person involved in the issue - and externality - in this case, a negative externality.

571 Orlitzky, Schmidt, and Rynes (2003, p. 424-425).

572 Friedman (1970).

573 I say "a" methodology because there are more than one. See, e.g: Ulen (2017, p. 5-7).

574 Ulen (2017, p. 1).

575 Regarding which I am aware of the different types of criticism. However, it goes beyond the scope of the thesis to debate or to take a position relatively to them. As methodological choice, they serve well the purpose of modelling reality for scientific analysis.

576 Pacces and Visscher (2011, p. 88); Geistfeld (2001, p. 250). See also: Blaug (1993); Hennipman (1992); Hutchison (1964).

577 Hertog (2013, p. 9).

578 Hertog $(2013$, p. 10).

579 Philipsen (2009, p. 205). 
When addressing an externality, Coase is the main name to look at, ${ }^{580}$ as a starting point. So, in a public interest theory, applying the Coasen Theorem would be the first step in the analysis, as will be better explained in subtopic 6.1.2.2. The subtopic also follows the subsequent steps proposed by the public interest theories: Pigou tax or subsidy; regulation (such as quality standards) or liability rules; and market-based instruments.

Criticism of such a theory, and especially criticism regarding the conditions demanded by the Coase theorem, led to different versions of the public interest theory. The main aspect to this thesis is the criticism of a naivety ${ }^{581}$ and gap between theory and reality to what concerns the bargaining proposed by Coase - between parties affected in a market failure. In the case of the plastic pollution, not only are transaction costs too high, but also information costs are elevated (because of the same reasons that cause the failure of information asymmetry). This is also particularly interesting because the usual answer to it is that "regulation may be more efficient in this case because the government can obtain information less expensively". ${ }^{82}$ However, "market failure and private law failure have to be compared with regulatory failure", ${ }^{583}$ and the international context of the plastic soup, together with the referred information asymmetry, point in the direction of a potential regulatory failure. Thus, the main reason to look in the direction of a regulatory mix.

The criticism also led, however, to new economic perspectives of regulation, with the use of economic tools in the political science analysis. ${ }^{584}$ Those are called private interest theories (or public choice theory ${ }^{585}$ ), which are very diverse ${ }^{586}$ but generally resumed as a research strategy based on models of individual choice assumed to be instrumentally rational, ${ }^{587}$ and with an important role of the public agent - either if passive or active, depending on the school of thinking. Such a perspective is particularly relevant to this thesis in what concerns, naturally, the political aspects. Therefore, with concepts such as rent-seeking ${ }^{588}$ and entry-barriers.

Still inside the discussion on market versus government failures, I must highlight the importance of the Miller's ${ }^{589}$ theory about self-regulation and Shavell's ${ }^{590}$ criteria for regulation. Both will be addressed on subtopic 6.1.1.1, when discussing the need for a mixed approach.

The concepts mentioned here - as well as other relevant economic concepts - will be explained and applied in this and in the next chapter, as they are needed.

\subsection{The Law and Economics in the Four Stages to Fight the Plastic Pollution in the Oceans ${ }^{591}$}

The descriptions and discussions about the international instruments lead to the conclusion that, in general, the problem with the plastic pollution in the oceans is not addressed by any of those instruments in a direct way. This is an aspect of major concern mainly for two reasons: the plastic soup is already considered by some as the largest environmental harm caused by mankind; ${ }^{.52}$ and since it affects international waters, it is essentially an international law problem.

$580 \quad$ Miceli (2017, p. 11).

581 Hertog (2013, p. 23); Noll (1983); Noll (1989).

582 Hertog (2013, p. 23).

583 Ogus (2004, Kindle pos. 1670).

584 Stearns (2017, p. 44).

585 Sometimes also referred to in a narrower concept, as the private interest approach proposed by the Virginia School.

586 See, e.g.: Stigler (1971); Peltzman (1976); Peltzman (1989); Posner (1974); Becker (1983).

587 See, e.g.: Farber (2017, p. 181); Hertog (2013, p. 24-25).

588 See, e.g.: Tullock (1993); Buchanan, Tollison, and Tullock (1980); Krueger (1974).

589 Miller (1985).

590 Shavell (1984).

591 Some of the conclusions here described are based on an earlier publication: Goncalves and Faure (2019).

592 Waters (2016). 
Of course there are a few instruments of a broader nature, for example those that prohibit a discharge of waste, which naturally includes plastic. There is, however, a consensus in the literature regarding the lack of effectiveness of most of those instruments. The analysis of Agenda 21 reinforces such a perspective by highlighting the failure of the international community regarding the plastic soup and the oceans in a broader sense, demonstrating that "in the 20 years since Rio, the state of world's oceans and coastal areas has continued to decline". 593

However, as mentioned before, the international instruments and their complexity have several positive as well as several negative aspects. On the positive side we could identify, for example, that: UNCLOS covers six types of sources of marine pollution; the London Protocol of 2006 explicitly prohibits the dumping of plastics into the oceans; the Basel Convention is showing flexibility in negotiations to include provisions regarding plastic waste; Agenda 21 helped to bring sustainable human development closer to the heart of development; the GPA is achieving many intergovernmental advances regarding land-based activities; the FAO Code - when implemented - induces good national results; and the SDG's are expected to be successful.

A more specific analysis of the effectiveness of the international instruments discussed and, mainly, to address the next steps, comes from the two perspectives already explained. The first regards the ex ante perspective, with the focus on the emission of plastics into the ocean, which obviously should be avoided. It concerns broader issues like the production and consumption of plastics, but mostly the disposal of plastics which ultimately makes them end up in the oceans. The second aspect addresses the issue more from an ex post perspective and therefore looks at recovery. This therefore refers to the problem of the plastics already present in the ocean. Such an analysis is made by evaluating possible solutions and by discussing lessons learned.

Public regulation is not, however, the only legal pathway, even in the international scenario. Case studies have also been presented and lessons learned from private initiatives. Therefore, the analysis under this topic will also consider the potential contributions of such players, such as companies and NGO's. Always keeping in mind the two-fold nature of the issue: ex ante and ex post perspectives.

\subsubsection{Ex ante Perspective}

From chapter 4, it appeared that the main problems with the current international instruments (both hard law and soft law) are that none of them explicitly deals with the prevention of emissions of plastic into the ocean. There is no explicit provision regarding the prevention of a discharge of plastics and more generally, there is equally a problem of the lack of effectiveness of most of the instruments.

Table 8 summarizes the way in which the eleven instruments discussed deal with the issue of plastic. To the extent that their particular instrument mentions the word plastic, it is put in the yes column.

\begin{tabular}{|l|l|l|}
\hline & Mention of plastics? & \\
\hline & YES & NO \\
\hline \multirow{4}{*}{ Hard Law } & - London Protocol (2006) & - UNCLOS \\
& - MARPOL (Annex V) & - London Convention \\
& - Basel Convention & - CBD \\
\hline \multirow{2}{*}{ Soft Law } & - GPA $^{595}$ & - Agenda 21 \\
& - SDG's & - FAO Code \\
\hline
\end{tabular}

Table 8 - Summary of mentions of plastics in the international instruments

\footnotetext{
593 Stakeholder Forum for a Sustainable Future (2012); Sebille (2015, p. 29).

594 Considered separately from the London Convention because parties may choose to sign only one or both.

595 This supposes that some of the programs adopted under the GPA refer to plastics.
} 
A first aspect that draws attention is the fact that two of the hard law documents that mention plastic do not prevent dumping from land-based activity, which represents - as mentioned before $-80 \%$ of the plastic that end up in the oceans. Secondly, one of the two soft law instruments that does mention plastics - the SDG's - only has to be reached by 2030, so they could just have started to produce effects. That makes it more difficult to evaluate practical outcomes.

This should be read together with the broader approach of each document and with their general effectiveness. Although it is a reduction of all the complex elements explained previously, table 9 is useful to help visualizing all of them at once. Thus, it is important to keep in mind that: (i) all instruments have several positive and negative aspects, but the table only displays them if related to possible outcomes to face the plastic pollution of the oceans; (ii) it leaves out the reference or not to plastic because it is already accounted for in table 8; and (iii) general effectiveness is assessed in a binary "yes or no" response, based on the literature review and conclusions offered in chapter 4, and not only regarding the plastic pollution of the oceans. None of those constraints influence the conclusions that will be derived from the descriptions.

\begin{tabular}{|c|c|c|c|}
\hline & Strengths & Weaknesses & Effectiveness \\
\hline UNCLOS & $\begin{array}{l}\text { - Addresses } 6 \text { sources } \\
\text { of marine pollution }\end{array}$ & $\begin{array}{l}\text { - No explicit mention } \\
\text { of plastics }\end{array}$ & Yes \\
\hline $\begin{array}{l}\text { London Convention } \\
\text { and London Protocol } \\
(2006)\end{array}$ & $\begin{array}{l}\text { - Offers guidelines to } \\
\text { assist national } \\
\text { authorities } \\
\text { - Counts with review } \\
\text { mechanisms }\end{array}$ & $\begin{array}{l}\text { - Plastic is not listed } \\
\text { as pollution to be } \\
\text { prevented by States } \\
\text { - Lack of provisions to } \\
\text { solve technical, } \\
\text { scientific and } \\
\text { financial obstacles to } \\
\text { change the behavior } \\
\text { of sea dumping } \\
\text { - Only covers } \\
\text { dumping from ships, } \\
\text { platforms and } \\
\text { aircrafts }\end{array}$ & Yes \\
\hline MARPOL & $\begin{array}{l}\text { - Prohibits the discharge } \\
\text { of all plastics into the } \\
\text { sea }\end{array}$ & $\begin{array}{l}\text { - Only mention of } \\
\text { plastic is in an annex } \\
\text { - Only prevents } \\
\text { pollution from ships } \\
\text { - Flags of convenience }\end{array}$ & Yes \\
\hline CBD & $\begin{array}{l}\text { - Jakarta mandate } \\
\text { brings a checklist of } \\
\text { concrete measures } \\
\text { - Strategic plan } \\
\text { - Aichi targets }\end{array}$ & - 2010 goals failed & No \\
\hline CMS & - Strategic plan & $\begin{array}{l}\text { - Resources } \\
\text { constraints }\end{array}$ & Yes \\
\hline Basel Convention & $\begin{array}{l}\text { - Relative flexibility } \\
\text { and agility to } \\
\text { incorporate provisions } \\
\text { regarding plastics }\end{array}$ & $\begin{array}{l}\text { - Traditional } \\
\text { approach, and } \\
\text { dependent upon } \\
\text { national regulation } \\
\text { - Long terms before } \\
\text { amendments enter } \\
\text { into force }\end{array}$ & No \\
\hline Agenda 21 & $\begin{array}{l}\text { - Helped to bring } \\
\text { sustainable human } \\
\text { development closer to } \\
\text { the heart of }\end{array}$ & $\begin{array}{l}\text { - Failure towards } \\
\text { sustainable } \\
\text { consumption and } \\
\text { production patterns } \\
\end{array}$ & Yes \\
\hline
\end{tabular}




\begin{tabular}{|c|c|c|c|}
\hline & Strengths & Weaknesses & Effectiveness \\
\hline & $\begin{array}{l}\text { development } \\
\text { - } \text { CSD }\end{array}$ & $\begin{array}{l}\text { (business as usual } \\
\text { prevailed) } \\
\text { - State of oceans } \\
\text { severely declined in } \\
\text { the } 20 \text { years after }\end{array}$ & \\
\hline GPA & $\begin{array}{l}\text { - Addresses the } \\
\text { connection between } \\
\text { terrestrial, freshwater, } \\
\text { coastal and marine } \\
\text { ecosystems } \\
\text { - Focus on land-based } \\
\text { activities } \\
\text { - GPLM } \\
\text { - Valuing plastics report } \\
\text { - Access to high } \\
\text { political levels } \\
\text { - Online marine litter } \\
\text { network } \\
\text { - Activities to raise } \\
\text { awareness } \\
\text { - Help to develop } \\
\text { regional programmes }\end{array}$ & $\begin{array}{l}\text { - Non-binding } \\
\text { - Thus, lack of } \\
\text { compliance } \\
\text { mechanisms }\end{array}$ & Yes \\
\hline FAO Code & $\begin{array}{l}\text { - Influence in regional } \\
\text { and national initiatives } \\
\text { - Good results in } \\
\text { countries that adopted }\end{array}$ & $\begin{array}{l}\text { - Administrative } \\
\text { inertia } \\
\text { - Lack of political will } \\
\text { - Short sighted } \\
\text { economic } \\
\text { considerations }\end{array}$ & Yes \\
\hline
\end{tabular}

Table 9 - Summary of plastic-related aspects and effectiveness of the international instruments ${ }^{596}$

The overview provided in table 9 implies that, in a broader perspective, international law is making progress in those areas. However, if we compare the information displayed in both tables, the results related to the plastic pollution of the oceans is much worse. Two of the hard law instruments that refer to plastics - London Protocol 2006 and MARPOL - do not cover land-based activities, and they face enforcement difficulties. Even with the third one - the Basel Convention -, which starts to look at the plastic pollution, not only are the new provisions not yet into force but also the general assessment of the convention's effectiveness is negative. The one with the best opportunities, the GPA, is soft law and, as such, faces problems with States' willingness and the lack of compliance mechanisms, even though with some good results.

Therefore, the central matter seems to be the necessity of addressing land-based sources of the plastic pollution. In this respect, regional, national and local actions gain prominence.

After the analysis made so far, it can be concluded that international instruments implemented through or with the help of regional actions are the ones showing the best results. ${ }^{597}$ Take, for example, the literature referred to in the topic about Agenda 21. Also, the GPA regional programmes, because although they are still under analysis to conclude on practical results, the regional and local progress

596 This table does not include SDG's, whose outcomes can only be measured after 2030, or, for partial remarks, after a few more years of implementation.

597 Obviously there are regional actions, for example also at the EU level to prevent emission of wastes into the waters. See in that respect, e.g.: Romph and Calster (2018). However, given the focus on international law instruments, EU law is beyond the reach of this research. 
went much faster than globally. The example of SDGs is an additional nice example of some possibilities of progress at this level. Finally,

one alternative [to either a top-down or bottom-up approach] could be a development strategy building on horizontal collaboration between actors and organizations. Collaboration can take place in the form of networks, innovation systems, partnerships, clusters or Triple Helix, where the aim is to achieve something that participants cannot do individually. ${ }^{598}$

Such an alternative is more likely to be achieved at regional and local levels, where the transaction costs for the parties involved are significantly lower, never excluding, of course, the possibility of an international framework.

The need to approach the land-based sources, combined with the good results that literature indicates to regional programmes, brings a glance toward a differentiated approach to face the ex ante edge of the plastic pollution of the oceans. Therefore, we must come to balanced conclusions with respect to the effectiveness of the current international legal instruments as well as the need to employ other instruments. The current hard law instruments, do not appear very effective and most of them do not explicitly address the prevention of plastic pollution. Some soft law instruments do, and especially when they act through regional initiatives seem to have been most effective. However, although the plastic pollution is by nature undoubtedly a transboundary problem, which would necessitate a remedy via international law, it is not necessary to plead in favor of yet another international law instrument aiming at the prevention of plastic pollution. The feasibility of such a new instrument coming into being is relatively small and, moreover, actions to prevent the plastic soup have necessarily to be taken together with actions at the domestic level, as indicated before that $80 \%$ of the pollution of the oceans is land-based. The current international legal framework should therefore be considered in combination with solutions at the regional and domestic levels. In addition, solutions based on corporate social responsibility of the plastic producers could also stimulate the reduction and recycling of plastic and, therefore, preventing them from ending up in the oceans.

Before addressing those possible interactions with private initiatives, it is important to look back and try to understand the lessons learned that may help facing the plastic pollution of the oceans.

\subsubsection{Lessons Learned from the Public International Instruments and the Need for a Mixed Approach}

In what concerns the public international law, the main lessons to be learned concern the paths to be chosen, being them globalized, regionalized or localized, would have to consider the importance of some of the aspects indicated in Table 9. A cross-reference between the general effectiveness of each instrument and its respective weaknesses and strengths made it possible to summarize these lessons in seven suggestions, that show the goals of an international regulatory framework to face the plastic soup:

1. addressing all sources of plastic pollution and the connection between terrestrial, freshwater, coastal and marine ecosystems;

2. the need to establish guidelines, targets and indicators, helping the goals to become more specific and more easily evaluated;

3. foreseeing the possibility of reviewing and of compliance mechanisms;

4. strengthening technical, scientific and financial resources;

5. clarifying economic impacts - and mainly gains - of the changes involved in adopting the instrument;

6. gathering and interpreting data and information;

7. enabling the involvement of companies and NGO's for inputs in the decision-making process. 
As highlighted before, and summarized in suggestion number 7, a mixed approach within public and private solutions is to be stimulated. Firstly, for attempting to bring together the positive aspects of each perspective, and to ease the negative aspects and obstacles of each perspective. Secondly, for helping with the issue of information asymmetry, which is an important obstacle especially for governments and civil society.

Regarding the first aspect, of mixed different instruments to potentialize action, it has already pointed to the central role of States in setting goals and priorities, of civil society, especially through NGO's, in mediating interests and expanding research and pressure, and of companies in innovating and leading informed changes.

This relates directly to the second aspect, concerning the information asymmetry. ${ }^{599}$ In the case of social and environmental impacts of plastic production, especially regarding the numbers and technologies involved, the asymmetry causes unbalances that may not be corrected by the mechanism of voluntary exchange. ${ }^{600}$

From the public interest approach, such a market failure could be solved through public regulation. The two aspects related to plastics in that case ask for different regulation approaches: (i) for corporate governance, those would be within regulatory and governance strategies; (ii) for products, those would be quality regulation.

Quality regulation, in its turn, also has different forms. With information regulation, the goal is: (i) to prohibit false and misleading information; and/or (ii) enforce mandatory disclosure of information; and/or (iii) create a certification. With quality standards, there are three different kinds: (i) target standards; (ii) performance standards; (iii) specification standards. Finally, with licensing, the aim is to exclude from the market products or services which do not comply with minimum standards. From the public interest perspective, the main arguments relate to information costs. Not only "the granting of product licenses may play an important role in reducing information costs in certain circumstances", ${ }^{601}$ but also, for products that may generate huge externalities and that "involve considerable technological complexity, the information necessary to determine their quality may be secured and assimilated more cheaply by a centralized agency". ${ }^{602}$ Moreover, under some circumstances, the elapsed time between marketing and the harmful consequences may be so lengthy, as is the case with plastic, that other regulatory techniques, usually ex post, have their effectiveness substantially reduced.

Shavell's criteria ${ }^{603}$ for regulation may come to help understanding of how to address information asymmetry. In the case of the plastic pollution in the international scenario, there are two main possibilities regarding the knowledge distribution between parties: either private parties possess superior knowledge than the regulator, or neither the regulator nor private parties possess enough knowledge.

When the case is that the private parties possess superior knowledge than the regulator,

then to vest in the regulator the power of control would create a great chance of error. If the regulator overestimates the potential for harm, its standard will be too stringent, and the same will be the case if it underestimates the value of the activity

599 A market failure of "imbalance of information between parties to an exchange, one so severe that exchange is impeded" Cooter and Ulen (2016, p. 41). And "law can be understood as a response to imperfect and costly information on the part of decision makers". Miceli (2004, p. 16).

600 E.g., warranty. See: Cooter and Ulen (2016, p. 41-42).

601 Ogus, 2004, Kindle pos. 6737.

602 Ogus, 2004, Kindle pos. 6748.

603 See Shavell (1984). 
or the cost of reducing risk. If the regulator makes the reverse mistakes, moreover, it will announce standards that are lax. ${ }^{604}$

Therefore, for such a situation, liability rules could come up with better results. Especially strict liability, since the obligation to pay regardless of negligence motivates to "balance the true costs of reducing risks against the expected savings in losses caused". ${ }^{605}$ However, there is not even a need to analyze the other kinds of liability, because such an approach may only be effective if the possibilities exist to bring companies to court and if companies are capable of paying the harm. In the international context, corporations are usually expected to be able to pay for damage, however, they are not subjects under the international law, which makes it impossible to bring them to court. In other words, liability may be a solution when incentivized locally, but not purely internationally.

When the case is that neither private parties nor regulators possess enough knowledge, it is in everybody's interest to acquire better information. Those making profit only do not have perfect knowledge of their own business when it is too costly to obtain.

\begin{abstract}
In these contexts a regulator might obtain information by committing social resources to the task, while private parties would have an insufficient incentive to do this for familiar reasons: A party who generates information will be unable to capture its full value if others can learn of the information without paying for it. For parties to undertake individually to acquire information might result in wasteful, duplicative expenditure, and a cooperative venture by parties might be stymied by the usual problems of inducing all to lend their support. Continuing, once a regulator obtains information, it may find the information difficult to communicate to private parties because of its technical nature or because the parties are hard to identify or are too numerous. ${ }^{606}$
\end{abstract}

This means that both private parties and regulators not only have interests in acquiring the knowledge but also lack the motivation to do so on their own. It points, again, in the direction of the need for cooperation between international players.

Since self-regulation is a part of the solution, some aspects must be taken into consideration. Despite the historical dominance of command-and-control regulation, there has been an increase of attention in market-based and incentive-based instruments, ${ }^{607}$ which can be explained for many reasons. Revesz and Stavins ${ }^{608}$ list six important ones: (i) ideological (political) grounds, including an increase in adhesion of the political center to market-based instruments; (ii) increased pollution control costs; (iii) support from some segments of the environmental community; (iv) the examples of SO2 allowance and CFC phaseout were meant to reduce emissions, not simply reallocate, and the market-based instruments "are most likely to be politically acceptable when proposed to achieve environmental improvements that would not otherwise be feasible (politically or economically)" ${ }^{\prime 609}$; (v) separation of ends and means; (vi) lack of continuation in initiatives from the public sector. Although those were researched in the United States of America, there is a similarity to the international scenario, where we are moving towards a consensus among environmental economists that threats to the environment in that context may be faced with high success and modest costs through a market-based program, ${ }^{610}$ and

604 Shavell (1984, p. 359).

605 Shavell (1984, p. 359).

606 Shavell (1984, p. 360).

607 Revesz and Stavins (2004, p. 558-560 and 562).

608 Revesz and Stavins (2004, p. 562-563).

609 Revesz and Stavins (2004, p. 563).

610 Krugman $(2015$, p. 164). The author is referring to climate change, but the essencial aspects to conclude on both climate change and the plastic soup are the same. Mostly, we are dealing with a complex environmental threat, with local causes - and sources difficult to precisely identify - but international implications. 
where globalization may have a positive influence on pressuring firms in low-regulation countries to join self-regulation efforts. ${ }^{611}$

Considering that public regulation significantly affects the implementation efficiency of selfregulation inside companies, ${ }^{612}$ it is particularly important to identify factors that lead market-based solutions to be advisable. Miller's arguments in favor of self-regulation align with the ones discussed in this thesis. Self-regulation has the theoretical advantages of: (i) superior knowledge or better conditions to obtain knowledge; (ii) being more flexible and, thus, more open to innovation and changes; (iii) possibility of lower costs or of sharing the burden of costs within the market. ${ }^{613}$ Of course, some caution is also needed, such as attention to public interests and the democratic legitimacy of decision-making.

\subsubsection{Lessons Learned from the Private Initiatives and the Need for a Mixed Approach}

The contributions of the present research are to direct which lessons can be learned from the private actions that are starting related to plastics or that are already being developed in other sustainable issues. Similar to the reasoning regarding the public international instruments, those lessons were learned from the four case studies presented in chapter 5 .

For instance, the Dutch deals indicate that it is necessary to build trust between governments, companies, and civil society, enhancing their respective roles. More than that, this example, together with the example of the New Plastics Economy and its Pacts, shows that scalability is one of the positive aspects of such an approach, including in the international scenario.

Market solutions are especially important to assist in companies' engagement which includes shareholders. Life Cycle Assessment, labeling, certification, and experiences like the Dow Jones Sustainability Indices are potential approaches that still need to include the plastics issues.

All those possibilities are applicable to the three stages of the ex ante perspective: production, consumption, and final destination. Nonetheless, there are some particularities regarding the production stage to consider also.

Faure and Dalhammar ${ }^{614}$ identified some of the synergies and contradictions between product policies and derived some principles for how to create a policy framework to address product life cycle. Regarding the synergies, they summarize: ${ }^{615}$

- The bans and restrictions on chemicals in products improve recycling practices, at least in the long run [...], as both the health and safety of recycling workers and the recyclability potential of the materials are improved. This means that rules on chemicals generally support EPR [extended producer responsibility] rules.

- Ecodesign rules that increase product life span, or improve product durability, can aid product reparability and remanufacturing practices. This is because products that are of higher quality tend to be easier to repair and remanufacture. ${ }^{616}$

- The existence of various labels, certification schemes and voluntary industry schemes can aid public procurement of green products: criteria in eco-labeling are important sources of information when public procurers start to apply

611 Christmann and Taylor (2001).

${ }_{612}$ Short and Toffel (2010).

613 Miller (1985, p. 897-898).

614 Faure and Dalhammar (2018).

615 Faure and Dalhammar (2018, p. 65).

616 Westblom (2015). 
sustainability criteria for new product groups, and labeling schemes can also be used to provide evidence of compliance. ${ }^{617}$

$[\ldots]$

The contradictions, on the other hand, are: ${ }^{618}$

- It is crucial that mandatory requirements (MEPS) are coordinated with standards applied in labeling and procurement. For instance, if requirements in ecolabeling are not updated often enough, a product may apply an eco-label though it barely complies with mandatory standards $[\ldots]$

- While rules on chemicals in products improve recycling in the long run, they may impede the use of recycled materials in the short run. This can happen if for example manufacturers are reluctant to use recycled materials in new products out of fear that this reuse may breach regulations concerning chemical compounds. ${ }^{619}[\ldots]$

- There is also a danger that in particular legal systems government public procurement (GPP) criteria may exclude remanufactured products. This raises a specific problem. As such, public procurement of remanufactured goods, such as for example furniture, may be socially and economically desirable as it promotes the reuse and recycling of particular products. However, a recent study from Sweden showed how GPP criteria can exclude remanufactured furniture. This is because there may not be information available for remanufactured furniture on GPP criteria related to chemicals and other aspects; while this information is available for new furniture.

- Some criteria applied in public procurement may de facto make it extremely difficult for competitors across the border to compete. If that is the case those restrictions could obviously affect the functioning of the internal market, and thus reduce competition. ${ }^{620}[\ldots]$

- There are indications that when public procurers use eco-label criteria as the basis for GPP criteria, this is not always done in an appropriate way. One example concerns when procurers 'cherry pick' GPP criteria from many different schemes (different eco-labels, TCO labeling ${ }^{621}$ etc.), without clearly communicating what the basis is for particular criteria. Given that producers will have incentives to comply with the specific criteria this may lead to heavy administrative burdens and therefore to increased transaction costs. ${ }^{622}$

Those considerations raise the important concept of public procurement. They point out that marketbased instruments increase the possibilities of a more efficient use of public money, with higher standards of conduct and when purchasing goods, services, and works. Considering that public procurements account for "an average of 12 percent of gross domestic product (GDP) in OECD countries, and up to 30 percent of GDP in many developing countries", ${ }^{623}$ it does not come as surprise that GPP is already being used as a means to foster sustainability and environmental protection. The so called Green Public Procurement - or Sustainable Public Procurement (SPP) - uses environmental criteria for contracts and biddings. In some cases, the setting of such criteria need at least some kind of justification related to requirements and their importance from an environmental point of view to the

617 Leire and Dalhammar (2018).

618 Faure and Dalhammar (2018, p. 65).

619 Tojo and Thidell (2018).

620 Dalhammar and Leire (2017).

621 TCO Certified (2019).

622 Dalhammar and Leire (2017).

623 UN Environment (2017, p. VIII). 
contract in question. ${ }^{624}$ Also, questions arise if environmentally driven criteria may unlawfully direct biddings, since "public procurement should be performed in a non-discriminatory and transparent manner that gives rise to undistorted competition, thus allowing administration to obtain best value for money". ${ }^{625}$

Despite those and others divergences that may rise, the interconnection between sustainable policies and public procurement in national contexts is straightforward. In the international scenario it may seem not that direct, but there are already initiatives to this regard. The international acknowledgment that "procurements processes that consider social, economic and environmental factors are able to drive sustainability along value chains" ${ }^{26}$ came with the SDG's, under the provision of target 12.7. This aligns with the international principles of sustainable development, proportionality, and transparency. ${ }^{627}$ Therefore, including sustainable behavior regarding plastic use as one of the criteria could be a way of complying with international law.

Another aspect, that will be discussed in the next topic and that relates to the production side, is taxation. Although a Pigouvian $\operatorname{tax}^{628}$ is primarily a solution applied ex post, it relates to the impacts it may or it may not cause in the prevention stage. This happens because taxation functions are two-fold: (i) revenue generating; (ii) providing incentives aimed at preventing pollution. Both effects are needed in the case of the plastic soup, making taxation an attractive solution. When applied to the international context, it has the benefit of aligning with Principle 16 of the Rio Declaration. ${ }^{629}$ However, it also raises the challenge of the absence of an authority with the competence and/or jurisdiction to enforce or even create such a norm. Funding, on the other hand, serves similar purposes, however with less deterrent effect, and may be used internationally.

We also need to go back to the five reasons stated in chapter 5 regarding why companies would engage in fighting the plastic pollution in the oceans, and the respective joint possibilities with governments and civil society.

Reason number one was good public relations. This can be related to the production stage in more than one way. The main one being that more sustainable production techniques can be translated to common language for marketing purposes. Since we saw that packaging is a great part of the plastic problem, this may be easily communicated by the product itself, depending on the case. It is important to remember that, then, it was concluded that the role of government and civil society to that is to help preventing green and blue-washing.

Reason number two was attracting investments. Its relation is primarily with the production stage. Investments may go, for example, to production itself or to technology development. Both options could help in innovating to prevent further plastic pollution in the oceans. It is important to remember that many of the changes essential to effective movements towards such a goal are either non-existent or small in range. To change either one of them, there is a need for investments.

Reasons number three and four are related to being the leader, rather than the follower. When this thought is applied to production, it gains an even broader dimension, since the hypothesis of being forcedly (by regulation, for example) shifted into a new production way may be particularly costly. Once again, attention is drawn to the importance of preventing rent-seeking. In a public choice analysis, in which regulation is considered as the product in a political market of supply and demand, the demand part is constituted by several interest groups and the supply part is constituted by politicians who want the support of those groups. The wealth transfer (or rent) will happen if

\footnotetext{
624 Palmujoki, Parikka-Alhola, and Ekroos (2010, p. 261).

625 Weishaar (2013, p. 2).

626 UN Environment (2017, p. V).

627 Palmujoki, Parikka-Alhola, and Ekroos (2010, p. 251).

628 A kind of taxation that aims to correct a negative externality by charging it to the causer. It will be further explained and discussed on topic 6.1.2.2(c).

629 United Nations (1992, Principle 16).
} 


\begin{abstract}
the transactions costs for the group of bringing together individuals to defend a common interest are relatively small and if the information costs incurred by the public at large in discovering the rent-seeking behaviour are relatively high. These conditions for rent-seeking may often be met in cases of environmental regulation. The fact that a transfer to an interest group has taken place will often be disguised by arguing that environmental protection or victim protection is provided by the particular piece of legislation. Transactions costs are often low if only a few firms come together to defend a common interest. ${ }^{630}$
\end{abstract}

In other words, although companies' involvement and even influence is desirable as a means of obtaining information and achieving faster results, especially in the production edge, this should happen in a way that regulation does not become a bargaining object between politicians looking for votes and companies looking to loosen regulation.

Reason number five is achieving financial benefits or incentives. Those are very common in the production stage, especially through tax reductions or exemptions for products considered sustainable.

When any initiative is taken, Scheltema's eleven indicators explained in chapter 5 may always assist on assessing the potential effectiveness of planned actions.

The good public relations mentioned in reason number one also relate directly to the consumption stage of the problem. More sustainable options together with more transparent communication may lead to better consumer choices.

The third and last stage of the ex ante perspective, final destination, includes all actions that enable closing the loop, towards a circular economy. Those are, naturally, the technical solutions for reusing and recycling, for example, but, from a policy perspective, it is mainly the action from companies and governments that makes it possible for consumers to give the appropriate destination for products after using

\title{
6.1.2 Ex post Perspective: Perceptions and Lessons Learned
}

Beginning with the public international law, it has already been demonstrated that most of the solutions that can currently be found in both international hard and soft law instruments focus on preventing plastics from ending up in the oceans. That obviously is important, given the old saying that "prevention is better than cure". However, it was equally indicated that those solutions are yet far from perfect and the plastic pollution of the oceans continues to increase. Moreover, even if (hypothetically) the emission of plastics into the ocean could be stopped, there would still be an enormous plastic soup that is currently polluting the oceans. This question, how from an ex post perspective, the current pollution could be cured is not addressed in either of the legal and policy instruments we have discussed so far. The question arises of to what extent a legal solution is necessary or indicated to facilitate technical solutions. In order to contribute to that debate, there will first be a review of the possible technical solutions to the plastic soup, building upon the overview provided in chapter 2. It will establish that there are specific impediments that may restrict the implementation of those technical solutions. The question of whether legal instruments are needed to stimulate the implementation of those technical solutions will then be analyzed using a law and economics approach. The final subsection summarizes the findings with respect to the question of whether a legal solution is needed to implement the technical solutions.

As seen, there are still no solutions coming from the private sector regarding the recovery of plastics from international waters. Therefore, no initiatives can be used for the purpose of lessons learned and

630 Faure, Peeters, and Wibisana (2006, p. 250). 
building solutions. Private actors are, however, again an important part of the solution, and are thus included in the analysis and suggestions.

\subsubsection{Technical Solutions}

I will first review the status of implementation of the technical solutions that were discussed in section chapter 2. To the extent that those technical solutions have not been implemented yet, the question arises of what are the causes of that specific failure.

Going back to the proposed technical solutions, regarding the ex post perspective, the existing solutions are the two bacteria capable of decomposing PET - one discovered in nature, the other one genetically modified to do so -, and the initiative from The Ocean Clean Up. As mentioned in the overview of the plastic pollution problem, ${ }^{631}$ it cannot describe every single initiative around the world, but the ones selected are capable of representing the different available formats. In other words, leaving aside some initiatives that have the same nature and, thus, face the same challenges, does not influence the results here discussed.

Firstly, I analyze the two possibilities using the bacteria that eat plastics. They are, however, very recent. Their presentation to the academic world only happened at the end of 2017, which makes it very complex to assess the status of implementation. It is too soon to affirm if it is not being used because it will be in a near future or because there are no perspectives to do so. From this, one can only estimate what challenges could arise. One challenge is that obviously an innovation would need the protection of intellectual property rights. Assuming that a patent can be granted to the inventor that should, in light of the economics of patents, provide sufficient incentives to invest in research and development. Marketing the patent provides a monopoly right which would allow the inventor to recover the initial costs of research and development. That is the well-known law and economics theory of patents. The question is not so much whether the patent protection can protect adequately inventors against potential free-riding and thus generate sufficient incentives for innovation. A more important question is probably whether the invention could be marketed in such a way that sufficient funds could be generated to recover the initial costs.

Another solution discussed previously was provided by the Ocean Clean-Up, an NGO which would, to put it shortly, clean up the ocean on a voluntary basis. Also that solution has particular challenges. According to the information on the organization's website, everything is progressing as planned. Not only is funding not a concern, but they would be, alone, able to implement the system on a global scale - meaning the five gyres - by 2020 , and reduce plastics in the oceans to close to zero by 2050 . This is almost too good to be true. Recall that the data mentioned in chapter 2 show a minimum amount of plastics of 8 million tons leaking into the ocean each year. The question therefore arises whether the expectation that the Ocean Clean-Up would be able to remove all plastics by 2050 is not the result of some over-optimism. The concern is even more relevant if it is considered that only in late 2019 they seemed to have the first working prototype in the North Pacific. The website does not make precisely clear how this amazing result would be achieved; there is some reason to believe that this positive presentation may also be related to the desire to acquire sponsoring for the initiative.

The way the initiative is presented, it seems that voluntary clean-up could provide this solution. The organization does not mention specific obstacles. That does not mean, however, that there are no lessons related to difficulties that may be faced by non-profit organizations engaging in cleaning the oceans. The NGO was supported in different ways by the Dutch government, at different occasions. ${ }^{632}$ The government inter alia supported the foundation in obtaining the research permits necessary to conduct the studies in the seas and beaches that were under the sovereignty of foreign countries. The government also supported the NGO by providing the Dutch "flag" to the cleaning system, thus

\footnotetext{
631 Presented supra in 2.4 .
}

632 Passenier (2018). 
equating it to a Dutch seagoing vessel. ${ }^{633}$ Still, the major challenge faced by the NGO was again a financial one. This can be derived from the milestones described by The Ocean Clean Up, ${ }^{634}$ which follow also from the situation with other organizations, such as The Great Bubble Barrier. ${ }^{635}$

For the Ocean Cleanup, a great part of the funding came from a very successful crowdfunding, which collected 2.2 million dollars. Nowadays, the foundation counts several partnerships such as Akzo Nobel, Deloitte, the government of the Netherlands, etc. For the Great Bubble Barrier, it is still the main challenge. As at July $11^{\text {th }}$, 2018, its crowdfunding campaign raised 53,753 euros, while they needed 25,000 to build a scale model for demonstrations, 50,000 to build a bubble barrier without a catchment system, and 100,000 to build a fully functioning bubble barrier. ${ }^{636}$

A striking feature is that so far there are only non-profit organizations which are active in the ex post clean-up of the oceans. Corporations at best match the activities of NGOs. That raises the interesting question of why so far corporations have not more actively engaged in the clean-up of the plastic pollution. ${ }^{637}$ The most logical answer is that there is no profitable market, especially because companies claim that recovery is still too costive ${ }^{638}$ But there may be other impediments as well. Those findings, therefore, call for an economic approach to the plastic soup problem, examining whether it would be possible to create sufficient financial incentives for the cleaning up of the plastic pollution from the ocean.

\subsubsection{A Law and Economics Approach}

The starting point for analyzing the plastic soup from an economic perspective should be that the plastic pollution in the oceans is not just a huge environmental and social problem, but that it also constitutes an economic waste. Firstly, from a social perspective, since "the economic costs of marine litter are often borne by those affected rather than those responsible for the problem". ${ }^{639}$ In that sense, there are the millions lost in fishing and tourism revenue, and the cleaning costs for governments and

633 Hoogland (2018). The full text of the agreement (in Dutch and English) is available at: https://zoek.officielebekend makingen.nl/stcrt-2018-31907.html\#d17e790.

634 Since the crowdfunding is an important one. See more: The Ocean Cleanup (2017c).

635 Although it is not an innovation to clean the oceans, but to prevent plastics from inner waters to end up in the oceans, it serves the purpose to illustrate the initial difficulty of new ideas through non-profit organizations to raise money.

636 The Great Bubble Barrier (2018).

637 There are only a few incipient activities, and all of them not yet of recovering from international waters, such as:

- Adidas, in partnership with Parley, is producing and selling shoes made from recovered plastics. From November 15, 2016, to March 15, 2018, they sold one million pairs, while their financial performance is continuously increasing. The same partnership is producing jerseys out of recovered plastics, which are already being used by Real Madrid and Bayern Munchen. See: Climate Action (2018); Dreizen (2017); Stylo Urbano (2018).

- Procter \& Gamble, after initiatives focusing on recycling plastics, is releasing (April 2018) a limited edition of Head and Shoulder's bottles produced from recovered plastics. Technical aspects bring a future environmental concern, however. Because of the color of the new plastics, they add black pigments, making the recycling of those bottles virtually impossible. Combining their solution with the new pigment mentioned in the section about the existing technical solutions could come as an alternative, in my perspective. P\&G has also launched (October 2017) a 100\% recycled bottle, being $10 \%$ of plastics recovered from oceans, and $90 \%$ from post-consumer recycled plastics. See: Dreizen (2017).

- "Dell, which is using $25 \%$ ocean plastic in its $100 \%$ post-consumer recycled content laptop trays, stress that this is a deliberate aspect to their sustainability initiatives". See: Dreizen (2017). Those initiatives, however, use plastics from bottles recovered from beaches, not the high seas, which shows that they are actually not still dealing with the core of the problem addressed by this thesis.

639 Surfrider Foundation \& UCLA’s Frank G. Wells Environmental Law Clinic (2013, p. 4). 
communities, which in the United States alone, for example, are estimated in 10.8 billion dollars per year - and that's only for coastal areas, since the plastic soup is not being addressed yet. ${ }^{640}$

Therefore, it is a negative externality that, as a market failure, not only needs to be corrected but it is economically interesting to be corrected. A UNEP report ${ }^{641}$ from 2014 estimates a total natural capital cost of 110 billion dollars per year in services and products, and that does not even include microplastics or impacts by plastic-in-supply-chain, because of a lack of information. This same report also highlights that, in the long term, companies that spontaneously take those costs into account are more efficient and have higher values in the market. Besides, there is also the loss of a potential feedstock and, consequently, of a potential new market, which could be a source of more profits for companies.

Nevertheless, the activity is not yet being conducted. The profitability of an economic activity usually provides enough incentives to create a new market, unless there are barriers to market entry or market failures. "In general, such barriers can arise from two sources: first, from statutory and other legal restrictions on entry; and second, from technological conditions of production known as economies of scale". ${ }^{642}$

Regarding the first barrier, the question arises whether the lack of regulation of the plastic soup in the high seas would constitute a barrier to undertake action. The answer to that question is not so clear. One could argue that the waste that has been disposed of is a so-called res nullius, to which no one claims any particular property rights, and as a result of which no one could also object when someone takes the initiative to clean up the waste. Yet, it may be that the uncertainty concerning the legal status could precisely also be a barrier to take action. Whether that is actually the case is simply not known.

Regarding the second barrier, economies of scale, this refers to "a condition of production in which the greater the level of output, the lower the average cost of production" ${ }^{643}$ However, there is no data available to allow the conclusion that this is the case with the recovery of plastic from the oceans. It is, of course, a possibility, but that will have to be left to future research.

There are several ways in which the plastic soup problem could be approached from an economic perspective. A first possible approach is to consider the plastic as an asset with a positive economic value. From an economic perspective the plastic could then be considered as non-excludable and rivalrous goods. The costs of excluding the use of non-paying consumers would be too high and at the same time consumption by one may exclude the consumption by others.

a) Creating property rights?

This is a framework economically defined as the tragedy of the commons. ${ }^{644}$ The tragedy of the commons basically emerges because of the absence of property rights and a case of open access to a

640 Surfrider Foundation \& UCLA’s Frank G. Wells Environmental Law Clinic (2013).

641 United Nations Environment Program - UNEP (2014, p. 28-29).

642 Cooter and Ulen (2016, p. 29).

643 Cooter and Ulen (2016, p. 29).

644 "The tragedy of the commons develops in this way. Picture a pasture open to all. It is to be expected that each herdsman will try to keep as many cattle as possible on the commons. Such an arrangement may work reasonably satisfactorily for centuries because tribal wars, poaching, and disease keep the numbers of both man and beast well below the carrying capacity of the land. Finally, however, comes the day of reckoning, that is, the day when the long-desired goal of social stability becomes a reality. At this point, the inherent logic of the commons remorselessly generates tragedy. As a rational being, each herdsman seeks to maximize his gain. Explicitly or implicitly, more or less consciously, he asks, 'What is the utility to me of adding one more animal to my herd?' This utility has one negative and one positive component. 1) The positive component is a function of the increment of one animal. Since the herdsman receives all the proceeds from the sale of the additional animal, the positive utility is nearly +1.2 ) The negative component is a function of the additional overgrazing created by one more animal. Since, however, the effects of overgrazing are shared by all the herdsmen, the negative utility for any particular decision making herdsman is only a fraction of -1 . Adding together the component partial utilities, the rational herdsman 
resource. The problem with an open access resource is that everyone could, in theory, take for example resources from the ocean. To the extent that those assets are valuable, an open access resource will easily become subject to overharvesting. Pure open access would therefore lead to a depletion of the species. ${ }^{645}$ Under the open access regime, private ownership is simply established by the person who takes first access. The first mover advantage will in practice lead to a race whereby all try to harvest as much as possible, and as quickly as possible from the resource in order to avoid others doing so. Empirical evidence showed that this has for example led to over-exploitation of surf clams: in order to increase the catch, clam fishermen invested too much in equipment in order to be able to harvest clams rapidly. ${ }^{646}$ Also in oil extraction there has been a tendency to over-capitalize in order to pump more quickly since ownership rights are only attached upon extraction, not upon discovery. ${ }^{647}$ These examples (and of course over-fishing could easily be added) show that without rules regulating the use of those common resources (like forests or the oceans) extinction may be the result. Thus this underscores the importance for society of developing mechanisms that allow an exclusive control of such a resource, i.e. vesting property rights.

The question arises of to what extent this scenario is applicable to the plastic soup. If plastic indeed had an economic value, one could suppose that the first movers in this open access regime would indeed have come in to recover the plastic. However, such an over-harvesting is not what can be observed. But the problem may be a related one. The problem may be that the absence of legal clarity with respect to the legal status of the plastic would inhibit private actors from engaging in this new market. ${ }^{648} \mathrm{~A}$ first conclusion is therefore that to the extent that a market solution to remove the plastic in the ocean is not emerging yet due to legal uncertainty, regulation may be necessary to clarify the legal status of the plastic in order to create the opportunities for the market to emerge. Yet, this suggestion is formulated with some caution as it is not certain that it is really legal uncertainty which inhibits commercial parties from removing the plastic.

b) Application of the Coase theorem?

To the extent that a positive economic value of the plastic cannot be established, the plastic pollution of the oceans remains a negative externality. The traditional starting point to analyze negative externalities provided in Law and Economics is the application of the so-called Coase theorem. ${ }^{649}$

The Coase Theorem originally designed that "it is always possible to modify by transactions on the market the initial legal delimitation of rights. And, of course, if such market transactions are costless, such a rearrangement of rights will always take place if it would lead to an increase in the value of production". ${ }^{650}$ More usually, we would say that if the transaction costs are zero or sufficiently low, negotiation will lead to an efficient allocation of resources, irrespective of the initial distribution of property rights.

However, it has been discussed that in the case of the plastic soup not only is the externality problem not being solved, but it is also increasing. This indicates that the transaction costs are apparently not low enough to allow bargaining. This is natural in an international scenario, including so many countries, organizations, and other actors. This may inhibit efficient bargaining.

concludes that the only sensible course for him to pursue is to add another animal to his herd. And another; and another.... But this is the conclusion reached by each and every rational herdsman sharing a commons. Therein is the tragedy. Each man is locked into a system that compels him to increase his herd without limit-in a world that is limited. Ruin is the destination toward which all men rush, each pursuing his own best interest in a society that believes in the freedom of the commons. Freedom in a commons brings ruin to all”. Hardin (1968, p. 1243-1248).

645 Faure and Skogh (2003, p. 40).

646 Litz (1994, p. 335).

647 Libecap and Wiggins (1994, p. 87).

648 Financial aspects could also be an explanation, but I already addressed this issue previously. Furthermore, specifically regarding corporations, investments usually are enhanced when there is legal certainty.

649 Coase (1960).

650 Coase (1960, p. 15). 
The major problem inhibiting efficient bargaining can be related to the fact that the stakeholders involved are not clearly identified. As long as property rights over the plastic are not clear, even if for example one company would like to take the plastic, it is not clear at all with whom he would have to bargain to obtain the plastic. More likely we are again in the hypothesis where there is an absence of property rights and hence open access as discussed in the previous subsection. The plastic soup is also not a classic coasean bargaining situation as there are no clearly identifiable victims who could negotiate with either the polluters (who would in most cases not be identifiable) or with the corporation who might offer a solution.

\section{c) Taxation?}

If transaction costs remain prohibitive, the classic response to externalities is the Pigouvian tax. Originally discussed by Pigou, ${ }^{651}$ the idea of such taxation is precisely to correct a negative externality by charging it to the causer - in this case, the polluter.

Before applying the idea to the specific situation of the plastic pollution of the oceans, I should clarify why the main criticism to taxation would not apply in this case. Such criticism comes from Carlton and Loury's conclusion that, in the long run, a Pigouvian Tax "will not in general lead to an efficient allocation of resources". ${ }^{652} \mathrm{We}$ can even leave aside their suggestions and the discussions with Kohn ${ }^{653}$ because at this moment, the concern with the plastic pollution of the oceans is to raise money to start the cleaning. Thus, the discussion of the long term is, of course, important, but does not apply to the present moment or concerns. Moreover, the discussion on the efficiency of the Pigouvian Tax is also related to the impacts it may or may not cause from the ex ante perspective. Indeed, taxation has two functions: the one is revenue generating; the other is that it precisely provides incentives aimed at preventing pollution. Both effects would be needed in the case of the plastic soup, making taxation potentially an ideal solution. In addition, such a solution would be coherent with the polluter-pays principle, as provided by article 16 of the Rio Declaration. ${ }^{654}$

Moving, then, to the application of this kind of taxation to the problem, we need to assess if it is possible to identify the polluters that would be responsible for paying, and if there is a regulation format that could enable the creation of the tax. From the discussions about the sources of the plastic pollution and of the companies' role in the process - presented in the overview about the plastic soup -, it is possible to assume that corporations would be a first natural choice to bear the tax burden. However, corporations are not recognized as subjects of international law. ${ }^{655}$ There is also no international authority with competence to establish a tax. Therefore, taxation would have to be imposed by nation states. Theoretically, an international instrument could be created that leads states to create the tax nationally and pass the revenues to an international organization responsible for spending it for the recovery of plastic from the oceans. This or other similar initiatives would, however, face many challenges: discussing and approving an international instrument; determining the organization that would be responsible; selecting the initiatives or institutions that would receive the investments; and so on. We can recall that the largest part of the plastic soup is situated on the high seas and the discussion on UNCLOS taught that it is only the flag state that has jurisdiction on the high seas. ${ }^{656}$ The major problem therefore is that taxation ex post (i.e. on the plastic already in the

651 Pigou (1932).

652 Carlton and Loury (1980, p. 559).

653 Cf: Carlton and Loury (1980, p. 559-566); Kohn (1986, p. 625-630); Carlton and Loury (1986, p. 631634).

654 "National authorities should endeavour to promote the internalization of environmental costs and the use of economic instruments, taking into account the approach that the polluter should, in principle, bear the cost of pollution, with due regard to the public interest and without distorting international trade and investment". United Nationas (1992, Principle 16).

655 There is an ongoing discussion in the literature regarding such status. However, since there is still no consensus, it would prevent a solution going towards an international binding document directly imposing obligations on corporations. See more on that academic debate inter alia in: Alvarez (2011); Duruigbo (2008); Charney (1983); Cassel and Ramasastry (2016).

656 See section .4.2.1. 
ocean) will not be feasible for the simple reason that there may not be any authority with jurisdiction to impose and collect the tax. Taxation could be an instrument addressing the ex ante prevention, but in this case, at the national or regional level.

d) Liability rules?

Another well-known instrument to address negative externalities is the use of liability rules. ${ }^{657}$ However, in an international scenario, it does not seem to be the most effective or even efficient solution, as already somehow addressed in the topic about the ex ante perspective. "The law of international responsibility and liability for environmental harm is a complicated mix of customary law, sparse precedents from arbitral or judicial panels, liability provisions in international agreements, and domestic law". ${ }^{658}$ Furthermore, liability regarding international environmental damage is a field that still needs development, ${ }^{659}$ which means that solutions through this path demand time that the environment does not have.

It would also not be clear how a liability regime could be implemented at the international level. Within the international legal framework, this would imply a liability or responsibility of states for violating primary international law obligations. ${ }^{660}$ To the extent it was already possible to attribute the existing plastic soup problem to the acts of one particular state (which will in most cases be practically impossible) a finding of such a liability would not necessarily result in a clean-up of the already existing plastic soup. The "polluter state" will not necessarily have jurisdiction over the territory where the plastic soup is located and may therefore not have the possibility of engaging in clean-up. Liability could at best be considered as a classic private law remedy under domestic law. Liability could only lead to incentives for prevention and compensation if the plastic soup could be attributed to particular sources, which may often be impossible.

Liability rules are, therefore, not a likely solution.

e) Funding?

An alternative which is to some extent related to the taxation solution is the creation of an international compensation fund. A compensation fund could potentially solve the financial aspect by raising revenues for cleaning up the plastic soup. Depending upon who finances the fund, it could equally contribute to prevention. To the extent that the states finance the fund, it could be created through international law. Since contributions by the states to the fund could be differentiated, for example taking into account GDP, the creation of a fund could equally align with the principle of common and differentiated possibilities as it is described in Principle 7 of the Rio Declaration. ${ }^{661}$

In that sense, some experiences may enlighten the vicissitudes of such a solution. Examples are the Multilateral Fund for the implementation of the Montreal Protocol, the Green Climate Fund, the Climate Investment Funds, the Global Environmental Facility, and the Oil Pollution Compensation Funds.

657 Or responsibility, if the distinction proposed by Kearney were adopted: ““'[T] $]$ he term 'responsibility' should be used only in connection with internationally wrongful acts and that, with reference to the possible injurious consequences arising out of the performance of certain lawful activities, the more suitable term 'liability' should be used". United Nations (1974, p. 211).

658 Percival (2015).

659 Sands and Peel (2012, p. 869).

660 For example, those mentioned in sections 4.2 and 4.3.

661 "States shall co-operate in a spirit of global partnership to conserve, protect and restore the health and integrity of the Earth's ecosystem. In view of the different contributions to global environmental degradation, States have common but differentiated responsibilities. The developed countries acknowledge the responsibility that they bear in the international pursuit of sustainable development in view of the pressures their societies place on the global environment and of the technologies and financial resources they command". United Nations (1992, Principle 7). 
Regarding the first one, many analysis are cautiously optimistic, ${ }^{662}$ but with the caveat that the case of "the stock of ozone-depleting chemicals was technically discoverable and calculable, and substitutes were for the most part already present or on offer" ${ }^{663}$ which is clearly not the case with the plastic pollution. ${ }^{664}$

\subsubsection{Implementation}

The plastic pollution of the oceans is a huge problem, both in quantity and in quality. There may be some solutions to remove the plastic. However, notwithstanding some optimistic voices from NGOs who engage in voluntary clean-up, it is not likely that without financing the existing plastic pollution will be removed. With the use of a law and economics approach, a variety of different legal and policy instruments could be employed to arrange this clean-up. The solutions may depend upon the question whether the plastic could be re-used (and would have an economic value) or the case where the plastic would only be considered to have a negative value and would thus be a negative externality. However, no matter which of these options applies, I made clear that one important impediment to solving the current plastic soup is the absence of any legal regulation. In economic terms, the high seas, but also the plastic pollution in it, are an open access resource. The absence of legal rules specifying the rights to that plastic may inhibit - regardless to which extent - the emergence of a market solution. To the extent that legal uncertainty inhibits this market solution, a legal clarification would thus be needed. This could be provided either by allocating property rights or via regulation. The regulation would ideally both aim at the prevention of plastics further ending up in the oceans and focus on an ex post removal of the plastic currently in the oceans.

The most suited instrument, assuming that the plastic has a negative value, to guarantee its clean-up would be taxation. Taxation could potentially provide incentives and could generate the funds necessary to organize the clean-up. And even if one would not imagine a classic Pigouvian tax on polluters (which could probably not be identified), a similar result (of financing the clean-up) could be solved through the creation of a fund. However, also in that case some regulation is necessary to make clear what the specific status is of the plastic soup and of the cleaning structures in the high seas. This indicates that the search for a solution for the clean-up of the plastic soup not only constitutes of a search for an optimal mix of instruments; the question is equally important at which level of governance solutions would have to be implemented.

No matter which type of solution is preferred (creation of property rights, creation of a fund financed by industry or by states) some rules would have to be put in place to organize a clean-up. As this clean-up would have to take place in the high seas it is obvious that this solution cannot come from domestic law, but must rely on an international approach. One way of solving this is to look for options within existing treaties. A first possibility would be to address the options provided through an amendment of UNCLOS. UNCLOS is a fruitful instrument, since its scope is to set the grounds for jurisdiction in international waters, focusing on solving problems related to sovereignty and jurisdiction issues in international waters. Furthermore, as seen, it already brings provisions related to pollution of the oceans. That is why the first possibility is to use UNCLOS' text and/or tools to start the framework for plastic recovery from the oceans.

It cannot be ignored, however, the hurdles it would imply. The main one being that UNCLOS is already so accepted in the international community to the point of being considered customary law,

662 See, e.g.: Jordan and O'Riordan (1998, p. 171); Raubenheimer and Mcllgorm (2017); Biermann and Simonis (1999); Luken and Grof (2006); Garcia (2014).

663 Jordan and O'Riordan (1998, p. 171-175).

664 Raubenheimer and Mcllgorm had suggested a model based on the Montreal Protocol to address the marine plastic debris problem. However, the conditions that explain the success of the Montreal Protocol (that technical solutions were available as well as substitutes for the ozone depleting substances) unfortunately does not apply to the problem of the plastic soup. Raubenheimer and McIlgorm (2017). 
meaning that alterations in the text are virtually impossible. ${ }^{665}$ Moreover, according to UNCLOS' article 313(2), if any State party objects the amendment, it is considered rejected, increasing the challenge.

From there, the secondary hurdle is derived: even if the amendment passes, it would only bind the States who are parties to the convention, but not necessarily the others, as, for example, the United States of America, because it would not have the status of customary law that most UNCLOS' provisions have. "It is not the written text which contributes towards the customary law, but the instances whereby States apply these rules in a concrete case, or refer to them, or vote upon them, which do so". ${ }^{666}$ Besides, "State practice, in order to give rise to customary law, must be accompanied by opinion juris, i.e., by a belief (or rather a statement) by States that certain conduct is required or permitted by customary law". ${ }^{667}$

Another possibility related to existing instruments is to use the experience of soft law instruments such as the GPA. The GPA so far seems to show positive results and also provides promising options through the so-called IGR's. Once again, using this experience could mean using the Programme itself or starting a new one, based on its text and/or tools, focused solely on plastics. Actually, being optimistic, the GPA is already going in this direction, as we may conclude from the progression of the themes and outcomes of the IGR's.

An alternative is obviously to start all over again and to create a new convention just to solve the plastic soup. However, this is, in my opinion, not feasible. It is simply not very likely that there would be sufficient support among countries to create such a new internationally binding instrument. It may, moreover, take many years before such an instrument could come into existence.

However, as I also indicated previously, as far as the ex ante prevention is concerned, solutions cannot only come from the international level, but equally need implementation in domestic law. For example, the imposition of a tax to stimulate reducing plastic or recycling or an extended producer responsibility imposed upon the producers of plastic, would have to be implemented at the domestic (or regional) level. Although those instruments primarily aim at prevention (reducing emissions of plastics into the oceans) they could potentially also generate finances for cleaning up the current plastic soup.

\subsection{Priorization and Indications for an Appropriate Regulatory Mix}

\subsubsection{How to Prioritize?}

It is very common, especially regarding environmental issues, that "the policies [are] adopted in a rather ad hoc manner when there has been a "policy window" that creates political impetus for new policies; thus, the time sequencing (e.g. the order in which policies are implemented) and the interaction between policies may not be optimal" ${ }^{668}$ The main goal of this thesis is precisely to contribute to international law having a better start in fighting the plastic pollution in the oceans.

The research allows the conclusion that two steps are essential: (i) prioritizing the sources and approaches; and (ii) engaging all actors and potentializing their respective roles, through the lessons learned from the existing environmental initiatives. Always, of course, considering the outcomes of the economic analysis made.

\footnotetext{
665 Pedrozo (2010, p. 164).

666 Villiger (1985, p. 10).

667 Akehurst (1976, p. 47).

668 Faure and Dalhammar (2018, p. 66).
} 
For prioritizing, a previously mentioned Dutch report ${ }^{669}$ comes as a good example, and needs to be more closely analyzed for the purposes of this topic. The Quick Scan and Prioritization of Microplastic Sources and Emissions was elaborated for prioritizing sources and emissions of microplastics, to help the Dutch Government structuring its policy to reduce microplastics in the environment. The aim is precisely to prevent the common pitfall of addressing the matters as they come, in an unstructured way. Thus, it defined microplastics, monitored the microplastic emissions, and prioritized the sources through a multicriteria analysis, to then construct a priority list which enabled the conclusions and recommendations.

For the inventory, a wide range of data previously compiled by other organizations such as the European Union and United Nations was used.

An important aspect in which the report succeeds is that an effective policy needs to consider, simultaneously, relevance, urgency, and feasibility. On those grounds, ${ }^{670}$ the report's methodology uses the following five criteria: ${ }^{671}$

- Relevance:

- volume of the emission

- Feasibility:

- essentiality of the source (are plastics/microplastics indispensable for the relevant product/process/sector?)

- possibility of quick win measures

- Urgency:

- $\quad$ social perception

- presence of alternatives for the consumer.

Those are, however, just the beginning. Prioritization means to order according to the importance of each of the listed activities, and it has to be done systematically. The first step implemented by the report is to attribute scores to each of the criteria, since they are "largely qualitative in nature". ${ }^{672}$ The score is a whole number ranging from 0 to 2 , assigned by the experts to each of the sources, following the guideline: ${ }^{673}$

A) Scale of the emissions: $0=$ Small $1=$ Moderate $2=$ Large.

B) Indispensability: For this criterion, it considered the feasibility of removing or replacing plastics/microplastics with an alternative material or ingredient. $0=$ Replacement or removal of microplastics is not possible. 1 = Replacement or removal of microplastics is only possible to a limited extent. 2 = Replacement or removal of microplastics is possible.

C) Opportunities for quick wins: Opportunities for emission reduction or treatment of primary and secondary microplastics. This can relate to technical possibilities as well as to information, education, behavioral change and support for this change. $0=$ No chance of further emission reduction. 1 = Only limited or complicated and expensive methods are available. $2=$ Opportunities for quick wins exist.

D) Public opinion: Public awareness or unrest regarding certain products or sectors is a factor that must be taken into account. A higher score is assigned to products or sectors that gain a great deal of media attention or for which public risk perception is high. $0=$ Not a sensitive social issue. 1 = Not currently a sensitive social issue, but this situation may change. $2=$ A great deal of public attention already exists.

E) Consumer options: If consumers lack information or options to minimize the emission of microplastics, then this can necessitate government action. Options comprise knowledge of the

669 National Institute for Public Health and the Environment (RIVM) (2014).

670 National Institute for Public Health and the Environment (RIVM) (2014, p. 21).

671 National Institute for Public Health and the Environment (RIVM) (2014, p. 4 and p. 21).

672 National Institute for Public Health and the Environment (RIVM) (2014, p. 21).

673 National Institute for Public Health and the Environment (RIVM) (2014, p. 22). 
presence of microplastics in products, the availability of alternative products, possibility to dispose of the microplastics in a way that it does not lead to exposure of the environment. Therefore, the fewer options there are, the higher the priority score. The perspective for action is indicated by the customer/consumer, not by the producer. $0=$ Perspective for action clearly exists. $1=$ Only limited perspective for action exists. $2=$ No perspective for action exists.

More than that, the quantification assigns weighting factors - in fractions - for each criterion, "to designate the degree to which each of the separate criteria contributes to the definitive priority list. The sum total of all of the weighting factors must be $1 " 674$. Such a definition, though, has a political nature, since it serves the purpose of indicating which approaches are considered more important to the administration.

Table 10 and equation 1 , reproduced from the report, ${ }^{675}$ summarize, respectively, the weighting and the final priority score (which is rounded off to the nearest whole number).

\begin{tabular}{|c|c|c|c|c|c|c|}
\hline \multirow[b]{2}{*}{ Subcriterion } & & \multirow[b]{2}{*}{ Standard } & \multicolumn{4}{|c|}{ Alternative weighting } \\
\hline & & & A & B & c & D \\
\hline & Relevance & & & & & \\
\hline \multirow[t]{2}{*}{1} & - Volume of microplastic emissions & $1 / 3$ & $1 / 5$ & $1 / 2$ & $1 / 4$ & $1 / 4$ \\
\hline & Achievability criteria & & & & & \\
\hline 2 & $\begin{array}{l}\text { Are any alternatives to microplastics } \\
\text { available for the relevant } \\
\text { product/process/sector? }\end{array}$ & $1 / 6$ & $1 / 5$ & $1 / 8$ & $1 / 4$ & $1 / 8$ \\
\hline \multirow[t]{2}{*}{3} & $\begin{array}{l}\text { Opportunities for emission } \\
\text { reduction/treatment/quick wins. }\end{array}$ & $1 / 6$ & $1 / 5$ & $1 / 8$ & $1 / 4$ & $1 / 8$ \\
\hline & Urgency & & & & & \\
\hline 4 & $\circ \quad$ Public opinion & $1 / 6$ & $1 / 5$ & $1 / 8$ & $1 / 8$ & $1 / 4$ \\
\hline 5 & $\circ \quad$ Consumer options & $1 / 6$ & $1 / 5$ & $1 / 8$ & $1 / 8$ & $1 / 4$ \\
\hline
\end{tabular}

Table 10 - Weighting factors for determining the contribution of various criteria to the prioritization of sources of microplastics.

$$
\text { Priority score }=5 \times \sum_{i=1}^{5}\left({\text { Weighting } \left.\text { factor }_{i} \times \text { Criterion }_{\text {score }}\right)}\right)
$$

Equation 1 - determining the final score

All of the aspects incorporated by the report may be transposed to the plastics discussion - not only microplastics - and to the international scenario, since they align with the indications brought by this thesis. In the international scenario, however, a sixth criterion must be included: the possibility of acting through international regulation (either public international law or private initiatives). As was indicated earlier, some actions are not feasible through international law, or demand a more intricate set of actions. So, its individual score may be estimated from the findings in the present thesis, using the bullet indications presented next. The weight to it cannot be given similarly to the other criteria, since a relative impossibility to act through international regulation may even make action impossible. This is why the criterion score is used to influence the whole equation. Still, such a theoretical impossibility should not prevent practical attempts to look for new solutions. This is why the score to

674 National Institute for Public Health and the Environment (RIVM) (2014, p. 23).

675 National Institute for Public Health and the Environment (RIVM) (2014, p. 23). 
criterion number six has a different 0.5 scale, from $0.5-2$. The proposal to incorporate such a criterion is summarized in equation 2, also standardized in a scale from $0-10$.

\section{International priority score}

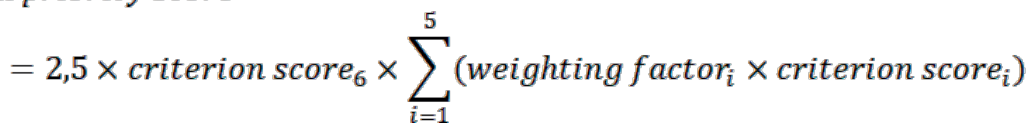

Equation 2 - determining the final international score

The second step, as mentioned, is to adequately score the sixth criterion, by applying the indications derived in this thesis:

- Ability to address different sources of marine pollution and the connection between terrestrial, freshwater, coastal, and marine ecosystem;

- Offer of guidelines to regional and national actors;

- Inclusion of review and compliance mechanisms;

- Inclusion of a checklist of concrete measures, guidelines, targets, indicators, and other measures and evaluation tools;

- Possibility of building strategic plans;

- Relative flexibility and agility to incorporate innovations, and tools to strengthen technical, scientific, and financial resources;

- Incorporation of the proportion between land-based and oceanic activities;

- Ability to address each of the stages of the ex ante perspective and to clean the plastic that is already in the oceans;

- Ability to generate revenue;

- Networking possibilities;

- Transparency mechanisms;

- Forecast of positive and negative economic impacts of the changes involved in adopting the regulation;

- Being based upon, gathering, and interpreting data and information;

- Possibility of upscaling actions;

- Incorporation of other actors than the ones responsible for the regulation, in all of its phases.

It is also important to weight the costs and benefits of the alternatives, to make sure they are not worse than the original problem. This means, for instance, foreseeing side-effects and considering the TWAIL alerts.

\subsubsection{How Different Forms of Regulation Interact in Practice}

This thesis aligns with the recent work that is suggesting that a mixed regulation between public and private initiatives is necessary to adequately address environmental issues. ${ }^{676}$ As stated before, a core step after prioritizing actions to fight the plastic pollution in the oceans, is building a harmonized approach between public regulation and private initiatives.

Neither public regulation is enough for the complexity ${ }^{677}$ of the issue, nor can private initiatives fully replace public policy, although it helps filling the governance gap. ${ }^{678}$ The different regulation forms may coexist in a variety of ways, which may be summarized in three types - complementary, rivalry,

676 Bartley (2011); Haufler (2001); Kolben (2007); Locke et al. (2007); Pessoa (2006); Trubek and Trubek (2007); Utting (2005); Weil (2005).

677 For an analysis of transnational environmental challenges - from the example of climate change - from the perspective of complexity theories and complex systems, see e.g.: Pattberg and Widerber (2019).

678 Lyon et al. (2018, p. 8). 
or transformation, ${ }^{679}$ - all applicable to the problem of the plastic soup. Such a complexity, however, also raises the concern that the smart mix is not so big and diverse that it makes it hard to understand and, consequently, to implement, ${ }^{680}$ since "a policy mix may easily become a policy mess". ${ }^{681}$ Still, "given the complexity and wideness of the whole environmental problem, the ideal of a clear, transparent, and easy to understand legislative package is illusionary". ${ }^{82}$

As a result, the challenge asks for caution on balancing the amount and the diversity of policies. Finding a way on how to make the public and private worlds work together respecting those boundaries is a complicated task, even more in the international scenario, where even pure public regulation involves too many factors.

In sum, transnational environmental governance conjures an image of polycentricity. A diversity of international and domestic laws and regulations operate in parallel with market-based $[\ldots]$ and private actors operate alongside state actors and international organizations. ${ }^{683}$

Therefore, three main aspects may be considered when analyzing or constructing the mix, ${ }^{684}$ which is context-specific. ${ }^{685}$ The first one concerns the level of a public regulation - if national or international, for example. As already clarified, in this thesis the focus is on the international context, naturally considering that it will interact with others, whose specificities are, however, outside of the scope of the research. The second one concerns the forms of regulation - public versus private -, which is the discussion that is in the core of the main research question of this thesis. And closely related to the second, the third one is also addressed by this thesis and concerns the specific policy instruments to be addressed.

Provided there is such a focus on constructing a regulatory mix, understanding the roles of governments and, mainly, of companies in such a context may help visualizing the aspects that are to be placed together. Eberlein, when answering the question of who fills the governance gap, reminds us:

Governments play an indirect, catalytic role, and maintain regulatory share by working through regulatory intermediaries such as the GRI [Global Reporting Initiative]. Corporations play a political, regulatory role, accepting self-regulatory commitments in exchange for organizational benefits including regulatory access. A major organizational studies contribution is that we theorize orchestration from a corporate perspective, identifying mechanisms through which orchestration may reduce barriers to corporate engagement with the public good. ${ }^{686}$

Because of the undeniable importance of companies' political role, some even affirm that "corporate political responsibility', [is] defined as 'a firm's disclosure of its political activities and advocacy of socially and environmentally beneficial public policies ${ }^{\prime 687}$ into CSR metrics. While this definition is debatable, it underscores the need for many more tangible boundaries regarding a political role". ${ }^{688}$ This role of non-state actors is even more perceptible in the added value it brings in the area of transnational problems, in which the ability of states to regulate and enforce norms is often limited. ${ }^{689}$

\footnotetext{
679 Trubek and Trubek (2007, p. 543).

680 Peeters (2014).

681 Sorell and Sijm (2003, p. 434).

682 Peeters and Uylenburg (2014, p. 235).

683 Van Erp et al. (2019a, p. 4).

684 Van Erp et al. (2019a, p. 9).

685 Van Erp et al. (2019b, p. 341).

686 Eberlein (2019, p. 1139).

687 Lyon et al. (2018, p. 8).

688 Eberlein (2019, p. 1139).

689 Van Erp et al. (2019a, p. 10).
} 
Notwithstanding the cautious optimism in this thesis and in other studies about the smart mix and business participation, some say that "even after the financial crisis, most business associations and firms reject a smart mix in favour of voluntarism and soft law without hard sanctions" ${ }^{690}$ This is one of the reasons why this thesis maintains that a hard goal should be established by governments, with a period of adaptation long enough to allow leader companies to act, but short enough to urge for action. The adaptation period would then function similarly to the Dutch deals studied in this thesis. Therefore, in that first moment, the mix would count on more private regulation than public, with a switch in the other direction once the deadline for adaptation is reached.

An important aspect to be kept in mind is that the governments should also use the adaptation period, its tools, and the negotiations, as a means to gather data and information about the sector. This helps to solve the information asymmetry that is a common failure regarding the plastic market. Thus, this also helps to build better public regulations to follow, as well as to prevent green and blue-washing.

As discussed along the thesis, companies would be incentivized to join during the voluntary period to be the leaders and to participate in policy shaping.

This is not to say that it is an easy balance to achieve, but those are good indicators on how to construct the smart mix when the subject is plastic pollution. However, the international context, here analyzed, adds in complexity, since bargaining and follow up during an adaptation period is harder. The question that follows, then, is how to accomplish such an indication for building a mix in international law.

"Economic globalization creates challenges for political steering which exceed the capabilities of any single state. It has produced a growing need (and claim) to make use of the problem-solving potential of non-state actors in order to master these challenges more effectively". ${ }^{691}$ The role of companies and other private actors is, then even stronger in creating a smart mix. A corporation's political activity beyond the domestic has different shapes, mainly because "in global governance, corporations are often insiders, directly involved in crafting public policy, wielding influence based on a combination of expertise, financial clout, global scale and operational capacity". ${ }^{692}$ Similarly, there is also a difference in scale when influencing stakeholders to shape political standards. ${ }^{693}$

This means that the inclusion of companies in the international discussion should come easier, but, at the same time, it means more care should be taken with rent-seeking, as explained in 6.1.1.1. The main difference, though, is probably the establishment of the goals, that in the international context would need to be two-fold. First, among the States themselves, who are subjects of international law. This could be accomplished, for instance, through a soft law instrument - which turns out to be more effective than hard law ones, being indicated for a quicker start.

While research into 'smart' combinations of constellations offers promise, ultimately, under capitalism, barriers to corporate engagement with the public good cannot be removed, they can only be reduced or, pun intended, softened. Soft steering appears particularly well adapted to many global governance issues where traditional state authority is in short supply. At the same time, it accommodates the reality of corporations as self-interested actors pursuing their own political interest. ${ }^{694}$

Second, internally to each country, which only afterwards could show results for the first step. Synthesizing, there are two levels of dialogue in this case.

Another sensitive point when dealing internationally is the potential contradiction between the interests of the global North and those of the global South, which was addressed in chapter 3 . This

690 Kinderman (2016, p. 29).

691 Wolf (2008, p. 255). See also: Scherer and Palazzo (2011).

692 Eberlein (2019, p. 1140).

693 See, e.g.: Oliver and Holzinger (2008, p. 507); Flohr et al. (2010); Banerjee (2014); Eberlein (2019).

694 Eberlein (2019, p. 1140). 
demands care in the international negotiations themselves, using TWAIL, for example. And it demands care with the national implementation of the international goals, when transposing them, since the mix in national regulation should differ, depending on the national conditions. ${ }^{695}$

All four case studies discussed in this thesis - New Plastics Economy, Dutch Deals, Dow Jones Sustainability Index, and reporting initiatives - align with the mix indications stated. However, the New Plastics Economy and the Dow Jones Sustainability Index - as some other reporting initiatives also raise some other issues, since they are part of the mix without interacting with the mix. So, it seems that the motivation for those two is different: it comes from the market. It does not mean, however, that it cannot be used for the same purposes of solving or softening market failures, especially the information asymmetry. They may also serve as a mechanism for gathering data and building better informed policies. Neither are already being used in this manner, denoting an underutilization of the instruments.

Those are, of course, not the only ways to combine instruments in a smart mix. Perhaps, the most important lesson is that every kind of regulation has its positive and negative aspects, and that classic international law is insufficient ${ }^{696}$ to face a challenge such as fighting the plastic pollution in the oceans. Still, answering to an important question when constructing a smart mix ${ }^{697}$ state-led law and initiatives would play a central role in the international plastic policies, with States - mediated by international organizations and through soft law instruments - orchestrating goals and determining the pace necessary to achieve them. Of course orchestrating a mix is not a straight and univocal way. "Feedbacks and unintended consequences (both positive and negative) undermine the linearconsequential ontology of orchestration". ${ }^{698}$ That is the reason why the moment is to start, reevaluating the strategies along the way, to adjust them depending on the feedbacks and consequences. The contribution of this thesis is to help starting and advancing with a higher success potential.

695 See, e.g., an assessment using cases from World Bank models: Rooij (2010).

696 See also: Trubek and Trubek (2007, p. 564).

697 Van Erp et. al. (2019a, p. 10).

698 Pattberg and Widerberg (2019, p. 65). 


\section{FINAL CONSIDERATIONS}

The legal field has the challenging task to deal with all the complexity and dynamism of social relations. When the issues are international, such challenges are even vaster, and a governance gap arises, especially regarding environmental impacts. The protection of human rights and of the environment cannot, however, be harmed. Therefore, with pressing matters, action must be fast and must consider all subjects involved, regardless of their legal status. It is essential, then, to ponder the contributions of, for instance, States, civil organizations, and corporations. Under those premises, this thesis aimed to answer the question of how to construct a regulatory mix to face the challenges caused by the plastic pollution of the oceans.

It started by sketching the nature of the plastic soup problem, describing the fact that more than $80 \%$ of the plastic pollution of the oceans comes from land-based sources, but also indicating that the magnitude of the pollution problem is today already beyond imagination with at least 8 million tons of plastics still leaking into the oceans each year. That shows that this is a problem that cannot be ignored by environmental law. Since the problem is mostly manifested in international waters, the primary perspective was to analyze to what extent the problem is addressed in current international law instruments.

To some extent we are confronted with a paradox: as the plastic is located in international waters, the solution should by definition be international. But that is precisely why it may be very difficult to implement. It is for that reason that one may have to consider the limits of solving the plastic soup problem (especially the clean-up) via international law instruments. The current private approach of voluntary solutions could be further stimulated especially if companies, based on their corporate social responsibility, join those voluntary initiatives to help clean-up.

Domestic law also remains crucial, not only to implement for example ex ante regulation aiming at the reduction and recycling of plastics. Domestic law could (for example via a taxation system) also, intermediating, generate finances to clean-up the current plastic soup problem. However, if the plastic soup could effectively be cleaned up it still needs an international legal framework to be able to proceed to such a clean-up. That, once more, shows that the problem of the plastic soup, central to this research, is very complex. It undoubtedly necessitates a mix of domestic law, a new international legal instrument (or amendment) and voluntary private initiatives.

\subsection{Concluding Remarks on the Research Question}

How can a mix of private pathways and public international regulation be constructed, to incentivize more sustainable behavior and effectively face the problem of the plastic pollution in the oceans, both preventing further pollution and recovering the already existing one? In order to arrive at an answer to that research question, the thesis has addressed four other intermediary questions:

(i) what are, in fact, the challenges presented regarding the plastic pollution in the oceans?

(ii) what is the main relevance of an international approach even for the ex ante perspective, to which there is a massive contribution from land-based sources?

(iii) what are the possibilities and limitations in public international law - hard and soft law - to face the problem of the plastic pollution of the oceans?

(iv) what are those possibilities and limitations in private initiatives?

Four steps, described in four secondary questions, before it is possible to address the research question. All five are summarized and objectively answered here - sections 7.1.1 to 7.1.5. 


\subsubsection{The Challenge of the Plastic Pollution of the Oceans}

An overview of the plastic sources, destinations, and impacts - as made in chapter 2, demonstrates the complexity of the problem and what are, in fact, the challenges presented. Six aspects summarize them: (i) plastics are produced and used in many different manners, meaning the need for different solutions; (ii) pollution originates at all stages of the chain - production, consumption, and final destination; (iii) recovering the plastic that is already in the oceans - and continuously increasing - is, at the moment, a virtually impossible task; (iv) the solutions must be analyzed for each particular case; (v) it is an international problem caused mostly by national actions; (vi) it involves all social actors States, individuals, corporations, and organizations.

The overview also indicates, however, the priority data to be considered when moving towards solutions, for instance: (i) $80 \%$ of the plastic ending in the ocean comes from land-based sources; ${ }^{699}$ (ii) packaging answers for $26 \%$ of the volume of plastic used $;^{700}$ (iii) $50 \%$ of the plastic produced is used only once; ${ }^{701}$ (iv) there are methodologies already available to prioritize action; ${ }^{702}$ (v) attempts and partial solutions seem to be emerging everywhere - geographically and from public and private initiatives - although they are still far from solving the plastic soup; and, consequently, (vi) it is necessary to have further investments in research, technology, and innovation, for the development of solutions involving all stages that lead to the plastic pollution of the oceans, as well as to recover the tons of plastics that are already in the oceans; and (vii) the main issues vary depending on the country where the pollution originates, especially between the so called developing and developed world.

\subsubsection{An International Approach}

The main concern of the second question is with the recent research placing a vast majority of landbased plastic pollution sources in the least developed countries from Asia and Africa. For a hasty observer, those would demonstrate that the developing world is to blame and, maybe, therefore should find a solution, for the plastic soup. Immediate sources are not, however, the only causes to the problem. It comes without saying that we must not disregard the importance of finding solutions, and especially national and local solutions, to those contributions from the global South. The chapter even highlights the importance of Multilateral Environmental Agreements towards a solution, which is international but focused on the countries from the global South. It does, however, highlight the relevance to see the problem in its entirety. That is why it describes two central roles played by the global North: (i) production and placement in the market of the plastic products, through multinational companies; and (ii) exports of the collected recyclable waste to the developing world.

Furthermore, the deficiencies concerning waste management from the developing world are also a reflection of global discrepancies; a consequence of social and economic deficiencies, which necessarily reflect on environmental protection. The concerns with global heterogeneity are also at the core of Third World Approaches to International Law (TWAIL), and the reason why it was used to address the plastic soup case. Using that theory, it was possible to derive the practical aspects to be considered, and, consequently, to conclude that there are legal solutions that combine remedies to the producer edge with remedies to the post-consumer edge. Those are the solutions indicated as priorities for the upcoming decisions that will hopefully come in the near future to face the plastic pollution in the oceans through public international law. Public international law may also contribute to solutions by encouraging a more responsible international trade of plastic products or plastic waste, or by helping technological and financial transfer, for example.

699 Sheavly (2005).

700 World Economic Forum, Ellen MacArthur Foundation and McKinsey \& Company (2016, p. 17).

701 Hollman, Bouwmeester, and Peters (2013, p. 8).

702 E.g.: Odegard et al. (2017); National Institute for Public Health and the Environment (RIVM) (2014); Woldendorp (2017). 


\subsubsection{The International Instruments to Address the Plastic Soup}

The results concerning the current international instruments to address the plastic soup were simply disappointing. Many international conventions (hard law instruments) do not mention plastics at all; there are only three (the London Protocol 2006, MARPOL Annex V, and the Basel Convention) that refer to plastics. Plastics receive more attention in some soft law instruments, such as the GPA and the SDGs. Still, the major problem with all of the instruments reviewed is that, even when they contain prohibitions on dumping plastic into the oceans, it is mostly very generally and vaguely, and do not go further, on more concrete measures against the plastic pollution. For their effectiveness those instruments of course need transposition and implementation at the domestic level. One problem is that most of the conventions where plastic is mentioned focus on emissions from ships, but the most important source (land-based emissions) does not feature in most of the international instruments reviewed. Moreover, the fact that there is no effective enforcement is illustrated by the continuing emissions of plastic into the ocean.

On the ex post edge, I reviewed a variety of instruments that could theoretically be implemented to pursue the goal to eliminate the current plastic soup, none of which addresses that crucial question. I also consider that, in some cases, the plastic may have an economic value, if coupled with technical solutions stimulation, as a result of which market solutions to stimulate clean-up could be implemented - as further discussed in chapter 6. However, a major problem is that most of the plastic is situated in the high seas. It is therefore argued that if any solution is to be put in place, a legal framework would have to be created to establish at least a clear background with respect to the status of the plastic waste. In the absence of such a clear legal status (whether via a convention or through the creation of property rights), incentives to stimulate clean-up might fail. It is suggested that such a legal framework could be created perhaps via UNCLOS (if a hard law solution is preferred) or through the GPA. However, it is clear that there are many impediments in the creation of such an international tool, even if it were merely based on the amendment of an existing instrument.

In other words, the analysis in chapter 4 made it clear that international law, neither hard law nor soft law, yet provides convincing solutions for the plastic soup problem. That, together with the fact that private companies are directly and greatly related to the problem, is the reason why in chapter 5, I looked at Corporate Social Responsibility (CSR) and other private initiatives to face the plastic soup.

\subsubsection{Private Initiatives to Face the Plastic Soup}

The answer to the question about possibilities and limitations in private initiatives was a bit different. It is already established that "profitability and $\mathrm{C}[\mathrm{S}] \mathrm{R}$ should not necessarily be considered opposites". ${ }^{703}$ This partially explains why companies are not only willing, but also are starting, to engage. The four case studies made in chapter 5 enabled listing five motives why companies would indeed engage in the fight against the plastic soup: (i) public relations and marketing; (ii) attracting investments; (iii) choice on how to act towards change; (iv) influence on policy-making; and (v) achieving financial benefits or incentives. All of those reasons are directly related to the interactions between companies and either civil society or government, or both.

There are, of course, also concerns. The two main ones being information asymmetry and green (or blue) washing. Actually, it identified three central challenges to enhance private action, which are directly linked to those concerns: (i) lack of transparency from companies regarding information and data that only themselves hold but that are essential for policy-making; (ii) dependency on the financial markets and consequent lack of economic motivation, since the indicators for investors still fail to account specifically for the plastic pollution impacts; and (iii) for the existing initiatives, the need to gain scale.

703 Lu, and Faure (2016, p. 262). 
Regarding the ex post edge, there are fewer private initiatives. The only one directly dealing with the problem in the high seas is the Ocean Cleanup Foundation, an organization from civil society. The challenges they faced regarding the rule of international law were solved through friendly interaction with government. There are also a few initiatives from companies, which, however, use plastics from bottles recovered from beaches, not the high seas, which shows that they are actually not yet directly dealing with the core of the problem addressed by this thesis. Even so, they indirectly act, since they recover plastics that would probably end up in high seas. Besides, they serve to show that recovering and recycling plastics meet the purposes of the company, including profitability. The main distinction is that recovering plastics from international waters would include investments in technology, meaning higher costs.

Additionally, chapter 5 made an ex ante effectiveness evaluation of the initiatives. Ex ante because they are all still very recent, which makes it impossible to adequately assess if they achieved their respective goals. It concluded that none of the four cases succeed in all of the indicators. The one showing better results in such an assessment, however, is the Dow Jones Sustainability Index, which is, however, not yet considering plastics to the assessment.

\subsubsection{How to Construct a Mix to Effectively Face the Problem of the Plastic Pollution of the Oceans?}

Finally, it was possible to directly address the research question, of how to construct a mix of private pathways and public international regulation, to incentivize more sustainable behavior and effectively face the problem of the plastic pollution in the oceans.

An economic analysis of law made it possible to indicate the paths that seem more adequate to face the challenges identified.

A first important assessment is that, even from an economic perspective, it is not smart to leave the problem as it is. This was shown in chapter 5 (at 5.1.2.1), which situated the plastic pollution as a market failure and gave figure examples of the financial losses of not addressing the issue.

From the analysis made, it became clear that both private and public initiatives are necessary to adequately address the problem. Also, although there is a governance gap on what concerns the international context, here analyzed, it is not only the lack of public regulation that justifies the emergence and the necessity of CSR and other private actions. On the contrary, public and private regulation interact in different ways, sometimes as substitutes, sometimes as complements. ${ }^{704}$ The major challenge is, then, how to couple them in effective ways for each situation, in this case, to fight the plastic pollution in international waters.

Chapter 6 used economic tools to analyze the public international instruments and the private initiatives described in the thesis. Then, it summarized the lessons learned into two steps that may guide an effective start on how to construct a mix between public and private initiatives to face the plastic pollution in the oceans: (i) prioritizing sources and emissions to be addressed; (ii) enhancing the roles of governments, companies, and civil society. It finalized proposing a mathematical, objective, approach for applying the conclusions to the practical challenges.

On the ex post edge, theoretical classic instruments from economics, such as the creation of property rights, taxation and compensation funds could serve the goals of financing the clean-up and preventing further pollution. Nonetheless, it is an approach that is hardly achievable in public international law. Taxation may only be instituted by States, since there is no competent authority to establish an international tax. The creation of property rights could be done through existing instruments like UNCLOS, but it would still not solve the problem of the necessary funds to develop and implement technology for the recovery of the plastic from the oceans. And funds not only take a long time to

704 See also: Locke, Rissing, and Pal (2013); Peeters and Muller (2018). 
establish but are numerous now, making it more difficult to agree on a new one. This does not mean, however, that it should not be done. It just means that they should be accompanied by other measures such as supporting private initiatives, from civil organizations and from companies.

Therefore, to construct a mix of private pathways and public international regulation to face the problem of the plastic pollution of the oceans, it is necessary to:

1) Involve States, companies, and civil organizations, and potentialize the roles that each of them play better;

2) Establish priorities by applying equation 2 (section 6.2.1);

3) When using instruments from public international law:

a) Choose structures that are already functioning, when available - such as UNCLOS, London Convention, GPA or Agenda 21, considering the aspects analyzed under section 6.1.1 -, instead of creating new ones;

b) Consider the lessons learned: address all sources of plastic pollution and integrate ecosystems; establish guidelines, targets, and indications; foresee reviewing and compliance mechanisms; strengthen technical, scientific, and financial resources; clarify economic impacts; and gather and interpret data and information.

\subsection{Academic Contribution of the Thesis}

It is surprising that, as far as I could acknowledge, this research is the first legal ${ }^{705}$ one to address comprehensively an environmental problem that according to some is considered one of the largest ecological problems of this century. ${ }^{706}$ The reason why there is so little literature addressing this problem of the plastic soup, is probably that it is also very difficult to grasp, especially in legal terms. Not only should a distinction be made between incentives to be provided for a reduction of emissions of plastic into the oceans; at the same time solutions need to be developed to remove the plastic which currently already is in the oceans. Especially the latter is a difficult issue, as most of the plastic is located in legal no-mans-land, being the high seas on which, according to UNCLOS, only the flag states have jurisdiction. These flag states obviously wish to exercise their jurisdiction on ships and not on the pollution of the oceans where their ships would sail.

The interdisciplinary nature increases the complexity for academics to deal with the issue. That includes other science fields, but is also a particularly difficult challenge for law, that may - or at least should - not disregard the complex nature of the problem when developing and implementing policy. This thesis also contributes to such an interdisciplinary approach, by using the research from other relevant fields as premises, and by analyzing the issue through economic tools.

The economic analysis also leads to a more practical approach, focused on effectiveness, which brings essentially theoretical academic research closer to possible de facto implementation. A last innovative aspect, and, thus, contribution to academics, is assessing recent activities, making it more difficult but more useful to evaluate effectiveness.

\subsection{Societal Relevance of the Thesis}

The problem of the plastic pollution of the oceans has an undeniable sustainable character. The three pillars - environmental, social, and economic - are not only in the implications and consequences of such a pollution, but also in the solutions it requires, involving the three pillars, as well as the need for integration between the different players. Therefore, this thesis also has its societal relevance grounded in those three pillars.

\footnotetext{
705 There are many papers about plastic pollution in the oceans in other fields, especially Chemistry, as presented along the thesis.

706 National Geographic (2018); Amcham Brasil (2018); Wright and Henson (2018).
} 
Environmentally, the amount and the impacts of the plastic pollution in the oceans are huge and increasing. Moreover, the predictions show how important it is to act, and act fast. Socially, the environmental aspects are, of course, already relevant, but other human rights are negatively affected as well. Some examples are the impacts on human health - from eating, ${ }^{707}$ drinking, ${ }^{708}$ and even breathing ${ }^{709}$ microplastics, for instance -, or on families who survive from the damaged coral reefs. ${ }^{710}$ Economically, not only are there the costs that come as a consequence from the previous two dimensions, but also the costs that a transition to less plastic or circular economy will mean.

Also for those reasons, action towards a solution needs to come as soon as possible, making any research that helps with the task very relevant to society. A relevance that comes from the proposed solutions themselves, but also from structuring the voluminous and recent information available.

\subsection{Policy Recommendations}

Due to the positive characteristic of the economic analysis made during the thesis and, mainly, the complexity of the issue, the thesis never searched for a final solution to the problem of the plastic pollution in the oceans. Still, the answer to the research question is, essentially, a policy recommendation.

The research does lead to policy and societal implications, mainly by achieving its central goal of indicating pathways that seem to have a higher potential to face the plastic pollution in the oceans. But also by fulfilling the intermediate steps, especially when assessing the effectiveness of public international instruments and private initiatives. Furthermore, the partial and final conclusions of the thesis may be transposed to help policy-making in local and regional contexts.

The answer to the research question, previously stated, may be summarized in three main aspects.

The first of those aspects is to bring dialogue to the policy-making process, including all actors involved, governments, companies, and civil society, and potentializing their respective roles. This means also acting through mixed approaches from public regulation and private initiatives.

The second aspect is to avoid common pitfalls in international public law, especially not trying to build a whole new framework, which is too bureaucratic and demands time that the fight against the plastic pollution does not have. The recommendation, thus, is to use already existing structures that seem to be working well. As indicated before, structures such as UN organizations, well established hard law instruments such as UNCLOS, and appealing to soft law instruments such as GPA and SDG's.

The third aspect is prioritization. It is important to structure policy-making and, by consequence, to have a viable, achievable, policy. Instead of the common behavior to construct new legislation for every issue that emerges. ${ }^{711}$

\subsection{Limits and Further Research}

The possibilities through regional and national approaches are, naturally, a first limitation of this research, since it is focused on the international options. They are, of course, important, especially because of the proximity of the main sources of plastic pollution. However, when dealing with the international perspectives, regional and national approaches only arise to the extent that they may be influenced by international solutions.

707 Haffner (2017).

708 Carrigton (2017).

709 Vianello et al. (2019).

710 De Guchte (2005).

711 Faure and Dalhammar (2018, p. 66). 
Another limitation concerns the extent of the economic analysis. For instance, the principal-agent problem related to the managers and stakeholders was not addressed, as it escapes the scope of the research. Even broader, the methodology of economic analysis of law is, by itself, also a limit. As any other methodology, it establishes constraints related to the premises it is based upon. This is a limit but not a problem, since the premises and models of a methodology are known and controlled.

A fourth - expected - limitation of the thesis follows from its inter-disciplinary nature. For example, regarding the technical solutions. Not only is the comprehension brought in the thesis restricted to that of the author - who is someone from a different field -, but also, there are too many technicalities to be grasped in one single research project.

All of those limits also constitute points for further research, both in the legal field and in others. Besides, the thesis pointed to the very interesting and still unexplored field for legal research on the role that international courts may play on fighting the plastic soup.

For research outside law, the thesis also indicates the need for more research in technologies for recovering plastics from the oceans, more efficient recycling techniques for plastic, and adequate substitutes, for instance.

More than that, the solutions indicated by the thesis open vast research possibilities. For example, for each of the plastic pollution problems, there is room for research, mainly to allow a more precise evaluation of each criterion when prioritizing according to the equation proposed. Or for each of the actors involved, there is room for research about their inner functioning. All of that opens possibilities for further research in the legal field and in others. 


\section{Valorisation Addendum}

This section aims at fulfilling the provision under article 22.5 of the Regulation governing the attainment of doctoral degrees at Maastricht University. The valorization addendum briefly discusses relevance, target groups, products, innovation, and implementation of the thesis, in a "process of creating value from knowledge by making knowledge suitable and/or available for economic and/or societal use and translating that knowledge into products, services, processes and entrepreneurial activity". ${ }^{712}$

1. Relevance: What is the social (and/or economic) relevance of the research results, in addition to the scientific relevance?

The increasing amount of plastics being released into the environment, and specifically into the oceans, is alarming and with severe consequences for nature and for humankind. Plastic pollution is already the largest environmental harm caused by humankind, ${ }^{713}$ together with climate change. Data are alarming, with estimates that at least 8 million tons of plastic end in the oceans yearly, and that, if the pace continuous, by 2050 there will be more plastics than fishes in the oceans. ${ }^{714}$ Nevertheless, the production of plastics not only keeps increasing, at a growing rate, but it also increases faster than the world population growth. ${ }^{715}$ Many impacts of plastic pollution, especially on human health, are still unknown. However, research already shows that we are eating, ${ }^{716}$ drinking, ${ }^{717}$ and even breathing ${ }^{718}$ plastics. Besides, nature is suffering in countless ways, such as animal deaths by starvation and entanglement, ${ }^{719}$ destruction of coral reefs, ${ }^{720}$ transportation of invasive species,${ }^{721}$ and the spread of toxic materials. ${ }^{722}$

The legal field may contribute towards a solution on different levels, such as national, regional, and international, and from different perspectives of the problem. This thesis deals with the international approaches and the possibilities for a mix between public and private initiatives to address the problem of the plastic pollution in the oceans (or plastic soup), both from recovering the plastics that are already there and from preventing further pollution from entering the oceans.

The thesis has, therefore, social, environmental and economic relevance - for consequences as well as for potential solutions -, in addition to its scientific relevance. Socially, there is the need to prevent and mitigate the adverse consequences of the plastic pollution, such as the effects on coral reefs which destroy the earning sources of many families, or the pollution that reaches beaches and poses a risk to leisure and sports, or even on the most basic aspects affecting human health. Environmentally, the impacts are numerous on nature as a whole, but mainly leading to the death of animals by starvation or entanglement. Economically, the impacts are not only the effects of social and environment problems raised, but also the issues involved in the production-consumption logics, and the costs that will come with transitioning to less plastic and/or to a circular economy. From the three dimensions of relevance, comes the urgent need for science to deal with the problem, and, therefore, the importance of the contributions of the thesis lies mainly in the legal field, which is only starting to look for solutions for the plastic soup.

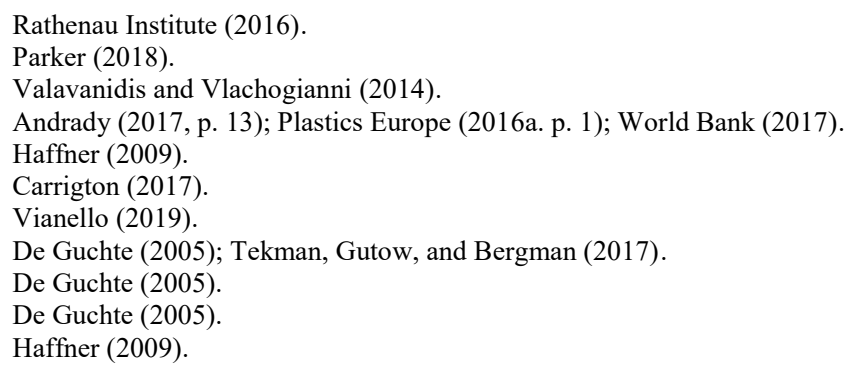


In such a context, I conducted the research in four intermediate steps until arriving at the answer to the research question.

The first step was understanding the current status of the plastic pollution in the oceans and which potential technical and technological solutions are being developed. The overview allowed tan indication of the data to be prioritized when moving towards solutions, for instance: (i) $80 \%$ of the plastic ending in the oceans comes from land-based sources; (ii) packaging answers for $26 \%$ of the volume of plastic used; (iii) $50 \%$ of the plastic produced is used only once; (iv) there are methodologies already available to prioritize action; (v) attempts and partial solutions seem to be emerging everywhere - geographically and from public and private initiatives - although they are still far from solving the plastic soup; and, consequently, (vi) it is necessary to have further investments in research, technology, and innovation, for the development of solutions involving all stages that lead to the plastic pollution of the oceans, as well as to recover the tons of plastics that are already in the oceans; and (vii) the main issues vary, depending on the country where the pollution originates, especially between the so called developing and developed world.

The second step was to clarify the importance of international action, even for preventing further plastic pollution and to highlight aspects to avoid common pitfalls in the North-South world dynamics. From there, the third step was to analyze the eleven international instruments - such as conventions, protocols, and agreements - that somehow relate to the plastic pollution problem. It made clear that no international law, neither hard law nor soft law, yet provides convincing solutions. That, together with the fact that private companies are directly and closely related to the problem, is the reason why the fourth step was to look at Corporate Social Responsibility (CSR) and other private initiatives to face the plastic soup.

This fourth step was made through four case studies: (i) the New Plastic Economy, which is, in summary, a compromise from several multinational companies to tackle the plastic pollution problems; (ii) the Dutch Deals, that have been in place in the Netherlands for several years and consist of a voluntary partnership between the government and private actors to solve environmental problems, and that already have some examples related to plastics; (iii) the Dow Jones Sustainability Index, which evaluates companies in the stock market based on a few socio-environmental indicators; and (iv) companies reporting in general. It concluded that none of the four cases succeed in all of the indicators of effectiveness. The one showing better results in such an assessment is the Dow Jones Sustainability Index, which is, however, not yet considering plastics in its assessment. Nonetheless, it also concluded on many positive aspects of those actions and why companies would indeed engage in the fight against the plastic soup, being mainly: (i) public relations and marketing; (ii) attracting investments; (iii) choice on how to act towards change; (iv) influence on policy-making; and (v) achieving financial benefits or incentives.

The fifth step was, then, the final one. I applied economic tools to analyze the previous conclusion. It made it possible to summarize lessons learned into two aspects that may guide an effective start on how to construct a mix between public and private initiatives to face the plastic pollution in the oceans: (i) prioritizing sources and emissions to be addressed; (ii) enhancing the roles of governments, companies, and civil society. It finalized proposing a mathematical, objective, approach for applying the conclusions to the practical challenges, through a simple equation. Finally, the economic analysis allowed the identification of three basic needs to construct a mix of private pathways and public international regulation to face the problem of the plastic pollution of the oceans: (i) to involve States, companies, and civil organizations, and to potentialize the roles that each of them play best; (ii) to establish priorities by applying the mentioned equation; and (iii) when using instruments from public international law, to both: a. Choose structures that are already functioning, when available - such as UNCLOS, the London Convention, GPA or Agenda 21 -, instead of creating new ones; b. Consider the lessons learned: address all sources of plastic pollution and integrate ecosystems; establish guidelines, targets, and indications; foresee reviewing and compliance mechanisms; strengthen technical, scientific, and financial resources; clarify economic impacts; and gather and interpret data and information. 
2. Target groups: For who, outside academic circles, are the research results of interest and why?

Because of the broad repercussions of the issue, the results of the research may be of interest to several circles. Its intended target groups, outside academic circles, are mainly international policy-makers, companies, and NGO's, since it addresses the roles which each of them are playing and which they may have in constructing a regulation mix.

To what concerns international policy-makers, the conclusions actually give the steps, by indicating not only which factors have to be taken into consideration, but also how to prioritize among the several different possibilities of action. Other groups may also benefit from the research outcomes, especially in the regulation levels not addressed by the thesis - such as national and regional - and for who the conclusions may be adapted. For instance, national governments may adapt the conclusions to the local context when setting priorities, designing policies, and dialoguing with national companies or with international companies based in their countries.

The same can be done by companies themselves and by civil society. By addressing the findings of the thesis, companies could learn how CSR may be implemented and how they may benefit themselves from contributing to preventing further plastic pollution and from contributing to the clean-up of plastics. Also, they could learn how to do so by being leaders, instead of laggards, which is essential in a competitive market.

Other than that, individuals may be impacted, mainly by raising awareness of the subject through the data regarding the amount and the consequences of the plastic pollution. Additionally, by understanding their critical role in changing daily habits and by organizing themselves to act in a broader picture. In that sense, understanding of the roles of governments and companies is also critical, because individuals and civil organizations have an important role to pressure them towards action.

Finally, it is interesting to note that one of the reasons for choosing the Law and Economics methodology - apart, of course, from its scientific adequacy - is to facilitate communication with the business sector, which is more familiar with the economic language than with other scientific approaches.

3. Activities and products: In which actual products, services, processes, activities or commercial activities can the research results be applied and given shape?

The main application is, naturally, in public policy-making, which may be guided by the results of the research. However, commercially speaking, the research results may help leading-companies in shaping more sustainable policies, even by reaching out to governments to initiate join efforts and by trying to diminish the costs of implementation and to shape common solutions.

In a general perspective, the results of the research are meant to be applied in - mainly legal activities and products directed at preventing further plastic pollution and diminishing the plastic soup. As well as legal solutions to enable financing for the efforts for cleaning up the oceans from the already existing plastic pollution.

The thesis also already presents a final product by itself: clear approaches, indications, and steps on how to build a mix of public regulation and private initiatives to fight the plastic soup, in a process preferably orchestrated by governments, but with horizontal contributions also from companies and civil society. In that sense, the equation and the clear steps provided are a finished product, ready to be implemented. 
4. Innovation: To what extent can they be called innovative compared to the existing range of products, services, processes, activities and commercial activities?

The thesis brings different innovative perspectives. Mainly, it addresses a legal approach towards a comprehensive solution for the plastic pollution in the oceans, which, to the best of my knowledge, has not been done so far.

An important innovation brought by the thesis is the careful distinction between the incentives and instruments that may prevent further plastics from going into the oceans, and the actions regarding the recovery of the millions of tons of pollution that are already there. With this, the thesis makes it clear that ex ante and ex post need different, and integrated, instruments at different levels to be effective. More than that, the thesis indicates possible ways to analyze such effectiveness and indicates by which instruments and which approaches to begin the international fight against the plastic pollution in the oceans.

Finally, the conclusions of the thesis - indicated in topic number 1 of this valorization addendum are, of course, innovative. They bring a clear final product: the steps indicating how to build a mix of public regulation and private initiatives to face the plastic soup.

5. Planning \& Implementation: How will these valorisation plans be implemented? What is the schedule, what are the possible risks, what are the market opportunities and what are the costs?

The innovative character of the analysis of the thesis means that there are costs and risks involved in implementing the discussed changes. However, these are costs and risks related to market opportunities, for companies, and to enhancing social and environmental balance, for governments. In other words, they are the regular costs for sustainable innovation.

Unfortunately, this also means that these are costs that are difficult to convince companies that they should incur. The companies that could contribute the most with diminishing plastic production and, consequently, plastic pollution, are those whose products are highly dependent on plastics but, at the same time, could be replaced by a different material that is already available. To illustrate, we can take the example of the beverage industry, which could replace plastic bottles by glass ones or even new materials, as the edible packaging described in the research. However, the bigger corporations, such as Coca-Cola or Nestlè, for example, are not willing to do so on a large scale anytime soon, because of the costs that it would require for the production. Actually, they are, so far, not even willing to provide information and data regarding their contributions to the plastic chain.

On the other hand, the thesis demonstrates that it may be interesting for companies to join efforts on the prevention of further plastic pollution. From the four case studies of private initiatives, it summarizes five main reasons why companies would engage, as already described in the topic number 1 of this valorization addendum. In addition, the thesis makes clear that the role of government and civil society is essential so companies truly act, jointly with States setting the goals and the pace for implementation.

The costs to recover the millions of tons of plastics that are already polluting the oceans are also huge. In this case, they even include, necessarily, investments in research to develop technology for such cleaning, as well as for making profitable use of the recovered plastics. In that case, public regulation plays a larger role, for example, enabling funding and collaborating with legal solutions - such as property rights or flags to vessels. Private initiatives are of course also welcomed, mainly by (partially) financing research and actions from civil society, as happens with The Ocean Cleanup Foundation. All of that is also discussed in detail in the thesis.

Regarding timing and schedule, most of the actions could start immediately, although involving plans of short, medium, and long terms. The results, on the other hand, will mostly take longer to be 
achieved, which is the main reason why the actions should be initiated immediately to face such an urgent matter. Feedback and constant assessment of the actions implemented are essential, and those come afterwards, mostly with medium and long terms planning. 


\section{Summary}

The increasing amount of plastics being released in the environment, and specifically in the oceans, is alarming and with severe consequences to nature and to humankind. Plastic pollution is already the largest environmental harm caused by humankind, ${ }^{723}$ together with climate change. Data are alarming, with estimates that at least 8 million tons of plastic end in the oceans yearly, and that, if the pace continuous, by 2050 there will be more plastics than fish in the oceans. ${ }^{724}$ Nevertheless, the production of plastics not only keeps increasing, by a growing rate, but it also increases faster than the world population growth. ${ }^{725}$ Many impacts of plastic pollution, especially on human health, are still unknown. However, research already shows that we are eating, ${ }^{726}$ drinking, ${ }^{727}$ and even breathing ${ }^{728}$ plastics. Besides, nature is suffering with countless harms, such as animal deaths by starvation and entanglement, ${ }^{729}$ destruction of coral reefs, ${ }^{730}$ transportation of invasive species, ${ }^{731}$ and the spread of toxic materials. $^{732}$

The legal field may contribute towards a solution in different levels, such as national, regional, and international, and from different perspectives of the problem. My thesis deals with the international approaches and the possibilities on how to construct a mix between public and private initiatives to address the problem of the plastic pollution in the oceans (or plastic soup), both from recovering the plastics that are already there and from preventing further pollution from entering the oceans.

In such a context, I conducted the research in four intermediate steps until arriving to the answer to the research question. The first step was understanding the current status of the plastic pollution in the oceans and which potential technical and technological solutions are being developed. The second step was to clarify the importance of international action, even for preventing further plastic pollution, and to highlight aspects to avoid common pitfalls in the North-South world dynamics. From there, the third step was to analyze the eleven international instruments - such as conventions, protocols, and agreements - that somehow relate to the plastic pollution problem. It made clear that international law, neither hard law nor soft law, yet provides convincing solutions. That, together with the fact that private companies are directly and greatly related to the problem, is the reason why the fourth step was to look at Corporate Social Responsibility (CSR) and other private initiatives to face the plastic soup. This fourth step was made through four case studies: (i) the New Plastic Economy; (ii) the Dutch Deals; (iii) the Dow Jones Sustainability Index; and (iv) companies reporting in general. It concluded that none of the four cases succeed in all of the indicators of effectiveness. Nonetheless, it also concluded on many positive aspects of those actions and why would companies indeed engage in the fight against the plastic soup.

The fifth step was, then, the final one. I applied economic tools to analyze the previous conclusion. It made it possible to summarize lessons learned into two aspects that may guide an effective start on how to construct a mix between public and private initiatives to face the plastic pollution in the oceans: (i) prioritizing sources and emissions to be addressed; (ii) enhancing the roles of governments, companies, and civil society. It finalizes proposing a mathematical, objective, approach for applying the conclusions to the practical challenges, through a simple equation.

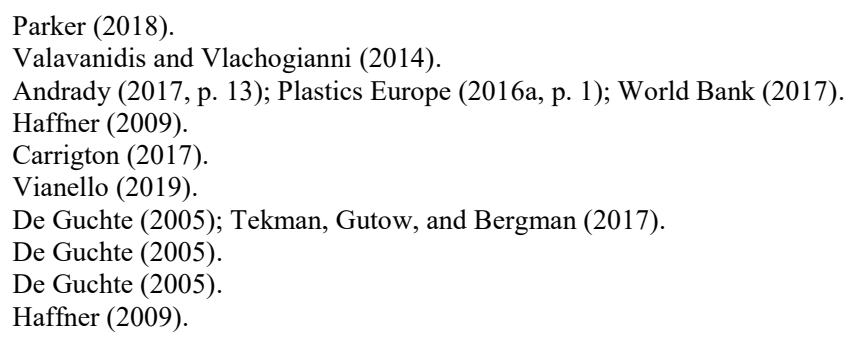




\section{References}

1996 Protocol to the Convention on the Prevention of Marine Pollution by Dumping of Wastes and Other Matter, 1972 (as amended in 2006). Available at: http://www.imo.org/en/OurWork/Environment/LCLP/Documents/PROTOCOLAmended2006.pdf. Accessed on November 9, 2017.

AALL, Carlo. Municipal Environmental Policy in Norway: From 'mainstream' policy to 'real' Agenda 21? Local Environment, 5(4), 2000, pp. 451-465.

AALL, Carlo. The early experiences of local climate change adaptation in Norwegian compared with that of local environmental policy, Local Agenda 21 and local climate change mitigation. Local Environment, 17(6-7), 2012, pp. 579-595.

AFRICAN COMMISSION ON HUMAN AND PEOPLES' RIGHTS. Case Ogoni People v. NigeriaACHPR/COMM/A044/1. 27 May 2002. Available at: https://docs.escr-net.org/usr_doc/serac.pdf. Accessed on February 28, 2020.

AKEHURST, Michael. Custom as a Source of International Law. In: British Yearbook of International Law, 1976, pp. 1-53.

ALAM, Shawkat et al. (eds.) International Environmental Law and the Global South. New York: Cambridge University Press, 2015.

ALBERSMEIER, Friederike; SCHULZE, Holger; SPILLER, Achim. Evaluation and Reliability of the Organic Certification System: Perceptions by Farmers in Latin America. Sustainable Development, 17, 2009, pp. 311-324.

ALEGRE MARTÍNEZ, M.Á. Los deberes en la constitución española: esencialidad y problemática. Teoría y Realidad Constitucional, n. 23, 2009.

ALLSOP, Michelle et al. Plastic Debris in the World's Ocean. November 2, 2006. Available at: $<$ http://www.greenpeace.org/international/en/publications/reports/plastic_ocean_report/>. Accessed on August 19, 2017.

ALSTON, Philip; GOODMAN, Ryan. International Human Rights. Oxford: Oxford University Press, 2013.

ALVAREZ, Jose. Are Corporations "Subjects" of International Law? Santa Clara Journal of International Law, 9(1) 2011, pp. 1-36.

Amcham Brasil. Plástico é o maior desafio ambiental do século XXI, segundo ONU Meio Ambiente. Available at: https://economia.estadao.com.br/blogs/ecoando/plastico-e-o-maior-desafio-ambiental-doseculo-xxi-segundo-onu-meio-ambiente/. Accessed on June 11, 2018.

AMCOR. Creating a New World of Packaging: Sustainability Review 2016. 2016. Available at: https://d2491pxl8gaali.cloudfront.net/CorporateSite/media/Sustain-Reports/2016_

Sustainability_Review.pdf. Accessed on 21 September 2017

ANDERSON III, H. Edwin. The Nationality of Ships and Flags of Convenience: Economics, Politics, and Alternatives. The Maritime Lawyer, 12, 1996, pp. 139-170. 
ANDRADY, Anthony L. The plastic in microplastics: a review. Marine Pollution Bulletin, 119, 2017, pp. 12-22.

ANDRADRY, Anthony L. The plastic in microplastics: a review. Marine Pollution Bulletin, 119, 2017, pp. 12-22.

Annex $V$ of the International Convention for the Prevention of Pollution from Ships. 2011. Available at: $\quad<\mathrm{http} / / \mathrm{www}$.imo.org/en/OurWork/Environment/PollutionPrevention/Garbage/Documents/2014\%20revision/RESOLUTION\%20MEPC.201(62)\%20Revised\%20MARPOL\%20Annex\%20V.pd f\#search=annex\%20V\%20to\%20MARPOL > . Accessed on October 18, 2017.

ANTON, Donald K.; SHELTON, Dinah L. Environmental Protection and Human Rights. New York: Cambridge University Press, 2011.

Association of Southeast Asian Nations - ASEAN. ASEAN Member States. Available at: https://asean.org/asean/asean-member-states/. Accessed on February 24, 2020.

ATKINSON, Adrian. Surabaya, Indonesia: Local Agenda 21 in the context of radical political reform. City, 5(1), 2001. pp. 47-65.

ATTENBOROUGH, Daniel. Giving purpose to the corporate purpose debate: an Equitable Maximisation and Viability principle. Legal Studies, 32(1), March 2012, pp. 4-34.

Austrian Development Cooperation. Guidelines for Project and Programme Evaluations - final draft. July 2009. Available at: https://www.oecd.org/development/ evaluation/dcdndep/47069197.pdf. Accessed on December 29, 2018.

BACKER, Larry Cata. Multinational Corporations as Objects and Sources of Transnational Regulation. ILSA Journal of International \& Comparative Law, 14(2), 2008, pp. 499-523.

BADERIN, Mashood A.; SSENYONJO, Manisuli. Development of International Human Rights Law Before and After the UDH. In: BADERIN, Mashood A.; SSENYONJO, Manisuli (eds.), International Human Rights Law: Six Decades after the UDHR and Beyond, Farnham: Ashgate, 2010, pp. 3-27.

BADARU, Opeoluwa Adetoro. Examining the utility of Third World Approaches to International Law for International Human Rights Law. International Community Law Review, 10(4), 2008, pp. 379-382.

BALDWIN, Austin K.; CORSI, Steven R.; MASON, Sherri A. Plastic Debris in 29 Great Lakes Tributaries: Relations to Watershed Attributes and Hydrology. Environ. Sci. Technol, 50(19), 2016, pp. 10377-10385.

BANERJEE, S.B. A critical perspective on corporate social responsibility: Towards a global governance framework. Critical Perspectives on International Business, 10, 2014, pp. 84-95.

BARNES, D.K.A.; MILNER, P. Drifting plastic and its consequences for sessile organism dispersal in the Atlantic Ocean. Marine Biology, 146, 2005, pp. 815-825.

BARRETT, Brendan; USUI, Mikoto. Local Agenda 21 in Japan: Transforming local environmental governance. Local Environment, 7(1), 2002, pp. 49-67.

BARTLEY, Tim. Transnational governance as the layering of rules: intersections of public and private standards. Theoretical Inquiries in Law, 12(2), 2011, pp. 517-542.

BAYÓN MOHINO, J.C. Los deberes positivos generales y la determinación de sus límites (observaciones al artículo de Ernesto Garzón Valdés). Doxa, n. 3, 1986. 
Beat the Microbead App. Available at: http://get.beatthemicrobead.org/ Accessed on January 09, 2018.

BECATOROS, Elena. More than 90 percent of world's coral reefs will die by 2050. March 13, 2017. Available at: http://www.independent.co.uk/environment/ environment-90-percent-coral-reefs-die2050-climate-change-bleaching-pollution-a7626911.htlm?amp. Accessed on August 31, 2017.

BECKERS, Anna. Enforcing corporate social responsibility codes: On global self-regulation and national private law (International studies in the theory of private law, volume 12). Oxford: Hart Publishing, 2015.

BECKERS, Anna. The Regulation of Market Communication and Market Behaviour: Corporate Social Responsibility and the Directives on Unfair Commercial Practices and Unfair Contract Terms. Common Market Law Review, 54(2), 2017, pp. 475-516.

BENGTSSON, Simon; WERKER, Alan; VISSER, Cindy; KORVING, Leon. PHARIO: Stepping Stone to a Sustainable Value Chain for PHA Bioplastic Using Municipal Activated Sludge. Amersfoort: Stichting Toegepast Onderzoek Waterbeheer, 2018.

BERNAZ, Nadia. International soft law initiatives on business and human rights. In: BERNAZ, Nadia (Ed.). Business and Human Rights. London: Routledge, 2017, pp. 164-207.

BERRY, Jeffrey M.; PORTNEY, Kent E. The Tea Party versus Agenda 21: local groups and sustainability policies in U.S. cities. Environmental Politics, 26(1), 2017, pp. 118-137.

BIERMANN, Frank; SIMONIS, Udo E. The Multilateral Ozone Fund: A case study on institutional learning. International Journal of Social Economics, 26(1/2/3), 1999, pp. 239-273.

BLAUG, Mark. Pieter Hennipman on Paretian Welfare Economics: a Comment. De Economist, 1, 1993, pp. 127-129.

BLOIS, D. de. Incorporating the Impacts of Plastics in the Aquatic Environment in Life Cycle Assessment: A Preliminary Assessment, Leiden University: Thesis Research Project - Industrial Ecology, 2017.

BODANSKY, Daniel; BRUNNEE, Jutta; HEY, Ellen. International Environmental Law: Mapping the Field. In: BODANSKY, Daniel; BRUNNEE, Jutta; HEY, Ellen [Eds.]. The Oxford Handbook of International Environmental Law. September 2012. Available at: $<$ http://www.oxfordhandbooks.com/view/10.1093/oxfordhb/9780199552153.001.0001/oxfordhb9780199552153-e-1?print>. Accessed on December 5, 2017.

BRUCH, Carl; BRODERICK, John. International Law and Processes. In: FAURE, Michael (ed.) Elgar Encyclopedia of Environmental Law. Vol. 2. Cheltenham: Edward Elgar Publishing, 2016, pp. $35-51$.

BRULIN, Gran; SVENSSON, Lennart. Managing Sustainable Development Programmes: A Learning Approach To Change eBook Collection (EBSCOhost), EBSCOhost, 2011.

BUCHANAN, James M.; TOLLISON, Robert D.; TULLOCK, Gordon. Toward a Theory of RentSeeking. College Station: Texas A\&M University Press, 1980.

CABRERA, G. Countries with plastic bag bans. August 28, 2017. Available at: $<$ http://www.abc.net.au/news/2017-08-28/countries-with-plastic-bag-bans/8850284>. Accessed on August 31, 2017. 
CAMILLERI, Mark Anthony. Corporate Sustainability, Social Responsibility and Environmental Management: an introduction to theory and practice with case studies. Basel: Springer International Publishing AG, 2017.

CARLINI, Giulia; KLEINE, Konstantin. Advancing the international regulation of plastic pollution beyond the United Nations Environment Assembly resolution on marine litter and microplastics. Review of European, Comparative \& International Environmental Law, 27(3), 2019, pp. 234-244.

CARLISLE, Rodney P. Sovereignty for Sale: The Origins and Evolution of the Panamanian and Liberian Flags of Convenience. Annapolis: Naval Institute Press, 1981.

CARLTON, Dennis W.; LOURY, Glenn C. The Limitations of Pigouvian Taxes as a Long-Run Remedy for Externalities. The Quarterly Journal of Economics, 95(3), 1980, pp. 559-566.

CARLTON, Dennis W.; LOURY, Glenn C. The Limitation of Pigouvian Taxes as a Long-Run Remedy for Externalities: An Extension of Results. The Quarterly Journal of Economics, 101(3), 1986, pp. 631-634.

CARRINGTON, Damian. We are living on a plastic planet. What does it mean to our health? September 06, 2017. Available at: <https://www.theguardian.com/ environment/2017/sep/06/we-areliving-on-a-plastic-planet-what-does-it-mean-for-our-health>. Accessed on September 08, 2017.

CARRINGTON, Damian. Heathrow third runway ruled illegal over climate change. 27 February 2020. Available at: https:/www.theguardian.com/environment/2020/feb/27/heathrow-third-runwayruled-illegal-over-climate-change. Accessed on February 27, 2020.

CARTER, Norma; SILVA, Fernando Nunes da; MAGALHAES, Fernanda. Local Agenda 21: Progress in Portugal. European Urban and Regional Studies, 7(2), 2000, pp. 181-186.

Casa Civil da Presidência da República, Instituto de Pesquisa Econômica Aplicada. Avaliação de políticas públicas: guia prático de análise ex ante. Vol. 1. Brasília: Ipea, 2018.

CASSEL, Douglas; RAMASASTRY, Anita. White Paper: Options for a Treaty on Business and Human Rights. Notre Dame Journal of International and Comparative Law, 6(1), 2016, pp. 1-50.

CHANG, Dong-shang; KUO, Li-chin Regina. The Effects of Sustainable Development on Firms Financial Performance - an Empirical Approach. Sustainable Development, 16(6), 2008, pp. 365-380.

CHARNEY, Jonathan I. Transnational Corporations and Developing Public International Law. Duke Law Journal, 1983, pp. 748-788.

CHIMNI, B.S. Third world approaches to international law: A manifesto. International Community Law Review, 8(1), 2006, pp. 3-27.

CHOI, Yearn-Hong. Local Agenda 21: Seoul Toward an Environmental City. International Journal of Urban Sciences, 3(2), 1999, pp. 109-121.

CHOW, Lorraine. Kenya Enforces World's Toughest Law Against Plastic Bags. August 28, 2017. Available at: <https://www.ecowatch.com/kenya-plastic-bag-ban-2478631203.html $>$. Accessed on September 01, 2017.

CHRISTMANN, Petra; TAYLOR, Glen. Globalization and the Environment: Determinants of SelfRegulation in China. Journal of International Business Studies, 32, 2001, pp. 439-458. 
CLAPP, Jennifer; DAUVERGNE, Peter. Brief History of International Environmental Cooperation. In: NICHOLSON, Simon; WAPNER, Paul (eds.), Global Environmental Politics: from person to planet. New York: Routledge, 2016, pp. 121-136.

Climate Action. Adidas has sold one million shoes made from recycled ocean plastic. March 15, 2018. Available at: http://www.climateactionprogramme.org/news/adidas-has-sold-one-million-shoes-madefrom-recycled-ocean-plastic?utm_source=ActiveCampaign\&utm_medium=email\&utm_content $=$ -

Adidas $+\quad$ has + sold + one + million + shoes + made + from + recycle $\bar{d}+$ ocean + plastic +-+ Climate + Action + News\&utm_campaign=CA+Newsletter+16+March+2018. Accessed on June 16, 2018.

COASE, Ronald H. The Problem of Social Cost. The Journal of Law and Economics, 3, 1960, pp. 144.

COLL, Marta; et al. Sustainability implications of honouring the Code of Conduct for Responsible Fisheries. Global Environmental Change, 23, 2013, pp. 157-166.

Convention on Biological Diversity. 1995. Available at: https://www.cbd.int/doc/legal/cbd-en.pdf. Accessed on October 25, 2017.

Convention on the Conservation of Migratory Species of Wild Animals. 1975. Available at: http://www.cms.int/sites/default/files/instrument/CMS-text.en_.PDF. Accessed on October 27, 2017.

Convention on the Prevention of Marine Pollution by Dumping of Wastes and Other Matter (with amendments). 1972. Available at: http://www.imo.org/en/OurWork/Environment/ LCLP/Documents/LC1972.pdf. Accessed on October 18, 2017.

COOTER, Robert; ULEN, Thomas. Law and Economics. 6th ed., Berkeley: Berkeley Law Books, 2016. Available at: http://scholarship.law.berkeley.edu/books/2.

COSTA, Daiane. Lei Contra Sacolas Plástica não Pega no Rio. April 15, 2015. Available at: $<$ https://oglobo.globo.com/economia/defesa-do-consumidor/lei-contra-sacolas-plasticas-nao-pega-norio-15876913>. Accessed on September 01, 2017.

CULLET, Philippe. Differential Treatment in Environmental Law: Addressing Critiques and Conceptualizing the Next Steps. Transnational Environmental Law, 5(2), 2016, pp. 305-327.

CUNHA, Renato. Até 2024, todos os produtos da Adidas usarão apenas plástico recuperado do oceano. Available at: http://www.stylourbano.com.br/ate-2024-todos-os-produtos-da-adidas-usaraoapenas-plastico-recuperado-do-oceano/. Accessed on February 17, 2018.

DALHAMMAR, Carl.; LEIRE, Caroline. Långsiktiga effekter av miljöanpassad upphandling. Uppdragsforskningsrapport 2017:5. Konkurrensverket: Stockholm, 2017.

DAM, Cees van. Enhancing Human Rights Protection: A Company Lawyer's Business. Inaugural Lecture Rotterdam School of Management, Erasmus University, 18 September 2015.

DAM, Jinke van et al. Overview of recent developments in sustainable biomass certification. Biomass and Bioenergy, 32, 2008, pp. 749-780.

DECONINCK, Sam; WILDE, Bruno de. Benefits and Challenges of Bio- and Oxo-degradable plastics (DSL1), Gent: OWS, 2013.

DE GUCHTE, Cees Van. Sixth Meeting of the UN Open-ended Informal Consultative Processes on Oceans \& the Law of the Sea. Marine litter. June 6-10, 2005. Available at: 
http://www.un.org/Depts/los/consultative_process/consultative_process.htm. Accessed on: August 28, 2017.

DELZEIT, R.; HOLM-MULLER, K. Steps to discern sustainability criteria for a certification scheme of bioethanol in Brazil: Approach and difficulties. Energy, 34, 2009, pp. 662-668.

DÍAZ REVORIO, F. J. Derechos humanos y deberes fundamentales. Sobre el concepto de deber constitucional y los deberes en la Constitución Española de 1978. Revista del Instituto de Ciencias Jurídicas de Puebla, 5(28), 2011, pp. 278-310.

DI COSIMO, G. Dovere di difesa della patria, servizio militare, servizio civile. Archivio Pace Diritti Umani, 2011, pp. 55-66.

DOW. Redefining The Role of Business in Society: 2016 Sustainability Report. 2016. Available at: http://www.dow.com/-/media/dow/business-units/dow-us/pdf/science-and-sustainability/dow_2016_

sustainability_reportold.ashx?la=en-us. Accessed on September 21, 2017

DREIZEN, Charlotte. Where and How Ocean Plastic is Being Used as Feedstock. March, 2017. Available at: http://greenblue.org/where-and-how-ocean-plastic-is-being-used-as-feedstock/. Accessed on June 16, 2018.

DUPONT. Dupont Sustainability Reporting. Available at: http://www.dupont.com/ corporatefunctions/sustainability/sustainability-commitments/performance-reporting/ sustainabilityreports.html. Accessed on September 21, 2017.

DUPUY, Pierre-Marie; VIÑUALES, Jorge E. International Environmental Law. Cambridge: Cambridge University Press, 2015.

DURUIGBO, Emeka. Corporate Accountability and Liability for International Human Rights Abuses: Recent Changes and Recurring Challenges. Northwestern Journal of International Human Rights, 6(222), 2008, pp. 222-261.

Dutch Government. Policy Documents on Raw Materials. 2015. Available at: $<$ https://ec.europa.eu/docsroom/documents/10004/attachments/1/translations/en/renditions/pdf $>$. Accessed on: July 26, 2018.

DW. Big business vow to tackle plastic problem. January 17, 2017. Available at: http://www.dw.com/ en/big-businesses-vow-to-tackle-plastics-problem/a-37157762. Accessed on September 14, 2017.

DW. After China's import ban, where to with the world's waste? April 5, 2019. Available at: https://www.dw.com/en/after-chinas-import-ban-where-to-with-the-worlds-waste/a-48213871.

Accessed on August 24, 2019.

EBBESON, Jonas. The rule of law in governance of complex socio-ecological changes. Global Environmental Change, 20, 2010, pp. 414-422.

EBERLEIN, Burkard. Who Fills the Global Governance Gap? Rethinking the Roles of Business and Government in Global Governance. Organization Studies, 40(8), 2019, pp. 1125-1145.

ECHA - European Chemicals Agency. Microplastic: call for evidence on the use of intentionally added microplastic particles in products of any kind. 2018. Available at: $<$ https://echa.europa.eu/previous-calls-for-comments-and-evidence/-/substance-

rev/19224/term?_viewsubstances_WAR_echarevsubstanceportlet_SEARCH_CRITERIA_EC_NUMB $\mathrm{ER}=\&$ \&viewsubstances_WAR_echarevsubstanceportlet_DISS $=$ true $>$. Accessed on: July $\overline{31}, 2 \overline{0} 18$. 
ECKEBERG, Katarina; FORSBERG, Björn. Implementing agenda 21 in local government: The Swedish experience. Local Environment, 3(3), 1998, pp. 333-347.

EIJS, Judith. Interview given to Luisa Cortat Simonetti Goncalves. Maastricht (by telephone), 29 June 2018. Available at: luisacortat.com.

EIJSBOUTS, Jan. Corporate responsibility, beyond voluntarism: Regulatory options to reinforce the licence to operate. Inaugural Lecture delivered in an informal and abbreviated form at the acceptance of the appointment of Extraordinary Professor Corporate Social Responsibility at the Faculty of Law, Maastricht University, Maastricht, 20 October 2011.

EIJSBOUTS, Jan. Corporate Codes as Private Co-Regulatory Instruments in Corporate Governance and Responsibility and Their Enforcement. Indiana Journal of Global Legal Studies, 24(1), 2017, pp. 181-205.

ELGERT, Laureen. Certified discourse? The politics of developing soy certification standards. Geoforum, 43, 2012, pp. 295-304.

ELLEN MACARTHUR FOUNDATION. The New Plastics Economy: Rethinking the Future of Plastics. 2016. Available at: https://newplasticseconomy.org/assets/doc/EllenMacArthurFoundation_TheNewPlasticsEconomy_Pages.pdf. Accessed on 27 March, 2017.

ELLEN MACARTHUR FOUNDATION. New Plastics Economy initiative brings together 40 leading companies and cities. 2017(a). Available at: https://www.ellenmacarthurfoundation. org/news/newplastics-economy-initiative-brings-together-40-leading-companies-and-cities Accessed on 21 September 2017.

ELLEN MACARTHUR FOUNDATION. The New Plastics Economy: catalysing action. 2017(b). Available at: <https://newplasticseconomy.org/assets/doc/New-Plastics-Economy_ CatalysingAction_13-1-17.pdf $>$. Accessed on April 17 $7^{\text {th }}, 2018$.

ELLEN MACARTHUR FOUNDATION. Eleven companies take major step towards a New Plastics Economy. January 22, 2018(a). Available at: https://www.ellenmacarthurfoundation.org/news/11companies-take-major-step-towards-a-new-plastics-economy. Accessed on 16 January, 2019.

ELLEN MACARTHUR FOUNDATION. 'A line in the sand' - Ellen MacArthur Foundation Launches New Plastics Economy Global Commitment to eliminate plastic waste at source. October 29, 2018(b). Available at: https://www.ellenmacarthurfoundation.org/news/a-line-in-the-sand-ellenmacarthur-foundation-launch-global-commitment-to-eliminate-plastic-pollution-at-the-source.

Accessed on 16 January, 2019.

ENDO, S. et al. Concentration of polychlorinated biphenyls (PCBs) in beached resin pellets: Variability among individual particles and regional differences. Marine Pollution Bulletin, 50, 2005, pp. 1103-1114.

EROGLU, Yrd. Doç Dr. Muzaffer. How to Achieve Sustainable Companies: Soft Law (Corporate Social Responsibility and Sustainable Investment) or Hard Law (Company Law). Kadin Has Universitesi, Hukuk Fakultesi Dergisi, Haziran 2014, Cilt: 2 - Say 1:1. pp. 87-108.

ERP, Judith Van. Reputational Sanctions in Private and Public Regulation. Erasmus Law Review, 1(5), 2008, pp. 145-162.

ESPINER, Tom. Climate campaigners win Heathrow expansion case. 27 February 2020. Available at: https://www.bbc.com/news/business-51658693. Accessed on February 27, 2020. 
EUROPEAN COMMISSION. Council Regulation (EC) No 2371/2002 of 20 December 2002 on the conservation and sustainable exploitation of fisheries resources under the common fisheries policy. Official Journal (OJ) L 358/59 of 31 December 2002.

EUROPEAN COMMISSION. Public Procurement for a Circular Economy: Good practice and guidance. 2017. Available at: <http://www.oneplanetnetwork.org/sites/default/files/eu_public_procurement_circular_economy_2017.pdf>. Accessed on: July 30, 2018.

EUROPEAN COMMISSION. Full list of all identified agreements. Available at: $<$ http://ec.europa.eu/social/BlobServlet?docId=7000\&langId=en>. Accessed on April 13 ${ }^{\text {th }}, 2018$ (a).

EUROPEAN COMMISSION. Our Oceans, Seas and Coasts: The Barcelona Convention. Available at: $\quad \mathrm{http} / /$ ec.europa.eu/environment/marine/international-cooperation/regional-sea-conventions/barcelona-convention/index_en.htm. Accessed on February 10, 2018(b).

EUROPEAN COMMISSION. Communication from the Commission to the European Parliament, the Council, the European Economic and Social Committee of the Regions: A renewed EU strategy 201114 for Corporate Social Responsibility. Brussels, October 25 ${ }^{\text {th }}$, 2011. Available at: $<\mathrm{http} / /$ www.europarl.europa.eu/RegData/docs_autres_institutions/commission_europeenne/com/2011 /0681/COM_COM(2011)0681_EN.pdf $>$. Accessed on April 12 ${ }^{\text {th }}, 2018$.

EUROPEAN COMMISSION. EU and China join forces to improve international ocean governance. September 10, 2019. Available at: https://ec.europa.eu/maritimeaffairs/press/eu-and-china-join-forcesimprove-international-ocean-governance_en. Accessed on: February 21, 2020.

EUROPEAN COURT OF HUMAN RIGHTS. Case of Powell and Rayner v. The United Kingdom (Application no. 9310/81). 21 February 1990. Available at: https://hudoc.echr.coe.int/eng\#\{\%22itemid\%22:[\%22001-57622\%22]\}. Accessed on February 28, 2020.

EUROPEAN COURT OF HUMAN RIGHTS. Case of López Ostra v. Spain (Application no. 16798/90). 09 December 1994. Available at: https://hudoc.echr.coe.int/eng\#\{\%22itemid\%22:[\%22001-57905\%22]\}. Accessed on February 28, 2020.

EUROPEAN COURT OF HUMAN RIGHTS. Case of Guerra and others v. Italy (116/1996/735/932). 19 February 1998. Available at: https://hudoc.echr.coe.int/eng\#\{\%22itemid\%22:[\%2200158135\%22]\} Accessed on February 28, 2020.

EUROPEAN COURT OF HUMAN RIGHTS. Case of Hatton and others $v$. The United Kingdom (Application no. 36022/97). 8 July 2003. Available at: https://hudoc.echr.coe.int/eng\#\{\%22itemid\%22:[\%22001-61188\%22]\}. Accessed on February 28, 2020.

EUROPEAN COURT OF HUMAN RIGHTS. Case of Öneryildiz v. Turkey (Application no. 46117/99). November 10, 2004. Available at: https://hudoc.echr.coe.int/eng\#\{\%22itemid\%22:[\%22001-67401\%22]\}. Accessed on February 28, 2020.

EUROPEAN COURT OF HUMAN RIGHTS. Case of Tasskin and others v. Turkey (Application no. 48939/99). November 30, 2004. Available at: https://hudoc.echr.coe.int/eng\#\{\%22itemid\%22:[\%22001-67614\%22]\}. Accessed on February 28, 2020.

EUROPEAN COURT OF HUMAN RIGHTS. Case of Fadeyeva v. Russia (Application no. 55723/00). 9 June 2005. Available at: https://hudoc.echr.coe.int/eng\#\{\%22itemid\%22:[\%2200169315\%22]\}. Accessed on February 28, 2020.

EUROPEAN COURT OF HUMAN RIGHTS. Case of Dzemyuk v. Ukraine (Application no. 42488/02). 4 September 2014. Available at: https://hudoc.echr.coe.int/sites/fra/pages/search.aspx?i=001-146357. Accessed on February 28, 2020. 
FARBER, Daniel A. Public Choice Theory and Legal Institutions. In: PARISI, Francesco. The Oxford Handbook of Law and Economics. Oxford: Oxford University Press, 2017, pp. 181-201.

FARNELLI, Gian Maria; TANZI, Attila. Convention on the Prevention of Marine Pollution by Dumping of Wastes and Other Matter 1972 and 1996 Protocol, In: FITZMAURICE, Malgosia; TANZI, Attila (eds.), Elgar Encyclopedia of Environmental Law, Vol. 5. Cheltenham: Edward Elgar, 2017, pp. 175-183.

FAURE, Michael. How law and economics may contribute to the harmonisation of tort law in Europe. 2003. Available at: https://www.researchgate.net/publication/ 241873105How_law_and_economics_may_contribute_to_the_harmonisation_of tort_law_in_Europe. Accessed on September 29, 2017.

FAURE, Michael G.; DALHAMMAR, Carl. Principles for the Design of a Policy Framework to Address Product Life Cycle Impacts. In: MAITRE-EKERN, Eléonore; DALHAMMAR, Carl; BUGGE, Hans Christian (eds.), Preventing Environmental Damage from Products: An Analysis of the Policy and Regulatory Framework in Europe. Cambridge: Cambridge University Press, 2018, pp. 5786.

FAURE, Michael; SKOGH, Goran. The Economic Analysis of Environmental Policy and Law: An Introduction. Amsterdam: Elsevier, 2003.

FAURE, Michael; WEISHAAR, Stefan E. The role of environmental taxation: economics and the law. 2012. University of Groeningen Faculty of Law Research Paper Series. N. 04/2014.Available at: $\mathrm{http}: / / \mathrm{ssrn} . \mathrm{com} / \mathrm{abstract}=2370360$. Accessed on June 18, 2017.

FAURE, Michael G; PEETERS, Marjan; WIBISANA, Andri. Economic Instruments: Suited to Developing Countries? In: FAURE, Michael G.; NIESSEN, Nicole (eds.), Environmental Law in Development: Lessons from the Indonesian Experience. Cheltenham: Edward Elgar, 2006, pp. 218262.

FEARS, Darryl. A campaign to eliminate plastic straws is sucking in thousands of converts. 24 June, 2017. Available at: <https://www.washingtonpost.com/national/health-science/a-campaign-toeliminate-plastic-straws-is-sucking-in-thousands-of-converts/2017/06/ 24/d53f70cc-4c5a-11e7-9669250d0b15f83b_story.html?utm_term=.1d9bd75213e7>. Accessed on August 21, 2017.

FIDÉLIS, Teresa; PIRES, Sara Moreno. Surrender or resistance to the implementation of Local Agenda 21 in Portugal: the challenges of local governance for sustainable development. Journal of Environmental Planning and Management, 52(4), 2009, pp. 497-518.

Fifth ASEAN State of the Environment Report. Jakarta: ASEAN Secretariat, November 2017.

FINSKA, Linda; HOWDEN, Julie Gjortz. Troubled waters-Where is the bridge? Confronting marine plastic pollution from international watercourses. Review of European, Comparative \& International Environmental Law, 27(3), 2019, pp. 245-253.

FISNER, M.; TANIGUCHI, S; MOREIRA, F.; BICEGO, M. C.; TURRA, A. Polycyclic aromatic hydrocarbons (PAHs) in plastic pellets: Variability in the concentration and composition at different sediment depths in a sandy beach. Marine Pollution Bulletin, 70, 2013, pp. 219-226.

FLOHR, A. et al. The role of business in global governance: Corporations as norm entrepreneurs. Basingstoke, UK: Palgrave Macmillan, 2010. 
FOLHA VITÓRIA. Sacolas plásticas voltam a ser distribuidas gratuitamente em supermercados de Vila Velha. July 25, 2012. Available at: <http://m.folhavitoria.com.br/politica/noticia/2012/07/sacolasplasticas-voltam-a-ser-distribuidas-gratuitamente-em-supermercados-de-vila-velha.html $>$. Accessed on September 01, 2017.

Food and Agriculture Organization of the United Nations - FAO (Corporate Document Repository). List of delegates and observers. 1995. Available at: http://www.fao.org/docrep/x5585E/x5585e0c.htm\#b.listofdelegatesandobservers. Accessed on January 17, 2018.

Food and Agriculture Organization of the United Nations - FAO. Code of Conduct for Responsible Fisheries. 1995. Available at: http://www.fao.org/3/a-v9878e.pdf. Accessed on October 27, 2017.

Fourth ASEAN State of the Environment Report 2009. Jakarta: ASEAN Secretariat, October 2009.

FRANEKER, Jan A. van; LAW, Kara Lavender. Seabirds, gyres and global trends. Environmental Pollution, 203, 2015, pp. 89-96.

FRIEDMAN, Milton. The Methodology of Positive Economics. In: FRIEDMAN, Milton, Essays in Positive Economics. Chicago: University of Chicago Press, 1953, pp. 3-43.

FRIEDMAN, Milton. The Social Responsibility of Business is to Increase its Profits. The New York Times Magazine, September 13, 1970. Available at: <https://www.colorado.edu/studentgroups/libertarians/issues/friedman-soc-resp-business.html>. Accessed on 13 April 2018.

G1. Cientistas descobrem bactéria capaz de desintegrar plástico de garrafa PET. March 03, 2016. Available at: $<$ http://g1.globo.com/natureza/noticia/2016/03/ cientistas-descobrem-bacteria-capaz-dedesintegrar-plastico-de-garrafa-pet.html>. Accessed on September 04, 2017.

GALGANI F.; JAUNET S.; CAMPILLO A.; GUENEGEN X.; HIS E. Distribution and abundance of debris on the continental shelf of the North-Western Mediterranean. Marine Pollution Bulletin, 30(11), 1995, pp. 713-717.

GÁNDARA, Alejandra Martínez. The Law and Economics of Eco-Label. Thesis presented to the European Doctorate in Law and Economics. 25 April 2013. Available at: http://amsdottorato.unibo.it/5630/1/Thesis_Print_Version_\%282\%29.pdf. Accessed on December 29, 2018. p. 345 and 368.

GARCIA, Jackson M. Climate and Environmental Protection: International Funding. New York: Nova Science Publishers, 2014.

GARZÓN VALDÉS, E. Algunos comentarios críticos a las críticas de Juan Carlos Bayón y Francisco Laporta. Doxa, 3, 1986a, pp. 65-68.

GARZÓN VALDÉS, E. Los deberes positivos generales y su fundamentación. Doxa, 3, 1986b, pp. 17-33.

GEISTFELD, Mark. Economics, Moral Philosophy, and the Positive Analysis of Tort Law. In: POSTEMA, Gerald J. Philosophy and the Law of Torts. Cambridge: Cambridge University Press, 2001, pp. 250-275.

GEREMIAS, Daiana. Bolhas de água comestíveis podem substituir garrafas plásticas. April 13, 2017. Available at: https://www.tecmundo.com.br/curiosidade/ 115821-bolhas-agua-comestiveis-substituirgarrafas-plasticas.htm. Accessed on September 03, 2017. 
GIRARD, Nicholas et al. Microbeads: "Tip of the Toxic Plastic-berg"? Regulation, Alternatives, and Future Implications. Institute for Science, Society and Policy, April 11, 2016.

GLENDON, M.A. The Rule of Law in the Universal Declaration of the Human Rights. Northwestern Journal of International Human Rights, 2(1), 2004, article 5 [online]. Available on: https://scholarlycommons.law.northwestern.edu/cgi/viewcontent.cgi?article=1008\&context=njihr. Accessed on February 26, 2020.

GLOBAL JUSTICE NOW. 69 of the richest 100 entities on the planet are corporations, not governments, figures show. 2018. Available at: https:/www.globaljustice.org.uk/news/2018/oct/17/69richest-100-entities-planet-are-corporations-not-governments-figures-show. Accessed on October 21, 2018.

GONÇALVES, Luísa Cortat Simonetti. Um Passo Na Direção do Uso de Ferramentas Democráticas no Âmbito Internacional: a experiência dos diálogos pelo desenvolvimento sustentável na Rio+20. In: CONPEDI/UFF (org.). Direitos fundamentais e democracia I. 1ed. Rio de Janeiro: CONPEDI, 2012, pp. 135-164.

GONÇALVES, Luísa Cortat Simonetti; FABRIZ, Daury César. Dever Fundamental: a construção de um conceito. In: DE MARCO, Christian Magnus et al. (eds.), Série Direitos Fundamentais Civis: teoria geral e mecanismos de efetividade no Brasil e na Espanha - tomo I. Joaçaba: editora Unoesc, 2013, pp. 87-96.

GONÇALVES, Luísa Cortat Simonetti; FAURE, Michael Gerbert. International Law Instruments to Address the Plastic Soup. William \& Mary Environmental Law and Policy Review, 43(3), 2019, pp. 870-948.

GONÇALVES, Luísa Cortat Simonetti; PEDRA, Adriano Sant'Ana. Direito Internacional dos Deveres Humanos: reflexões para uma teoria internacional envolvendo atores privados. 2019 (publication pending)

GONZALEZ, Carmen. Environmental Justice, Human Rights, and the Global South. Santa Clara Journal of International Law, 13(1), 2015, pp. 151-160.

Government of the Netherlands. Green Deals Overview: progress report Green Deals 2011-2015. 2015. Available at: <https://www.greendeals.nl/wp-content/uploads/2015/06/Progress_reoprt_2011_2015_Green_Deals_ENG.pdf>. Accessed on April 23, 2018.

Government of the Netherlands. Breakthrough in combating plastic soup. March 12, 2018. Available at: $\quad<$ https://www.government.nl/topics/circular-economy/news/2018/03/12/breakthrough-incombating-plastic-soup $>$. Accessed on: August 31, 2018.

GREEN, Laura. Global Marine Plastic Waste and the Newly Recommended Amendment to the Basel Convention: a Bandage or a Bandaid? September 12, 2018. Available at: https://www.ejiltalk.org/global-marine-plastic-waste-and-the-newly-recommended-amendment-to-thebasel-convention-a-bandage-or-a-bandaid. Accessed on September 12, 2018.

Green Deal. GD166 - Scheepsafvalketen. 2014(a). Available at: <https://www.greendeals.nl/gd166scheepsafvalketen/>. Accessed on: July 26, 2018.

Green Deal. GD174 - Grondstoffen Waterschappen. 2014(b). Available at: $<$ https://www.greendeals.nl/gd174-grondstoffen-waterschappen/>. Accessed on: July 30, 2018. 
Green Deal. C-174 Green Deal Grondstoffen Unie van Waterschappen - Rijk. 2015(a). Available at: $<$ https://www.greendeals.nl/wp-content/uploads/2015/06/GD174-Grondstoffen-UvW-Rijk.pdf>. Accessed on: July 30, 2018.

Green Deal. Green Deal on Bioplastic. 2015(b). Available at: https://www.greendeals.nl/wpcontent/uploads/2015/06/GD157-samenvatting-Productie-Bioplastics-uit-Groente-Fruit-entuinafval.pdf Accessed on July 3, 2018.

Green Deal. International Green Deal North Sea Resources Roundabout. 2016. Available at: $<$ https://www.greendeals.nl/wp-content/uploads/2016/03/International-Green-Deal-text-NSRR.pdf>. Accessed on: July 30, 2018.

Green Deal. English. Available at: <https://www.greendeals.nl/english/>. Accessed on July 23, 2018(e).

Green Deal. Green Deal Approach. Available at: <https://www.greendeals.nl/english/green-dealapproach/>. Accessed on July 24, 2018(b).

Green Deal. Schepen kunnen gratis hun plastic inleveren. Available at: $<$ https://www.greendeals.nl/schepen-kunnen-gratis-hun-plastic-inleveren/>. Accessed on August 07, 2018(d).

GREENPEACE. Plastic Debris in World's Oceans. 2011(?) Available at: $<$ http://www.greenpeace.org/international/Global/international/planet-

2/report/2007/8/plastic_ocean_report.pdf $>$. Accessed on August 19, 2017.

GREENPEACE. Bottling it: the failure of major soft drink companies to address ocean plastic pollution. 2017a Available at: https://storage.googleapis.com/gpuk-static/legacy/BottlingIt_FINAL.pdf Accessed on August 20, 2017.

GREENPEACE. The Case Against Coca-Cola: how the world's biggest soft drink company is failing to address ocean plastic pollution. 2017b Available at: https://storage.googleapis.com/gpukstatic/legacy/the-case-against-coca-cola.pdf Accessed on August 20, 2017.

GREENPEACE. The Recycling Myth: Malaysia and the Broken Global Recycling System. November 2018. Available at: https://storage.googleapis.com/planet4-malaysia-stateless/2019/04/2fe6f833-therecycling-myth-malaysia-and-the-broken-global-recycling-system.pdf Accessed on August 24, 2019.

GREENPEACE. The Trash Vortex. 2017c. Available at: <http:/www.greenpeace.org/ international/en/campaigns/oceans/fit-for-the-future/pollution/trash-vortex/ $>$. Accessed on August 18, 2017.

GROCHOWALSKA, Justyna. The Implementation of Agenda 21 in Poland. Eur. Env., 8, 1998, pp. 79-85.

GROSZ, Mirina. Sustainable Waste Trade Under WTO Law: Chances and Risks of the Legal Frameworks' Regulation of Transboundary Movements of Wastes. Boston: Martinus Nijhoff Publishers, 2011.

GUZMAN, Andrew T.; MEYER, Timothy L. International Soft Law, Journal of Legal Analysis, 2, 2010, pp. 171-225.

HACKETT, David P. An Assessment of the Basel Convention on the Control of Transboundary Movements of Hazardous Waste and their Disposal. American University Journal of International Law and Policy, 5(2) ,1990, pp. 291-324. 
HAFFNER, Peter. An Intimation of the Apocalypse. NZZ Folio 07/2009. Available at: $<$ http://www.plasticgarbageproject.org/en/plastic-garbage/problems/plastic-garbage-gyre/peterhaffner-an-intimation-of-the-apokalypse/>. Accessed on August 19, 2017.

HAMANN, Renan. No futuro, você vai beber o refrigerante e comer a garrafa. February 23, 2012. Available at: $<$ https://m.tecmundo.com.br/ciencia/19705-no-futuro-voce-vai-beber-o-refrigerante-ecomer-a-garrafa.htm>. Accessed on September 03, 2017.

HARDIN, Garrett. The Tragedy of the Commons. Science, 162(3859), 1968, pp. 1243-1248.

HARRIS, Paul; UDAGAWA, Chihiro. Defusing the bombshell? Agenda 21 and economic development in China. Review of International Political Economy, 11(3), 2004, pp. 618-640.

HARRIS, Susan M. Does sustainability sell? Market responses to sustainability certification. Management of Environmental Quality. An International Journal, 18(1), 2007a, pp. 50-60.

HARRIS, Susan M. Green TickTM: an example of sustainability certification of goods and services. Management of Environmental Quality. An International Journal, 18(2), 2007b, pp. 167-178.

HATANAKA, Maki; BUSCH, Lawrence. Third-Party Certification in the Global Agrifood System: An Objective or Socially Mediated Governance Mechanism? Sociologia Ruralis, 48(1), 2008, pp. 7391.

HAUfLER, V. A Public Role for the Private Sector: Industry Self-Regulation in a Global Economy. Washington, DC: Carnegie Endowment for International Peace, 2001.

HAYWARD, Lauren. Does the Stock Market Value Inclusion on a Sustainability Index? An Event Study Using the Dow Jones Sustainability North America Index. Economics Department Student Scholarship 3, 2018.

HEINE, Dirk; FAURE, Michael; LAN, Chih-Ching. Augmenting Forest Sustainability Certificates with Fiscal Instruments. Rotterdam Institute of Law and Economics (RILE) Working Paper Series No. 2015/7. November 13, 2017.

HELIAS, Virginie. Vice President for Global Sustainability, P\&G, Maala Conference. 2017. Available at: https://www.youtube.com/watch?v=hDhGO5Y45lw. Accessed on July 11, 2018.

HENNIPMAN, Pieter. The Reasoning of a Great Methodologist: Marg Blaug on the Nature of Paretian Welfare Economics. De Economist, 4, 1992, pp. 413-445.

HERTOG, Johannes Aleidus den. Public and Private Interests in Regulation: Essays in the Law \& Economics of Regulation. Doctoral thesis presented to the Utrecht University on February $5^{\text {th }}, 2013$. Available at: https://dspace.library.uu.nl/handle/1874/724. Accessed on March 5, 2020.

HEY, Ellen. Reflections on an International Environmental Court. New York: Kluwer Law International, 2000.

HICKMAN, Matt. Kanye enacts world's toughest plastic bag ban. August 30, 2017. Available at: $<$ https://www.mnn.com/lifestyle/recycling/blogs/kenya-enacts-worlds-toughest-plastic-bag-ban>. Accessed on September 01, 2017.

HOLLMAN, P.C.H.; BOUWMEESTER, H.; PETERS, R.J.B. Microplastics in the aquatic food chain: sources, measurement, occurrence and potential health risks. Wageningen, RIKILT Wageningen UR (University \& Research Centre), RIKILT report 2013.003. 
HOOGLAND, Ellen. The Dutch State to Support the Ocean Cleanup's High Seas Activities. June 8, 2018. Available at: https://www.theoceancleanup.com/updates/the-dutch-state-to-support-the-oceancleanups-high-seas-activities/. Accessed on July 2, 2018.

HOPEWELL, J.; DVORAK, R.; KOSIOR, E. Plastics recycling: challenges and opportunities. Philosophical Transactions of the Royal Society of London. Series B, Biological sciences, 364, 2009, pp. 2115-2126.

HOSCH, Gilles; FERRARO, Gianluca; FAILLIER, Pierre. The 1995 FAO Code of Conduct for Responsible Fisheries: Adopting, implementing or scoring results? Marine Policy, 35, 2011, pp. 189200.

HOURELD, Katharine; NDISO, John. Kenya imposes world's toughest law against plastic bags. August 28, 2017. Available at: < https://www.reuters.com/article/us-kenya-plastic/kenya-imposesworlds-toughest-law-against-plastic-bags-idUSKCN1B80NW>. Accessed on September 01, 2017.

HOVING, Henk. Interview conducted by Luisa Cortat Simonetti Goncalves in The Hague, on June 12th, 2018. Available at: luisacortat.com.

HUTCHISON, Terence W. Positive Economics and Policy Objectives. London: George Allen \& Unwin, 1964.

INDORAMA VENTURES. Indorama Ventures Sustainability Report 2016. 2016. Available at: www.indoramaventures.com/EN/CSResponsibility/pdf/sustainability_report_2016.pdf. Accessed on September 26, 2017.

INTER-AMERICAN COURT OF HUMAN RIGHTS. Case of the Mayagna (Sumo) Awas Tingni Community v. Nicaragua. Judgement on 31 August 2001. Available at: http://www.corteidh.or.cr/docs/casos/articulos/seriec_79_ing.pdf. Accessed on February 28, 2020.

INTER-AMERICAN COURT OF HUMAN RIGHTS. Case of the Saramaka People v. Suriname. Judgement on 28 November 2007. Available at: http://www.corteidh.or.cr/docs/casos/articulos/seriec_172_ing.pdf. Accessed on February 28, 2020.

INTER-AMERICAN COURT OF HUMAN RIGHTS. Case of the Kichwa Indigenous People of Sarayaku v. Ecuador. Judgement on 27 June 2012. Available at: http://corteidh.or.cr/docs/casos/articulos/seriec_245_ing.pdf. Accessed on February 28, 2020.

INTER-AMERICAN COURT OF HUMAN RIGHTS. Case of the Afro-Descendant Communities Displaced From The Cacarica River Basin (Operation Genesis) V. Colombia. Judgement on 20 November 2013. Available at: http://www.corteidh.or.cr/docs/casos/articulos/seriec_270_ing.pdf. Accessed on February 28, 2020.

INTERNATIONAL COURT OF JUSTICE. Statute of the International Court of Justice. 1945. Available at: https://www.icj-cij.org/en/statute. Accessed on March 3, 2020.

INTERNATIONAL MARINE ORGANIZATION - IMO. Convention on the Prevention of Marine Pollution by Dumping of Wastes and Other Matter. 1978. Available at: http://www.imo.org/en/OurWork/Environment/LCLP/Pages/default.aspx. Accessed on February 2, 2018.

INTERNATIONAL MARITIME ORGANIZATION - IMO. List of conventions, other multilateral instruments and amendments in respect of which the organization performs depositary and other functions (as at 10 July 2017). Available at: http://www.imo.org/en/About/Conventions/StatusOfConventions/Documents/List $\% 20$ of $\% 20$ instruments.pdf. Accessed on November 8, 2017. 
INTERNATIONAL MARITIME ORGANIZATION - IMO. Status of Conventions: excel chart listing ratifications by state. 2017. Available at: http://www.imo.org/en/About/Conventions/StatusOfConventions/Documents/status-x.xls. Accessed on October 31, 2017.

INTERNATIONAL NAVIGATION ASSOCIATION - ENVIRONMENT COMMISSION. Report of the Working Group 136: Sustainable Maritime Navigation. January, 2013. Available at: http://www.imo.org/en/OurWork/Environment/LCLP/recentevents/Documents/PIANC \%20report\%20for\%20SG37.pdf. Accessed on November 10, 2017.

IUCN Eastern Africa Programme, Conservation of Coastal and Marine Biodiversity in the Eastern Africa Region: progress in implementation of the Jakarta Mandate by the contracting parties to the Nairobi Convention. April 2001. Available at: https://portals.iucn.org/library/sites/library/files/documents/2001-027.pdf. Accessed on November 12, 2017.

JACKSON, Guy; MORPETH, Nigel. Local Agenda 21 and Community Participation in Tourism Policy and Planning: Future or Fallacy. Current Issues in Tourism, 2(2), 1999, pp. 1-38.

JAMBECK, Jenna R. et al. Plastic waste: inputs from land into the ocean. Science, 347, 2015, pp. 768771.

JAMBECK, Jenna R. et al. Dataset on Plastic Waste in LMCs. August 6, 2018. Available at: https://data.opendevelopmentmekong.net/dataset/dataset-on-plastic-waste-in-lmcs-

jambeck/resource/b270b23b-0192-4f86-bc59-160866690f21?inner_span=True. Accessed on February $24,2020$.

JANSEN, Judith; VELDHUIS, Floor; SCHREUDER, Marleen. Towards a European ban in microbeads. February 17, 2017. Available at: $<$ http://leidenlawblog.nl/articles/ towards-a-europeanban-on-microbeads>. Accessed on: July 31, 2018.

Japan Ministry of Economy, Trade and Industry - METI. Fourteenth Meeting of the Conference of the Parties to the Basel Convention (COP14) Held. May 14 ${ }^{\text {th }}$. 2019. Available at: https://www.meti.go.jp/english/press/2019/0514_002.html. Accessed on September 29, 2019.

Jeffrey Sachs Center on Sustainable Development. Sustainable Development Goals (SDGS). Available at: http://jeffreysachs.center/sdg. Accessed on November 14, 2017.

JENNINGS, Sir Robert. Need for an Environmental Court? Environmental Policy and Law, 20, 1992, pp. 312-314.

JOHNSTON, Ian. Microbeads ban: Government to outlaw microplastics in cosmetic products. July 21, 2017. Available at: <http://www.independent.co.uk/environment/ microbeads-ban-bill-ukcosmetic-products-government-outlaws-microplastics-a7852346.html?amp $>$. Accessed on August 31, 2017.

JORBY, Sofie Adolfsson. Local Agenda 21 in Practice - A Swedish Example. Sustainable Development, 8, 2000, pp. 201-214.

JORBY, Sofie Adolfsson. Local Agenda 21 in Four Swedish Municipalities: A Tool towards Sustainability? Journal of Environmental Planning and Management, 45(2), 2002, pp. 219-244.

JORDAN, Andrew; O'RIORDAN, Tim. The Multilateral Ozone Fund of the Montreal Protocol: Institutions for global environmental change. Global Environmental Change, 8(2), 1998, pp. 171-175. 
KAISER, Jocelyn. The Dirt on Ocean Garbage Patches. Science, 328, 2010, pp. 1506-1506. Downloaded from science.sciencemag.org on August 11, 2017.

KARLSSON, Sylvia. The North-South Knowledge Divide: Consequences for Global Environmental Governance. In: Daniel C Esty and Maria H Ivanova (eds.), Global Environmental Governance, volume 2, Yale Center for Environmental Law and Policy, 2002, pp. 53-76.

KARUMBA, Tony. Hasta cuatro años de cárcel por usar bolsas de plástico en Kenia. September 01, 2017. Available at: <https://elpais.com/elpais/2017/08/31/album/1504192893_734936.html\#1504192893_734936_1504200196>. Accessed on September 01, 2017.

KATZ, Cheryl. Piling Up: How China's Ban on Importing Waste Has Stalled Global Recycling. March 7, 2019. Available at: https://e360.yale.edu/features/piling-up-how-chinas-ban-on-importingwaste-has-stalled-global-recycling. Accessed on August 24, 2019.

KAZA, Silpa et al. What a waste 2.0: A Global Snapshot of Solid Waste Management to 2050. Urban Development Series. Washington, DC: World Bank, 2018.

KELLENBERG, Derek; LEVINSON, Arik. Waste or Effort? International Environmental Agreements. National Bureau of Economic Research October 2013, Working Paper 19533, p. 29.

KERKMEESTER, Heico. Methodology: General. In: BOUCKAERT, Boudewijn; GEEST, Gerrit de (eds.), Encyclopedia of Law and Economics. Volume I: The History and Methodology of Law and Economics. Cheltenham: Edward Elgar, 2000, pp. 383-401.

KERN, Kristine; KOLL, Claudia; SCHOPHAUS, Malte. The diffusion of Local Agenda 21 in Germany: Comparing the German federal states. Environmental Politics, 16(4), 2007, pp. 604-624.

KHAKEE, Abdul. Assessing Institutional Capital Building in a Local Agenda 21 Process in Goteborg. Planning Theory \& Practice, 3(1), 2002, pp. 53-68.

KHENG-LIAN, Koh; ROBINSON, Nicholas A.; LIN-HENG, Lye. ASEAN Environmental Legal Integration: Sustainable Goals? Cambridge: Cambridge University Press, 2016.

KINDERMAN, Daniel. Time for a reality check: Is business willing to support a smart mix of complementary regulation in private governance? Policy and Society, 35, 2016, pp. 29-42.

KNIGHT, Stephen. Agenda 21 in New Zealand: Not Dead, Just Resting. Australian Journal of Environmental Management, 7(4), 2000, pp. 213-222.

KNOX, John. The Global Pact for the Environment: At the crossroads of human rights and the environment. Review of European, Comparative and International Environmental Law, 28(1), 2019, pp. $40-47$.

KOHN, Robert E. The Limitations of Pigouvian Taxes as a Long-Run Remedy for Externalities: Comment. The Quarterly Journal of Economics, 101(3), 1986, pp. 625-630.

KOLBEN, K. Integrative linkages: combining public and private regulatory approaches in the development of trade and labor regimes. Harvard International Law Journal, 48(1), 2007, pp. 203256.

KOLK, Ans; TULDER, Rob van; and WELTERS, Carlijn. International codes of conduct and corporate social responsibility: can transnational corporations regulate themselves? Transnational Corporations, 8(1), 1999, pp. 143-180. 
KOPPELL, Jonathan G.S. World Rule: Accountability, Legitimacy, and the Design of Global Governance. Chicago: University of Chicago Press, 2010.

KOUBI, M.G. La déférence, un devoir sans droit? Communications, 69, 2000, pp. 201-214.

KRALSTEIN, Michael. Post Consumer Recycled Resin. Available at: https://www.aaapolymer.com/post-consumer-recycled-resin/. Accessed on 21 January 2019.

KRUGMAN, Paul. Environmentall Economics 101: Overcoming Market Failures. In: NICHOLSON, Simon; WAPNER, Paul (eds.), Global Environmental Politics: from person to planet. New York: Routledge, 2015, pp. 164-172.

KRZAN, Andrej et al. Standardization and certification in the area of environmentally degradable plastics. Polymer Degradation and Stability, 91, 2006, pp. 2819-2833.

KUMMER, Katharina. The international regulation of transboundary traffic in hazardous wastes: The 1989 Basel convention. International and Comparative Law Quarterly, 41(3), 1992, pp. 530-562.

KVETON, Viktor; LOUDA, Jiri; SLAVIK, Jan; PELUCHA, Martin. Contribution of Local Agenda 21 to Practical Implementation of Sustainable Development: The Case of the Czech Republic. European Planning Studies, 22(3), 2014, pp. 515-536.

LA BRECQUE, Sara. 6 problematic plastic products and the companies finding solutions. June 28, 2017. Available at: https://www.theguardian.com/suez-circular-economy-zone/2017/jun/28/6problematic-plastic-products-and-the-companies-finding-solutions. Accessed on August 27, 2017.

LANCHESTER, F. Los deberes constitucionales en el derecho comparado. Revista de Derecho Constitucional Europeo, 7(13), 2010, pp. 67-81.

LANDES, Xavier. Pigouvian Tax. In: IDOWU, S.O. et al. (eds.), Encyclopedia of Corporate Social Responsibility. Berlin: Springer-Verlag Berlin Heidelberg, 2013, pp. 1846-1853.

LANT, Karla. Kenya just banned plastic bags - and the fine is up to $\$ 38.000,00$ and jail time. August 29, 2017. Available at: <http://www.businessinsider.com/kenya-just-banned-plastic-bags-20178? international $=$ true $\& \mathrm{r}=\mathrm{US} \& \mathrm{IR}=\mathrm{T}>$. Accessed on August 31, 2017.

LAPORTA, F. J. Algunos problemas de los deberes positivos generales (observaciones a un artículo de Ernesto Garzón Valdés). Doxa, 3, 1986, pp. 55-63.

LEBRETON, Laurent C.M. et al. River plastic emissions to the world's oceans. Nature Communications, 8, 2017, pp. 15611-15620.

LEE, Yen Nee. The world is scrambling now that China is refusing to be a trash dumping ground. April 16, 2018. Available at: https://www.cnbc.com/2018/04/16/climate-change-china-bans-import-offoreign-waste-to-stop-pollution.html. Accessed on March 20, 2020.

LEE, Yen Nee. Malaysia, following in China's footsteps, bans imports of plastic waste. January 25, 2019. Available at: https://www.cnbc.com/2019/01/25/climate-change-malaysia-following-chinabans-plastic-waste-imports.html. Accessed on August 24, 2019.

LEE, Ki-Hoon; SAEN, Reza Farzipoor. Measuring corporate sustainability management: A data envelopment analysis approach. Int. J. Production Economics, 140, 2012, pp. 219-226. 
LEEUWEN, Kees van; VRIES, Eli de; KOOP, Stef; ROEST, Kees. The Energy and Raw Materials Factory: Role and Potential Contribution to the Circular Economy of the Netherlands. Environmental Management, 61, 2018, pp. 786-795. https://doi.org/10.1007/s00267-018-0995-8.

LEIRE, Charlotte; DALHAMMAR, Carl. Long-Term Market Effects of Green Public Procurement. In: MAITRE-EKERN, Eléonore; DALHAMMAR, Carl; BUGGE, Hans Christian (eds.), Preventing Environmental Damage from Products: An Analysis of the Policy and Regulatory Framework in Europe. Cambridge: Cambridge University Press, 2018, pp. 303-334.

LESLIE, H.A. Review of Microplastics in Cosmetics: scientific background on a potential source of plastic particulate marine litter to support decision-making. IVM Institute for Environmental Studies. Report R14/29 July 2014.

LEWIS, Melissa; TROUWBORST, Arie. Bonn Convention on the Conservation of Migratory Species of Wild Animals 1979. In: FITZMAURICE, Malgosia; TANZI, Attila (eds.), Elgar Encyclopedia of Environmental Law. Vol. 5. Cheltenham: Edward Elgar, 2017, pp. 25-34.

LIBECAP, Gary D.; WIGGINS, Steven N. Contractual Responses to the Common Pool: Prorationing of Crude Oil Production. American Economic Review, 74, 1994, pp. 87-98.

LIMA, Paola. Sacola plástica é uma das maiores vilãs do meio ambiente. April 19, 2016. Available at: $<$ http://www12.senado.leg.br/noticias/materias/2016/04/19/sacola-plastica-e-uma-das-maiores-vilasdo-meio-ambiente>. Accessed on September 01, 2017.

LITZ, Franz T. Harnessing Market Forces in Natural Resources Management: Lessons from the Surf Clam Fishery. British Columbia Environmental Affairs Law Review, 21, 1994, p. 335-361.

LOCKE, Richard M. et. al. Beyond corporate codes of conduct: work organization and labour standards at Nike's suppliers. International Labour Review, 146, 2007, pp. 21-40.

LOCKE, Richard M. The Promise and Limits of Private Power. London: Cambridge University Press, 2013.

LOCKE, Richard M.; ROMIS, Monica. The promise and perils of private voluntary regulation: Labor standards and work organization in two Mexican garment factories, Review of International Political Economy, 17(1), 2010, pp. 45-74.

LOCKE, Richard M; RISSING, Ben A.; PAL, Timea. Complements or Substitutes? Private Codes, State Regulation and the Enforcement of Labour Standards in Global Supply Chains. British Journal of Employment Relations, 51(3), 2013, pp. 519-552.

LOFGREN, Kristine. Costa Rica aims to become the first country to ban all single-use plastics. July 08, 2017. Available at: <http://inhabitat.com/costarica-aims-to-become-the-first-country-to-ban-allsingle-use-plastics/?utm_cotent=buffer7860d\&utm>. Accessed on August 31, 2017.

L'OREAL. 2015 Annual Report. 2015. Available at: http://loreal-dam-front-resources-corp-encdn.brainsonic.com/ressources/afile/138434-b5625-resource-annual-report-2015.pdf. Accessed on September 21, 2017.

LOTT, John; KARPOFF, Jonathan M.; RANKINE, Graeme. Environmental Violations, Legal Penalties, and Reputation Costs. Chicago, Ill: University of Chicago, Law School, 1999.

LOZANO, Rodrigo. Analyzing the use of tools, initiatives, and approaches to promote sustainability in corporations. Corporate Social Responsibility and Environmental Management, 2019, pp. 1-17. 
LU, Mengxing; FAURE, Michael G. The Regulation of Corporate Environmental Responsibility. In: PHILIPSEN, Niels et al. (eds.), Market Integration: the EU experience and implications for regulatory reform in China, China-EU Law Series 2. Berlin: Springer-Verlag, 2016, pp. 239-265.

LUI, Kevin. Violators of Kenya's Tough New Plastic Bag Law Could Get Four Years Behind Bars. August 29, 2017. Available at: <http://time.com/4919720/kenya-plastic-bag-law-jail-fines/>. Accessed on September 01, 2017.

LUKEN, Ralph Luken; GROF, Tamas. The Montreal Protocol's multilateral fund and sustainable development. Ecological Economics, 56, 2006, pp. 241-255.

LYON, T. et al. CSR needs CPR: Corporate sustainability and politics. California Management Review, 60, 2018, pp. 5-24.

M\&S. Plan A|2025: Plan A 2025 Commitments. Available at: https://corporate.marks andspencer.com/documents/plan-a/plan-a-2025-commitments.pdf. Accessed on September 26, 2017.

MAGAR, Surya Bahadur et al. Growing trade of bioenergy in the EU: Public acceptability, policy harmonization, European standards and certification needs. Biomass and bioenergy, 35, 2011, pp. 3318-3327.

MAGRAW, Daniel Barstow; UDOMRITTHIRUJ, Patsorn. Water and multilateral environmental agreements: an incomplete jigsaw puzzle. In: MCCAFFREY, Stephen C.; LEB, Christina; DENOON, Riley T. (eds.), Research Book on International Water Law. Cheltenham: Edward Elgar Publishing, 2019, pp. 166-185.

MALHEIROS, Tadeu Fabricio; PHLIPPI Jr., Arlindo; COUTINHO, Sonia Maria Viggiani. Agenda 21 Nacional e Indicadores de Desenvolvimento Sustentavel: contexto brasileiro. Saúde Sociedade, 17(1), 2008, pp. 7-20.

Marine Litter Watch. Available at: https://www.eea.europa.eu/themes/water/europes-seas-andcoasts/marine-litterwatch. Accessed on January 09, 2018.

MARS. Sustainability at Mars, Incorporated. October, 2009. Available at: <https://www.pseg.com/ family/holdings/global/solar_source/pdf/Sustainability\%20Fact\%20Sheet.pdf $>$. Accessed on September 22, 2017.

MARS. Our Approach to Sustainability. Available at: http:/www.mars.com/global/sustainable-in-ageneration/our-approach-to-sustainability. 2017. Accessed on September 22, 2017.

MAZZUOLI, Valerio de Oliveira; TEIXEIRA, Gustavo de Faria Moreira. $O$ direito internacional do meio ambiente e o greening da Convenção Americana sobre Direitos Humanos, 2013. Available at: http://www.scielo.br/pdf/rdgv/v9n1/a08v9n1.pdf. Accessed on 25 August 2019.

MBENGUE, Makane Moise; ODILI, Nwamaka. West African approaches to international water law and treaty practice. In: MCCAFFREY, Stephen C.; LEB, Christina; DENOON, Riley T. (eds.), Research Book on International Water Law. Cheltenham: Edward Elgar Publishing, 2019, pp. 361378.

MCCALLION, Kenneth; SHARMA, Rajan. Environmental Justice without Boarders: The Need for an International Court of the Environment to Protect Fundamental Environmental Rights. George Washington Journal of International Law and Economics, 32, 2000, p. 351-365. 
MCCAULEY, Douglas. This is how China can be a friend to ocean conservation. 25 June 2019. Available at: https://www.weforum.org/agenda/2019/06/oceans-china-conservation/. Accessed on February 21, 2020.

MCCORQUODALE, Robert; SMIT, Lise; NEELY, Stuart; BROOKS, Robin. Human Rights Due Diligence in Law and Practice: Good Practices and Challenges for Business Enterprises. Business and Human Rights Journal, 2, 2017, pp. 195-224.

MCNAUGHTON, Sean; NOWAKOWSKI, Kelsey. How China's plastic waste ban forced a global recycling reckoning. June 2019. Available at: https://www.nationalgeographic.com/magazine/2019/06/china-plastic-waste-ban-impacting-countries-worldwide/\#close. Accessed on August 24, 2019.

MEADOWS, Donella et al. The Limits to Growth: A Report for the Club of Rome's Project on the Predicament of Mankind. New York: Universe, 1972.

MEIER-WEHREN, Bettina. The Global Programme of Action for the Protection of the Marine Environment from Land-Based Activities. New Zealand Journal of Environmental Law, 17, 2013, pp. $1-40$.

MERCER, David; JOTKOWITZ, Benjamin. Local Agenda 21 and Barriers to Sustainability at the Local Government Level in Victoria, Australia. Australian Geographer, 31(2), 2000, pp. 163-181.

MEYER-BISCH, P. Les devoirs de l'homme: de la réciprocité dans les droits de l'homme. Fribourg: Étidions Universitaires, 1989.

MICELI, Thomas J. The Economic Approach to Law. Stanford: Stanford University Press, 2004.

MICELI, Thomas J. Economic Models of Law. In: PARISI, Francesco (ed.), The Oxford Handbook of Law and Economics. Volume I: Methodology and concepts. Oxford: Oxford University Press, 2017, pp. 9-28.

MICKELSON, Karin. South, North, International Environmental Law, and International Environmental Lawyers. Yearbook of International Environmental Law, 11, 2000, p. 52-81.

MICKELSON, Karin. Beyond a Politics of the Possible: South-North Relations and Climate Justice. Melbourne Journal of International Law, 10, 2009, p. 411-423.

MILLER, James C. III. The FTC and Voluntary Standards: Maximizing the Net Benefits of SelfRegulation. Cato Journal, 4(3), 1985, pp. 897-904.

MITKIDIS, Katerina. Peterkova. Sustainability Clauses in International Supply Chain Contracts: Regulation, Enforceability and Effects of Ethical Requirements. Nordic Journal of Commercial Law, 1, 2014, pp. 1-30.

MORRIS, Jim. Lost at Sea: "Flags of Convenience" give owners a paper refuge. Houston Chronicle, 22, 1996, pp. 15-45.

MURPHY, Sean. Does the World Need a New International Environmental Court? George Washington Journal of International Law and Economics, 32, 2000, p. 333-349.

MUTUA, Makau. What is Twail? American Society of International Law Proceedings, 94(31), 2000, pp. 31-39. 
NABAIS, J.C. A face oculta dos direitos fundamentais: os deveres e os custos dos direitos. Revista Direito Mackenzie, 3(2), 2002, pp. 11-30.

NABAIS, J.C. Por uma liberdade com responsabilidade. Coimbra: Coimbra, 2007.

National Geographic. Plástico - Nós o criamos. Dependemos dele. Mas ele nos ameaça. May, 2018. Available at: https://www.nationalgeographicbrasil.com/2018/05/lixo-plastico-planeta-poluicao-lixaoconsumo. Accessed on June 1, 2018.

National Institute for Public Health and the Environment (RIVM). Quick Scan and Prioritization of Microplastic Sources and Emissions: RIVM Letter Report 2014-0156. 2014. Available at: https://www.rivm.nl/bibliotheek/rapporten/2014-0156.pdf. Accessed on May 10, 2018.

NATUREWORKS. About Nature Works. Available at: http://www.natureworksllc.com/About-Nature Works. Accessed on September 26, 2017.

New Plastics Economy. Plastics Pact. 2018(a). Available at: $<$ https://newplasticseconomy.org/projects/plastics-pact $>$. Accessed on: August 09, 2018.

New Plastics Economy. The initiative. 2018(b). Available at: <https://newplasticseconomy.org/ about>. Accessed on April 17 $7^{\text {th }}, 2018$.

New Plastics Economy. The New Plastics Economy. 2018(c). Available at: <https://newplastics economy.org/>. Accessed on April 17 $7^{\text {th }}, 2018$.

NOLL, Roger. The Political Foundations of Regulatory Policy. Zeitschrift fur die gesamte staatwissenschaft, 139, 1983, pp. 377-404.

NOLL, Roger. Economic perspectives on the politics of regulation. In: SCHMALENSEE, Richard; WILLIG, Robert D. (eds.), Handbook of Industrial Organization II. Amsterdam: Elsevier, 1989, pp. 1253-1287.

NOVAMONT. Sustainability Report 2015: the results of a constant commitment. 2015. Available at: http://www.novamont.com/public/RdS/RdS_VolumeI_ENGLISH.pdf. Accessed on September 27, 2017

OBERNDORFER, Ulrich; SCHMIDT, Peter; WAGNER, Marcus; ZIEGLER, Andreas. Does the stock market value the inclusion in a sustainability stock index? An event study analysis for German firms. Journal of Environmental Economics and Management, 66, 2013, pp. 497-509.

OBERTHUR, Sebastian. Clustering of multilateral environmental agreements: potentials and limitations. In: CHAMBERS, W. Bradnee; GREEN, Jessica F. (eds.), Reforming International Environmental Governance: From Institutional Limits to Innovative Reforms. New York: United Nations University Press, 2005, pp. 40-65.

OCEANS \& LAW OF THE SEA - UNITED NATIONS. The United Nations Convention on the Law of the Sea: A Historical Perspective. 1998. Available at: http://www.un.org/Depts/los/convention_agreements/convention_historical_perspective.htm. Accessed on November 8, 2017.

OCEANS \& LAW OF THE SEA - UNITED NATIONS. United Nations Convention on the Law of the Sea: Declarations made upon signature, ratification, accession or succession or anytime thereafter. 2018. Available at: <http://www.un.org/depts/los/convention_agreements/convention_declarations.htm>. Accessed on January 17, 2018. 
ODEGARD, Ingrid et al. Biobased Plastics in a Circular Economy: Policy suggestions for biobased and biobased biodegradable plastics. CE Delft: Delft, 2017. Available at: https://www.cedelft.eu/en/publications/2022/biobased-plastics-in-a-circular-economy. Accessed on November 17, 2017.

OEC. Which countries export Scrap Plastic? 2017(a). Available at: https://oec.world/en/visualize/tree_map/hs92/export/show/all/3915/2017/ Accessed on August 24, 2019.

OEC. Which countries import Scrap Plastic? 2017(b). Available at: https://oec.world/en/visualize/tree_map/hs92/import/show/all/3915/2017/. Accessed on August 24, 2019.

OECD. Extended Producer Responsibility. 2018. Available at: http://www.oecd.org/env/ toolsevaluation/extendedproducerresponsibility.htm. Accessed on October 16, 2018.

OECD. Where: global reach, 2019. Available at: https://www.oecd.org/about/members-and-partners/. Accessed on August 24, 2019.

O GLOBO. Produzir ou usar sacolas plásticas no Quênia poderá levar à prisão. August 28, 2017. Available at: <https://oglobo.globo.com/sociedade/sustentabilidade/ produzir-ou-usar-sacolasplasticas-no-quenia-podera-levar-prisao-21755715>. Accessed on September 01, 2017.

OGUS, Anthony I. Competition Between National Legal Systems: A Contribution of Economic Analysis to Comparative Law. International and Comparative Law Quarterly, 48, 1999, pp. 405-418.

OGUS, Anthony I. Regulation: Legal Form and Economic Theory. Portland: Hart Publishing, 2004 (ebook Kindle).

OKAFOR, Obiora. Newness, imperialism, and international legal reform in our time: A TWAIL perspective. Osgoode Hall Law Journal, 43(1-2), 2005, pp. 171-191.

OLIVER, C.; HOLZINGER, I. The effectiveness of strategic political management: A dynamic capabilities framework. Academy of Management Review, 33, 2008, pp. 496-520.

One Planet. Green Deal Circular Procurement. January 15, 2018. Available at: $<\mathrm{http}: / / \mathrm{www} . o n e p l a n e t$ network.org/initiative/green-deal-circular-procurement $>$. Accessed on: July 30,2018 .

OOSTERHUIS, Frans. Free plastic waste disposal in the ports of Rotterdam and Amsterdam. December, 2016. Available at: <https://ieep.eu/uploads/articles/attachments/552a9429-b172-44dab311-121a8d4623f0/NL\%20Port\%20Plastic\%20Waste\%20final.pdf? $\mathrm{v}=63$ 680923242>. Accessed on: July 26, 2018.

ORGANIZATION OF AFRICAN UNITY. African Charter on Human and Peoples Rights. 27 June 1981. Available at: http://www.humanrights.se/wp-content/uploads/2012/01/African-Charter-onHuman-and-Peoples-Rights.pdf. Accessed on February 28, 2020.

O'RIORDAN, Tim; VOISEY, Heather (eds.), Sustainable Development in Western Europe: coming to terms with Agenda 21. London: Frank Cass, 1997.

ORLITZKY, M., SCHMIDT, F. L.; RYNES, S. Corporate Social and Financial Performance: A MetaAnalysis. Organization Studies, 24(3), 2003, pp. 403-441. 
ORTAS, Eduardo; MONEVA, José M. Sustainability stock exchange indexes and investor expectations: Multivariate evidence from DJSI-Stoxx. Revista Española de Financiación y Contabilidad, XL(151), 2011, pp. 395-416.

P\&G. 2015 Sustainability Report. 2015. Available at: http://us.pg.com/media/PGCOMUS/Documents/PDF/Sustanability_PDF/sustainability_reports/PG2015SustainabilityReport.pdf?la=enUS. Accessed on September 14, 2017.

PACCES, Alessio M.; VISSCHER, Louis. Methodology of Law and Economics. In: KLINK, Bart van; TAKEMA, Sanne (eds.), Law and Method: Interdisciplinary Research into Law. Tubigen: Mohr Siebeck, 2011, pp. 85-107.

PAISLEY, Richard K.; CURLIER, Maaria. Creating basin mechanisms in Southern Africa. In: MCCAFFREY, Stephen C.; LEB, Christina; DENOON, Riley T. (eds.), Research Book on International Water Law. Cheltenham: Edward Elgar Publishing, 2019, pp. 341-360.

PALMUJOKI, Antti; PARIKKA-ALHOLA, Katriina; EKROOS, Ari. Green Public Procurement: Analysis on the Use of Environmental Criteria in Contracts. Review of European Community \& International Environmental Law, 19(2), 2010, pp. 250-262.

PALOMBELlA, G. De los derechos y de su relación con los deberes y los fines. Derechos y Libertades, 17, 2007, pp. 115-169.

PARKER, Laura. Planet or Plastic? I A whopping 91\% of plastic isn't recycled. December 20, 2018. Available at: <https://www.nationalgeographic.com/news/2017/07/plastic-produced-recycling-wasteocean-trash-debris-environment/>. Accessed on: November 18, 2019.

PASSENIER, Arnoud. Interviewed by Luisa Cortat Simonetti Goncalves. The Hague, June 25, 2018. Available at: luisacortat.com.

PATTBERG, Philipp; WIDERBERG, Oscar. Smart Mixes and the Challenge of Complexity: Lessons from Global Climate Governance. In: VAN ERP, Judith et al. (eds.), Smart Mixes for Transboundary Environmental Harm. Cambridge: Cambridge University Press, 2019, pp. 49-68.

PATTERSON, Alan; THEOBALD, Kate S. Sustainable Development, Agenda 21 and the New Local Governance in Britain. Regional Studies, 29(8), 1995, pp. 773-778.

PAUWELYN, Joost. Judicial mechanisms: Is there a need for a World Environment Court? In: CHAMBERS, Bradnee; GREEN, Jessica F. (eds.), Reforming International Environmental Governance: From Institutional Limits to Innovative Reforms. Tokyo: United Nations University Press, 2005, pp. 150-177.

PECES-BARBA MARTÍNEZ, G. Los deberes fundamentales. Doxa, 4, 1987, pp. 329-341.

PEDRA, Adriano Sant'Ana. A Importância dos Deveres Humanos na Efetivação de Direitos. In: ALEXY, Robert; et al. (eds.), Niveis de Efetivação dos Direitos Fundamentais Civis e Sociais: um diálogo Brasil e Alemanha. Joaçaba: Editora Unoesc, 2013, pp. 281-301.

PEDROZO, Raul. Is It Time for the United States to Join the Law of the Sea Convention. Journal of Maritime Law \& Commerce, 41(2), 2010, p. 151-166.

PEET, Gerard. London Dumping Convention: Obsolete or Effective? Marine Pollution Bulletin, 22(2), 1991, pp. 3-18. 
PEETERS, Marjan. Instrument mix or instrument mess? The administrative complexity of the EU legislative package for climate change. In: PEETERS, Marjan; UYLENBURG, Rosa, EU Environmental Legislation: legal perspectives on regulatory strategies. Cheltenham: Edward Elgar, 2014, pp.173-192.

PEETERS, Marjan; MULlER, Mathias. Private Control of Public Regulation: A Smart Mix? The Case of Greenhouse Gas Emission Reductions in the EU. In: ERP, J. van et al. (eds.), Smart Mixes of Environmental Governance. Cambridge: Cambridge University Press, 2018, pp. 259-284.

PEETERS, Marjan; UYLENBURG, Rosa. Concluding observations: Three core themes. In: PEETERS, Marjan; UYLENBURG, Rosa. EU Environmental Legislation: legal perspectives on regulatory strategies. Cheltenham: Edward Elgar, 2014, pp. 235-257.

PENSAMENTO VERDE. Estudante usa alga para criar garrafa de água biodegradável. April 01, 2016. Available at: <http://www.pensamentoverde.com.br/ ecoideias/estudante-usa-alga-para-criargarrafa-de-agua-biodegradavel/>. Accessed on September 03, 2017.

PERCIVAL, Robert V. International responsibility and liability for environmental harm. In: ALAM, S. et al. (eds.), Routledge Handbook of International Environmental Law, London: Routledge, 2015, pp. 681-696.

PESSOA, A. Public-Private Sector Partnerships in Developing Countries: Prospects and Drawbacks. FEP Working Papers 228, 2006, Universidade do Porto, Faculdade de Economia do Porto. Available at: http://ideas.repec.org/p/por/fepwps/ 228.html. Accessed on November 24, 2019.

PHILIPSEN, Niels J. Regulation of Liberal Professions and Competition Policy: developments in the EU and China. Journal of Competition Law and Economics, 6(2), 2009, pp. 203-231.

PIGOU, Arthur C. The Economics of Welfare. 4th ed. London: McMillan, 1932.

PIOVESAN, Flávia. Sistema Internacional de Proteção dos Direitos Humanos. I Colóquio Internacional de Direitos Humanos. São Paulo, Brasil, 2001. Available at: http://www.dhnet.org.br/direitos/sip/textos/a_pdf/piovesan_sip.pdf. Accessed on: October 26, 2016.

Planbureau voor de Leefomgeving. Evaluatie Green Deals Circulaire Economie: policy brief. June 13, 2016. Available at: <http://www.pbl.nl/sites/default/files/cms/publicaties/ pbl-2016-policy-briefevaluatie-Green-Deals-circulaire-economie_2450.pdf>. Accessed on: May 26, 2018.

PLASTIC POLLUTION COALITION. Plastic is a substance the Earth cannot digest: refuse singleuse plastic. 2017(a). Available at: <http://www.plasticpollutioncoalition.org/>. Accessed on August 29, 2017.

PLASTIC POLLUTION COALITION. Open Your Eyes (video). 2017(b). Available at: $<$ https://www.youtube.com/watch?v=9znvqIkIM-A $>$. Accessed on October $5^{\text {th }}, 2017$.

PLASTIC SOUP FOUNDATION. European ban on personal care products containing microplastic. September, 2016. Available at: <https://www.plasticsoupfoundation.org/en/2016/09/european-ban-onpersonal-care-products-containing-microplastics/>. Accessed on: 31 July, 2018.

PLASTIC SOUP FOUNDATION. Ocean Clean Wash. 2017(a). Available at: $<$ https://www.plasticsoupfoundation.org/en/psf-in-action/ocean-clean-wash/>. Accessed on August 21, 2017.

PLASTIC SOUP FOUNDATION. What is Plastic Soup? Gyres and Hotspots. 2017(b). Available at: $<$ https://www.plasticsoupfoundation.org/en/files/what-is-plastic-soup/>. Accessed on: August 19, 2017. 
PLASTICS EUROPE. World Plastics Production 1950-2015. 2016(a). Available at: https://committee.iso.org/files/live/sites/tc61/files/The\%20Plastic\%20Industry\%20Berlin\%20Aug\%20 2016\%20-\%20Copy.pdf. Accessed on March 9, 2018(a).

PLASTICS EUROPE. World Plastic Production 2006-2015. 2016(b). Available at: https://committee.iso.org/files/live/sites/tc61/files/The\%20Plastic\%20Industry\%20Berlin\%20Aug\%20 2016\%20-\%20Copy.pdf. Accessed on March 9, 2018(b).

PLASTICS EUROPE. Types of Plastic. 2017. Available at: <http://www.plasticseurope.org/what-isplastic/types-of-plastics-11148.aspx>. Accessed on August 18, 2017.

PONCIBÒ, Cristina. The Contractualization of Environmental Sustainability. European Review of Contract Law, 12(4), 2016, pp. 335-355.

POSNER, Richard A. Economic Analysis of Law. 6th ed. New York: Aspen Publishers, 2003.

POSTIGLIONE, Amedeo. A More Efficient International Law on the Environment and Setting up of an International Court for the Environment within the United Nations. Environmental Law, 20, 1990, pp. 321-328.

RAJAMANI, Lavanya. Differential Treatment in International Environmental Law. Oxford monographs in International Law, vol. 9. New York: Oxford University Press, 2006.

Rathenau Institute. Valorisation: researchers already do much more than they realise. February 15th, 2016. Available at: https://www.rathenau.nl/en/knowledge-policy/valorisation-researchers-already-domuch-more-they-realise. Accessed on March 12, 2020.

RAUBENHEIMER, Karen; MCILGORM, Alistair. Is the Montreal Protocol a model that can help solve the global marine plastic debris problem? Marine Policy, 81, 2017, pp. 322-329.

RAUBENHEIMER, Karen; MCILGORM, Alistair; ORAL, Nilufer. Towards an improved international framework to govern the life cycle of plastics Review of European, Comparative \& International Environmental Law, 27(3), 2019, pp. 210-221.

REST, Alfred. The Indispensability of an International Environmental Court. Review of European Community and International Environmental Law, 7, 1998, pp. 63-68.

REVESZ, R. L.; STAVINS, R. N. Environmental Law. In: POLINSKY, Mitchell; SHAVELL, Steven (eds.), Handbook of Law and Economics, vol. 1. Amsterdam: publisher, 2004, pp. 499-589.

ROBECOSAM. 2017 RobecoSAM Corporate Sustainability Assessment - Annual Scoring and Methodology Review. September 2017(a). Available at: <http://www.robecosam.com/images/CSA_2017_Annual_Scoring_Methodology_Review.pdf>. Accessed on: June 05, 2018.

ROBECOSAM. Measuring Intangibles: RobecoSAM's Corporate Sustainability Assessment Methodology. February 2017(b). Available at: <http://www.robecosam.com/images/Measuring_Intangibles_CSA_methodology.pdf $>$. Accessed on: June 04, 2018.

ROBECOSAM. About us. 2018(a). Available at: <http://www.sustainability-indices.com/>. Accessed on June 04, 2018.

ROBECOSAM. Corporate Sustainability Assessment Timeline. 2018(b). Available at: $<$ http://www.robecosam.com/images/RobecoSAM_Timeline.pdf $>$. Accessed on June 04, 2018. 
ROBECOSAM. DJSI index family. 2018(c). Available at: <http://www.sustainabilityindices.com/index-family-overview/djsi-family-overview/index.jsp>. Accessed on June 04, 2018(c).

ROBECOSAM. RobecoSAM Corporate Sustainability Assessment 2018: Criterion Weights by RobecoSAM Industry. 2018(d). Available at: <http://www.robecosam.com/images/RobecoSAM Corporate_Sustainability_Assessment_Weightings_2018.pdf $>$. Accessed on June 04, 2018(d).

ROBECOSAM. The Corporate Sustainability Assessment at a glance. 2018(e). Available at: $<$ http://www.robecosam.com/en/sustainability-insights/about-sustainability/corporate-sustainabilityassessment/index.jsp>. Accessed on June 04, 2018.

ROCA, V. ¿De qué hablamos cuando hablamos de deberes jurídicos? (Algunas consideraciones sobre las fuentes del Derecho a partir de la tesis de Nino del caso especial). Doxa, 25, 2002, pp. 471-501.

ROGERS, Kara. Microplastics: Plastic Particulate. April 22, 2019. Available at: $<$ https://www.britannica.com/technology/microplastic>. Accessed on December 4, 2019.

ROMPH, Thomas J. De; CALSTER, Geert Van. REACH in a Circular Economy: The Obstacles for Plastics Recyclers and Regulators. RECIEL, 27, 2018, pp. 267-277.

ROOIJ, Benjamin van. Greening Industry Without Enforcement? An Assessment of the World Bank's Pollution Regulation Model for Developing Countries. Law and Policy, 32(1), 2010, pp. 127-152.

ROWLEY, Timothy J.; BERMAN, Shawn. A brand new brand of corporate social performance. Business \& Society, 39, 2000, pp. 397-418.

RUBIN, Paul H. Some Notes on Methodology in Law and Economics. Research in Law and Economics, 7, 1985, pp. 29-39.

RUBIO LLORENTE, F. Los deberes constitucionales. Revista Española de Derecho Constitucional, Madrid, 21(61), 2001, pp. 11-56.

RUGGIE, John Gerard. The Social Construction of the UN Guiding Principles on Business and Human Rights. Corporate Responsibility Initiative Working Paper No. 67. Cambridge, MA: John F. Kennedy School of Government, Harvard University, June 2017.

RÜHMKORF, A. Corporate Social Responsibility, Private Law and Global Supply Chains. Cheltenham: Edward Elgar, 2015.

S\&P Dow Jones Indices. DJSI World. 2018. Available at: $<$ https://eu.spindices.com/indices/equity/dow-jones-sustainability-world-index>. Accessed on June 04, 2018.

SANCASSIANI, Walter. Local agenda 21 in Italy: an effective governance tool for facilitating local communities' participation and promoting capacity building for sustainability. Local Environment, 10(2), 2005, pp. 189-200.

SANDS, Philippe; PEEL, Jacqueline. Principles of International Environmental Law, 3rd ed. Cambridge: Cambridge University Press, 2012.

SCHELTEMA, Martijn. An assessment of the effectiveness of international private regulation in the corporate social responsibility arena: a legal perspective, $M J, 21(3), 2014$, pp. 383-405.

SCHERER, Andreas Georg; PALAZZO, Guido. Globalization and Corporate Social Responsibility. In: CRANE, A.; MCWILLIAMS, A.; MATTEN, D.; MOON, J.; SIEGEL, D.J. (eds.), The Oxford Handbook of Corporate Social Responsibility, Oxford: Oxford University Press, 2008, pp. 413-431. 
SCHERER, Andreas Georg; PALAZZO, Guido. The New Political Role of Business in a Globalized World: A Review of a New Perspective on CSR and its Implications for the Firm, Governance, and Democracy. Journal of Management Studies, 48(4), 2011, pp. 899-931.

SCHMIDT, Christian; KRAUTH, Tobias; and WAGNER, Stephan. Export of Plastic Debris by Rivers into the Sea. Environ. Sci. Technol, 51, 2017, pp. 12246-12253.

SCHMIEDEKNECHT, Maud H. Dow Jones Sustainability Indices. In: IDOWU, S.O.; CAPALDI, N; ZU, L.; GUPTA, A.D. (eds.), Encyclopedia of Corporate Social Responsibility. Springer: Berlin, Heidelberg, 2013, pp. 832-838.

SCHMITZ, Norbert. Certification to ensure sustainable production of biofuels. Biotechnology Journal, 2, 2007, pp. 1474-1480.

SCHNEIDER, William. The Basel convention ban on hazardous waste exports: Paradigm of efficacy or exercise in futility. Suffolk Transnational Law Review, 20(1), 1996, pp. 247-288.

SCOTT, Alister. Whose Futures? A Comparative Study of Local Agenda 21 in Mid Wales. Planning Practice and Research, 14(4), 1999, pp. 401-421.

SEARCY, Cory; ELKHHAWAS, Doaa. Corporate sustainability ratings: an investigation into how corporations use the Dow Jones Sustainability Index. Journal of Cleaner Production, 35, 2012, pp. 7992 .

SEBILLE, Erik van; et al. A global inventory of small floating plastic debris. Environmental Research Letters., 10, 2015, article n. 124006.

Secretariat of the Convention on Biological Diversity. Strategic Plan for Biodiversity 2011-2020 and the Aichi Targets: "Living in Harmony with Nature". [2011?]. Available at: https://www.cbd.int/doc/strategic-plan/2011-2020/Aichi-Targets-EN.pdf. Accessed on November 7, 2017.

SELMAN, Paul. Local Agenda 21: Substance or Spin? Journal of Environmental Planning and Management, 41(5), 1998, pp. 533-553.

SENDEN, Linda A.J. Soft law and its implications for institutional balance in the EC. Utrecht Law Review, 1(2), 2005, op. 79-99.

SHAVELL, Steven. Liability for Harm versus Regulation of Safety. Journal of Legal Studies, 13, 1984, pp. 357-374.

SHEAVLY, S.B. Sixth Meeting of the UN Open-ended Informal Consultative Processes on Oceans \& the Law of the Sea. Marine debris - an overview of a critical issue for our oceans. June 6-10, 2005. Available at: http://www.un.org/Depts/los/ consultative_process/consultative_process.htm. Accessed on: August 28, 2017.

SHEN, Maocai et al. Recent advances in toxicological research of nanoplastics in the environment: A review. Environmental Pollution, 252(part A), 2019, pp. 511-521.

SHORT, Jodi L.; TOFFEL, Michael W. Making Self-Regulation More the Merely Symbolic: The Critical Role of the Legal Environment. Administrative Science Quarterly, 55, 2010, pp. 361-396. 
SMARDON, Richard C. A comparison of Local Agenda 21 implementation in North American, European and Indian cities. Management of Environmental Quality: An International Journal, 19(1), 2008, pp. 118-137.

SMEETS, Edward et al. The sustainability of Brazilian ethanol - An assessment of the possibilities of certified production. Biomass and Bioenergy, 32, 2008, pp. 781-813.

SNOWDON, Kathryn. Coca-Cola Producing More Than 100 Billion Throwaway Plastic Bottles Every Year, Says Greenpeace. April 13, 2017. Available at: http:/www.huffingtonpost.co.uk/entry/coca-cola-producing-more-than-100-billion-throwaway-plastic-bottles-greenpeace_uk_58eb557ce4b00de1410490ba. Accessed on 20 August 2017.

SOMBRE, Elizabeth R. De. Flagging Standards: Globalization and Environmental, Safety, and Labor Regulations at Sea. Massachussets: MIT Press, 2006.

SORELL, S.; SIJM, J. Carbon Trading in the Policy Mix. Oxford Review of Economic Policy, 19(3), 2003, pp. 420-437.

SOUZA, Leonardo da Rocha de; LEISTER, Margareth Anne. A influência da soft law na formação do direito ambiental. Revista de Direito Internacional [Brazilian Journal of International Law], 12(2), 2015, pp. 767-783.

SOUSA JUNIOR, Jose Geraldo de. Direito como Liberdade: O Direito Achado na Rua. Available at: $<$ http://www.direito.unb.br/images/PosGraduacao/Projetos_de_Pesquisa/Projeto_de_Pesquisa_Jose_Geraldo.pdf $>$. Accessed on January 22, 2018.

STAATSCOURANT VAN HET KONINKRIJK DER NEDERLANDEN. Convenant tussen de Minister van Infrastructuur en Waterstaat en The Ocean Cleanup betreffende de inzet van systemen bedoeld om plastic op volle zee, dat drijft in de bovenste waterlagen, op te ruimen. July 6, 2018. Available at: https://zoek.officielebekendmakingen.nl/stcrt-2018-31907.html\#d17e790. Accessed on July 11, 2018.

Stakeholder Forum for a Sustainable Future. Review of Implementation of Agenda 21 and the Rio Principles. January 2012. Available at: https://sustainabledevelopment.un.org/content/documents/641Synthesis_report_Web.pdf. Accessed on November 11, 2017.

STEARNS, Maxwell L. A public choice perspective. In: ULEN, Thomas S. (ed.), Methodologies of Law and Economics. Cheltenham: Edward Elgar, 2017, pp. 44-71.

STEINBERG, Florian; MIRANDA, Liliana. Local agenda 21, capacity building and the cities of Peru. Habitat International, 29, 2005, pp. 163-182.

STEKELENBURG, A. van; et al. The relation between sustainability performance and stock market returns: An empirical analysis of the Dow Jones Sustainability Index Europe. International Journal of Economics and Finance, 7(7), 2015, pp. 74-88.

STIGLER, G.J. The Theory of Economic Regulation. Bell Journal of Economics and Management Science, 2(1), 1971, pp. 3-21.

STRAW FREE. Top Reasons to Go Plastic Straw Free. 2017. Available at: $<\mathrm{https}$ ://strawfree.org/top_reasons_to_go_straw_free/>. Accessed on August 21, 2017.

Stylo Urbano. Até 2024 todos os produtos da Adidas usarão apenas plástico recuperado do oceano. March 20, 2018. Available at: http://www.stylourbano.com.br/ate-2024-todos-os-produtos-da-adidasusarao-apenas-plastico-recuperado-do-oceano/. Accessed on June 16, 2018. 
SUEZ. Protect the Oceans. 2017. Available at: https://www.suez.com/en/Who-we-are/A-commitedgroup/ Protect-the-oceans. Accessed on September 28, 2017.

SUPREME COURT OF THE NETHERLANDS. Climate Case Urgenda - ECLI:NL:HR:2019:2007. 20 December 2019. Available at: https://www.urgenda.nl/wp-content/uploads/ENG-Dutch-SupremeCourt-Urgenda-v-Netherlands-20-12-2019.pdf. Accessed on March 2, 2020.

Surfrider Foundation \& UCLA's Frank G. Wells Environmental Law Clinic. Federal Actions to Address Plastic Marine Pollution: preventing marine plastic pollution through upstream controls and life-cycle management. 2013. Available at: https://law.ucla.edu/ /media/Files/UCLA/Law/Pages/Publications/CEN_EMM_PUB\%20Surfrider\%20UCLA\%20-\%20Plastics\%20Solutions.ashx. Accessed on September $\overline{07}, 201 \overline{7}$.

SWANSON, Timothy. Negotiating Effective International Environmental Agreements: Is an Objective Approach to Differential Treatment Possible? International Environmental Agreements: Politics, Law and Economics, 1, 2001, pp. 125-153.

TCO Certified. About TCO Certified. 2019. Available at: <https://tcocertified.com/tco-certified/>. Accessed on November 4, 2019.

TEKMAN, Mine B.; GUTOW, Lars; BERGMAN, Melanie. Litterbase. 2017. Available at: $<$ http://litterbase.awi.de/interaction_graph>. Accessed on August 29, 2017.

Terrachoice. Sins of Greenwashing. 2007. Available at: <https://www.ul.com/insights/sinsgreenwashing $>$. Accessed on November 18, 2019.

TERRY, Beth. How I Kicked the Plastic Habit and How You Can Too. New York: Shyhorse Publishing, 2015.

THE CLUB OF ROME. History. 2020. Available on: http://www.clubofrome.org/about-us/history/. Accessed on February 26, 2020.

The Great Bubble Barrier. Milestones and Goals. 2018. Available at: https://thegreatbubblebarrier.com/en/timeline-en/. Accessed on July 11, 2018.

THE LOCAL. Davos: Plastic companies devise plan to reduce pollution. January 17, 2017. Available at: $\quad$ https://www.thelocal.ch/20170117/davos-plastic-companies-devise-plan-to-reduce-pollution. Accessed on September 10, 2017.

The Ministry of Infrastructure and the Environment and the Ministry of Economic Affairs. A Circular Economy in the Netherlands by 2050: Government-wide Programme for a Circular Economy. September 2016. Available at: <https://www.government.nl/ binaries/government/documents/policynotes/2016/09/14/a-circular-economy-in-the-netherlands-by-2050/17037+Circulaire+Economie_EN.PDF $>$. Accessed on March 9, 2018.

THE OCEAN CLEANUP. Our Concept. 2017(a). Available at: <https://www.theoceancleanup.com/technology/>. Accessed on September 04, 2017.

THE OCEAN CLEANUP. Technology. 2017(b). Available at: <https://www.theoceancleanup.com/>. Accessed on September 04, 2017.

THE OCEAN CLEANUP. Milestones. 2017(c). Available at: <https://www.theoceancleanup.com/milestones/>. Accessed on September 04, 2017.

The UK Plastics Pact. Together we can. 2018. Available at: <http://www.wrap.org.uk/content/the-ukplastics-pact>. Accessed on October 12, 2018. 
THOMAS, N. et al. EV0422: Assessing the Environmental Impacts of Oxo-degradable Plastics Cross Their Life Cycle. Loughborough: Department for Environmental, Food and Rural Affairs, 2010.

TOJO, Naoko; THIDELL, Ake. Material Recycling without Hazardous Substances. In: MAITREEKERN, Eléonore; DALHAMMAR, Carl; BUGGE, Hans Christian (eds.), Preventing Environmental Damage from Products: An Analysis of the Policy and Regulatory Framework in Europe. Cambridge: Cambridge University Press, 2018, pp. 253-275.

TREBILCOCK, M.J.; HOWSE, R. The Regulation of International Trade. London: Psychology Press, 2005.

TRUBEK, David M.; TRUBEK, Louise G. New governance and legal regulation: complementarity, rivalry, and transformation. Columbia Journal of European Law, 13, 2007, pp. 539-564.

TULDER, Rob van; WIJK, Jeroen van; and KOLK, Ans. From Chain Liability to Chain Responsibility: MNE approaches to implement safety and health codes in international supply chains. Journal of Business Ethics, 85(2), 2009, pp. 399-412.

TULLOCK, Gordon. Rent Seeking. Aldershot: Edward Elgar, 1993.

TURKER, Duygu. Phylantropic CSR. In: IDOWU, S.O. et al. (eds.), Encyclopedia of Corporate Social Responsibility. Berlin: Springer-Verlag Berlin Heidelberg, 2013, pp. 1834-1845.

UFRJ. Estudandes criam bactéria que come plástico dos oceanos e o transforma em água. Year. Available at: <http://www.microbiologia.ufrj.br/portal/index.php/pt/destaques/ novidades-sobre-amicro/443-estudantes-criam-bacteria-que-come-plastico-dos-oceanos-e-o-transforma-em-agua $>$.

Accessed on September 04, 2017.

ULEN, Thomas S. The changing methodologies of law and economics. In: ULEN, Thomas (ed.), Methodologies of Law and Economics. Cheltenham: Edward Elgar Publishing, 2017, pp. 1-17.

UN Atlas of the Oceans. GPA - Global Programme of Action: a commitment to global health from the land. [2012?]. Available at: http://www.oceansatlas.org/subtopic/en/c/796/ Accessed on November 12, 2017.

UN Bonn. Secretariat of the Convention on the Conservation of Migratory Species of Wild Animals (UNEP/CMS). 2017. Available at: http://unbonn.org/CMS. Accessed on October 27, 2017.

UN ENVIRONMENT - CMS. Parties and Range States. 2017. Available at: http://www.cms.int/en/parties-range-states Accessed on October 27, 2017.

UN ENVIRONMENT. Global Review of Sustainable Public Procurement. 2017. Available at: https://wedocs.unep.org/bitstream/handle/20.500.11822/20919/GlobalReview_Sust_Procurement.pdf? sequence $=1 \&$ is Allowed $=y$. Accessed on March 03, 2020.

UNDP \& Millennium. UN Millennium Development Library: Innovation: Applying Knowledge in Development, 2005.

UNEP - Basel Convention. Entry into force of amendment to UN treaty boosts efforts to prevent waste dumping. September 13, 2019(a). Available at: http://basel.int/Implementation/PublicAwareness/PressReleases/-

BanAmendmententryintoforce/tabid/8120/Default.aspx. Accessed on September 29, 2019.

UNEP - Basel Convention. Milestones. 2019(b). Available at: http://basel.int/TheConvention/ Overview/Milestones/tabid/2270/Default.aspx. Accessed on September 29, 2019. 
UNEP GPA. Marine Litter: Trash that kills. Sweden: Risbergs Uddevalla, 2001. Available at: https://wedocs.unep.org/rest/bitstreams/17739/retrieve. Accessed on August 29, 2017.

UNILEVER. Mobilising Collective Action - Unilever Sustainable Living Plan: Summary of Progress 2015. 2015. Available at: https://www.unilever.com/Images/uslp-mobilising-collective-actionsummary-of-progress-2015_tcm244-424809_en.pdf. Accessed on September 21, 2017.

UNITED NATIONS - Sustainable Development. United Nations Conference on Environment \& Development: Agenda 21. 3 to 14 June 1992. 1992. Available at: https://sustainabledevelopment.un.org/content/documents/Agenda21.pdf. Accessed on October 31, 2017.

UNITED NATIONS - Human Rights Office of the High Commissioner. Guiding Principles on Business and Human Rights: Implementing the United Nations "Protect, Respect and Remedy" Framework. 2011. Available at: <https://www.unglobalcompact.org/library/2>. Accessed on September 13, 2017.

UNITED NATIONS - UN. Report of the United Nations Conference on the Human Environment: Stockholm 5-16 June 1972. 1972. Available at: http://www.un-documents.net/aconf48-14r1.pdf. Accessed on November 7, 2017.

UNITED NATIONS - UN. Yearbook of the International Law Commission: Summary records of the twenty-fifth session 7 May-13 July 1973. volume I. New York, 1974.

UNITED NATIONS - UN. Report of the World Commission on Environment and Development, Our Common Future (UN Doc. A/42/427, 4 August 1987), Annex. 1987. Available at: https://sustainabledevelopment.un.org/content/documents/5987our-common-future.pdf. Accessed on September 23, 2018.

UNITED NATIONS - UN. The Rio Declaration on Environment and Development, 1992.

United Nations - UN. The Millenium Development Goals Report 2015. 2015. Available at: http://www.un.org/millenniumgoals/2015_MDG_Report/pdf/MDG\%202015\%20rev\%20(July\%201).pdf. Accessed on November 14, 2017.

United Nations - UN. Human Rights and the 2030 Agenda for Sustainable Development. 2016. Available at: $<$ http://www.ohchr.org/EN/Issues/MDG/Pages/The2030Agenda.aspx $>$. Accessed on 1 August 2016.

United Nations - UN. Our Ocean, Our Future: call for action. 2018(a). Available at: https://oceanconference.un.org/callforaction. Accessed on January 10, 2018.

UNITED NATIONS - UN. United Nations General Assembly. 2018(b). Available at: $<$ http://www.un.org/documents/ga/conf151/aconf15126-4.htm>. Accessed on January 17, 2018(b).

UNITED NATIONS - UN. Oceans and the Law of the Sea. 2019. Available at: $\mathrm{http}: / /$ www.un.org/en/sections/issues-depth/oceans-and-law-sea/ [https://perma.cc/4E 9D-AJNB]. Accessed on April 3, 2019.

United Nations: Economic and Social Council. Review of Further Developments in Fields with which the Sub-Comission Has Been Concerned - Human Rights and the Environment: Final report prepared by Mrs. Fatma Zohra Ksentini, Special Rapporteur. 6 July 1994. Available at: https://digitallibrary.un.org/record/226681. Accessed on February 28, 2020. 
United Nations Convention on the Law of the Oceans. 1982. Available at: http://www.un.org/Depts/los/convention_agreements/texts/unclos/unclos_e.pdf Accessed on November 8, 2017.

United Nations Department of Economic and Social Affairs - Division for Sustainable Development. National Institutions for Sustainable Development: A preliminary review of the institutional literature. October 2012. Available at: https://sustainabledevelopment.un.org/content/documents/1372Study2_final.pdf. Accessed on November 11, 2017).

United Nations Development Programme - UNDP. World leaders adopt Sustainable Development Goals. 2015. Available at: http:/www.undp.org/content/undp/en/home/presscenter/pressreleases/2015/09/24/undp-welcomes-adoption-of-sustainable-development-goals-by-worldleaders.html. Accessed on January 18, 2018.

United Nations Development Programme: Human Development Reports. 2019 Human Development Index Ranking. 2019. Available at: http://hdr.undp.org/en/content/2019-human-development-indexranking. Accessed on February 20, 2020.

United Nations Environment Assembly - UNEPEA. Resolution 1/6: Marine plastic debris and microplastics. 2012. Available at: http:/www.cep.unep.org/meetings/documents/c81d1c3338941a0141d8ed995f174bc2. Accessed on December 2, 2017.

United Nations Environmental Program: GPA Coordination Office. Partners in Implementing the GPA: regional seas. December 12, 1999. Available at: https://www.oceandocs.org/bitstream/handle/1834/559/bookregionalseas.pdf?sequence=1\&isAllowed=y. Accessed on January 22, 2018.

United Nations Environmental Program - UNEP. Abidjan Convention. 1984. Available at: http://abidjanconvention.org/. Accessed on February 10, 2018.

United Nations Environmental Program - UNEP. Basel Convention on the Control of Transboundary Movements of Hazardous Wastes and their Disposal. 1989. Available at: https://www.basel.int/Portals/4/Base1\%20Convention/docs/text/BaselConventionText-e.pdf Accessed on September 28, 2019.

United Nations Environmental Program - UNEP. Global Programme of Action for the Protection of the Marine Environment from Land-Based Activity. 1995. Available at: http://www.unep.org/ecosystems/resources/tools/global-programme-action-protection-marineenvironment-land-based-activities. Accessed on October 20, 2017.

United Nations Environmental Program - UNEP. The Global Programme of Action for the Protection of the Marine Environment from Land-Based Activity (GPA). 1995. Available at: https://wedocs.unep.org/bitstream/handle/20.500.11822/11144/wbrs18_pre_\%20\%288\%29.pdf?sequence $=1 \&$ is Allowed $=\mathrm{y}$. Accessed on October 20, 2017.

United Nations Environmental Program - UNEP. Partners in Implementing the Global Programme of Action for the Protection of the Marine Environment from Land-based Activities: Regional Seas. UNEP/GPA Coordination Office, issue 1. September 1999.

United Nations Environmental Program - UNEP. First Intergovernmental Review Meeting on the Implementation of the GPA. 2001. Available at: http:/web.unep.org/gpa/who-we-are/governance/firstintergovernmental-review-meeting-implementation-gpa. Accessed on November 11, 2017.

United Nations Environmental Program - UNEP. First Global Conference on Land-Ocean Connections. 2006. Available at: http://web.unep.org/gpa/who-we-are/governance/first-globalconference-land-ocean-connections. Accessed on November 12, 2017. 
United Nations Environmental Program - UNEP. Third Intergovernmental Review Meeting on the Implementation of the GPA. 2011. Available at: http://web.unep.org/gpa/who-weare/governance/third-intergovernmental-review-meeting-implementation-gpa. Accessed on November $11,2017$.

United Nations Environmental Program - UNEP. Valuing Plastics: The Business Case for Measuring, Managing and Disclosing Plastic Use in the Consumer Goods Industry. 2014. Available at: https://wedocs.unep.org/rest/bitstreams/16290/retrieve. Accessed on January 05, 2018.

United Nations Environmental Program - UNEP. Inputs to the Secretary-General's Report on Marine Debris, Plastics and Microplastics. 2016. Available at: http://www.un.org/depts/los/general_assembly/contributions_2016/UNEP_Contribution_to_ICP_on_marine_debris.pdf. Accessed on November 12, 2017.

United Nations Environmental Program - UNEP. CMS Convention on the Conservation of Migratory Species of Wild Animals: Agreements. 2017a. Available at: http://www.cms.int/en/cmsinstruments/agreements. Accessed on November 12, 2017.

United Nations Environmental Program - UNEP. Mobile Apps. 2017b. Available at: staging.unep.org/gpa/resources/Apps.asp. Accessed on November 07, 2017.

United Nations Environmental Program - UNEP. Fourth Intergovernmental Review Meeting of the Global Programme of Action. 2017c. Available at: http://web.unep.org/gpa/who-weare/governance/news/fourth-intergovernmental-review-meeting-global-programme-action. Accessed on January 10, 2018.

United Nations Environmental Program - UNEP. Enroll in our massive open online course on marine litter. 2019. Available at: https://www.unenvironment.org/news-and-stories/blogpost/enroll-ourmassive-open-online-course-marine-litter .Accessed on September 27, 2019.

UN Environment Programme - UNEP. Marine Litter. 2020. Available at: https://www.unenvironment.org/explore-topics/oceans-seas/what-we-do/working-regionalseas/marine-litter Accessed on February 24, 2020.

United Nations General Assembly. United Nations Millenium Declaration. September 8, 2000. Available at: http://www.un.org/millennium/declaration/ares552e.pdf. Accessed on November 14, 2017.

United Nations General Assembly. United Nations Millenium Declaration. 2000. Available at: http://www.un.org/millennium/declaration/ares552e.pdf. Accessed on November 14, 2017.

United Nations Human Rights Special Procedures. Framework Principles on Human Rights and the Environment: the main human rights obligations relating to the enjoyment of a safe, clean, healthy and sustainable environment. 2018. Available at: https:/www.ohchr.org/Documents/Issues/Environment/SREnvironment/FrameworkPrinciplesUserFriendlyVersion.pdf. Accessed on February 27, 2020

United Nations Sustainable Development Knowledge Platform. Agenda 21: UNCED 1992. Available at: https://sustainabledevelopment.un.org/outcomedocuments/agenda 21. Accessed on November 2, 2017.

United Nations Sustainable Development Knowledge Platform. Sustainable Development Goals. 2015. Available at: https://sustainabledevelopment.un.org/?menu=1300. Accessed on November 11, 2017.

United Nations University. About UNU. 2019. Available at: https://unu.edu/about/unu. Accessed on September 27, 2019. 
United States Environmental Protection Agency - EPA. How is Ocean Dumping Evaluated under the London Convention and London Protocol. 2017. Available at: https://www.epa.gov/oceandumping/ocean-dumping-international-treaties. Accessed on October 18, 2017.

UPRETY, Kishor. South Asian Water Treaty practice: an overview. In: MCCAFFREY, Stephen C.; LEB, Christina; DENOON, Riley T. (eds.), Research Book on International Water Law. Cheltenham: Edward Elgar Publishing, 2019, pp. 431-446.

UTTING, P. Rethinking Business Regulation: From Self-Regulation to Social Control. UNRISD Technology, Business and Society Programme Paper No. 15, 2005. Available at: http://www.isn.ethz.ch/isn/Digital-Library/Publications/Detail/?ots591=0C54E3B3-1E9C-BE1E2C24-A6A8C7060233\&lng=en\&id=102693. Accessed on November 24, 2019.

VALAVANIDIS, Athanasios; VLACHOGIANNI, Thomais. Microplastics in the Marine Environment: ubiquitous and persistent pollution problem in the world's oceans threatening marine biota. 30 June 2014. Researchgate. Available at: www.researchgate.net/publication/263477975. Accessed on August 9, 2017.

VAN ERP, Judith et al. Conclusion: Smart Mixes in Relation to Transboundary Environmental Harm. In: VAN ERP, Judith et al. (eds.), Smart Mixes for Transboundary Environmental Harm. Cambridge: Cambridge University Press, 2019a., pp. 329-343.

VAN ERP, Judith et al. Introduction: The Concept of Smart Mixes for Transboundary Environmental Harm. In: VAN ERP, Judith et al. (eds.), Smart Mixes for Transboundary Environmental Harm. Cambridge: Cambridge University Press, 2019b, pp. 3-24.

VARELA DÍAZ, S. La idea de deber constitucional. Revista Española de Derecho Constitucional, 4, 1982, pp. 69-96.

VEOLIA. Resourcing the World: Annual and Sustainability Report 2016. 2016. Available at: https://www.veolia.com/sites/g/files/dvc181/f/assets/documents/2017/04/veolia-annual-sustainabilityreport-2016.pdf. Accessed on September 27, 2017.

VERNENGO, R.J. Deberes prescriptivos y deberes descriptivos. Anuario de Filosofia del Derecho, 1993, pp. 263-273.

VERTINSKY, Ilan; ZHOU, Dongsheng. Product and process certification: Systems, regulations and international marketing strategies. International Marketing Review, 17(3), 2000, pp. 231-253.

VIANELLO, Alvise et al. Simulating human exposure to indoor airborne microplastics using a Breathing Thermal Maniking. Scientific Reports 9. June 17, 2019. Article number 8670.

VILLIGER, Mark E. Customary International Law and Treaties: A Study of Their Interactions and Interrelations with Special Consideration of the 1969 Vienna Convention on the Law of Treaties. Leiden: Brill, 1985.

VOGEL, David. Trading Up: Consumer and Environmental Regulation in the Global Economy. Cambridge: Harvard University Press, 1995.

VRIES, Eli de. Interview conducted by Luisa Cortat Simonetti Goncalves in Utrecht, on June 27th, 2018. Available at: luisacortat.com.

VTREK. Vtrek and Corvers Sign Green Deal Circular Procurement. June 11, 2018. Available at: $<$ https://www.vtrek.eu/news-events/vtrek-and-corvers-sign-green-deal-circular-procurement>.

Accessed on: July 31, 2018. 
WAHBA, H. Does the Market Value Corporate Environmental Responsibility? An Empirical Examination. Corporate Social Responsibility and Environmental Management, 15(2), 2008, pp. 8999.

WANG, Q.; DOU, J.; JIA, S. A Meta-Analytic Review of Corporate Social Responsibility and Corporate Financial Performance. Business \& Society, 55(8), 2016, pp. 1083-1121.

WATERS, Colin N. et al. The Anthropocene is functionally and stratigraphically distinct from the Holocene. Science, 351(6269), 2016, article number 2622, pp. 137-148.

WATSON, Ivan et al. China's recycling ban has sent America's plastic to Malaysia. Now they don't want it - so what next? April 27, 2019. Available at: https://edition.cnn.com/2019/04/26/asia/malaysia-plastic-recycle-intl/index.html. Accessed on August $24,2019$.

WEIL, D. Public enforcement/private monitoring: evaluating a new approach to regulating the minimum wage. Industrial and Labor Relations Review, 58(2), 2005, pp. 238-257.

WEIL, Prosper. Towards Relative Normativity in International Law. The American Journal of International Law, 77, 1983, pp. 413-442.

WEISHAAR, Stefan E. Cartels, Competition and Public Procurement: Law and Economics Approaches to Bid Rigging. Cheltenham: Edward Elgar, 2013.

WEISS, Norman; THOUVENIN, Jean-Marc (eds.), The Influence of Human Rights on International Law. Basel: Springer, 2015.

WENTWORTH, Adam. Adidas has sold one million shoes made from recycled ocean plastic. 15 March 2018. Available at: http://www.climateactionprogramme.org/news/ adidas-has-sold-onemillion-shoes-made-from-recycled-ocean-plastic. Accessed on: July 18, 2018.

WESTBLOM, Caroline. Towards a Circular Economy in Sweden - Barriers for new business models and the need for policy intervention. Master thesis presented for Lund University in 2015. Available at: < https://lup.lub.lu.se/student-papers/search/publication/8170322>. Accessed on November 4, 2019.

WHARTON HIGH SCHOOL. Biotech Innovation That Breaks Down Plastic and Feeds the Fish. 2016. Available at: <http://kwhs.wharton.upenn.edu/2016/03/biotech-innovation-that-breaks-downplastic-and-feeds-the-fish/>. Accessed on September 04, 2017.

WHITTAKER, Stella. Are Australian councils 'willing and able' to implement local Agenda 21 ? Local Environment, 2(3), 1997, pp. 319-328.

WIDAWSKI, Lisa. In my Backyard: How Enabling Hazardous Waste Trade to Developing Nations Can Improve the Basel Convention's Ability to Achieve Environmental Justice. Environmental Law 38(2), 2008, pp. 577-626.

WINTER, Caroline. Nestle Makes Billions Bottling Water It Pays Nearly Nothing For. September 21, 2017. Available at: <https://www.bloomberg.com/news/features/2017-09-21/nestl-makes-billionsbottling-water-it-pays-nearly-nothing-for $>$. Accessed on September 28, 2017.

WIRTH, David A. Trade Implications of the Basel Convention Amendment Banning North-South Trade in Hazardous Wastes. RECIEL, 7(3), 1998, pp. 237-248. 
WITTEVEEN+BOS. Evaluatie Green Deals Zwerfafval in zee: Eindrapport. 16 December 2019. Available at: https://www.kimonederlandbelgie.org/wp-content/uploads/Eindrapport-Evaluatie-GreenDeals-Witteveen-Bos.pdf. Accessed on February 17, 2020.

WOLDENDORP, Hans E. Microwave: de zondvloed van microplastics als wetgevings vraagstuk. Milieu \& Recht, 10, 2017, pp. 1-18.

WOLDENDORP, Hans E. Interview conducted by Luisa Cortat Simonetti Goncavles in Maastricht, on May 10th, 2018. Available at: luisacortat.com.

WOLF, K.D. Emerging patters of global governance: the new interplay between the state, business and civil society. In: SCHERER, Andreas Georg; PALAZZO, Guido. (eds.), Handbook of Research on Global Corporate Citizenship. Cheltenham: Edward Elgar, 2008, pp. 225-248.

WONG, Megan S. The United Nations Convention on the Law of the Sea 1982. In: FITZMAURICE, Malgosia; TANZI, Attila (eds.), Elgar Encyclopedia of Environmental Law, Vol. 5. Cheltenham: Edward Elgar, 2017, pp. 145-165.

WORLD'S TOP EXPORTS. Plastic Item Exports by Country. August 22, 2019. Available at: http://www.worldstopexports.com/plastic-item-exports-countr. Accessed on August 24, 2019.

WORLD BANK. Population, total. 2017. Available at: https://data.worldbank.org/indicator/SP.POP.TOTL. Accessed on November 14, 2017.

WORLD ECONOMIC FORUM, Ellen MacArthur Foundation and McKinsey \& Company. The New Plastics Economy - Rethinking the future of plastics. 2016. Available at: http://www.ellenmacarthurfoundation.org/publications. Accessed on 17 August 2017.

WORLD ECONOMIC FORUM, Ellen MacArthur Foundation and McKinsey \& Company, The New Plastics Economy - Rethinking the future of plastics. 2016. Available at: http://www.ellenmacarthurfoundation.org/publications). Accessed on 17 August 2017.

WRAP. The UK Plastic Summit 2018. 2018. Available at: <http://www.wrap.org.uk/content/ukplastics-pact-summit-2018>. Accessed on October 12th, 2018.

WRIGHT, Pam; HENSON, Bob. Earth Day 2018: the 10 most pressing environmental concerns facing our planet - and rays of hope for each. April 18, 2018. Available at: https://weather.com/science/environment/news/2018-04-18-earth-day-2018-10-concerning-thingsfuture-of-planet/. Accessed on May 22, 2018.

WWF. China: Marine. 2020. Available at: https://en.wwfchina.org/en/what_we_do/marine/. Accessed on February 21, 2020.

WYSOKINSKA, Zofia. Millenium Development Goals/UN and Sustainable Development Goals/UN As Instruments for Realising Sustainable Development Concept In The Global Economy. Comparative Economic Research, 20(1), 2017, pp. 101-118.

YANG, Xiaoliu; PANG, Jinwu. Implementing China's “Water Agenda 21”. Front Ecol Environ, 4(7), 2006, pp. 362-368.

YOSHIDA, Shosuke; HIRAGA, Kazumi; TAKEHANA, Toshihiko; TANIGUCHI, Ikuo; YAMAJI, Hironao; MAEDA, Yasuhito; TOYOHARA, Kiyotsuna; MIYAMOTO, Kenji; KIMURA, Yoshiharu; ODA, Kohei. A bacterium that degrades and assimilates poly(ethylene terephthalate). Science, 351(6278), 2016, pp. 1196-1199.

YOUNG, Robert J.C. Postcolonialism: An historical introduction. London: Blackwell, 2001. 
ZAGO, Ana Paula Pinheiro; JABBOUR, Charbell José Chiappetta; BRUHN, Nádia Campos Pereira. Corporate sustainability and value creation: the case of the "Dow Jones Sustainability Index". Gestão \& Produção, São Carlos, 25(3), 2018, pp. 531-544.

ZHANG, Jie J; JOGLEKAR, Nitin; VERMA, Rohit. Signaling eco-certification: Implications for service coproduction and resource efficiency. Journal of Service Management, 25(4), 2014, pp. 494511 .

ZIGANSHINA, Dinara R. Central Asia: the Aral Sea basin. In: MCCAFFREY, Stephen C.; LEB, Christina; DENOON, Riley T. (eds.), Research Book on International Water Law. Cheltenham: Edward Elgar Publishing, 2019, pp. 414-430. 


\section{Curriculum Vitae}

Luísa Cortat Simonetti Gonçalves Coutinho (Vitória, 1987) has a Law Degree (2007-2011) from Vitoria Law School (Faculdade de Direito de Vitoria - FDV), a Physics Degree (2005-2009) from the Federal University of Espirito Santo, and a Master's Degree in Fundamental Rights and Warranties (2012-2013) from FDV. She specialized in Environment and Economics (2014-2015) at the Federal University of Parana. She was an Erasmus Mundus student at the University of Coimbra (2010-2011). In 2016 and 2017, she started the double degree PhD programme at FDV and Maastricht University, during which she spent 13 months (2017-2018) in Maastricht, with a scholarship from CAPES.

She is currently a guest researcher at the Max Planck Institute Luxembourg for International, European and Regulatory Procedural Law (2020). In the past, she worked, among others, at FDV (2011-2019) as lecturer, coordinator of extension activities, coordinator of institutional relations, and head of international relations office, and at the Secretary of State for the Environment and Water Resources of the State of Espirito Santo (2015-2016) as legal coordinator. She has also served as civil diplomat representing Brazil in events like the IMF and World Bank Annual Meeting 2015 and the G20 Youth Summit Australia 2014, in this one as head delegate. She was granted several academic awards, the latest one being the Green Talents Award 2019, which is granted by the German Federal Ministry of Education and Research to honour young researchers, recognizing their outstanding achievements in making our societies more sustainable.

She has several works published, in peer-reviewed journals, book chapters, consultancies, and annals of events. Her areas of expertise and/or interest include: international environmental law, human rights, law and economics, public international law, environmental law, and constitutional law. 